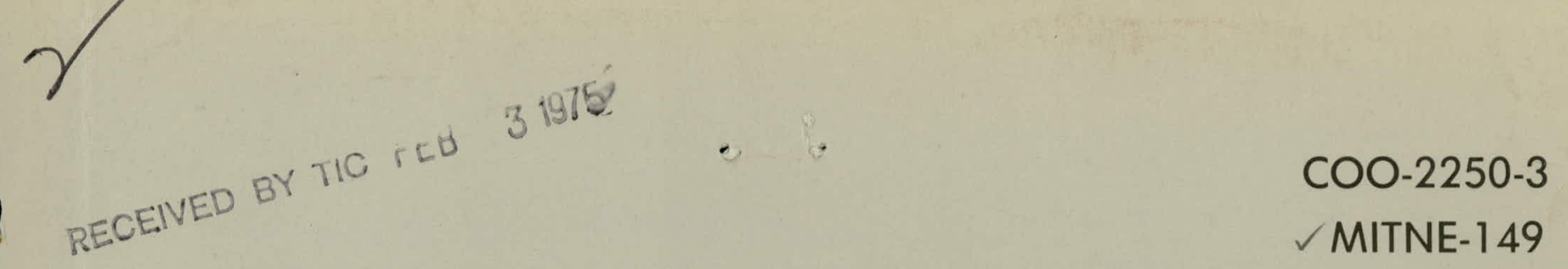

\title{
LMFBR BLANKET PHYSICS PROJECT PROGRESS REPORT NO. 4
}

\author{
June 30,1973 \\ Department of Nuclear Engineering \\ Massachusetts Institute of Technology \\ Cambridge, Massachusetts 02139
}

AEC Research and Development Report Contract AT (1 1-1) 2250

U.S. Atomic Energy Commission 


\section{DISCLAIMER}

This report was prepared as an account of work sponsored by an agency of the United States Government. Neither the United States Government nor any agency Thereof, nor any of their employees, makes any warranty, express or implied, or assumes any legal liability or responsibility for the accuracy, completeness, or usefulness of any information, apparatus, product, or process disclosed, or represents that its use would not infringe privately owned rights. Reference herein to any specific commercial product, process, or service by trade name, trademark, manufacturer, or otherwise does not necessarily constitute or imply its endorsement, recommendation, or favoring by the United States Government or any agency thereof. The views and opinions of authors expressed herein do not necessarily state or reflect those of the United States Government or any agency thereof. 


\section{DISCLAIMER}

Portions of this document may be illegible in electronic image products. Images are produced from the best available original document. 
IMASACHUSETTS INSTITUTE OF TECHNOLOGY

DEPARTMENT OF NUCLEAR ENGINEERING

Cambridge, Massachusetts 02139

$$
\text { COO-2250-3 MITNE-149 }
$$

AEC Research and Development Contract

UC-34 Physics

LMFBR BLANKET PHYSICS PROJECT PROGRESS REPORT NO. 4

June 30,1973

Contract AT (11-1) 2250

U.S. Atomic Energy Commission

Editors:

M.J. Driscoll

D.D. Lanning

I. Kaplan

A.T. Supple

Contributors:
A. Alvim
G.J. Brown
J.K. Chan
T.P. Choong
M. J. Dris coll
G.A. Ducat
I. A. Forbes
M. V. Gregory
S. Y. Ho
C.M. Hove
O.K. Kadiroglu
R.J. Kennerley
D.D. Lanning
J. L. Lazewatsky
L. Lederman
A.S. Leveckis
V.A. Miethe
P.A. Scheinert
A. M. Thompson
N.E. Todreas
C.P. Tzanos
P.J. Wood

Inis report was prepared as an account of work the United the United States Government. Neither Research Und States nor the United States Energy Research and Development Administration, nor any of their employees, nor any of their contractors, warranty, express or implied, employees, makes any liability or responsibilityplied, or assumes any legal or usefulness of or usefulness of any information, apparatus, product or infringe privately, or represents that its use would not 


\section{DISTRIBUTION}

$$
\text { COO-2250-3 MITNE-149 }
$$

AEC Research and Development Contract

$$
\begin{aligned}
& \text { AT }(11-1) 2250 \\
& \text { UC-34 Physics }
\end{aligned}
$$

1-3. U.S. Atomic Energy Commission, Headquarters Division of Reactor Development and Technology Reactor Physics Branch

4, 5. U.S. Atomic Energy Commission Cambridge Office

6. Dr. Paul Greebler, Manager Nuclear Energy Division Breeder Reactor Department General Electric Company 310 DeGuigne Drive Sunnyvale, California 94086

7. Dr. Harry Morewitz, Manager LMFBR Physics and Safety Projects Atomics International P.O. Box 309 Canoga Park, California 91305

8. Mr. Malcolm Dyos, Manager Nuclear Development, LMFBR Project Westinghouse Electric Corporation Advanced Reactors Division Waltz Mill Site P.O. Box 158 Madison, Pennsylvania 15663

9. Dr. Robert Avery, Director Reactor Physics Division Argonne National Laboratory 9700 South Cass Avenue Argonne, Illinois 60439

10. Dr. Charles A. Preskitt, Jr., Manager Atomic and Nuclear Department Gulf Radiation Technology P. O. Box 608 San Diego, California 92112 


\begin{abstract}
This is the fourth annual report of an experimental program for the investigation of the neutronics and photonics of benchmark mockups of LMFBR blankets.

During the period covered by the report, July 1, 1972 through June 30,1973 , work was devoted to completion of experimental measurements and data analysis on Blanket Mockup No. 3, a graphitereflected blanket, and to initiation of experimental work on Blanket Mockup No. 4, a steel-reflected assembly designed to mock up a demonstration plant blanket.

Work was also carried out on the analysis of a number of advanced blanket concepts, including the use of high-albedo reflectors, the use of thorium in place of uranium in the blanket region, and the "parfait" or completely internal blanket concept.

Finally, methods development work was initiated to develop the capability for making gamma heating measurements in the blanket mockups.
\end{abstract}




\section{TABLE OF CONTENTS}

Chapter 1. Introduction 12

1.1 Foreword . 12

1.2 Research Areas 13

1.3 Blanket Mockup No. $4 \quad 13$

1.4 Staff 18

1.5 References 19

Chapter 2. Neutron Spectrometry 20

2.1 Introduction $\quad 20$

2.2 Instrumental Methods 20

2.3 Foil Methods 21

2.4 Future Work $\quad 24$

2.5 References 26

Chapter 3. Heterógeneous Effects $\quad 27$

3.1 Introduction . . 27

3.2 Calculation of Flux Ratios in Unit Cells 28

3.3 Anisotropic Diffusion 32

3.4 Reactivity Effects of Heterogeneity 40

3. 5 Energy Self-Shielding of Resonances 41

3.6 Heterogeneous Effects in Reference FBR Designs 49

3.7 Heterogeneous Effects in FBR Blankets 56

3.8 Summary and Recommendations $\quad 59$

3.9 References 61

Chapter 4. Advanced Blanket Configurations 62

4.1 Introduction $\quad 62$

4.2 Blanket Heating Analysis $\quad 66$

4.2.1 Method of Analysis $\quad 66$

4.2.2 Fission Heating Analysis $\quad 67$

4.2.3 Gamma Heating Analysis 68

4.2.4 Neutron Heating Analysis $\quad 76$

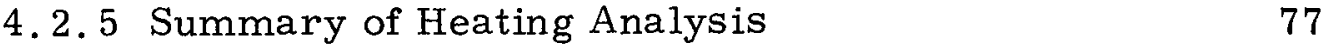


4. 3 Evaluation of Blanket Configurations : 81

4.3.1 Method of Burnup 81

4.3.2 Burnup-Economic Model $\quad 83$

4.3.3 Thermal-Hydraulic Economic Model “ ‘ 84

4.3.4 Results 88

4.4 Experimental Studies $\quad 91$

4.4.1 Description of the Experiment 91

4.4.2 Analysis of Experimental Results 93

4.5 Conclusions and Recommendations 96

4.6 References $\quad 99$

Chapter 5. Thorium Blankets 101

5.1 Introduction 101

5.2 Physics-Depletion Analysis : 102

5.2.1 Comparison of Blanket Breeding Performance " 102

5.2.2 Experimental Studies 106

5.3 Economic Analysis $\quad .113$

5.3.1 Comparative Blanket Economics 113

5.3.2 Comparison of Management Schemes 120

5.3.3 Economic Model 121

5.3.4 Effect of Uncertainties ". 124

5.4 Engineering and Physics Comparisons 125

5.4.1 Blanket Heating Characteristics 125

5.4.2 Reactor Physics Characteristics $\quad 127$

5.4.3 Blanket Interchangeability 129

5.5 Recommendations for Future Work 130

5.6 References $\quad 132$

Chapter 6. The Parfait Blanket Concept 135

6.1 Introduction 135

6.2 Neutronics 139

6.3 Core Engineering 149

6.4 Safety Considerations 153

6.5 Feasibility and Economics 156

6.6 Conclusions and Recommendations 160

6.7 References 162 
Chapter 7. Gamma Heating Measurements

7.1 Introduction

7.2 Calculations

7. 3 Experimental Methods

7.4 References

Chapter 8. Parametric Studies $\quad 167$

$\begin{array}{ll}8.1 \text { Introduction } & 167\end{array}$

8.2 Elastic Group-Transfer Cross Sections $\quad 167$

8. 3 Threshold Detector Traverses $\quad \therefore \quad 170$

8.4 Future Blankets 172

8.5 Epithermal Spectrum Facility 173

8.6 Fission-Track Counting 176

8.7 Effects of $\mathrm{H}_{2} \mathrm{O}$ Contamination $\quad 179$

8. 8 The Effect of Core Size on Radial Blanket Performance $\quad 179$

8.9 References $\quad 181$

Chapter 9. Summary, Conclusions and Future Work 182

9.1 Introduction $\quad \because 182$

9.2 Discussion $\quad 182$

9.3 Future Work 183

9.4 References $\quad 185$

$\begin{array}{ll}\text { Appendix A. } & \begin{array}{l}\text { Bibliography of Blanket Physics Project } \\ \text { Publications }\end{array} \\ \end{array}$

A. 1 Doctoral Theses 186

A. 2 S.M. and B.S. Theses 187

A. 3 Other Publications $\quad 189$ 
LIST OF FIGURES

1. 1 Schematic View of Blanket Assembly No. 4

1.2 Neutron Spectrum $9.5 \mathrm{~cm}$ into Blanket for Mockup No. 4 Driven by Different Assemblies

2.1 Neutron Spectrum Measured in Blanket Mockup No. 4 Using the Mixed-Powder Foil Method

3. 1. Unit Cell Model and Boundary Currents

3.2 Group-by-Group f-Factor Correlations

3. 3 One-Group Correlation

3.4 Heterogeneous Effects on Sodium-Void Reactivity 50

3. 5 Lattice Geometry

4.1 1000-MWe Reference Reactor Configurations

4.2 Fission Density in a Three-Row Depleted-U Blanket at Beginning of Life

4. 3 U-235 Equivalent Enrichment of U-238 as a Function of Position in a Radial Blanket

4. 4 Gamma Energy Deposition Traverses for Variously Enriched Blankets

4. 5 Excess Gamma Energy Deposition in the Blanket

4.6 Ratio of Excess Gamma Energy to Fission Energy Deposition in the Blanket

4.7 Effect of Enrichment on Neutron Heating

4.8 Contribution of the Excess Neutron Heating to the Total Neutron Heating Rate in the Blanket

4.9 Contributions to the Total Blanket Heating Rate

4.10 Overcooling Due to Temporal and Spatial Gradients

4. 11 Overhead View of Blanket Mockup No. 3 
5. 1 Schematic of Reference Reactor Design, 1000-MWe LMFBR

5. 2 Fissile Material Inventory in Batch Managed Uranium Radial and Axial Blankets

5. 3 Difference in Total Fissile Product Between Thorium and Uranium Blankets

5. 4 Comparison of Uranium Radial Blanket Fissile Inventories for Various Management Schemes

5. 5 Comparison of Thorium Radial Blanket Fissile Inventories for Batch Management and Zone Scatter Management

5. 6 Comparison of Calculated and Experimental Fission Rates for Thorium and Uranium Foil Traverses in BTF 4, Cross Sections from ABBN-FTR-200 Set

5. 7 Comparison of Differential Capture Rates in Radial Blanket

5.8 Comparison of Calculated and Experimental Capture Rates in Thorium and Uranium Foils; Predictions Made Using the 106-Group Modified ABBN Cross Section Set

5.9 Power Cost Contributions from Rows 1, 2 and 3 of a Batch Managed Th-232 Blanketed System for U-233 at $16.7 \$ / \mathrm{g}$

5. 10 Comparison of the Total Power Cost Contributions from Batch Managed Thorium and Uranium Radial Blankets

5.11 Comparison of the Total Power Cost Contribution from Batch Managed Thorium and Uranium Axial Blankets

5:12 Economic Comparison of Thorium and Uranium Blankets for 1000-MWe LMFBR

5.13 Break-Even Parity Ratio: Ratio of Value of U-233 to That of Fissile Pu Versus Value of Fissile Plutonium

5. 14 Comparison of Radial Blanket Row 1 Optimum Irradiation Time for Batch Irradiated Thorium and Uranium Blankets

5.15 Comparison of Radial Blanket Row 1 Optimum Enrichment for Batch Irradiated Thorium and Uranium Blankets

5. 16 Comparison of BOL Heating Rates External to the Core

5.17 Comparison of Uranium and Thorium Radial Blanket Heating Rates After 600 Days (2 Years) of Irradiation 
6. 1 The Parfait Blanket Concept

136

6. 2 Core Configurations for Evaluating the Effects of Internal Blanket Thickness

141

6.3 Parfait Performance Relative to the Reference Core as a Function of Internal Blanket Thickness

6.4 Total Flux Along Core Centerline for Reference Core and 30-cm IB Parfait

145

6. 5 Total Flux at Core Midplane for Reference Core and 30-cm IB Parfait

6.6 Performance Sensitivity to Fuel Volume Percent in Core

6. 7 EOC Wrapper Tube Dilation Due to Swelling.

6.8 EOC Wrapper Tube Elongation Due to Swelling

6.9 Fuel Cycle Costs as a Function of Fuel Volume Percent (Fabrication Charges for All Cores Normalized to the Reference Core with $30 \mathrm{v} / 0$ Fuel in Core)

7. 1 Ratio of Gamma to Neutron Flux in Blanket and Reflector

8. 1 Comparison of Calculated Mid-Blanket Neutron Spectra for Blanket Mockup No. 4

8.2 Comparison of the Effect of Cross Section Variations on U-238 Fission Traverses in the Iron Blanket Reflector

8.3 Replacement of Sodium by Aluminum in Blanket Mockup No. 4: Comparison of Mid-Blanket Neutron Spectra

8.4 Replacement of Sodium by Aluminum in Blanket Mockup No. 4: Comparison of U-238 Capture Traverses

8. 5 Comparison of Fission and Transistor Irradiation Facility Fluxes 


\section{LIST OF TABLES}

1. 1 Homogenized Atom Densities in Blanket No. 4

1.2 Neutron Spectrum $9.5 \mathrm{~cm}$ Into Blanket for Mockup No. 4 Driven by Different Assemblies

2. 1 Experimental Foil Activities

3.1 ANISN Slab Cell Total Fluxes

3.2 ANISN Cylindrical Cell Total Fluxes $\quad 34$

3.3 Comparison of Theory and ANISN Results 35

3.4 Case Descriptions for Table $3.3 \quad 36$

3.5 Diffusion Coefficients for Sample Cell $\quad 39$

3.6 Heterogeneous Reactivity Contributions ( $\mathrm{Na}$ In) 42

3.7. Heterogeneous Reactivity Contributions ( $\mathrm{Na}$ Out) $\quad 42$

3.8 Central Zone Sodium Voiding Reactivities $\quad 44$

3.9 Sodium Void Effects in Cylindrical Geometry 44

3.10 Heterogeneous Effects in 1000-MWe Designs $\quad 51$

3.11 Heterogeneous Effects in Demonstration Core $\quad 51$

3.12 Leakage Reactivity in Hexagonal and Triangular Lattices 52

3.13 Heterogeneous Effects in GCFRs . $\quad 54$

3.14 Effect of Anisotropic Streaming on 300-MWe GCFR $\quad 54$

3.15 Fuel Dispersal Accident $\quad 55$

3.16 Two-Piece Foil F-Factors for Metal Rods $\quad 57$

$3.17 \mathrm{U}-238$ Self-Shielded $\sigma_{\mathrm{a}} \quad \ldots \quad 57$

3. 18 Effect of Self-Shielding on Breeding Ratio $\quad 59$

4.1 Reference Reactor Parameters 65

4.2 Distribution of Energy Released in Fission $\quad 67$

4.3 Excess Gamma Energy Deposition 76 
4.4 Summary of Microscopic Energy Absorption Cross Sections for Evaluation of Neutron Heating

4. 5 Economic Environment

4.6 Definition of Parameters in the Thermal-Hydraulic Economic Model

4. 7 Relative Savings Realized by Various Advanced Blanket Configurations $\left(10^{5} \$ / \mathrm{yr}\right)$

4.8 Activation Foils Used in BTF Blanket Mockup No. 3

5.1 Reference Economic Environment

115

5.2 Comparison of Radial Blanket Power Cost Contributions for Various Management Schemes

5.3 Range of Variation of Economic Parameters

5. 4 Effect of Methods and Assumptions on Thorium Blanket Relative Economic Performance

5. 5 Summary of Differences in System Physics Characteristics Between Uranium and Thorium Blanketed LMFBRs

6. 1 Dimensional and Material Characteristics of the Reference. and Parfait Systems

6. 2 Neutron Energy Group Structure

6. 3 Parfait System Performance as a Function of Internal Blanket Thickness

6. 4 Comparison of Safety-Related Nuclear Parameters of the Reference and Parfait Configurations

6. 5 Equilibrium Fuel Cycle Cost Contributions by Region

6.6 Summary Evaluation of the $30-\mathrm{cm}$ IB Parfait Blanket Configuration Relative to the Reference Reactor

8.1 Errors in Blanket Flux and Capture Rates Due to Neglect of $\mathrm{H}_{2} \mathrm{O}$ Contamination 


\section{INTRODUCTION}

\subsection{Foreword}

This is the fourth annual report of the LMFBR Blanket Physics Project. This report covers work done since the last progress report, Reference (1), during the time period from July 1, 1972 through June 30, 19.73.

The MIT Blanket Research Project is part of the AEC's LMFBR development program, having as its primary objective the experimental investigation of clean, but realistic, benchmark mockups of the blanket-reflector region of large LMFBR reactors. The key experimental tool used in this work is the Blanket Test Facility at the MIT Research Reactor. The BTF contains a fission-converter plate tailored to deliver a neutron spectrum simulating LMFBR core leakage, which can be used to drive fast reactor blanket-reflector mockups.

Blanket subassemblies are constructed of uranium metal fuel rods, clad in carbon steel, surrounded by anhydrous sodium chromate. The homogenized mixture closely simulates $\mathrm{UO}_{2}$ fuel, stainless steel clad and sodium metal coolant. Recently completed work has also shown that all of the important heterogeneous effects are also closely simulated (2) .

To date, four blankets have been investigated. Blanket No. 1 was a borax-iron assembly used only for preliminary tests of system design performance; No. 2 was a 3-subassembly-row, steel-reflected mockup of a typical large (1000 MWe) LMFBR design; and No. 3 was a 2-row, graphite-reflected mockup of an advanced design. Blanket Mockup No. 4 currently under investigation is similar to No. 2 , except that the converter has been modified to drive it with a spectrum typical of a smaller, demonstration-reactor-sized core. 


\subsection{Research Areas}

During the report period work was carried out in the following areas:

1. Neutron spectrometry, both foil method and instrumental (Chapter 2).

2. Detailed analysis of the effects of heterogeneity on the neutron balance (Chapter 3 ).

3. Completion of the analysis of advanced blanket configurations, primarily the graphite-reflected blanket type which was studied experimentally in Blanket Mockup No. 3 (Chapter 4).

4. Completion of an analysis of the use of thorium in LMFBR blankets (Chapter 5).

5. Completion of an analysis of the characteristics of a completely internal blanket concept, the parfait blanket (Chapter 6).

6. Initiation of work on the analysis and measurement of gamma heating in LMFBR blankets (Chapter 7).

7. An extensive series of parametric studies, analytical, numerical and experimental, involving all aspects of project work (Chapter 8).

In the final chapter, general observations are made on the current status of the project and the projected future research program is outlined.

\subsection{Blanket Mockup No. 4}

Blanket Mockup No. 4 is a 3 -subassembly row, steel-reflected mockup driven by a simulated demonstration reactor core. The blanket itself is identical to Mockup No. 2, which has previously been described in detail (3). Figure 1.1 and Table 1.1 display and summarize the major features of this assembly. Figure 1.2 and Table 1.2 show the excellent agreement between calculated spectra for this blanket driven by the BTF converter and by a ZZPR-2 critical assembly core. 


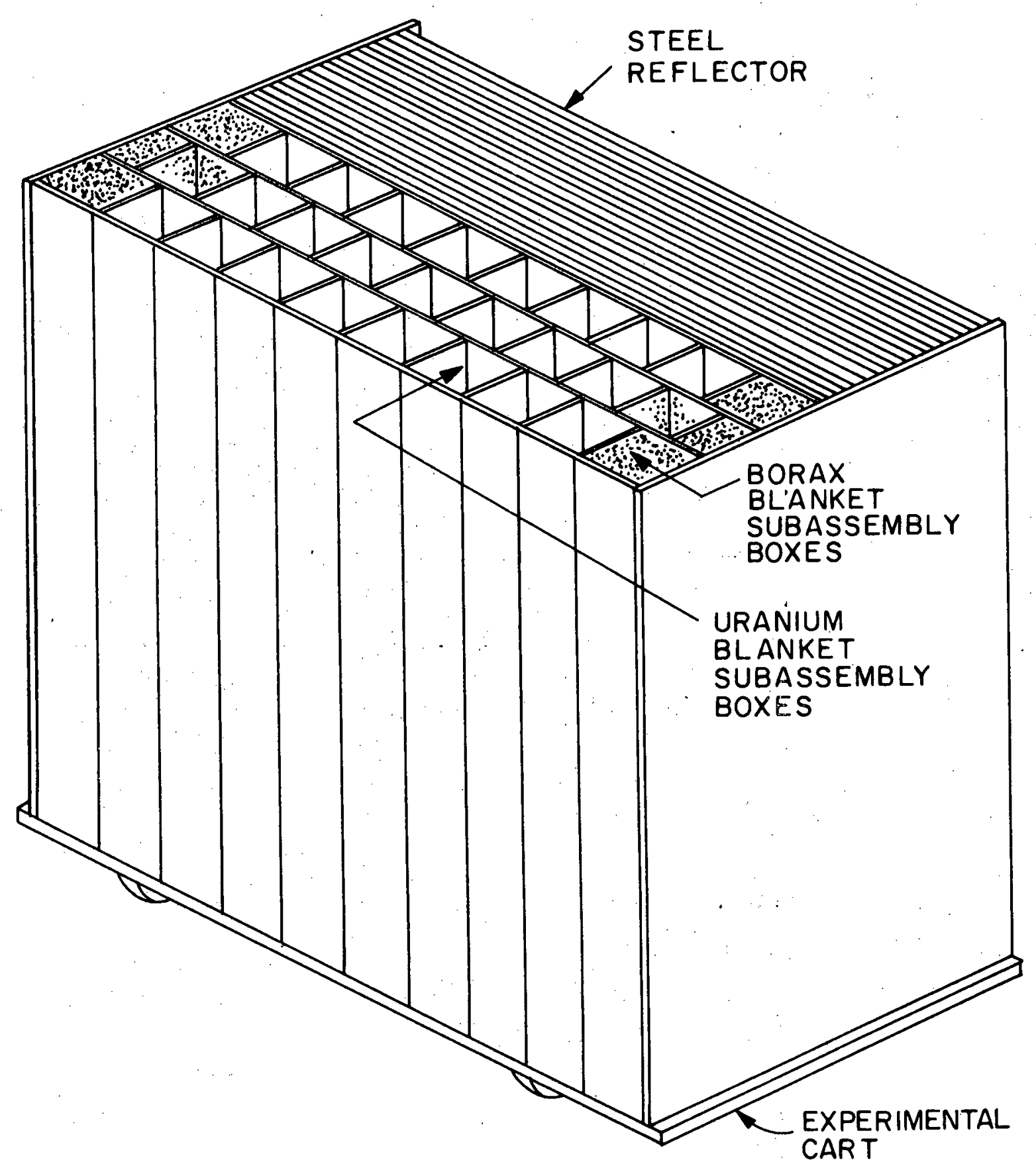

FIG. I.I SCHEMATIC VIEW OF BLANKET ASSEMBLY NO. 4 
TABLE 1.1

Homogenized Atom Densities in Blanket No. 4 (Atoms/barn-cm)

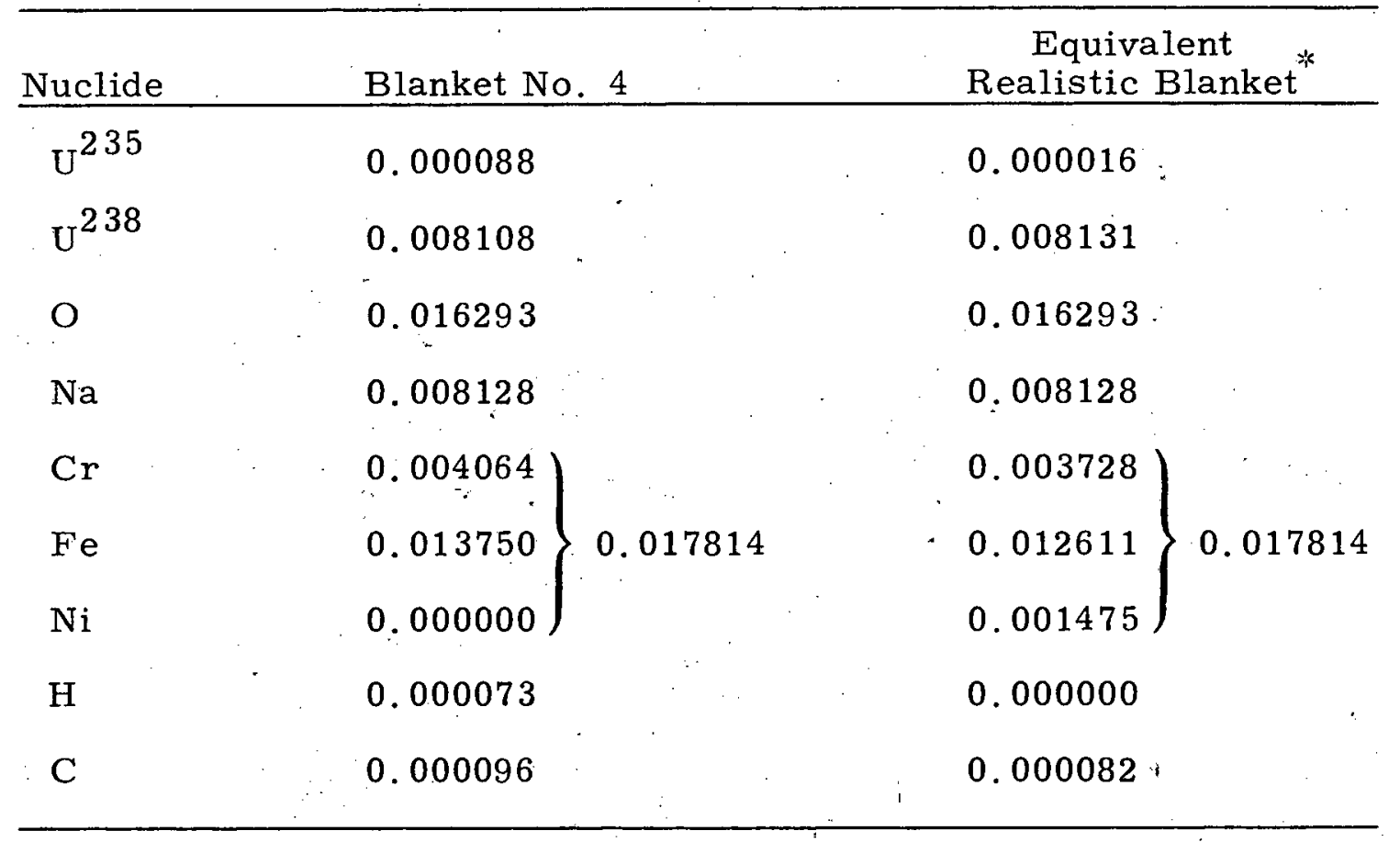

Nuclide Steel Reflector

C

0.000590

$\mathrm{Fe}$

0.084570

* Composed of $37.0 \mathrm{v} / \mathrm{o}$ depleted $\mathrm{UO}_{2}$ (at $90 \%$ of the theoretical density), $20.7 \mathrm{v} / \mathrm{o}$ Type 316 stainless steel, $32.0 \mathrm{v} / \mathrm{o}$ sodium and $10.3 \mathrm{v} / \mathrm{o}$ void. 
FIG. 1.2 MELTPON SPECTRLIN $9.5 \mathrm{cM}$ IMTO BLANKET FOR MOCKUP 10.4 DRIVEN BY DIFFERENT ASSEMBLIES

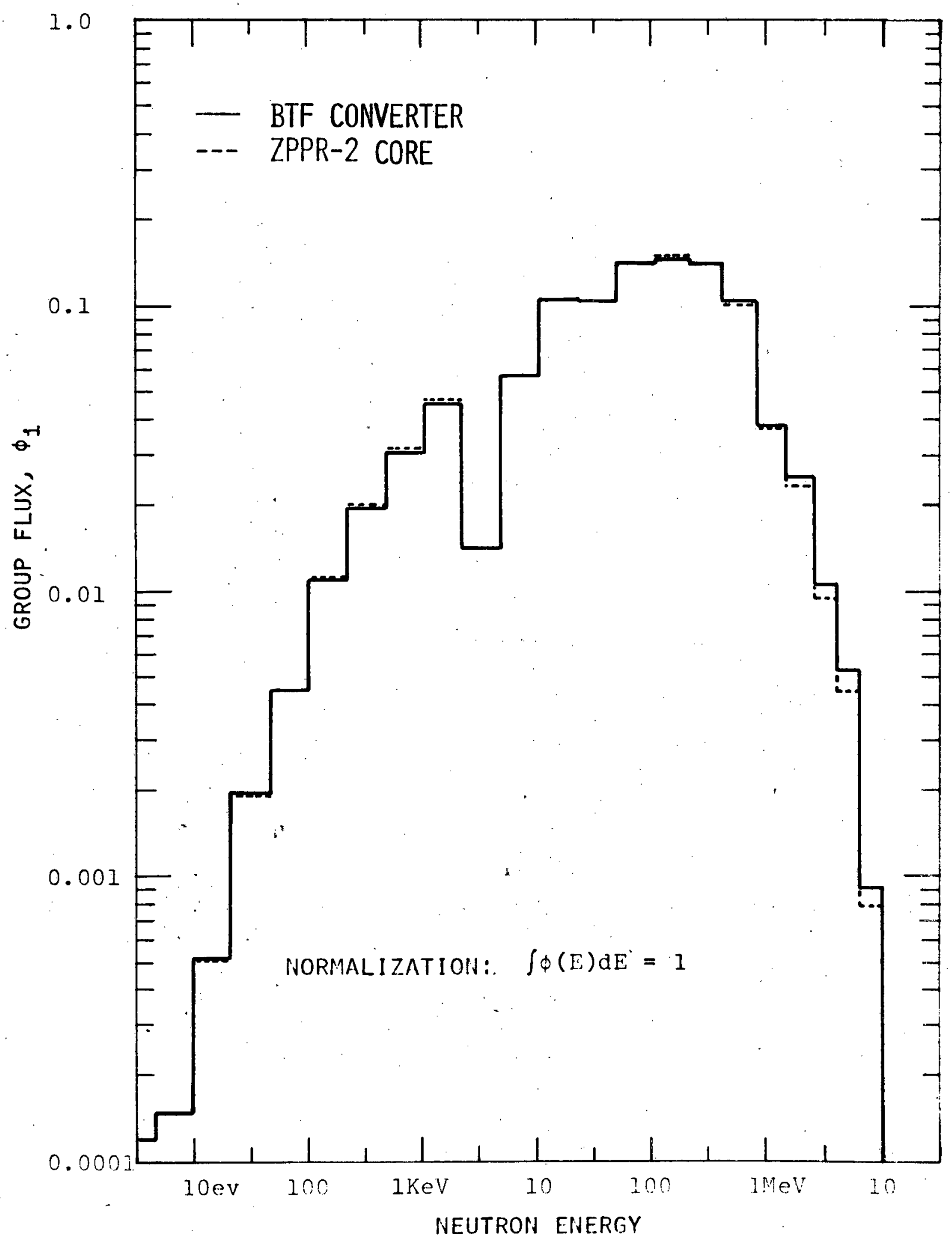


TABLE 1.2

Neutron Spectrum $9.5 \mathrm{~cm}$ Into Blanket for

Mockup No. 4 Driven by Different Assemblies

\begin{tabular}{|c|c|c|}
\hline Group ${ }^{*}$ & ZPPR-2 Core & BTF Converter \\
\hline 1 & 0.000779 & 0.000923 \\
\hline 2 & 0.00443 & 0.00532 \\
\hline 3 & 0.00936 & 0.0106 \\
\hline 4 & 0.0232 & 0.0252 \\
\hline 5 & 0.0377 & 0.0382 \\
\hline 6 & 0.0999 & 0.103 \\
\hline 7 & 0.142 & 0.141 \\
\hline 8 & 0.149 & 0.145 \\
\hline 9 & 0.143 & 0.142 \\
\hline 10 & 0.101 & 0.102 \\
\hline 11 & 0.103 & 0.103 \\
\hline 12 & 0.0564 & 0.0564 \\
\hline 13 & 0.0138 & 0.0140 \\
\hline 14 & 0.0463 & 0.0457 \\
\hline 15 & 0.0314 & 0.0304 \\
\hline 16 & 0.0199 & 0.0193 \\
\hline 17 & 0.0111 & 0.0109 \\
\hline 18 & 0.00444 & 0.00443 \\
\hline 19 & 0.00191 & 0.00193 \\
\hline 20 & 0.000508 & 0.000514 \\
\hline 21 & 0.000147 & 0.000148 \\
\hline 22 & 0.000119 & 0.000119 \\
\hline 23 & 0.0000777 & 0.0000784 \\
\hline 24 & 0.0000421 & 0.0000426 \\
\hline 25 & 0.0000165 & 0.0000357 \\
\hline 26 & 0.0000044 & 0.0000082 \\
\hline Total & 1.000 & 1.000 \\
\hline
\end{tabular}

* Group structure of: L.P. Abagyan et al., "Group Constants for Nuclear Reactor Calculations," Consultants Bureau (1964). 
Various chapters of this report describe research, most of which is centered about Blanket Mockup No. 4. A complete compendium of evaluated data on this mockup will be published during FY 1975 in a form suitable for use as an experimental benchmark.

\section{$1.4 \underline{\text { Staff }}$}

The project staff, including thesis students, during the report period was as follows:

M. J. Driscoll, Associate Professor of Nuclear Engineering

I. Kaplan, Professor of Nuclear Engineering

D. D. Lanning, Professor of Nuclear Engineering

N. E. Todreas, Associate Professor of Nuclear Engineering

V. A. Miethe; Computer Operations Assistant

A. T. Supple, Engineering Assistant

I. A. Forbes, DSR Staff (Summer 1972)

C. P. Tzanos, DSR Staff (Summer 1972)

A. Alvim, Special Project Student (Summer 1972)

G. J. Brown, Research Assistant, Sc.D. Student

J. K. Chan, Research Assistant, S. M. Student (since Jan. 1973)

T.- P. Choong, Research Assistant (Summer 1973), S. M. Student

G. A. Ducat, Research Assistant, Sc.D. Student

M. V. Gregory, Research Assistant, Sc.D. Student (to Feb. 1973)

S. Y. Ho, Research Assistant (Summer 1972), S. M. Student

C. M. Hove, Course 22.39 Project Student, Spring 1973

O. K. Kadiroglu, Research Assistant, Sc.D. Student (since April 1973)

R. J. Kennerley, S. M. Student

J. L. Lazewatsky, Laboratory Assistant (Summer 1972)

L. Lederman, Course 22.39 Project Student (Spring 1973); Laboratory Assistant (Summer 1973)

A. S. Leveckis, Undergraduate Research Opportunities Student (Fall 1972); Laboratory Assistant (Spring 1973)

P. A. Scheinert, Research Assistant (Summer 1973), Nuclear Engineer Degree Student

A. M. Thompson, Research Assistant (Spring 1973), S. M. Student

P. J. Wood, Sc. D. Student 


\subsection{References}

(1) LMFBR Blanket Physics Project Progress Report No. 3, COO-3060-6, MITNE-143, June 30, 1972.

(2) M. V. Gregory, M. J. Driscoll and D. D. Lanning, "Heterogeneous Effects in Fast Breeder Reactors," COO-2250-1, MITNE-142, Jan. 1973.

(3) T. C. Leung et al., "Neutronics of an LMFBR Blanket Mock-Up," COO-3060-1, MITNE-127, Jan. 1972. 


\section{NEUTRON SPECTROMETRY}

\subsection{Introduction}

Comparisons of measured and calculated neutron spectra are of obvious utility in reactor physics evaluations, and a continuing effort in this area is carried out as part of the work done on the MIT blanket mockups. Both instrumental and foil methods have been used: applications in each area are described in this chapter.

\subsection{Instrumental Methods}

An extensive effort to acquire and apply state-of-the-art instrumental neutron spectrometers was made in 1971-72, and the results have been reported by Ortiz et al., (1). The Li-6, He-3 and p-recoil spectrometers discussed in this topical report have since been used for a number of applications. Choong (2) used the Li-6 spectrometer to examine fast neutron penetration in the steel reflector of Blanket Mockup No. 4. His work, discussed further in Chapter 8 of this report, showed that the previously reported disagreement between calculated and measured threshold foil activation could be explained, and that it did not signify anomalously high fast neutron penetration through the reflector. Lal (3) used the He-3 spectrometer to confirm that the neutron spectrum in the MITR Transistor Irradiation Facility was a good approximation to an unperturbed fission neutron spectrum and therefore useful for foil calibration purposes. A significant result demonstrated in these investigations was that the semiconductor detectors used in these spectrometers were too sensitive to radiation damage to warrant their continued use in blanket mockup studies unless a capability for in-house fabrication were to be developed. Because of the many advantages of the proton-recoil type spectrometer, it was instead decided to concentrate on this apparatus for all future applications. Kennerley (4) accordingly refurbished Ortiz's instrumentation, and engaged in an extensive investigation of improved 
experimental techniques. An improved detector design has been ordered from a British firm, and tentative plans made for its future use in Blanket Mockup No. 4.

\subsection{Foil Methods}

Work on the mixed-powder foil technique, the development of which has been under way at MIT for some time now, has been completed $(\underline{5}, \underline{6})$. This method involves the use of capsules containing a mixture of "foil" materials in powder form. After irradiation, the foil activities are measured simultaneously using high resolution $\mathrm{Ge}(\mathrm{Li})$ gamma spectrometry. Calibration of the same capsules in a thermal spectrum is employed to normalize out much of the experimental error. Finally, the foil activity data are input to a spectrumunfolding code for determination of the ambient neutron spectrum to which the foil capsule was exposed.

The emphasis in the present work was upon determination of the neutron spectrum in the sub-keV energy range. Cross section sensi-. tivity to this region and other factors such as useful half-life of . activation products, and overall detectability of decay gamma photons, led to selection of six materials as foil detectors: Au-197, Mn-55, $\mathrm{Na}-23, \mathrm{As}-75, \mathrm{La}-139$ and $\mathrm{Pr}-141$. Niobium and vanadium were demonistrated to be suitable capsule materials because of their negligible neutron activation in a fast breeder reactor spectrum, and because of their proven compatibility with sodium coolant, which makes this method satisfactory for possible future use in operating LMFBRs.

Four foil capsules (two each of $\mathrm{Nb}$ and $\mathrm{V}$ ) having a 25-mil wall thickness, 2.5 in length and 0.25 in diameter were fabricated; each contained approximately $3 \mathrm{mg} \mathrm{Au}, 15 \mathrm{mg} \mathrm{As,} 35 \mathrm{mg} \mathrm{Mn}, 65 \mathrm{mg} \mathrm{La}$, $600 \mathrm{mg} \mathrm{Na}$ and $800 \mathrm{mg} \mathrm{Pr}$. Each was irradiated at the center of the blanket region in Mockup No. 4 for 15 hours, cooled for 5 hours and counted for 5 hours. The standard counting facility constructed by Akalin (7), which employs a 17-cc lithium-drifted germanium semiconductor detector and a 2000-channel multichannel analyzer, was used to record the gamma spectra. The individual foil activities were 
extracted using the GAMANL'program (8). One month after the blanket irradiations, a thermal calibration irradiation of each capsule was carried out using beam tube $2 \mathrm{CH} 1$ in the MITR hohlraum: half-hour irradiations, 10 hours of cooling and a 2-hour counting session were employed. Corrections for epithermal activation in these runs were found to be negligible.

The spectrum unfolding problem can then be expressed in terms of the preceding data as follows:

$$
\left|\overline{\sigma_{\mathrm{a}}} \cdot \frac{\mathrm{C}_{\mathrm{F}}}{\mathrm{C}_{\mathrm{T}}}\right|_{\mathrm{j}}=\sum_{\mathrm{g}=1}^{\mathrm{G}} \sigma_{j \mathrm{~g}} \phi_{\mathrm{g}} \quad \mathrm{j}=1 \ldots \mathrm{N}
$$

where

$$
\begin{aligned}
\bar{\sigma}_{\mathrm{a}}= & \text { Maxwellian-averaged thermal cross section for neutron } \\
& \text { absorption by foil material nuclide } \mathrm{j} \\
\mathrm{C}_{\mathrm{F}}= & \text { total peak area counts for daughter product of } \mathrm{j} \text {, GAMANL } \\
& \text { output, (corrected for irradiation, cooling and counting } \\
& \text { times) obtained in the fast reactor blanket irradiation } \\
\mathrm{C}_{\mathrm{T}}= & \text { similar data from the thermal calibration } \\
\sigma_{\mathrm{jg}}= & \text { gth-group multigroup cross section (in } \mathrm{G} \text {-group set) for } \\
& \text { activation of jth target nuclide } \\
\phi_{\mathrm{g}}= & \text { normalized group g neutron flux }
\end{aligned}
$$

The required cross section data, $\overline{\sigma_{a}}$ and $\sigma_{j g}$, were developed from ENDF/B-III using the SUPERTOG program ( $\underline{9})$.

$G$-group neutron spectra, $\phi_{g}$, were unfolded from the data using the MITSPECTRA code (ㄷ), a simplified version of the RFSP program (10), which is, in turn, an improved version of the SPECTRA code (11). In this program a function characterizing both the deviation between measured and calculated activities and between the initial and unknown spectra is minimized to give the following iterative algorithm for the flux:

$$
\phi_{\mathrm{k}+1}=\left(\mathrm{C}^{\mathrm{T}} \cdot \mathrm{F}^{2} \mathrm{C}+\mathrm{G}^{2}\right)^{-1}\left(\mathrm{C}^{\mathrm{T}} \mathrm{F}^{2} \mathrm{I}+\mathrm{G}^{2} \phi_{\mathrm{k}}\right)
$$


where $C$ is the normalized cross section matrix ( $\sigma_{j g}$ values divided by the measured foil activity $A_{j}$ ), and $F$ and $G$ diagonal matrices used for weighting and normalization; here $F$ is taken as the inverse of the standard deviations of the input activities and $G$ is the inverse of the normalized flux, $\phi_{\mathrm{n}}$ :

$$
\phi_{n}=\frac{\sum_{i=1}^{N}\left(C \phi_{o}\right)_{i}}{\sum_{i=1}^{N}\left(C \phi_{o}\right)_{i}^{2}} \cdot \phi_{o}
$$

References (10) and (11) describe in detail the mathematical advantages of this approach and discuss the relative merits of this method compared to other methods now in use. In the present work the initial guess for the flux vector, $\phi_{O}$, was generated using calculations with a 26-group ABBN-format cross section set and the ANISN program.

The experimental results obtained in the present set of experiments are shown in Table 2.1. All data have been normalized to gold, which is a convenient standard. The mean of the four capsule sets is shown together with the standard deviation from the mean. While the deviations appear somewhat large, it was found by subsequent parametric studies that uncertainties in cross section data and the initial flux guess are more important factors in the unfolding process. It is probably feasible to reduce these deviations to on the order of $\pm 5 \%$ in future applications. 
TABLE 2.1

Experimental Foil Activities

\begin{tabular}{lcc}
\hline Radionuclide & Mean (4 Determinations) & Standard Deviation \\
\hline Au-198 & 1.0 (normalized) & - \\
$\mathrm{Mn}-56$ & 0.129 & $25 \%$ \\
$\mathrm{Na}-24$ & 0.00108 & $8.2 \%$ \\
$\mathrm{As}-24$ & 0.507 & $14.0 \%$ \\
$\mathrm{La}-140$ & 0.0530 & $5.3 \%$ \\
$\mathrm{Pr}-142$ & 0.121 & $15 \%$ \\
\hline
\end{tabular}

Figure 2.1 shows the initial flux guess and the final iterate given by the SPECTRA program. Also shown are error bands generated by successive substitution of foil activities alternatively augmented and decreased by their standard deviation. The unfolded spectra in each case can reproduce the measured foil activities essentially exactly. The agreement between calculated and unfolded spectra is relatively good; the unfolded spectrum appears to be harder than the calculated spectrum in the interesting sub-keV region.

Work on this approach has now been concluded. Satisfactory results have been obtained. The specific need for improved cross section data for foil materials is evident. Improvements in the unfolding techniques will be of continued interest.

\subsection{Future Work}

Plans to reactivate the proton-recoil spectrometer have already been noted. In the foil method area some additional work will be carried out to determine whether improved sub-keV spectrometry can be realized using a combined and improved version of sandwichdetector (12) and foil-stack methods (13). 


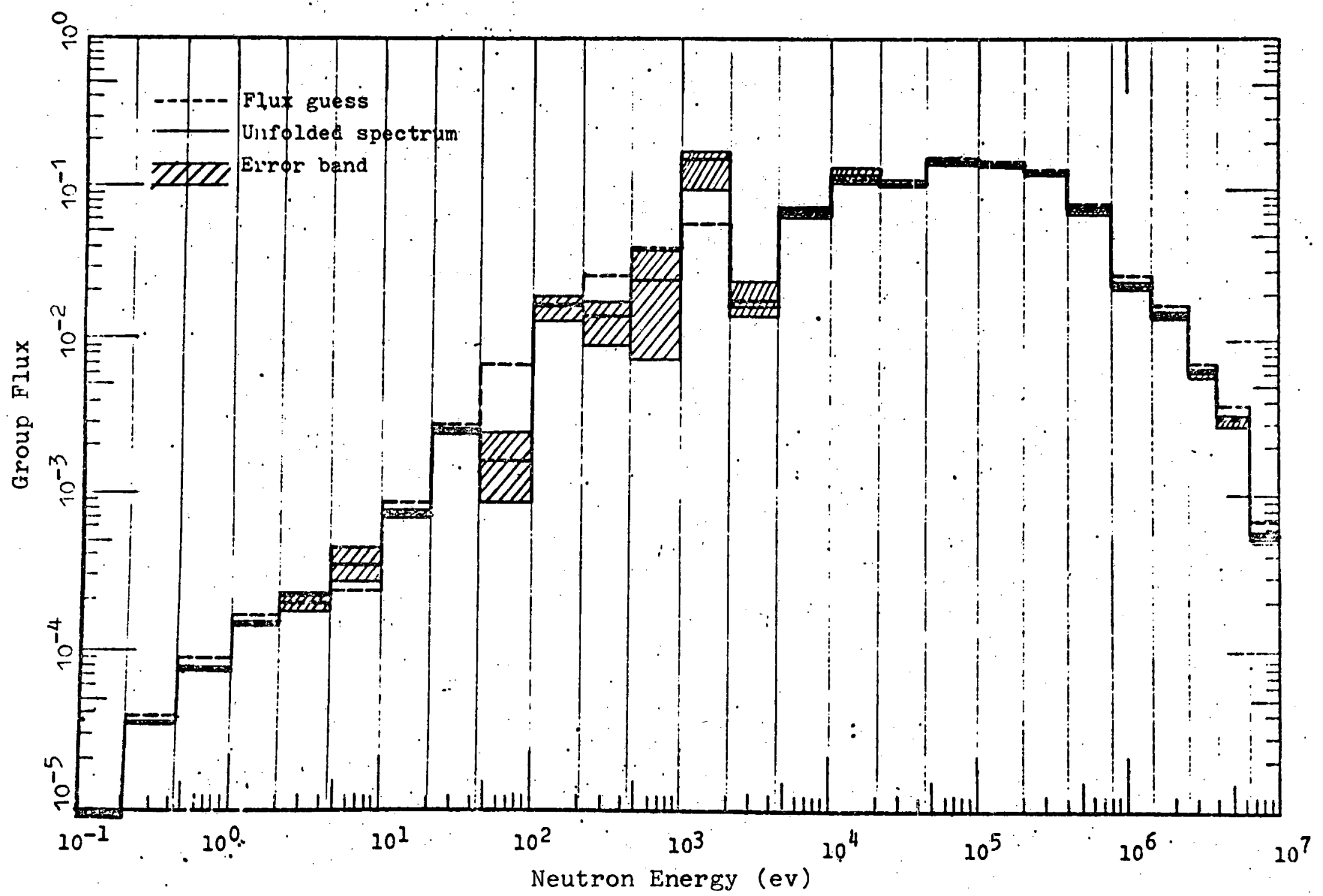

F1. 2.1: NEUTRON SPECTRUM MEASURED IN BLANKET MOCKUP NO. 4 USING THE MIXED-POWDER FOIL METHOD 


\subsection{References}

(1) N.R. Ortiz, I.C. Rickard, M.J. Driscoll and N.C. Rasmussen, "Instrumental Methods for Neutron Spectroscopy in the MIT Blanket Test Facility," COO-3060-3, MITNE-129, May 1972.

(2) T.P. Choong, "Fast Neutron Spectrometry in an LMFBR Blanket Reflector," S.M. Thesis, MIT Nucl. Eng. Dept., Aug. 1973.

(3) D. Lal, "Determination of the Neutron Spectrum in the MITR Transistor Irradiation Facility," B.S. Thesis, MIT Chem. Eng. Dept., June 1972.

(4) R.J. Kennerley, "Proton-Recoil Neutron Spectrometry in a Fast Reactor Blanket," S. M. Thesis, MIT Nucl. Eng. Dept., Aug. 1973.

(5) J. Chan, "A Foil-Method for Neutron Spectrometry in Fast Reactors," S. M. Thesis, MIT Nucl. Eng. Dept., Jan. 1974 (est.).

(6) Chapter 3, "Foil Methods for Neutron Spectrometry," in LMFBR Blanket Physics Project Progress Report No. 3, COO-3060-6, MITNE-143, June 30, 1972.

(7) O. Akalin, "Development of a Counting Facility for Activation Analysis," S.M. Thesis, MIT Nucl. Eng. Dept., Feb. 1972.

(8) T. Harper et al., "GAMANL, A Computer Program Applying, Fourier Transforms to the Analys is of Gamma Spectral Data," MIT-3944-2, MITNE-97, Aug. 1968.

(9) R.Q. Wright et al., "SUPERTOG: A Program to Generate Fine Group Constants and $\mathrm{P}_{\mathrm{n}}$ Scattering Matrices from ENDF/B," ORNL-TM-2679," Sept. 1969.

(10) A. Fischer and A. Turi, "The RFSP Programme for Unfolding Neutron Spectra from Activation Data,' INDC(HUN)-8/U, May 1972 .

(11) C.R. Green, J.A. Halbleib and J.V. Walker, "A Technique for Unfolding Neutron Spectra from Activation Measurements," SC-PR-67-746, Dec. 1967.

(12) A. Weitzberg, "Measurement of Epithermal Spectra in Fast Assemblies Using Resonance Sandwich Detectors," ANL-7320, 1966 .

(13) R.G. Nisle, "Self-Shielding in Stacked Foils," ANCR-1088, Page 446, Oct. 1972. 


\section{HETEROGENEOUS EFFECTS}

The work summarized in the present chapter is primarily concerned with evaluation of the effects of heterogeneity on fast reactor neutron balances. The complete results are presented in the topical report:

M. V. Gregory, M. J. Driscoll, D. D. Lanning, "Heterogeneous Effects in Fast Breeder Reactors," COO-2250-1, MITNE-142, Jan. 1973.

\subsection{Introduction}

The purpose of the research summarized here has been to develop and apply a consistent formalism describing the effects of heterogeneity on fast reactor core and blanket neutronics. Attention is focused upon the pin geometry characteristic of LMFBR power reactors, and emphasis is placed upon the development of simple methods which provide clear physical insight into the variety of phenomena involved, but which are sufficiently accurate for reactor physics design calculations. In addition, the emphasis is on a posteriori corrections to homogeneous calculations.

The simplest representation of a reactor is the homogeneous model; that is, all distinct regions are volume-homogenized. For a fast reactor, this type of homogenization is a fairly good approximation since the mean free path of a neutron is an order of magnitude larger than the unit cell diameter. The effects which such a homogenization overlook are termed the heterogeneous effects. In this work, the methods developed seek to calculate the corrections to the homogeneous representation due to three distinct heterogeneous phenomena: coarsegroup flux distributions within the unit cell, anisotropic diffusion, and resonance self-shielding.

In regard to the desired accuracy for calculations of various design parameters, one may note the following typical requirements: $\mathrm{k}_{\text {eff }} \pm 1 \%$, breeding ratio $\pm 3 \%$, whole-core sodium void reactivity 
$\pm 50 \zeta(1)$. Correct representation of heterogeneous effects, which will be shown to have effects significantly larger than the target precision goals, thus becomes a design necessity.

\subsection{Calculation of Flux Ratios in Unit Cells}

The spatial flux distribution within the unit cell is needed to appropriately average the cross sections for each region and thereby obtain the cell-average value:

$$
\Sigma=\frac{\Sigma_{1} \mathrm{~V}_{1}+\Sigma_{2} \mathrm{~V}_{2}\left(\bar{\phi}_{2} / \bar{\phi}_{1}\right)+\Sigma_{3} \mathrm{~V}_{3}\left(\bar{\phi}_{3} / \bar{\phi}_{1}\right)}{\mathrm{V}_{1}+\mathrm{V}_{2}\left(\bar{\phi}_{2} / \bar{\phi}_{1}\right)+\mathrm{V}_{3}\left(\bar{\phi}_{3} / \bar{\phi}_{1}\right)}
$$

where $\bar{\phi}_{i}=\int \phi(r) d V_{i} / V_{i}, V_{i}$ being the volume of region $i$. A threeregion unit cell is assumed (see Fig. 3.1) with $1=$ fuel, $2=\operatorname{clad}, 3=$ coolant. Note that the homogeneous model is tantamount to a flat cell flux: $\bar{\phi}_{1}=\bar{\phi}_{2}=\bar{\phi}_{3}$.

The flux ratios to be used in Eq. 3.1 may be obtained from unit cell calculations using a transport theory code such as ANISN (2). However, since the quantity of interest is the average flux within each region, a simple theory has been developed which yields the desired ratios directly in terms of certain probabilities:

$$
\begin{aligned}
& \mathrm{p}_{1}=\text { escape probability for neutrons born in fuel } \\
& \mathrm{p}_{3}=\text { escape probability for neutrons born in coolant } \\
& \mathrm{T}_{13}=\text { transmission probability from fuel to coolant } \\
& \mathrm{T}_{31}=\text { transmission probability from coolant to fuel } \\
& \mathrm{T}_{33}=\text { transmission probability from coolant to coolant } \\
& \mathrm{P}_{1}=\text { esia clad without entering fuel } \\
& \mathrm{P}_{3}=\text { escape probability for neutron entering coolant }
\end{aligned}
$$

Based on these probabilities, the boundary currents may be calculated by accounting for all possible events a neutron may experience (i.e. , a poor man's Monte Carlo calculation). For example, the current 


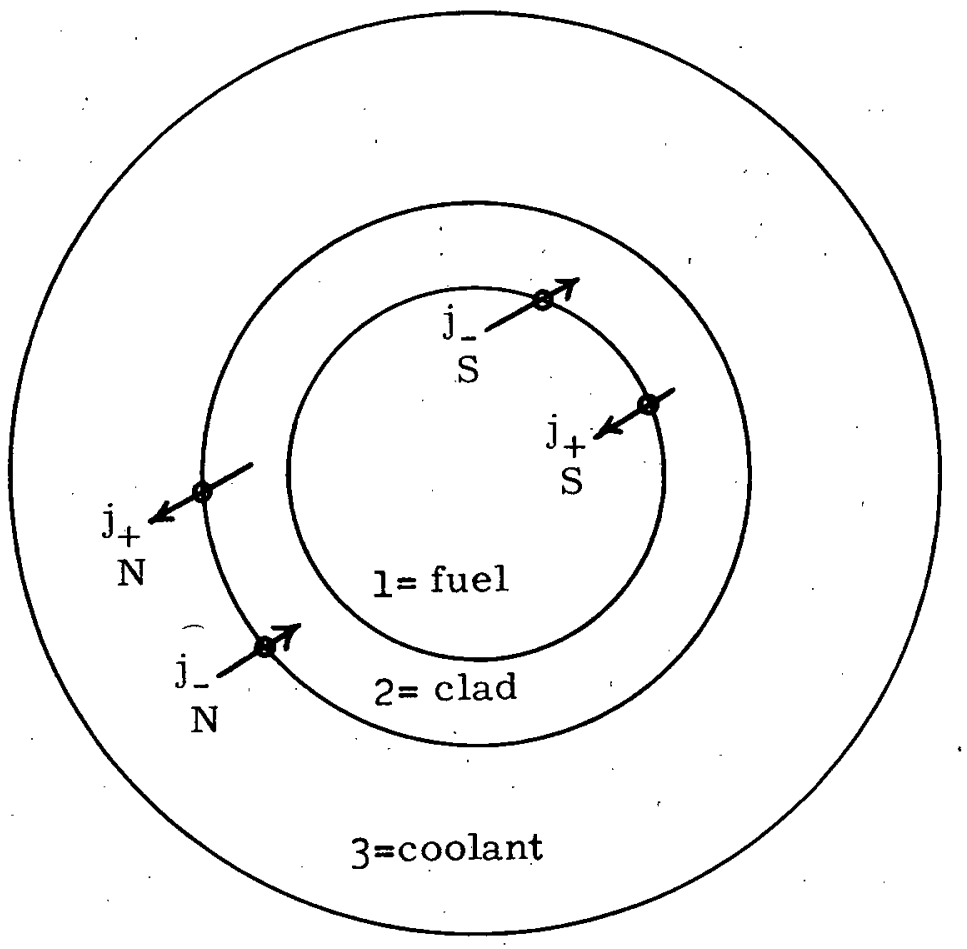

FIG. 3.1: UNIT CELL MODEL AND BOUNDARY CURRENTS 
entering the fuel region due to a uniform source in the fuel is calculated to be:

$$
\mathrm{j}_{\dot{\mathrm{s}}}=\mathrm{S}_{1} \mathrm{p}_{1} \frac{\mathrm{r}_{1}}{2}\left[\frac{\mathrm{T}_{13} \mathrm{P}_{3} \mathrm{~T}_{31}}{1-\mathrm{T}_{33} \mathrm{P}_{3}-\mathrm{P}_{1} \mathrm{~T}_{13} \mathrm{P}_{3} \mathrm{~T}_{31}}\right] \text {. }
$$

This expression is derived by starting with a neutron born in the fuel and calculating the probability of making multiple traversals of the clad and re-entering the fuel. The multiplicity of possible events is infinite, thus the result is an infinite series. However, the terms of that infinite series are products of probabilities (all less than 1.0), thus the closed form of Eq. 3.2 is achieved. Similar expressions are calculable for the other possible boundary currents.

The desired average fluxes are calculated by making a statement of neutron balance. Taking the fuel rod region:

$$
\begin{aligned}
& \Sigma_{\text {a } 1} \bar{\phi}_{1} \pi r_{1}^{2}=\text { loss rate/unit length by absorption } \\
& 2 \pi r_{1}\left(j_{+}-j_{s}\right)=\text { gain rate/unit length by net in-leakage } \\
& \pi \mathrm{r}_{1}^{2} \mathrm{~S}_{1}=\text { gain rate/unit length from internal sources }
\end{aligned}
$$

where $j_{\overline{\mathrm{S}}}$ is the current leaving the fuel region. Requiring losses to equal gains leads to:

$$
\bar{\phi}_{1}=\frac{2\left(j_{+}-j_{s}\right)+S_{1} r_{1}}{\Sigma_{a 1} r_{1}}
$$

Similar expressions may be obtained for the other average fluxes.

The escape probabilities are calculated from first order expressions:

$$
\begin{aligned}
& \mathrm{p}_{1}=\exp \left(-\Sigma_{\mathrm{a} 1} \bar{\ell}\right) \sim 1-\Sigma_{\mathrm{a} 1} \bar{\ell} \\
& \mathrm{P}_{1}=\exp \left(-\Sigma_{\mathrm{a} 1} \overline{\mathrm{L}}\right) \sim 1-\Sigma_{\mathrm{a} 1} \overline{\mathrm{L}}
\end{aligned}
$$

where $\bar{l}$ is the transmission mean chord length $\left(\bar{l}=2 r_{1}\right)$ and $\bar{L}$ is the escape mean chord length $\left(\overline{\mathrm{L}}=4 / 3 \mathrm{r}_{1}\right)$. The clad transmission probabilities are of a more complex form. However, the following 
approximate forms have been established:

$$
\begin{aligned}
& \mathrm{T}_{13}=1-2 \Sigma_{\mathrm{a} 2}\left(\mathrm{r}_{2}-\mathrm{r}_{1}\right), \\
& \mathrm{T}_{31}=\left(\mathrm{r}_{1} / \mathrm{r}_{2}\right) \mathrm{T}_{13}, \\
& \mathrm{~T}_{33}=\mathrm{T}_{13}-\mathrm{T}_{31},
\end{aligned}
$$

which compare very favorably with the exact results (expressible in terms of Bickley-Nayler functions) for the parameters typical of fast systems.

Calculation of sources in the unit cell requires some care. The minimum useful description is a two-group representation in which group 1 (called the first-flight group) extends from $1.4 \mathrm{MeV}$ up. Within that interval U-238 has a non-zero fission cross section, and, furthermore, group 1 is expected to peak at the center of the fuel rod. Group 2 encompasses all energies below $1.4 \mathrm{MeV}$, and is termed the multiply-collided group. ANISN unit cell calculations indicate that the source within each region may be considered spatially uniform (tilted. sources were found to have a negligible effect upon the flux ratios). Thus the group 1 source is taken as a constant in the fuel region and zero elsewhere. The source for the multiply-collided group is somewhat more complex: for the clad and coolant regions, the sources are proportional to the removal cross section for the region. For the fuel region, the sources for the multiply-collided group are both removal from the first-flight group and entrance of fission neutrons into the group:

$$
S_{\mathrm{MC}}^{(1)}=\Sigma_{12}^{(1)}+\chi_{2}\left[\nu \Sigma_{\mathrm{f} 1}^{(1)}+\nu \Sigma_{\mathrm{f} 2}^{(1)}\left(\frac{\phi_{2}}{\phi_{1}}\right)\right] \text {. }
$$

where the superscript " 1 " refers to the fuel region and the subscripts to the group number. With the calculation of the sources, one has all the required information for calculating the region-averaged fluxes from equations of the form of Eq. 3.3.

Equations accounting for a clad-region source proved intractable without the formulation of an extended reciprocity relation: the total flux in region $A$ due to a uniformly distributed source in region $B$ is 
the same as the total flux in region $B$ when the uniformly distributed source has been moved to region $A$. Since the conventional reciprocity theorem is valid only under more restrictive conditions, the postulated extended reciprocity relation requires verification. This was established by performing several ANISN computer "experiments." The results for three-region slab and cylindrical geometries are presented in Tables 3.1 and 3.2, with lines joining those fluxes postulated to be equal by the extended reciprocity relation. One concludes that the postulated relation is valid. Thus clad sources are treated by transforming them to the coolant or fuel regions, and clad escape probabilities need not be calculated.

The final validation of the model was provided by a series of 28

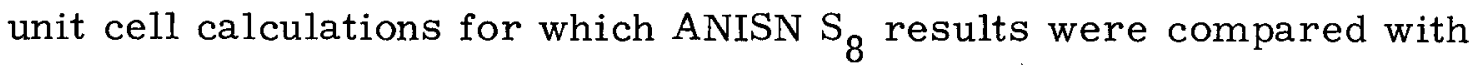
flux ratios predicted by the escape/transmission probability theory. The results of that comparison are presented in Tables 3.3 and 3.4. Some of the tests are stricter than required since the cell parameters are considerably outside the regime of realistic FBR values (e.g., . cases 2, 13, and 25), but even there the agreement is respectable. The agreement for cases typical of FBRs (e.g., cases 8, 11, and 28) is very good.

In summary, a method has been developed which yields the average flux ratios required for weighting region constants to take into account the spatial flux variation in the unit cell. The method's results compare favorably to ANISN $\mathrm{S}_{8}$ unit cell calculations and require significantly less calculational time. The method is easily implemented on a desk calculator or by a simple computer code (in the latter case the calculating time is at least an order of magnitude less than for ANISN).

\subsection{Anisotropic Diffusion}

The second heterogeneous effect identified is anisotropic diffusion. In a truly homogeneous medium, there is no ambiguity in defining the diffusion coefficient since the physical properties are constant along any path the neutron may choose. In that case:

$$
\mathrm{D}=\frac{1}{3 \Sigma_{\mathrm{tr}}}
$$


TABLE 3.1

ANISN Slab Cell Total Fluxes

\begin{tabular}{|c|c|c|c|c|}
\hline & $\mathrm{S}_{2}=1.0, \mathrm{~S}_{1}=\mathrm{S}_{3}=0$ & $\mathrm{~S}_{1}=1.0, \mathrm{~S}_{2}=\mathrm{S}_{3}=0$ & $\mathrm{~S}_{3}=1.0, \mathrm{~S}_{1}=\mathrm{S}_{2}=0$ & $\mathrm{~S}_{2}=1.0, \mathrm{~S}_{3}=\mathrm{S}_{1}=0$ \\
\hline$\phi_{\mathrm{T} 1}$ & 102.510 & 159.612 & 6.93964 & 102.510 \\
\hline$\phi_{\mathrm{T} 2}$ & 700.897 & 102.528 & 160.470 & 700.897 \\
\hline$\phi_{\mathrm{T} 3}$ & 160.507 & 6.93577 & 406.774 & -160.507 \\
\hline
\end{tabular}


TABLE 3.2

ANISN Cylindrical Cell Total Fluxes

\begin{tabular}{|c|c|c|c|c|}
\hline & $\mathrm{S}_{2}=1.0, \mathrm{~S}_{3}=\mathrm{S}_{1}=0$ & $\mathrm{~S}_{1}=1.0, \mathrm{~S}_{2}=\mathrm{S}_{3}=0$ & $\mathrm{~S}_{3}=1.0, \mathrm{~S}_{1}=\mathrm{S}_{2}=0$ & $\mathrm{~S}_{2}=1.0, \mathrm{~S}_{3}=\mathrm{S}_{1}=0$ \\
\hline$\phi_{\mathrm{T} 1}$ & 0.727015 & 1. 29643 & 3.14582 & 0.727015 \\
\hline$\phi_{\mathrm{T} 2}$ & 0.426476 & 0.726903 & 1.82684 & 0.426476 \\
\hline$\phi_{\mathrm{T} 3}$ & 1.82991 & 3.14662 & 8.08063 & 1.82991 \\
\hline
\end{tabular}


TABLE 3.3

Comparison of Theory and ANISN Results

\begin{tabular}{|c|c|c|c|c|c|c|}
\hline Case & $\bar{\phi}_{1} / \bar{\phi}_{3}$ & ANISN & $\Delta$ & $\bar{\phi}_{1} / \bar{\phi}_{2}$ & ANISN & $\Delta$ \\
\hline 1 & 0.97791 & 0.96640 & -0.01151 & 0.96303 & 0.96444 & 0.00141 \\
\hline 2 & 0.96939 & 0.96841 & -0.00098 & 0.98446 & 0.95890 & 0.02555 \\
\hline 3 & 0.95113 & 0.95253 & 0.00140 & 0.97495 & 0.96679 & -0.00816 \\
\hline 4 & 0.99146 & 0.99108 & -0.00038 & 0.99571 & 0.98683 & -0.00888 \\
\hline 5 & 0.96392 & 0.96499 & 0.00107 & 0.98163 & 0.97567 & -0.00596 \\
\hline 6 & 1.00129 & 0.99637 & -0.00492 & 1.00065 & 0.99792 & -0.00272 \\
\hline 7 & 0.99304 & 0.99930 & 0.00626 & 0.99651 & 0.99950 & 0.00299 \\
\hline 8 & 1.00074 & 1.00084 & 0.00010 & 1.00037 & 1.00036 & -0.00001 \\
\hline 9 & 0.99070 & 0.99069 & -0.00001 & 0.99570 & 0.99649 & 0.00079 \\
\hline 10 & 0.99762 & 0.99802 & 0.00040 & 0.99881 & 0.99876 & 0.00005 \\
\hline 11 & 1.00649 & 1.00699 & 0.00050 & 1.00426 & 1.00592 & 0.00166 \\
\hline 12 & 1.00724 & 1.00702 & -0.00022 & 1.00504 & 1.00513 & 0.00009 \\
\hline 13 & 1.13524 & 1.11145 & -0.02379 & 1.05477 & 1.06206 & 0.00729 \\
\hline 14 & 1.00454 & 1.00474 & 0.00020 & 1.00246 & 1.00274 & 0.00028 \\
\hline 15 & 1.00481 & 1.00510 & 0.00029 & 1.00273 & 1.00324 & 0.00051 \\
\hline 16 & 0.98417 & 0.98395 & -0.00022 & 0.99213 & 0.99256 & 0.00043 \\
\hline 17 & 0.95232 & 0.95436 & 0.00204 & 0.97255 & 0.97464 & 0.00209 \\
\hline 18 & 0.97961 & 0.98378 & 0.00417 & 0.99214 & 0.99268 & 0.00054 \\
\hline 19 & 0.98585 & 0.98545 & -0.00040 & 0.99229 & 0.99154 & -0.00075 \\
\hline 20 & 0.98559 & 0.98522 & -0.00037 & 0.99227 & 0.99170 & -0.00057 \\
\hline 21. & 0.94529 & 0.94733 & 0.00204 & 0.96657 & 0.96642 & -0.00015 \\
\hline 22 & 0.94700 & 0.94893 & 0.00192 & 0.96799 & 0.96863 & 0.00064 \\
\hline 23 & 1.00411 & 1.00419 & 0.00008 & 1.00283 & 1.00323 & 0.00040 \\
\hline 24 & 1.00428 & 1. 00427 & -0.00001 & 1.00285 & 1.00322 & 0.00037 \\
\hline 25 & 1.07465 & 1.06608 & -0.00857 & 1.03976 & 1.03986 & 0.00010 \\
\hline 26 & 1.00443 & 1.00455 & 0.00011 & 1.00312 & 1.00364 & 0.00052 \\
\hline 27 & 0.94499 & 0.94695 & 0.00196 & 0.96652 & 0.96641 & -0.00011 \\
\hline 28 & 1.00859 & 1.00907 & 0.00048 & 1.00523 & 1.00641 & 0.00118 \\
\hline
\end{tabular}

Note: see Table 3.4 for key to cases. 
TABLE 3.4

Case Descriptions for Table 3.3

Cell A: $\quad r_{1}=0.3 \mathrm{~cm}, r_{2}=0.375 \mathrm{~cm}, r_{3}=0.6 \mathrm{~cm}$

$\Sigma_{\mathrm{a} 1}=0.2 \mathrm{~cm}^{-1}, \Sigma_{\mathrm{a} 2}=0.01 \mathrm{~cm}^{-1}, \Sigma_{\mathrm{s} 2}=0.1 \mathrm{~cm}^{-1}, \Sigma_{\mathrm{a} 3}=0.005 \mathrm{~cm}^{-1}$

Cell B: (Carbide cell) $r_{1}=0.34036 \mathrm{~cm}, r_{2}=0.3683 \mathrm{~cm}, r_{3}=0.70309 \mathrm{~cm}$ $\Sigma_{\mathrm{a} 1}=0.01666 \mathrm{~cm}^{-1}, \Sigma_{\mathrm{s} 1}=0.30957 \mathrm{~cm}^{-1}, \Sigma_{\mathrm{a} 2}=5.63 \mathrm{E}-4 \mathrm{~cm}^{-1}$, . $\Sigma_{\mathrm{s} 2}=0.289374 \mathrm{~cm}^{-1}, \Sigma_{\mathrm{a} 3}=1.61 \mathrm{E}-5 \mathrm{~cm}^{-1}, \Sigma_{\mathrm{s} 3}=0.0868729 \mathrm{~cm}^{-1}$

Cell C: (Oxide cell) $r_{1}=0.2794 \mathrm{~cm}, r_{2}=0.3175 \mathrm{~cm}, r_{3}=0.535386 \mathrm{~cm}^{-1}$ $\Sigma_{\mathrm{a} 1}=0.0652 \mathrm{~cm}^{-1}, \Sigma_{\mathrm{a} 2}=0.05583 \mathrm{~cm}^{-1}, \Sigma_{\mathrm{s} 2}=1 . \mathrm{E}-5 \mathrm{~cm}^{-1}$, $\Sigma_{\mathrm{a} 3}=8.68 \mathrm{E}-3 \mathrm{~cm}^{-1}$

Cell D: (Carbide cell - first flight) same geometry as Cell B $\Sigma_{\mathrm{a} 1}=0.08836 \mathrm{~cm}^{-1}, \Sigma_{\mathrm{s} 1}=0.09522 \mathrm{~cm}^{-1}, \Sigma_{\mathrm{a} 2}=0.05583 \mathrm{~cm}^{-1}$, $\Sigma_{\mathrm{s} 2}=0.150161 \mathrm{~cm}^{-1}, \Sigma_{\mathrm{a} 3}=8.68 \mathrm{E}-3 \mathrm{~cm}^{-1}, \Sigma_{\mathrm{s} 3}=0.036297 \mathrm{~cm}^{-1}$

Cell E: $\quad r_{1}=0.3 \mathrm{~cm}, r_{2}=0.4 \mathrm{~cm}, r_{3}=0.6 \mathrm{~cm}$ $\Sigma_{\mathrm{a} 1}=0.2 \mathrm{~cm}^{-1}, \Sigma_{\mathrm{a} 2}=7.5 \mathrm{E}-3 \mathrm{~cm}^{-1}, \Sigma_{\mathrm{s} 2}=0.075 \mathrm{~cm}^{-1}, \Sigma_{\mathrm{a} 3}=5 . \mathrm{E}-3 \mathrm{~cm}^{-1}$

Cell F: Same geometry as Cell E

$$
\Sigma_{\mathrm{a} 1}=0.2 \mathrm{~cm}^{-1}, \Sigma_{\mathrm{a} 2}=0.01 \mathrm{~cm}^{-1}, \Sigma_{\mathrm{s} 2}=0.1 \mathrm{~cm}^{-1}, \Sigma_{\mathrm{a} 3}=5 . \mathrm{E}-3 \mathrm{~cm}^{-1}
$$

\begin{tabular}{|c|c|c|c|}
\hline Case & Description & Case & Description \\
\hline 1 & Cell A, $S_{1}=S_{3}=1.0, S_{2}=0$ & 6 & Cel1.B, $S_{1}=S_{2}=S_{3}=1.0$ \\
\hline 2 & Cell $\mathrm{A}, \mathrm{S}_{2}=1.0, \mathrm{~S}_{3}=\mathrm{S}_{1}=0$ & 7 & Cell B, $\mathrm{S}_{1}=0.17103, \mathrm{~S}_{2}=0.0565$, \\
\hline 3 & Cell A, $S_{2}=S_{3}=1.0, S_{1}=0$ & & 0 0 0817 \\
\hline 4 & $\operatorname{Cell~} \mathrm{A}, \mathrm{S}_{1}=\mathrm{S}_{2}=1.0, \mathrm{~S}_{3}=0$ & 8 & Cell B, $S_{1}=0.202289$ \\
\hline 5 & Cell A, $S_{1}=S_{2}=S_{3}=1.0$ & & $\begin{array}{l}S_{2}=0.0565 \\
S_{3}=0.008176\end{array}$ \\
\hline
\end{tabular}

(Continued) 
Table 3.4 continued

\begin{tabular}{|c|c|c|c|}
\hline Case & Description & Case & Description \\
\hline 9 & Cell C, $\mathrm{S}_{1}=\mathrm{S}_{3}=1.0, \mathrm{~S}_{2}=0$ & 19 & Case 14 except $S_{3}=1.0$ \\
\hline 10 & Cell C, $S_{1}=S_{2}=S_{3}=1.0$ & & $S_{1}=S_{2}=0$ \\
\hline 11 & Cell C, $\mathrm{S}_{1}=1.0, \mathrm{~S}_{2}=\mathrm{S}_{3}=0$ & 20 & $\begin{array}{c}\text { Case } 15 \text { except } S_{3}=1.0 \\
S=S=0\end{array}$ \\
\hline 12 & Case 11 except $\Sigma_{a 1}=0.2 \mathrm{~cm}^{-1}$ & 21 & $\begin{array}{c}S_{1}=S_{2}=0 \\
\text { Cell } \mathrm{E}, \mathrm{S}_{2}=1.0, \mathrm{~S}_{1}=\mathrm{S}_{2}=0\end{array}$ \\
\hline 13 & Case 11 except $\Sigma_{a 3}=0.2 \mathrm{~cm}^{-1}$ & 22 & Cell $\mathrm{A}, \mathrm{S}_{3}=1.0, \mathrm{~S}_{1}=\mathrm{S}_{2}=0$ \\
\hline 14 & Case 11 except $\Sigma_{\mathrm{a} 2}=\Sigma_{\mathrm{s} 2}=0$ & 23 & Cell $\mathrm{E}, \mathrm{S}_{1}=1.0, \mathrm{~S}_{2}=\mathrm{S}_{3}=0$ \\
\hline 15 & $\begin{aligned} \text { Case } 11 \text { except } \Sigma_{\mathrm{a} 2}= \\
\\
8.68 \mathrm{E}-3 \mathrm{~cm}^{-1}\end{aligned}$ & 24 & Cell $A, S_{1}=1.0, S_{2}=S_{3}=0$ \\
\hline 16 & Cell C, $S_{3}=1.0, S_{1}=S_{2}=0$ & 25 & Case 24 except $\Sigma_{a 3}=0.1 \mathrm{~cm}^{-1}$ \\
\hline 17 & Case 12 except $S_{3}=1.0$ & 26 & Cell $\mathrm{F}, \mathrm{S}_{1}=1.0, \mathrm{~S}_{2}=\mathrm{S}_{3}=0$ \\
\hline & $\mathrm{S}_{1}=\mathrm{S}_{2}=0$ & 27 & Cell $\mathrm{F}, \mathrm{S}_{3}=1.0, \mathrm{~S}_{2}=\mathrm{S}_{1}=0$ \\
\hline 18 & $\begin{array}{c}\text { Case } 13 \text { except } S_{3}=1.0 \\
S_{1}=S_{2}=0\end{array}$ & 28 & Cell $D, S_{1}=1.0, S_{2}=S_{3}=0$ \\
\hline
\end{tabular}


The customary procedure in FBR analysis is to adopt the homogeneous prescription with $\Sigma_{\text {tr }}$ equal to the volume-average of the regionwise $\Sigma_{\text {tri }}$. Such a treatment completely neglects the effect of anisotropic diffusion; that is, the preferential streaming of neutrons in an axial direction (the coolant channels). The effect of anisotropic diffusion is particularly marked when the sodium coolant is voided from the core, leaving voided channels for streaming. Clearly, a purely homogeneous treatment of the core is incapable of dealing properly with the phenomenon.

An analogy due to Selengut ( $\underline{3})$ is available which, though not strictly valid for FBR cells, serves to point out the salient features of anisotropic diffusion. In the diffusion approximation, the neutron current $j=-D \nabla \phi$ is analogous to the current in Ohm's law, in which case the diffusion coefficient corresponds to the electric conductance (the reciprocal of resistance). Equivalent diffusion coefficients may then be obtained by referring to the analogous case in circuit theory. Thus for a current parallel to the region interfaces, D is given by conductances in series:

$$
D_{\|}=\sum_{i} v_{i} D_{i}
$$

where $v_{i}$ is the volume fraction of the $i^{\text {th }}$ material in the cell. For a current normal to the region interfaces, $\mathrm{D}$ is given by conductances in parallel:

$$
\frac{1}{D_{\perp}}=\sum_{i} \frac{v_{i}}{D_{i}}
$$

(Note that the averaging of Eq. 3.12 yields the classical diffusion coefficient of Eq. 3.10.) Thus the directional diffusion coefficients are indeed different; however, the Selengut analogy is not applicable to FBR cells since its primary assumption is that the cell diameter is much larger than the neutron's mean free path (the antithesis of the case in a FBR cell).

Instead, the method of Benoist (3.4) has been adapted for FBR unit cells. By a series of complex manipulations of the integral transport equation, Benoist is able to derive the directional diffusion coefficients 
in terms of the so-called transport probabilities $P_{i j, k}$ :

$$
D_{k}=\frac{1}{3} \frac{\sum_{i} \sum_{j} v_{i} \bar{\phi}_{i} \lambda_{i} P_{i j, k}}{\sum_{i} v_{i} \bar{\phi}_{i}},
$$

where $k$ can be the axial or radial directions and $\lambda_{i}$ is the transport mean free path. For the regime of FBR parameters, $P_{i j, k}$ can be identified as the oriented first collision probability: the probability that a neutron born in region $i$ will have its first collision in region $j$, that probability being weighted differently in the axial and radial directions. For cylindrical geometry and.FBR parameters, the $P_{i j, k}$ reduce to first order functions of the optical thickness of each region.

Table 3.5 lists diffusion coefficients for a sample FBR cell. One notes that the Benoist theory predicts a slight degree of anisotropy, while the Selengut theory (which is recognized as fundamentally unsuited for FBR cells) greatly overestimates the anisotropy. The Benoist theory has been compared against experiments in thermal systems and found to be valid ( 5 ). Since its fundamental assumptions invoke the slow spatial variation of flux in the unit cell, Benoist's derivation is even more valid for fast cells than for thermal cells.

TABLE 3.5

Diffusion Coefficients for Sample Cell

\begin{tabular}{|c|c|c|c|c|c|}
\hline \multirow{2}{*}{\multicolumn{2}{|c|}{ Model }} & \multicolumn{2}{|c|}{$\mathrm{D}(\mathrm{cm})$} & & \\
\hline & & Group 1 & Group 2 & \multirow{4}{*}{\multicolumn{2}{|c|}{$D_{\text {het }} / D_{\text {hom }}$}} \\
\hline \multirow[t]{3}{*}{ Homogeneous } & $\mathrm{D}_{z}$ & 3.0917 & 1.4126 & & \\
\hline & $\mathrm{D}_{\mathrm{r}}$ & 3.0917 & 1.4126 & & \\
\hline & & & & & \\
\hline \multirow[t]{2}{*}{ Benoist } & $\mathrm{D}_{\mathrm{Z}}$ & 3.1150 & 1.4310 & 1.0075 & 1.0130 \\
\hline & $\mathrm{D}_{\mathrm{r}}^{\mathrm{z}}$ & 3.0963 & 1.4169 & 1.0014 & 1.0030 \\
\hline \multirow[t]{2}{*}{ Selengut } & $\mathrm{D}_{\mathrm{z}}$ & 4.7730 & 2.0076 & 1.5438 & 1. 4212 \\
\hline & $\mathrm{D}_{\mathrm{r}}^{\mathrm{z}}$ & 4.1276 & 1. 7746 & 1.3351 & 1.2563 \\
\hline
\end{tabular}


In summary, the calculation of anisotropic diffusion coefficients for the heterogeneous lattice is based on Benoist's theory. The resulting diffusion coefficients are larger than those for a homogeneous medium, thereby characterizing the increased leakage from the heterogeneous lattice.

\subsection{Reactivity Effects of Heterogeneity}

The previous two sections described the techniques for obtaining heterogeneous cell parameters: by spatial flux weighting of constants for the individual cell regions; by calculating anisotropic diffusion coefficients. The difference between these constants and those for the volume-homogenized core are sufficiently small that first order perturbation theory may be used to calculate the reactivity effect due to heterogeneity:

$$
\frac{\Delta \mathrm{k}}{\mathrm{k}}=\frac{\int_{\mathrm{V}}\left[\phi^{*}\right]^{\mathrm{T}}[\delta \mathrm{P}][\phi] d V}{\int_{\mathrm{V}}\left[\phi^{*}\right]^{\mathrm{T}}\left[\mathrm{P}_{\mathrm{O}}\right][\phi] \mathrm{dV}}-\frac{\int_{\mathrm{V}}[\nabla \phi *]^{\mathrm{T}}[\delta \mathrm{D}][\nabla \phi] \mathrm{dV}}{\int_{\mathrm{V}}\left[\phi^{*}\right]^{\mathrm{T}}\left[\mathrm{P}_{\mathrm{O}}\right][\phi] \mathrm{dV}},
$$

where the $\phi *$ are the adjoint fluxes, $\phi$ the fluxes, $\mathrm{P}_{\mathrm{o}}$ the fission production matrix, $\delta \mathrm{P}$ the perturbation matrix exclusive of changes in the diffusion constant, while $\delta \mathrm{D}$ is the perturbation in the latter quantity.

A more direct calculation of the heterogeneous reactivity effect is attainable by considering the multiplication constant to be a multivariable function. In the two-group model:

$$
\begin{gathered}
\mathrm{k}\left(\Sigma_{\mathrm{a} 1}, \Sigma_{\mathrm{a} 2}, \Sigma_{12}, \nu \Sigma_{\mathrm{f} 1}, \nu \Sigma_{\mathrm{f} 2}, \mathrm{D}_{1 \mathrm{r}} \mathrm{B}_{\mathrm{r}}^{2}, \mathrm{D}_{2 \mathrm{r}} \mathrm{B}_{\mathrm{r}}^{2}, \mathrm{D}_{1 \mathrm{z}} \mathrm{B}_{\mathrm{z}}^{2}, \mathrm{D}_{2 \mathrm{z}} \mathrm{B}_{\mathrm{z}}^{2}\right)= \\
\frac{\mathrm{x}_{1} \nu \Sigma_{\mathrm{f} 1}}{\Sigma_{12}+\Sigma_{\mathrm{a} 1}+\mathrm{D}_{1 \mathrm{r}} \mathrm{B}_{\mathrm{r}}^{2}+\mathrm{D}_{1 \mathrm{z}} \mathrm{B}_{\mathrm{z}}^{2}}+\frac{\mathrm{x}_{2} \nu \Sigma_{\mathrm{f} 2}}{\Sigma_{\mathrm{a} 2}+\mathrm{D}_{2 \mathrm{r}} \mathrm{B}_{\mathrm{r}}^{2}+\mathrm{D}_{2 \mathrm{z}} \mathrm{B}_{\mathrm{z}}^{2}} \\
+\frac{\mathrm{x}_{1} \nu \Sigma_{\mathrm{f} 2} \Sigma_{12}}{\left(\Sigma_{12}+\Sigma_{\mathrm{a} 1}+\mathrm{D}_{1 \mathrm{r}} \mathrm{B}_{\mathrm{r}}^{2}+\mathrm{D}_{1 \mathrm{z}} \mathrm{B}_{\mathrm{z}}^{2}\right)\left(\Sigma_{\mathrm{a} 2}+\mathrm{D}_{2 \mathrm{r}} \mathrm{B}_{\mathrm{r}}^{2}+\mathrm{D}_{2 \mathrm{z}} \mathrm{B}_{\mathrm{z}}^{2}\right)}
\end{gathered}
$$

from which the total differential, $k$, can be formed: 


$$
\begin{aligned}
\Delta \mathrm{k}= & \frac{\partial \mathrm{k}}{\partial \Sigma_{\mathrm{a} 1}} \Delta \Sigma_{\mathrm{a} 1}+\frac{\partial \mathrm{k}}{\partial \Sigma_{\mathrm{a} 2}} \Delta \Sigma_{\mathrm{a} 2}+\frac{\partial \mathrm{k}}{\partial \Sigma_{12}} \Delta \Sigma_{12}+\frac{\partial \mathrm{k}}{\partial \nu \Sigma_{\mathrm{f} 1}} \Delta \nu \Sigma_{\mathrm{f} 1} \\
& +\frac{\partial \mathrm{k}}{\partial \nu \Sigma_{\mathrm{f} 2}} \Delta \nu \Sigma_{\mathrm{f} 2}+\frac{\partial \mathrm{k}}{\partial \mathrm{D}_{1 \mathrm{r}_{\mathrm{r}}} \mathrm{B}_{1 \mathrm{r}}} \Delta \mathrm{D}_{\mathrm{r}}+\frac{\partial \mathrm{k}}{\partial \mathrm{D}_{1 \mathrm{z}} \mathrm{B}_{\mathrm{z}}^{2}} \Delta \mathrm{D}_{1 \mathrm{z}} \mathrm{B}_{\mathrm{z}}^{2} \\
& \frac{\partial \mathrm{k}}{\partial \mathrm{D}_{2 \mathrm{r}} \mathrm{B}_{\mathrm{r}}^{2}} \Delta \mathrm{D}_{2 \mathrm{r}} \mathrm{B}_{\mathrm{r}}^{2}+\frac{\partial \mathrm{k}}{\partial \mathrm{D}_{2 \mathrm{z}} \mathrm{B}_{\mathrm{z}}^{2}} \Delta \mathrm{D}_{2 \mathrm{z}} \mathrm{B}_{\mathrm{z}}^{2}
\end{aligned}
$$

The differentials in Eq. 3.16 are the differences between the homogeneous and heterogeneous constants. For an equivalent bare core (i.e., the core dimensions are augmented by the reflector savings provided by the blankets), the "direct" method and first order perturbation theory give identical values for $\Delta \mathrm{k} / \mathrm{k}$.

Tables 3.6 and 3.7 list the heterogeneous contributions for a typical 1000-MWe oxide-fueled FBR, for both sodium-in and sodiumout. Note that the spatial flux distribution effects virtually cancel out (e.g., augmented fission in the fuel is accompanied by augmented parasitic capture in the fuel). The main contribution is due to anisotropic diffusion, particularly for the voided case. These heterogeneous corrections imply that a homogeneous core representation overestimates the whole-core sodium void reactivity by $\$ 1.11$. As noted previously, these effects are to be superimposed upon the results of a homogeneous calculation which would typically predict a positive whole-core effect of several dollars.

\section{5 Energy Self-Shielding of Resonances}

Up to this point resonance self-shielding effects have been omitted (i.e., all calculations have employed infinite dilution cross sections). In order to investigate this effect, cross section sets for U-238 were generated using the MIDI code (6). The MIDI code calculates the flux in resonance $\mathrm{k}$ by:

$$
\phi_{k}(E)=\frac{\sigma_{n}}{\sigma_{n}+\sigma_{s r}(E)+\sigma_{a r}(E)} \text {, }
$$

where $\sigma_{n}$ is the total non-resonant scattering cross section per 
TABLE 3.6

Heterogeneous Reactivity Contributions ( $\mathrm{Na}$ In)

\begin{tabular}{|c|c|}
\hline Effect & Contribution \\
\hline Group 1 fission & $20.7 \zeta$ \\
\hline Group 1 absorption & -8.6 \\
\hline Group 1 removal & -3.8 \\
\hline Group 1 radial leakage & -0.7 \\
\hline Group 1 axial leakage & -7.2 \\
\hline Group 2 fission & -5.0 \\
\hline Group 2 absorption & $3.9^{\circ}$ \\
\hline Group 2 radial leakage & -4.9 \\
\hline \multirow[t]{2}{*}{ Group 2 axial leakage } & -44.1 \\
\hline & $-49.6 c$ \\
\hline
\end{tabular}

TABLE 3.7

Heterogeneous Reactivity Contributions (Na Out)

Group 1 fission

Group 1 absorption

Group 1 removal

Group 1 radial leakage

Group 1 axial leakage

Group 2 fission

Group 2 absorption

Group 2 radial leakage

Group 2 axial leakage
$12.9 \mathrm{C}$

$-5.5$

$-2.9$

$-1.9$

$-19.0$

2.4

$-1.8$

$-14.7$

$-130.5$

Total $-161.0 \mathrm{C}$ 
resonant absorber atom, constant within the resonance; where $\sigma_{\text {ar }}(\mathrm{E})$ is the microscopic resonant absorption cross section and $\sigma_{\mathrm{Sr}}(\mathrm{E})$ is the microscopic resonant scattering cross section. The self-shielded cross section is then found from:

$$
\sigma_{x}=\frac{\sum_{k=1}^{N} \int_{\Delta E} \sigma_{x k}(E) \phi_{k}(E) d E}{\int_{\Delta E} \phi(E) d E},
$$

where the $\mathrm{x}$-subscript refers to the cross section of interest and $\mathrm{N}$ is the number of resonances within the group.

The above calculation accounts for resonance self-shielding in a homogeneous medium. Resonance self-shielding in a heterogeneous unit cell is treated by an equivalence formalism; namely, the above procedures are followed except that $\sigma_{n}$ is modified by the addition of a heterogeneous correction:

$$
\sigma_{n}=\sigma_{n \text { hom }}+\frac{\Sigma_{n}}{N_{r}},
$$

where $\Sigma_{n}$ is a function of the Dancoff correction and the mean chord length for the lumped resonance material.

Using various types of resonance self-shielding models, 26-group ANISN and 2DB ( 7 ) calculations were performed. Table 3.8 summarizes central zone void reactivity effects for a spherical core representation in ANISN. One notes that the infinite dilution calculation is significantly different from the various self-shielded calculations, while the type of self-shielding model assumed has relatively little effect on the result.

In Table 3.9 similar results for a two-dimensional cylindrical representation in $2 \mathrm{DB}$ diffusion code calculations are reported. The same conclusions hold: infinite dilution calculations show a large discrepancy, while the details of the resonance self-shielding model (as long as some reasonable self-shielding is prescribed) are relatively unimportant. In particular, the effect of heterogeneous resonance self-shielding as compared to homogeneous resonance self-shielding is to reduce the sodium voiding reactivity by $22 c$. 
TABLE 3.8

Central Zone Sodium Voiding Reactivities

\begin{tabular}{lc}
\hline \multicolumn{1}{c}{ Case } & $\Delta \mathrm{k} / \mathrm{k}$ \\
\hline Infinitely dilute & $+\$ 12.56$ \\
Heterogeneous self-shielded & $+\$ 2.51$ \\
Heterogeneous self-shielded (Na In self-shielding) & $+\$ 2.73$ \\
Homogeneous self-shielded & $+\$ 2.44$ \\
Homogeneous self-shielded (Na In $\sigma_{\mathrm{a}}$ self-shielding) & $+\$ 2.30$ \\
N.B. $\quad \beta \equiv 0.0033$ & \\
\hline
\end{tabular}

TABLE 3.9

Sodium Void Effects in Cylindrical Geometry

Case

$\Delta \mathrm{k} / \mathrm{k}$

$12 \% / 16 \%$ loadings:

Infinite dilute, whole core

$+\$ 6.79$

Infinite dilute, central core

$+\$ 4.27$

Heterogeneous self-shielded, whole core

$-\$ 2.75$

$10.5 \% / 14 \%$ loadings:

Heterogeneous self-shielded, whole core

$-\$ 3.55$

Heterogeneous self-shielded, central zone

$+\$ 0.14$

Homogeneous self-shielded, whole core

$-\$ 3.33$

Homogeneous self-shielded, central zone

$+\$ 0.23$

N.B. $\beta \equiv 0.0033$ 
In the spirit of developing a simple method for calculating the selfshielding changes for cross sections (and thereby by-pass MIDI-type calculations), correlations of the self-shielding factors were obtained. The basis of the correlations is Sheaffer's one-group method ( 1 ) which defines two spectral indices:

$$
\begin{aligned}
& \mathrm{S}=\frac{\nu \Sigma_{\mathrm{f}}}{\nu \Sigma_{\mathrm{f}}+\xi \Sigma_{\mathrm{tr}}}, \\
& \mathrm{R}=\frac{\nu \Sigma_{\mathrm{f}}}{\Sigma_{\mathrm{r}}},
\end{aligned}
$$

where all constants are for a single group $\left(\Sigma_{r}\right.$ being the cross section for removal below 1.4 MeV). These indices are used to correlate one-group microscopic cross sections in the form:

$$
\sigma_{j}=\sigma_{o j} x^{g_{j}}
$$

where $\chi$ is the appropriate spectral index ( $R$ for the fission cross section of fertile material and $S$ for all other cross sections). The correlation parameters $\sigma_{o j}$ and $g_{j}$ are tabulated by Shaeffer for most elements of interest ( $j$ refers to the type of cross section). A rapidly converging iterative process is used to calculate the spectral indices and one-group cross sections.

In the present work a trial-and-error procedure was employed to find the best (i.e., yielding the smoothest curve) correlation for the f-factor, defined as the ratio of the self-shielded cross section to the infinitely dilute cross section (such a formalism is suggested by the Bondarenko f-factors [9] ). This was first carried out on a group-bygroup basis with the best correlation found to be: 


$$
f_{i} \quad \text { vs. } \quad \Sigma_{a i}^{28}\left[\frac{1}{\Sigma_{a}}+\frac{1}{\xi \Sigma_{t r}}\right]
$$

where the quantities within the brackets are one-group values and $\Sigma_{a i}^{28}$ is the microscopic absorption cross section for U-238 in group $i$.

Figure 3.2 demonstrates the resulting fit for the top three resonance groups (2.15 keV to $21.5 \mathrm{keV}$ ) over a range of cases (hence neutron spectra) characteristic of $\mathrm{Pu}-239$ enrichments from $9 \%$ to $25 \%$ and coolant-to-fuel volume ratios from 1.0 to 2.0 . Similar results are obtained for the other groups.

A one-group correlation was also established with the inclusion of additional parameters. The best correlations were found to be:

$$
\mathrm{f}_{\mathrm{a}} \text { vs. } \Sigma_{\mathrm{a}}^{28}\left[\frac{1}{\Sigma_{\mathrm{a}}}-\frac{1.40}{\xi \Sigma_{\mathrm{tr}}}\right]
$$

and

$$
f_{s} \text { vs. } \Sigma_{a}^{28}\left[\frac{1}{\nu \Sigma_{f}}-\frac{1.00}{\xi \Sigma_{t r}}\right] \text {. }
$$

Figure 3.3 illustrates the one-group correlation fit for $\mathrm{f}_{\mathrm{a}}$ (a similar result is found for $f_{s}$ ). All data points for the correlations were generated using the MIDI code. The one-group collapses were carried out using ANISN for a critical spherical geometry.

The one-group f-factor correlations allow U-238 self-shielding effects to be incorporated into Sheaffer's model (originally formulated in terms of infinite dilution constants). The correlations provide the self-shielded U-238 cross sections, which in turn alter the $\mathrm{S}$ and $\mathrm{R}$ spectral indices so that the one-group cross sections for all other materials can also be corrected to account for the changed spectrum.

In summary, resonance self-shielding effects are found to be important in calculating multiplication constants; however, the finer details of self-shielding (i.e., homogeneous vs. heterogeneous) are relatively less important. Self-shielding f-factors are expressible in terms of correlation functions based on one-group constants. 

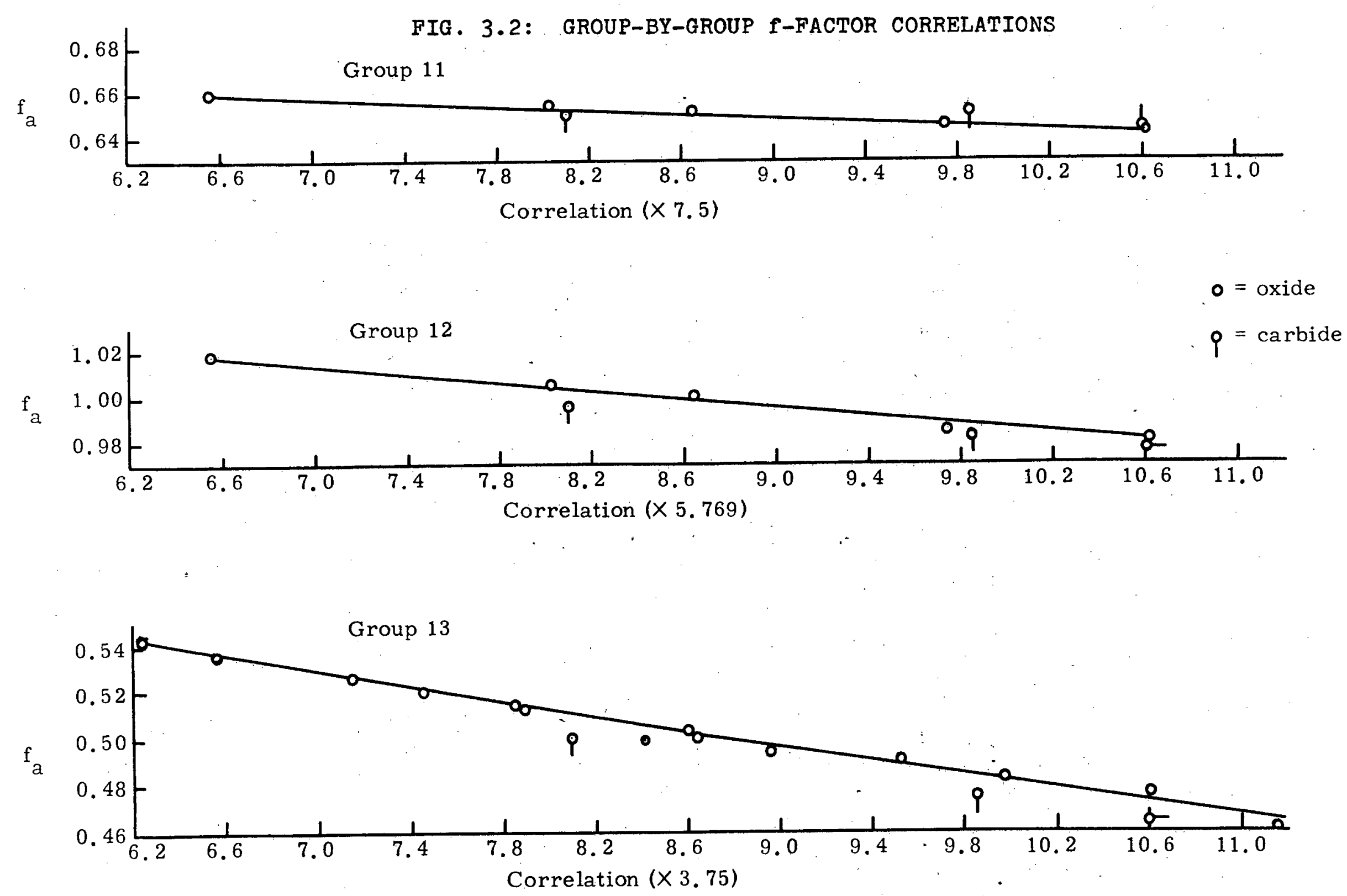
ONE-GROUP SELF-SHIELDING FACTORS FOR U-238

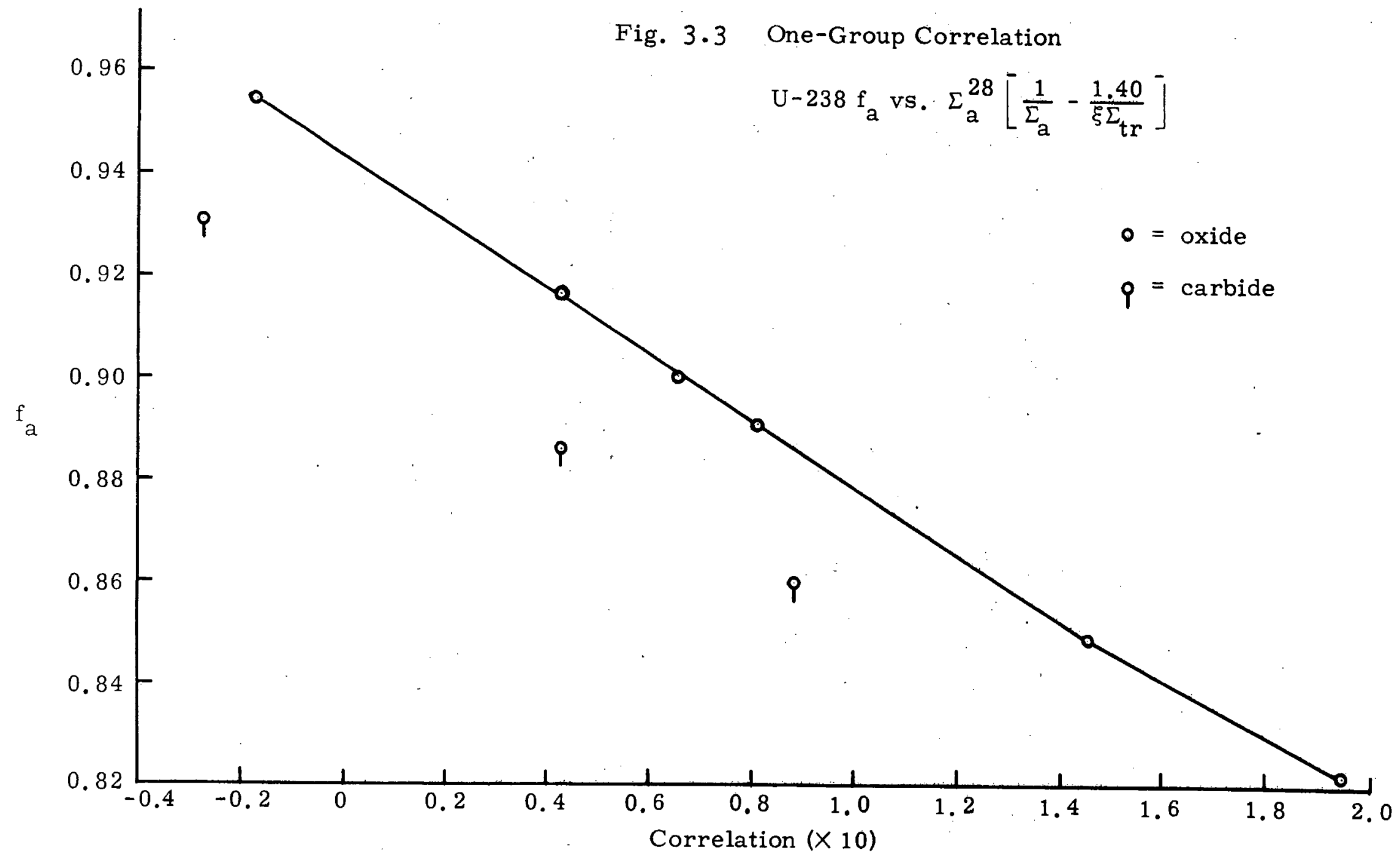




\subsection{Heterogeneous Effects in Reference FBR Designs}

The methods outlined in the preceding sections were then used to analyze proposed FBR designs for significant heterogeneous effects. Figure 3.4 summarizes the operative effects for a typical case. In Table 3.10, the results for four 1000-MWe FBR designs are presented. Resonance selfshielding effects add on a contribution of the order of $-9 \mathrm{c}$ to the net void effects listed in Table 3.10. Similar results for a 300-MWe design are summarized in Table 3.11. For the smaller core, the anisotropic diffusion component becomes more significant.

Parametric studies indicate that the negative heterogeneity effect can be increased by judicious choice of design variables. Increasing lattice pitch (which increases the sodium fraction) and core enrichment (which reduces core size) serve to increase the important contribution of anisotropic diffusion. In addition, by using on open hexagonal lattice : geometry in place of the typical triangular pitch lattice (see Fig. 3.5), it is possible to double the negative anisotropic diffusion contribution while keeping the fuel-to-coolant volume ratio identical. In Table 3.12, the standard GE triangular pitch design is compared to an equivalent.(i.e.,. same fuel-to-coolant volume ratio) open hexagonal lattice. The augmentation in anisotropic leakage is due to the central sodium space (occupied by a rod in the triangular pitch lattice) acting as an efficient streaming channel for neutrons.

The GCFR has also been studied. It is neutronically equivalent to the voided LMFBR and thus one expects a large heterogeneity contribution due to anisotropic diffusion. The GCFR results tabulated in Table 3.13 fulfill that expectation. Pellaud $(\underline{10})$ has calculated the effects of anisotropic diffusion using both o one-group perturbation theory calculation and a ten-group, two-dimensional anisotropic diffusion theory code. In Table 3.14 his results are compared to the value predicted by the two-group, equivalent bare core method developed in this work. The agreement is good.

The final aspect of the reference designs evaluated in this work is the fuel dispersal accident (i.e., the loss of heterogeneity accident). This entails the postulated disruptive homogenization of the entire core (the question of possible mechanisms was not investigated), whose major effect is the loss of the negative reactivity tied up in anisotropic diffusion. Table 3.15 presents the calculated reactivity insertions for the various designs (resonance self-shielding reduces the listed sodium-in values by approximately $10 c$ and the listed sodium-out values by $2 c)$. The positive reactivity insertion is sizeable only for the 


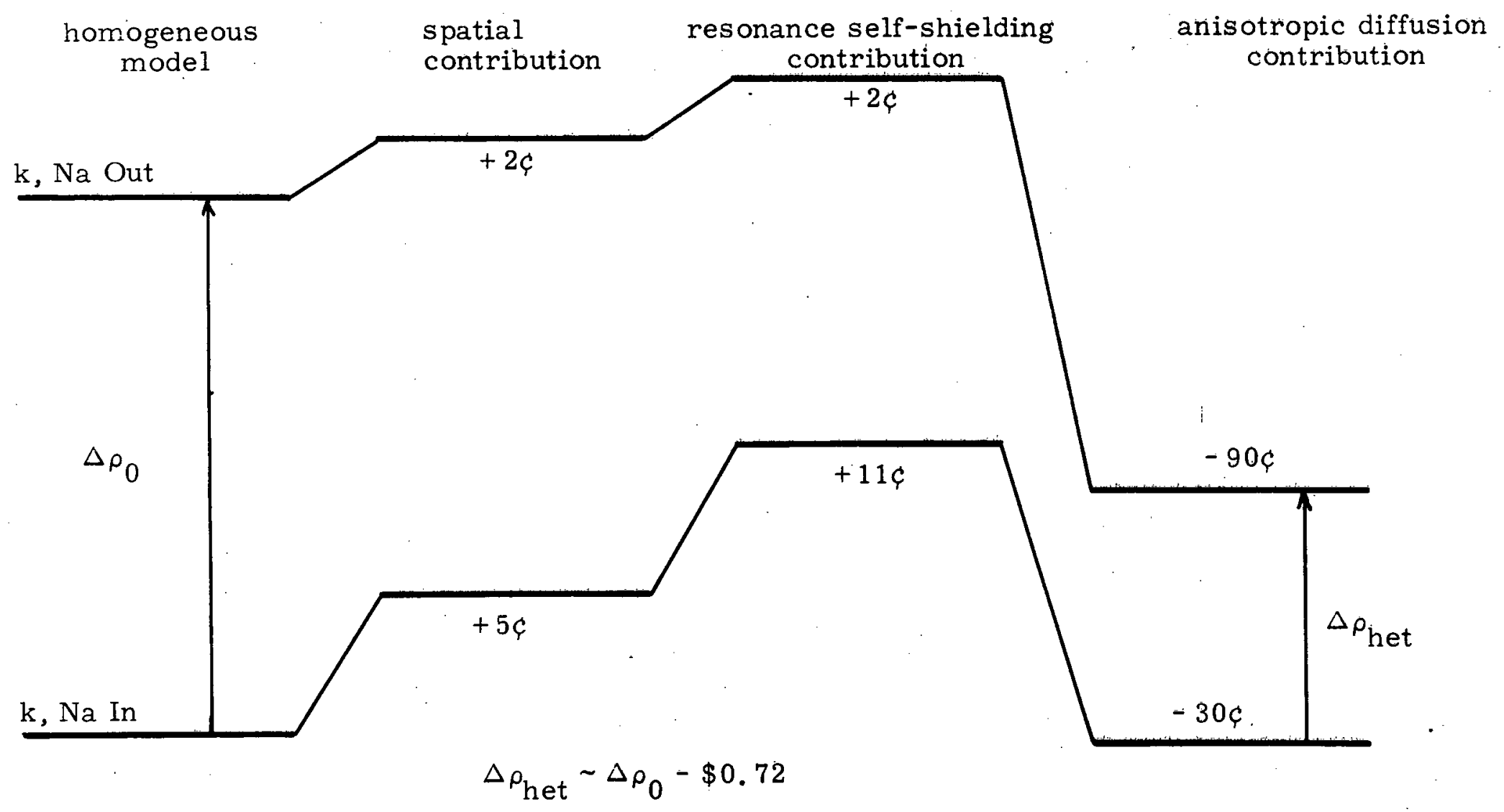

Fig. 3.4 Heterogeneous Effects on Sodium-Void Reactivity 
TABLE 3.10

Heterogeneous Effects in 1000-MWe Designs (cents* of reactivity - exclusive of self-shielding)

\begin{tabular}{lrrrr}
\hline & AI & B \& W & GE & CE \\
\hline Na In & & & & \\
Spatial & 5.8 & 3.6 & 3.5 & 3.1 \\
Ani. Diff. & -31.9 & -33.1 & -31.5 & -33.5 \\
Net & -26.1 & -29.5 & -28.0 & -30.5 \\
Na Out & & & & \\
Spatial & 3.6 & 1.2 & 1.2 & 2.0 \\
Ani. Diff. & -95.7 & -98.0 & -88.7 & -84.1 \\
Net & -92.1 & -96.8 & -87.5 & -82.2 \\
Net Void Effect & -66.0 & -67.3 & -59.5 & -51.7 \\
* $\beta=0.0033$ for oxide cores (AI, B \& W, GE) & & \\
$\beta=0.0040$ for carbide core (CE) & &
\end{tabular}

TABLE 3.11

Heterogeneous Effects in Demonstration Core (cents * of reactivity - exclusive of self-shielding)

$\mathrm{Na}$ In

Spatial

Ani. Diff.

Net

$\mathrm{Na}$ Out

Spatial

Ani. Diff.

Net

Net Void Effect

$$
\begin{array}{r}
\frac{c}{13.3} \\
-43.6 \\
-30.3
\end{array}
$$

12.4

$-131.7$

$-119.3$

$-89.0$

$$
{ }^{*} \beta=0.0033
$$


TABLE 3.12

Leakage Reactivity in Hexagonal and Triangular Lattices ${ }^{*}$ (cents of reactivity)

$\underline{\mathrm{Na} \text { In }}$

$\begin{array}{lrr}\text { Group } 1 \text { radial } & -0.6 & -0.3 \\ \text { Group } 1 \text { axial } & -7.6 & -4.3 \\ \text { Group } 2 \text { radial } & -3.7 & -1.8 \\ \text { Group } 2 \text { axial } & -43.9 & -25.1 \\ \quad \text { Total } & -55.8 & -31.5\end{array}$

$\underline{\mathrm{Na} \text { Out }}$

\begin{abstract}
Group 1 radial
Group 1 axial

Group 2 radial

Group 2 axial
\end{abstract}

Total

$$
-1.4
$$

$-18.1$

$-11.1$

$-130.9$

$-161.5$

$-105.7$
$-0.7$

$-10.1$

$-5.4$

$-72.5$

$-88.7$

$-57.2$

Net Void Effect

* Same volume fraction of fuel. 


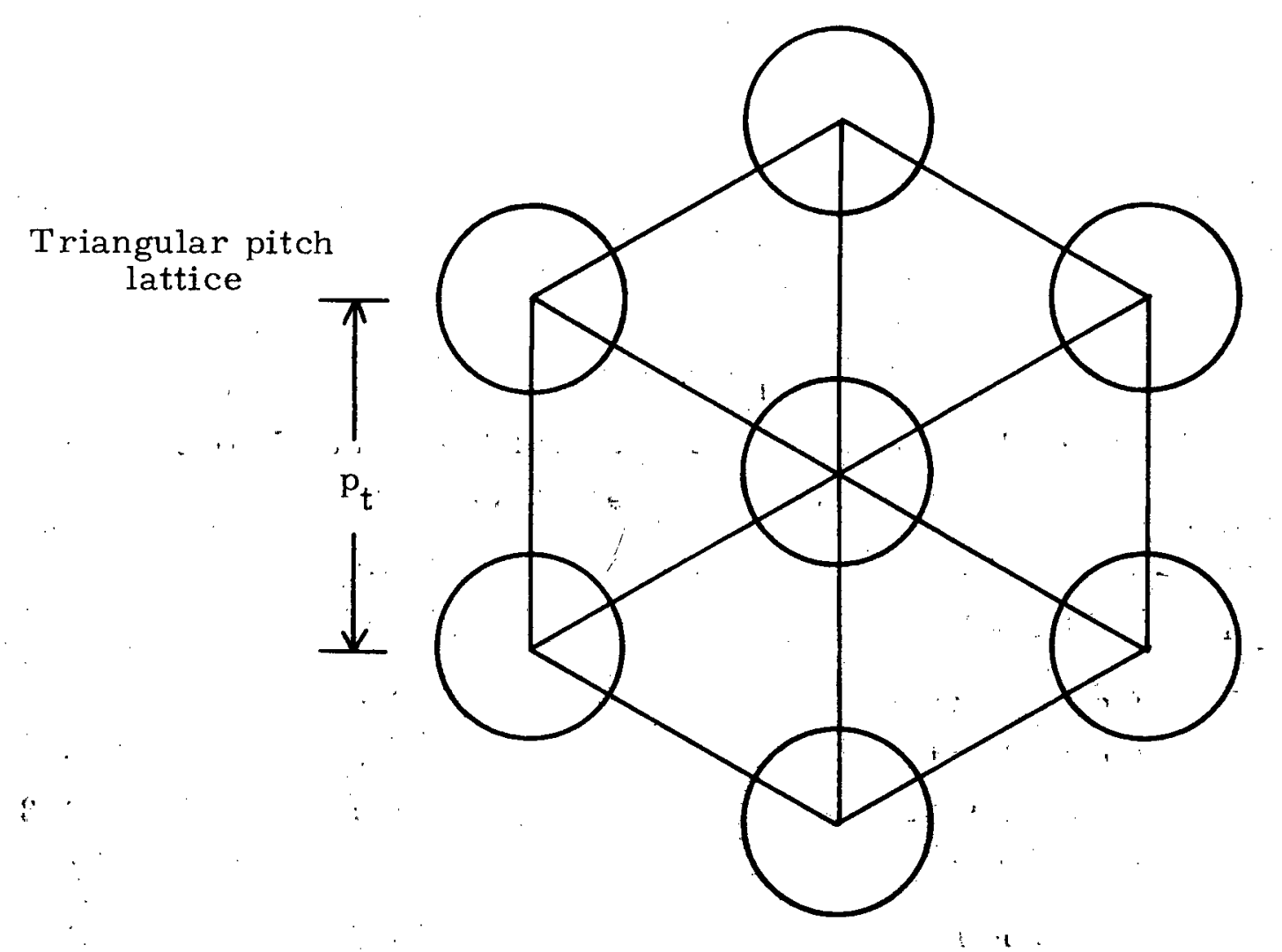

53

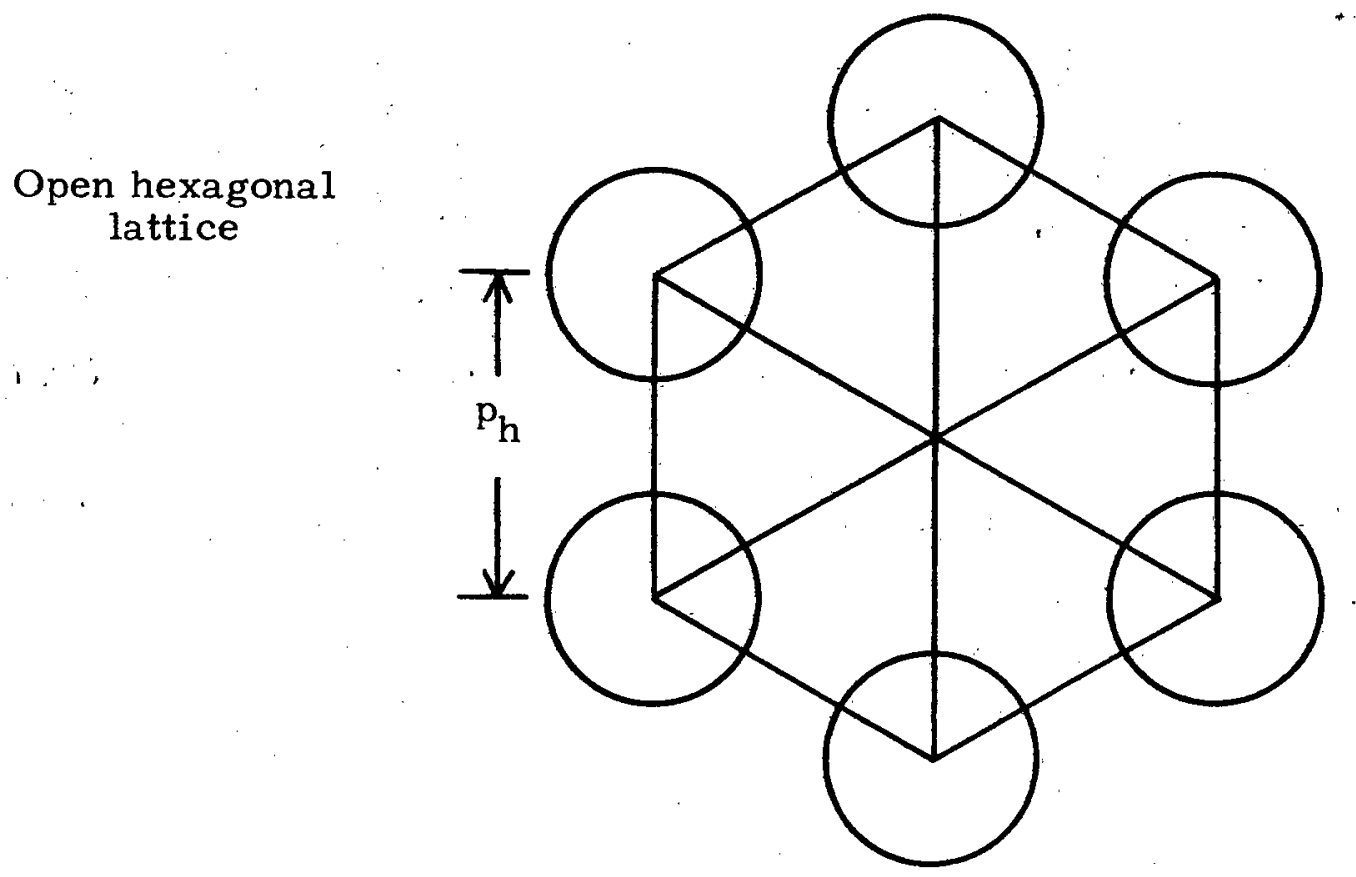

Fig. 3.5 Lattice Geometry 
TABLE 3.13

Heterogeneous Effects in GCFRs

(cents* of reactivity - exclusive of self-shielding)

\begin{tabular}{lrc} 
& $\frac{300 \mathrm{MWe}}{2}$ & $\frac{1000 \mathrm{MWe}}{2}$ \\
Spatial & 13.4 & 8.6 \\
Ani. Diff. & -270.6 & -249.3 \\
Net & -257.2 & -240.7 \\
${ }^{*} \beta=0.0033$ & & \\
\hline
\end{tabular}

TABLE 3.14

Effect of Anisotropic Streaming on 300-MWe GCFR

Pellaud - 1 Group Pellaud-10 Groups DELKHET ${ }^{*}-2$ Groups

$\Delta \mathrm{k} \quad-0.011 \quad-0.008 \quad-0.00893$

* Code programmed to employ present method. 
TABLE 3.15

Fuel Dispersal Accident

(dollars of reactivity - exclusive of self-shielding)

\begin{tabular}{ccc}
\hline $1000 \mathrm{MWe}$ & $\underline{\mathrm{NaIn}}$ & $\underline{\mathrm{Na} \text { Out }}$ \\
$\mathrm{AI}$ & $\$ 0.26$ & $\$ 0.92$ \\
$\mathrm{~B} \& \mathrm{~W}$ & $\$ 0.30$ & $\$ 0.97$ \\
$\mathrm{GE}$ & $\$ 0.28$ & $\$ 0.88$ \\
$\mathrm{CE}$ & $\$ 0.30$ & $\$ 0.82$ \\
GGA & - & $\$ 2.41$
\end{tabular}

$300 \mathrm{MWe}$

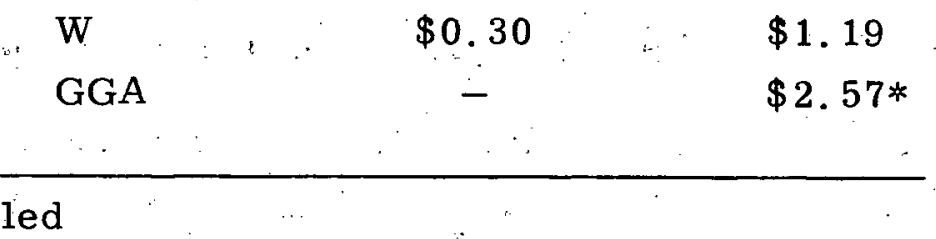


voided-core cases. If one postulates a sodium-voiding accident which leads to an explosive homogenization of the core, the heterogeneous effects act differently during different phases of the accident: during the initial voiding of the core, heterogeneity reduces the reactivity insertion; however, once core-homogenization occurs, the reactivity associated with heterogeneity materializes as a positive reactivity insertion. Thus careful modelling of this genre of postulated accidents requires consideration of anisotropic diffusion effects (and to a lesser degree, the effects of spatial flux distribution and heterogeneous resonance self-shielding) for a realistic physical description of the underlying processes.

\section{7 Heterogeneous Effects in FBR Blankets}

Experimental measurements of intra-rod activation profiles have been undertaken in the MIT Blanket Test Facility. Six-piece foil measurements (11) have established that the activation profile within the rod takes the form of a universal shape function:

$$
A(r)=C_{0}+C_{1} E\left[(r / a)^{2}\right]
$$

where $C_{0}$ and $C_{1}$ are constants, a is the rod radius, and $\mathscr{E}$ the complete elliptic integral of the second kind. Two-piece foil measurements have been performed as well $(12,13)$.

In the present work, comparison of group-by-group heterogeneous resonance self-shielded cross sections for both the BTF unit cell and a typical blanket unit cell indicates that the BTF mockup duplicates the heterogeneous characteristics (as well as the homogeneous composition) of a realistic FBR blanket. From the foil activation measurements, an index of self-shielding, the activation ratio $F$, has been calculated:

$$
F=\frac{\bar{A}_{f}}{A_{s}}=\frac{\int_{0}^{a} A(r) d V / \int_{0}^{a} d V}{A(a)},
$$

that is, the ratio of the average activation within the rod to the activation at the surface. Table 3.16 summarizes the results of measurements in two blankets (No. 2 =steel reflector, No. 3 =graphite reflector) 
TABLE 3.16

Two-Piece Foil F-Factors for Metal Rods

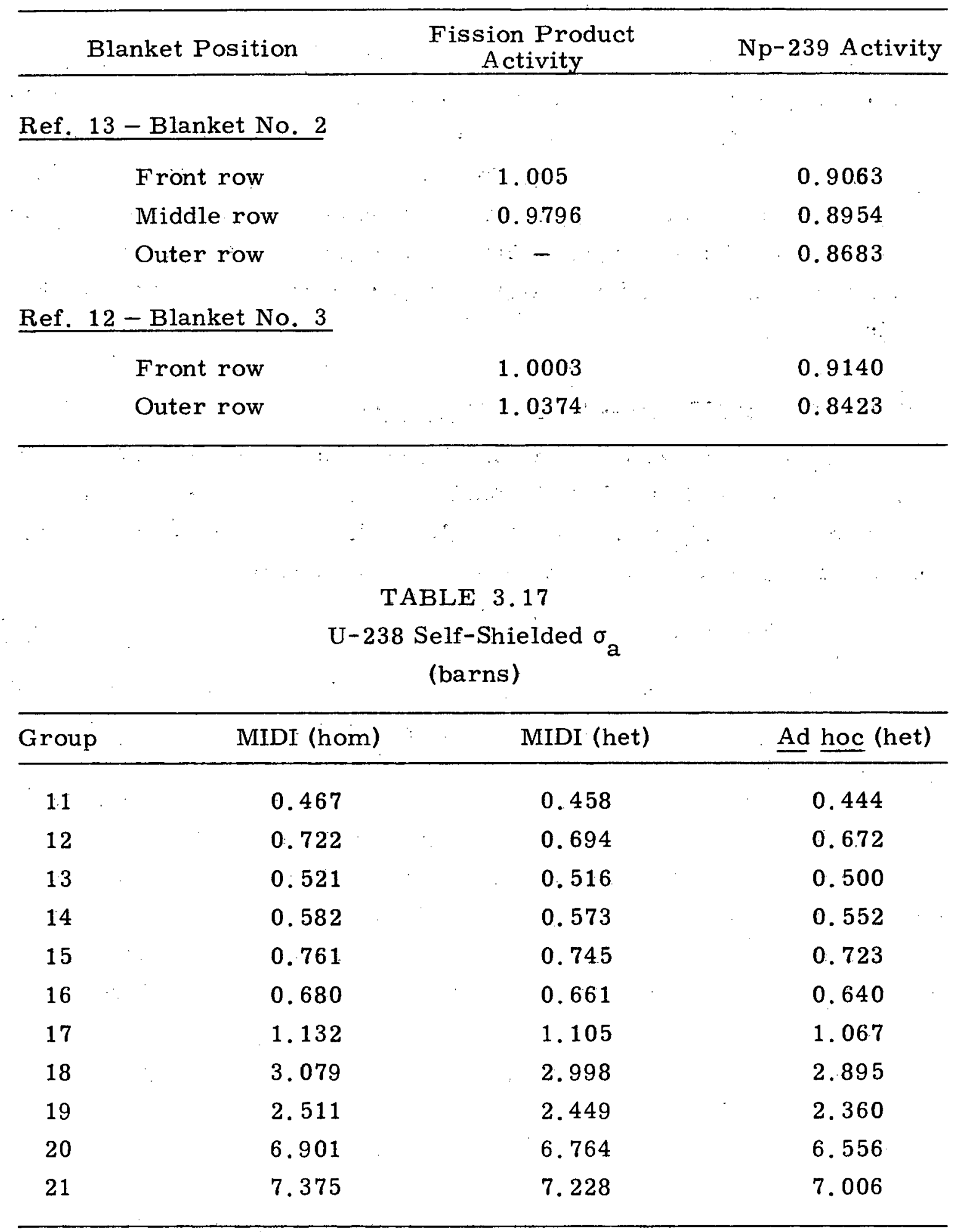


and at various positions. The error band on $F$ due to experimental uncertainty is $\pm 5 \%$ for the fission product activation measurements and $\pm 0.5 \%$ for the $\mathrm{Np}-239$ activation measurements. The latter measurements indicate a $10 \%$ depression in the U-238 capture profile (surfaceto-average) which increases with increasing blanket depth, due to spectral softening (i.e., more neutrons populating the lower, resonance-dominated groups).

The observed activation dip is not calculable using coarse-group multi-group theory (such as 26-group. ANISN calculations), which yields a negligible dip (less than 1\%). A method has been developed, however, whereby the activation dip is calculated in terms of $f$-factors given by MIDI U-238 resonance calculations. By equating fine-group reaction rates in the heterogeneous and homogeneous unit cells, it is possible to write:

$$
F=\left\{1+\frac{1-f *}{2 f *(1-v)}\right\}^{-1},
$$

where $\mathrm{F}$ is the activation ratio of Table $3.16, \mathrm{v}$ the fuel-to-coolant volume ratio, and $f *$ the flux weighted value of the group-by-group ratios of the heterogeneously self-shielded U-238 absorption cross section to the homogeneously self-shielded U-238 absorption cross section. Use of Eq. 3.25 predicts $F=0.96$ compared to the experimental value $F=0.90$. This is still an underestimate of the activation dip but somewhat improved on the multi-group prediction of virtually no dip. However, an ad hoc $3 \%$ decrease in the MIDI cross sections (see Table 3.17) serves to give a value of $F=0.90$ using Eq. 3.25. Thus a slight decrease in the theoretical group-by-group self-shielded cross sections is required to give the measured activation dip. Or from a different perspective, the calculated activation dip is exceedingly sensitive to the calculated resonance self-shielded cross sections; thus experiments of this type provide a strict test of the method used to calculate heterogeneous resonance self-shielding. The implication of these results may be that the equivalence formulae utilized in the MIDI code underpredict heterogeneous resonance self-shielding by several percent. Alternatively, the discrepancy may be due to errors in the input library of resonance parameters (e.g., resonance height, spacing, width). 
The effect of heterogeneity on the total breeding ratio was investigated with the conclusion that it is negligible (with a maximum effect of $+0.6 \%$ for the GCFR). Self-shielding, on the other hand, is found to significantly decrease the breeding ratio, though homogeneous and heterogeneous self-shielding give substantially the same result. Table 3.18 summarizes the breeding ratios calculated for various

TABLE 3.18

Effect of Self-Shielding on Breeding Ratio

\begin{tabular}{lll}
\hline \multicolumn{1}{c}{ Case } & $\mathrm{k}$ & $\mathrm{BR}$ \\
\hline Infinite dilution $(12 \% / 16 \%)$ & 1.000 & 1.4977 \\
Het. self-shielded $(12 \% / 16 \%)$ & 1.071 & 1.1982 \\
Het. self-shielded $(10.5 \% / 14 \%)$ & 1.003 & 1.3489 \\
Hom. self-shielded $(10.5 \% / 14 \%)$ & 1.003 & 1.3508 \\
\hline
\end{tabular}

self-shielding models. Neglecting self-shielding is seen to give an overenriched core (high $\mathrm{k}_{\text {eff }}$ ) and a low breeding ratio. As a corollary, one concludes that calculations with $\mathrm{k}_{\text {eff }}$ significantly different from 1.0 result in a considerable error in the breeding ratio.

\subsection{Summary and Recommendations}

In summary, four general conclusions may be drawn from the present work:

1. It is sufficient to account for only homogeneous resonance self-shielding and anisotropic diffusion to obtain key parameters within their target accuracy (i.e., $\mathbf{k} \pm 1 \%$, $\mathrm{BR} \pm 3 \%$, whole-core $\mathrm{Na}$ void \pm 50 ) . Specifically, one may neglect coarse-group spatial flux effects.

2. All heterogeneous effects serve to decrease the positive sodium void effect, hence most contemporary calculations which ignore one or more of the heterogeneous effects (particularly anisotropic diffusion) are overly conservative. 
3. The Bondarenko $\mathrm{f}$-factor formalism is adequate to deal with resonance self-shielding effects.

4. The BTF U-metal blanket is a good simulator of a real LMFBR blanket in terms of heterogeneity (established here) and, of course, on a homogenized basis (established previously).

Recommendations for future work may be divided into five areas:

1. Further work in coupling measurement of intra-rod activation profiles with their prediction by heterogeneous resonance self-shielding theory is in order. Such experiments would provide checks on equivalence formulations and resonance parameters.

2. The self-shielding correlations, thus far developed for U-238 alone, should be expanded to consider resonance self-shielding of Pu-239 and other significant elements such as Th-232.

3. A more detailed core representation within the context of the simple model is in order. Gross heterogeneities such as control rod regions and in-core test loops are not amenable to a homogeneous core treatment. In addition, local voiding effects should be examined in the light of heterogeneous effects.

4. The significant positive reactivity insertions in the loss of heterogeneity accident (i.e., the fuel dispersal accident) suggest that further analysis should seek to ascertain if any realistic mechanisms can be established for its propagation, and whether it leads to any significant augmentation of the dispersal.

5. The escape/transmission probability unit cell theory is a candidate for wider applicability due to its computational efficiency. On a fine-group level it has the potential of replacing the equivalence principles currently in use by providing a direct calculation of heterogeneous resonance self-shielding effects. 


\subsection{References}

(1) P. Greebler and B. A. Hutchins, "Significance of Integral Parameters in the Design and Performance of Fast Breeder Reactors," in Proceedings of National Topical Meeting on New Developments in Reactor Physics and Shielding, CONF-720901, U.S. Atomic Energy Commission, 928 (1972).

(2) Ward W. Engle, Jr., "A User's Manual for ANISN, A OneDimensional Discrete Ordinates Transport Code with Anisotropic Scattering," K-1693, Union Carbide (1967).

(3) D.S. Selengut, "Diffusion Coefficients for Heterogeneous Systems," in Nuclear Physics Research Quarterly Report, HW-60220, Hanford Atomic Product Operation, 65 (1959).

(4) P. Benoist, "Théorie du Coefficient de Diffusion des Neutrons dans un Réseau Comportant des Cavités," University of Paris Thesis (1964).

(5) E.E. Pilat, H. Gueron, and D.D. Lanning, "Measurement of the Diffusion Coefficient in a Highly Anisotropic Medium," Trans. Am. Nucl. Soc. , $\underline{8}, 446$ (1965).

(6) V.C. Rogers; "MIDI - A Fortran Code for the Calculation of . Average Cross Sections in the Resonance Energy Region," MIT Internal Document (16 July 1971).

(7) W.W. Little, Jr. and R.W. Hardie, "2DB User's Manual Revision 1," BNWL-831 REV1, Battelle Memorial Institute (1969).

(8) M.K. Sheaffer, M.J. Driscoll, and I. Kaplan, "A One-Group Method for Fast Reactor Calculations," Nucl. Sci. Eng. , 48, 459 (1972).

(9) I. I. Bondarenko et al., Group Constants for Nuclear Reactor Calculations, Consultants Bureau, New York (1964).

(10) B. Pellaud, "Physics Design of the Gas-Cooled Fast Breeder Reactor Demonstration Plant," GA-10509, Gulf General Atomic (1971).

(11) A.M. Thompson, "Activation Profiles in Reactor Fuel Elements," S.B. Thesis, MIT Dept. of Physics (June 1972).

(12) L. T. Kim, "Heterogeneous Effect in LMFBR Blanket Using Activation Method," MIT Course 22.39 Project Report (1972).

(13) P. DeLaquil, III, Private Communication. 


\section{ADVANCED BLANKET CONFIGURATIONS}

This work, which considers topics such as the economic advantages of blanket pre-enrichment, quantification of the cost of blanket overcooling, and the use of high-albedo reflectors for the blanket, will be reported in the topical report:

G. J. Brown and M. J. Driscoll, "Evaluation of HighPerformance LMFBR Blanket Configurations," COO-2250-4, MITNE-150 (est. 1974).

\subsection{Introduction}

The blanket and reflector regions surrounding the core of an LMFBR serve many functions. Chief among these are fertile-tofissile conversion, reflection of neutrons, power production, and neutron and gamma shielding. It is clear that these functions are interrelated, and all must be analyzed in concert in designing the blanket region.

The purpose of the research summarized here has been to identify and evaluate the performance of an advanced radial blanket-reflector configuration, including experimental verification of the neutronic analysis. To accomplish this latter task, the Blanket Test Facility at the MIT Research Reactor was utilized (see Section 4.4). In the overall evaluation design, decisions were made with respect to a) blanket thickness, b) initial blanket fissile enrichment (seeding), c) reflector composition, and d) orificing scheme. Various blanketreflector configurations differing in certain of the above parameters were studied using state-of-the-art computer methods.

Figure 4.1 depicts the major material subdivisions used to describe the 1000-MWe LMFBR chosen as the subject for this study. Included are both a two-dimensional configuration used in the burnup studies and a one-dimensional configuration used in the blanket-heating analysis (developed from the two-dimensional results by determining a $25-\mathrm{cm}$ reflector savings). 
2 dimensional $(R-Z)$ model

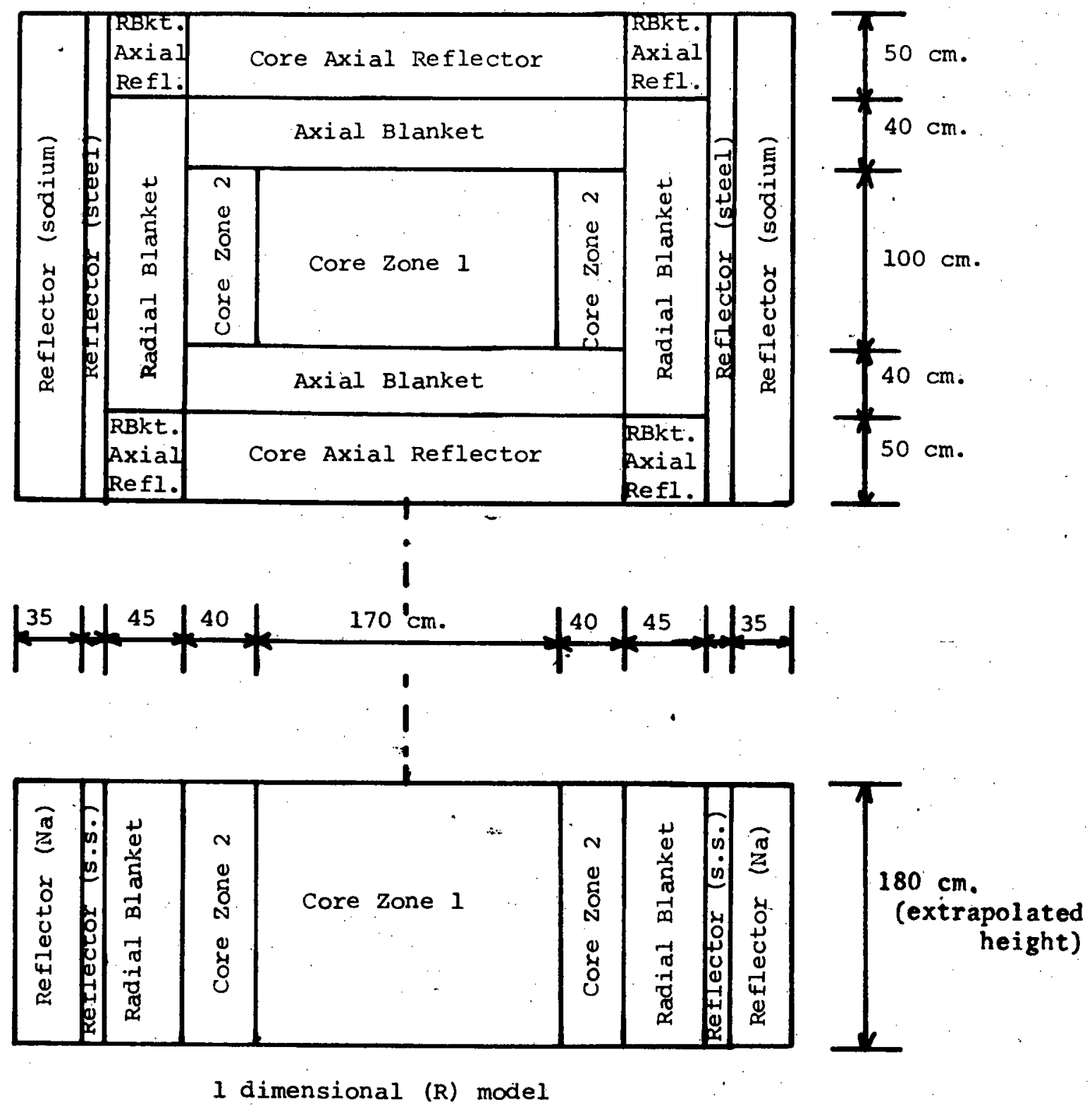

Fig. 4. 1 1000MWe Reference Reactor Configurations 
The main features to note in this cylindrically symmetric layout are two approximately equal-volume core enrichment zones, a core height-to-diameter ratio (H/D) of 0.4 , a $40-\mathrm{cm}$-thick axial blanket on the top and bottom of the core, and of particular concern to this study, the "base-case" blanket-reflector configuration consisting of a 3-row (45-cm-thick) radial blanket surrounded by a steel reflector. Table 4.1 summarizes the pertinent data for this reference configuration which closely resembles the reference LMFBR used for the original MIT Blanket Test Facility desing calculations (1) and other 1000-MWe LMFBR blanket studies $(\underline{2}, \underline{3})$.

For this study the ranking of the alternative configurations was according to economic criteria determined by evaluating the levelized fuel cycle cost contribution of the radial blanket region, taking into account not only the usual burnup economic parameters (including fissile revenue and fabrication, reprocessing and carrying charges) but also the economic penalty associated with blanket overcooling due to the steep power gradient across the blanket region.

Batch blanket management was selected for this study due to its simplicity of implementation (i.e., blanket elements see only one position in the reactor, minimizing reactor down time devoted to blanket refueling and/or repositioning) and due to the fact that approximately the same amount of plutonium is bred from an equivalent number of blanket elements regardless. of management scheme (e.g. , out-in or in-out management) over the same time interval (e.g., see Ref. 3, 4 or 5).

The best overall configuration identified in this evaluation was a 2-row blanket, fueled with depleted uranium (i.e., no blanket seeding), surrounded by a 1-row graphite reflector, incorporating individual (row-by-row) orificing. Relative to the base case configuration, a savings of over $0.20 \mathrm{mills} / \mathrm{kW}-\mathrm{hr}$ (equivalent to approximately $\$ 1.4$ $\times 10^{6}$ per year) can thereby be achieved. 
TABLE 4.1

Reference Reactor Parameters

\begin{tabular}{|c|c|c|c|c|c|c|}
\hline & \multirow[b]{2}{*}{$\begin{array}{l}\mathrm{Ht} \\
(\mathrm{cm})\end{array}$} & \multirow[b]{2}{*}{$\begin{array}{l}\text { Rad. } \\
\text { Thick. } \\
\text { (cm) }\end{array}$} & \multirow{2}{*}{$\begin{array}{l}\text { No. of } \\
\text { Equiv. b } \\
\text { Assems. }\end{array}$} & \multicolumn{3}{|c|}{ Percent by Volume } \\
\hline & & & & Fuel $^{\mathrm{c}}$ & Coolant ${ }^{\mathrm{d}}$ & Structure ${ }^{\mathrm{e}}$ \\
\hline \multicolumn{7}{|l|}{ Core } \\
\hline Zone 1 & 100 & 85 & 127 & $30(85 \%$ t.d. $)$ & 50 & 20 \\
\hline Zone 2 & 100 & 40 & 118 & $30(85 \%$ t.d. $)$ & 50 & 20 \\
\hline $\begin{array}{l}\text { Axial } \\
\text { Blanket }^{a}\end{array}$ & 80 & 125 & 245 & $30(85 \%$ t.d. $)$ & 50 & 20 \\
\hline \multicolumn{7}{|l|}{$\begin{array}{l}\text { Radial } \\
\text { Blanket }\end{array}$} \\
\hline Row 1 & 180 & 15 & 63 & $50(95 \%$ t.d. $)$ & 30 & 20 \\
\hline Row 2 & 180 & 15 & 70 & $50(95 \%$ t.d. $)$ & 30 & 20 \\
\hline Row 3 & 180 & 15 & 77 & $50(95 \%$ t.d. $)$ & 30 & 20 \\
\hline \multicolumn{7}{|l|}{$\begin{array}{l}\text { Axial } \\
\text { Reflector }\end{array}$} \\
\hline $\begin{array}{c}\text { For axial } \\
\text { blanket }\end{array}$ & 50 & 125 & 245 & - & 50 & 50 \\
\hline $\begin{array}{c}\text { For radial } \\
\text { blanket }\end{array}$ & 50 & 45 & 210 & - & 30 & 70 \\
\hline \multicolumn{7}{|l|}{$\begin{array}{l}\text { Radial } \\
\text { Reflector }\end{array}$} \\
\hline Inner & 140 & 15 & 84 & - & 20 & 80 \\
\hline Outer & 140 & 35 & 222 & - & 100 & - \\
\hline
\end{tabular}

${ }^{a}$ Axial blanket and reflector heights refer to thickness above or below core.

${ }^{\mathrm{b}}$ Assumes hexagonal assemblies $15 \mathrm{~cm}$ across the flats.

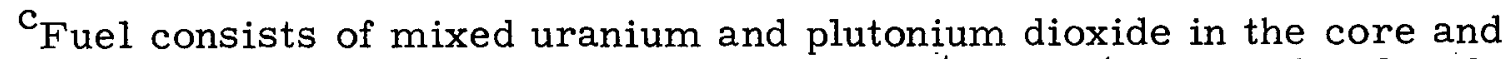
uranium dioxide in the blanket. The $100 \mathrm{v} / \mathrm{o}, 100 \% \mathrm{t}$. d. molecular density is taken as 0.02447 atoms/barn-cm. Plutonium is assumed to be typical . light water reactor discharge $\mathrm{Pu}$ at $30,000 \mathrm{MWD} / \mathrm{T}$ : 63\% $\mathrm{Pu}-239 /$ $22 \% \mathrm{Pu}-240 / 12 \% \mathrm{Pu}-241 / 3 \% \mathrm{Pu}-242$.

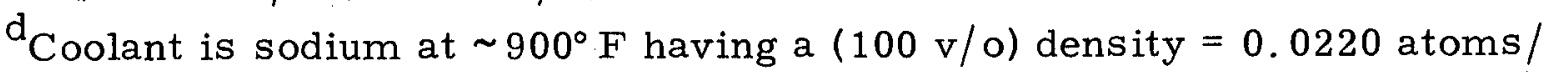
barn-cm.

$\mathrm{e}_{\text {Structure is stainless steel with } 17.7 \% \text { chromium } / 8.3 \% \text { nickel } / 74.0 \% \text { iron }}$ having a $(100 \mathrm{v} / \mathrm{o})$ density $=0.0850$ atoms $/ \mathrm{barn}-\mathrm{cm}$. 


\subsection{Blanket Heating Analysis}

A detailed blanket-heating analys is is necessary in order to determine blanket radial power profiles. The analysis is complicated by the fact that the energy deposited at a given point in the blanket is not only due to local fission events (including capture) but also due to the absorption of core-leakage gamma rays and neutrons. The analysis is further complicated by the fact that the relative effect of coreleakage gamma rays and neutrons compared to the local fission heating rate changes with time. It was found, however, that adequate estimates of the radial power distribution can be simply obtained by superposition of local and leakage effects for each of the major contributions, namely:
a) fission heating rate
b) gamma ray heating rate
c) neutron heating rate.

\subsubsection{Method of Analysis}

The methods of analysis employed in determining the power distributions for the three contributions to the heating rates are all similar. A criticality calculation was made with the ANISN transport code ( $\underline{6}$ ), S-8 option, (which was shown sufficient by Leung [7]). This yielded multigroup fluxes of both neutrons and gamma rays which were then used to calculate the volumetric energy deposition rates, $E$, for the various heating contributions in the blanket by application of the following equation:

$$
E(r)=\sum_{i, j} N_{j}(r) \sigma_{i j}^{E} \phi_{i}(r),
$$

where

$\mathrm{N}_{j}(r)$ is the $\mathrm{j}^{\text {th }}$ material number density (atoms/barn-cm) at a particular radius, $r(\mathrm{~cm})$;

$\sigma_{i j}^{E}$ is the microscopic energy absorption cross section for material $j$, energy group i ( $M e V$-barns);

$\phi_{i}(r)$ is the radial flux in energy group $i$, at a particular radius, $r$ (particles $/ \mathrm{cm}^{2}-\mathrm{sec}$ ). 
Two multigroup cross section sets were employed to analyze the three contributions to the total heating rate. A 26-group neutron cross section set developed from the so-called "Russian" or "ABBN" set ( ) was utilized to acquire fission heating rates and neutron heating rates. A 40-group coupled neutron (22 groups)-gamma (18 groups) cross section set developed at ORNL ( $\underline{9})$ was used for determining the gamma heating rates.

\subsubsection{Fission Heating Analysis}

There are approximately 200 million electron volts of recoverable energy released per fission reaction. Table 4.2 summarizes the energy contributions from fission fragments, beta rays, gamma rays, and neutrons. For the fission heating analysis, it was assumed that all the energy is deposited locally, yielding "conventional" heating rates. Thus the microscopic fission energy absorption cross section is given simply by the microscopic fission cross section times the energy released per fission, $200 \mathrm{MeV}$.

TABLE 4.2

Distribution of Energy Released in Fission

\begin{tabular}{|c|c|}
\hline Type & Recoverable Energy $(\mathrm{MeV})$ \\
\hline Fission fragments & 167 \\
\hline \multicolumn{2}{|l|}{ Fission product decay } \\
\hline$\beta$ rays & 7 \\
\hline$\gamma$ rays & 7 \\
\hline (neutrinos) & (11; not recoverable) \\
\hline Prompt $\gamma$ rays & 7 \\
\hline $\begin{array}{l}\text { Fission neutrons (including } \\
\text { inelastic scatter } \gamma^{\prime} s \text { ) }\end{array}$ & 5 \\
\hline Capture $\gamma$ rays & $\begin{array}{l}7 \\
\text { (varies with reactor } \\
\text { composition) }\end{array}$ \\
\hline TOTAL & 200 \\
\hline
\end{tabular}


Figure 4.2 shows the relative fission power density as a function of radius for the base case, 3-row depleted uranium radial blanket. Analysis of the fission power distribution with respect to fertile (U-238) and fissile (U-235) fissions yields the interesting result that fast fissions in the fertile isotope dominate the total fission rate in the first half of the blanket, whereas the fissile fissions dominate in the latter half of the blanket. This result indicates the importance of considering the presence of $\mathrm{U}-235$ even in the very small quantities occurring in depleted uranium $(0.2 \mathrm{w} / \mathrm{o})$, and the importance of fast fissions in the fertile isotope.

The relative effect of fast fission decreases with distance into the blanket and with increasing fissile enrichment, as indicated by Fig. 4.3. The ordinate in Fig. 4.3 is labelled the "U-235 equivalent enrichment of U-238" and is determined by extrapolating fission rate data from variously enriched blankets (ranging from $0.2 \mathrm{w} / \mathrm{o}$ to $2.5 \mathrm{w} / \mathrm{o}$ ) to zero fission rate. Since there are fissions due to U-238, even at zero fissile enrichment, an effective enrichment for the U-238 could be determined. This effective enrichment decreases exponentially with radial distance into the blanket (the abscissa of Fig. 4.3). This relationship can be explained by noting that the fast flux also falls off exponentially in the blanket, as shown by the U-238 fission rate in Fig. 4.2.

\subsubsection{Gamma Heating Analysis}

For this analysis a 40 -group coupled neutron (22 groups)gamma (18 groups) cross section set was employed (9). With this cross section set the production of gamma rays is treated by appropriate downscatter from the upper 22 neutron groups into the lower 18 gamma groups; and one multigroup $\mathrm{S}_{\mathrm{n}}$ solution suffices for both neutron and gamma ray distributions. Gamma rays are produced by:

1. Nuclear fission

2. Fission product decay

3. Neutron capture product decay

4. Inelastic scatter of neutrons

5. Annihilation of positrons. 


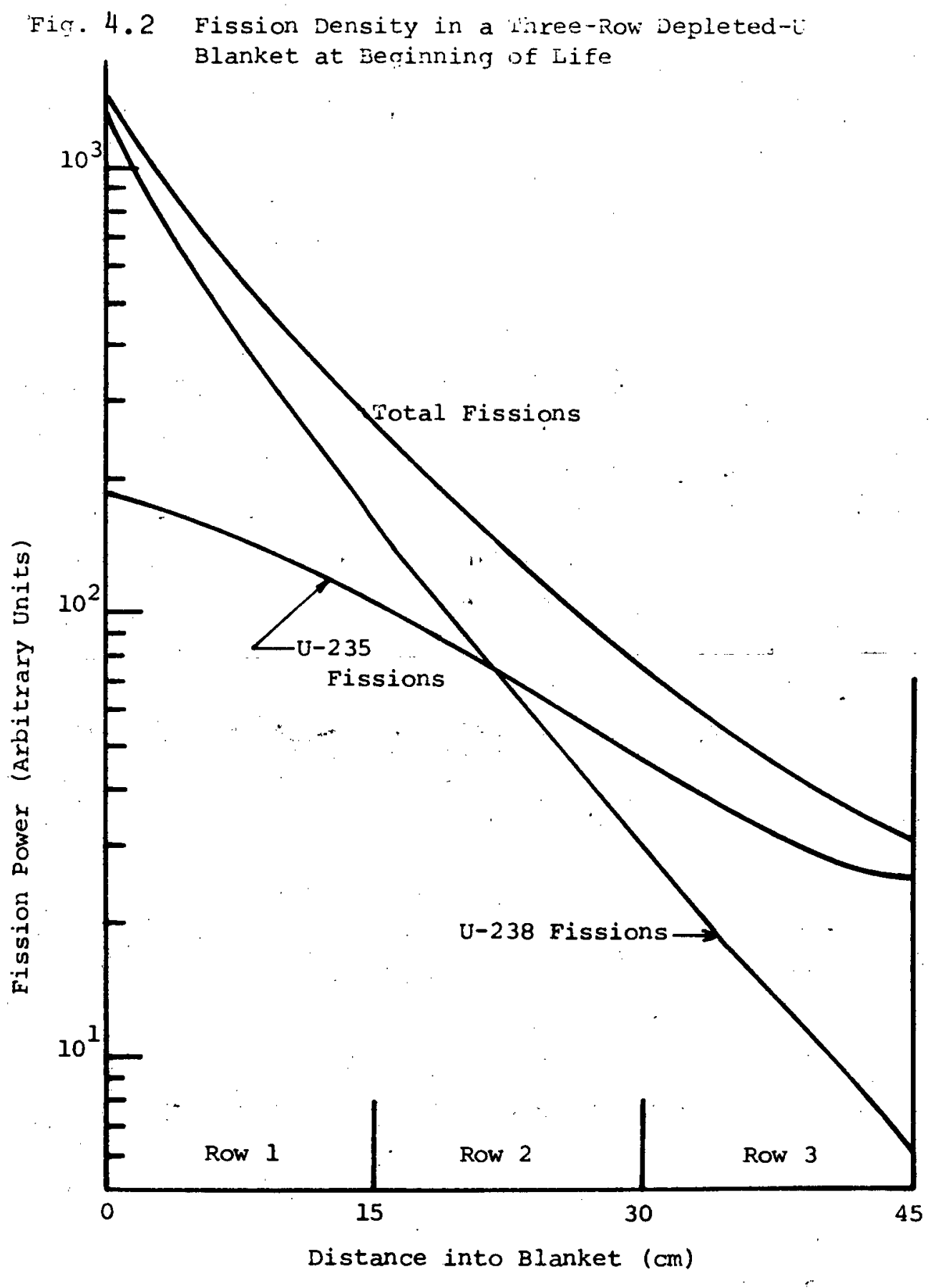




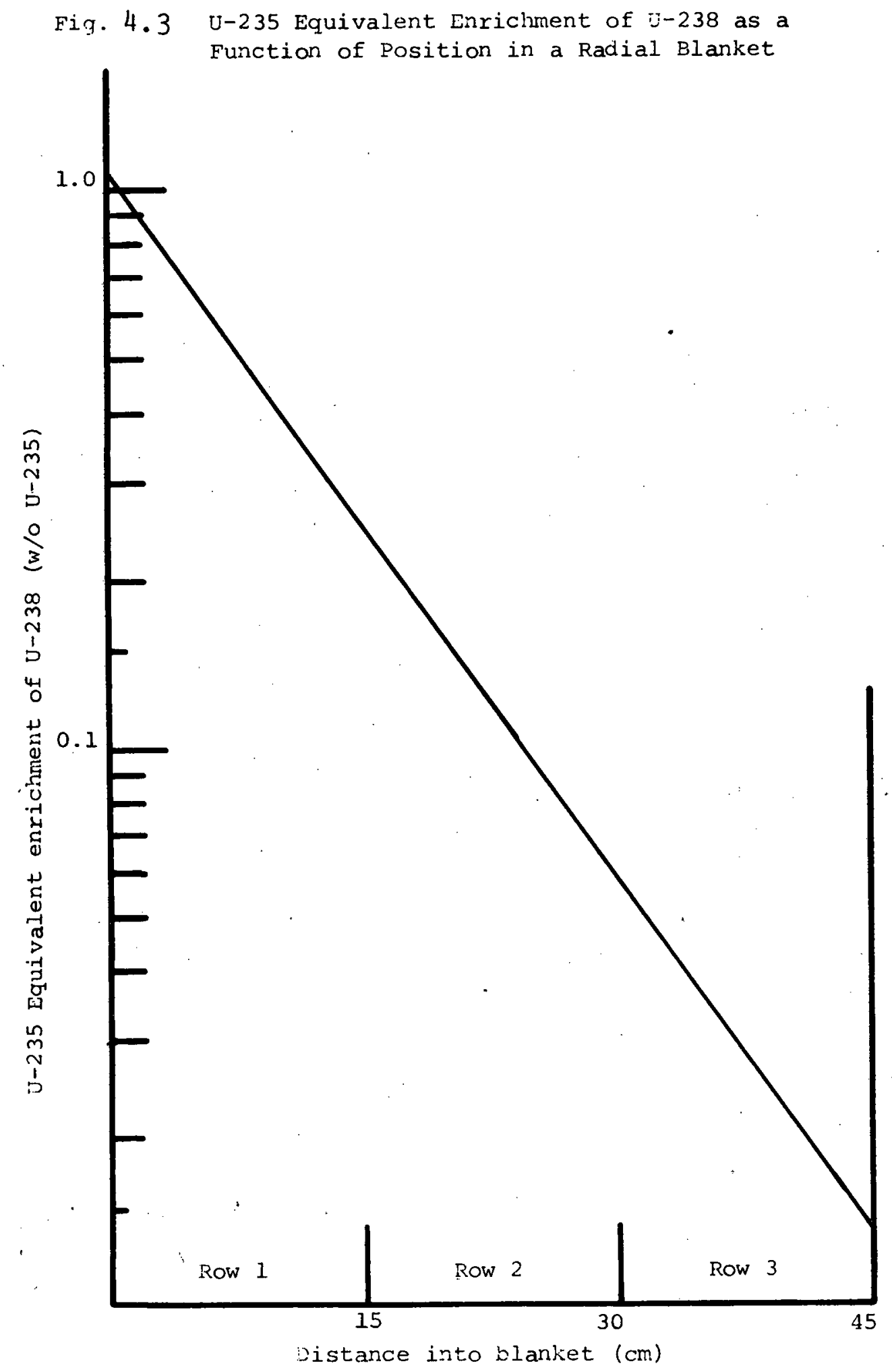


Microscopic gamma energy absorption cross sections in units of MeVbarns were conveniently included in the cross section set so that the calculation of the volumetric energy deposition rate (Eq. 4.1) could be straightforwardly performed. Gamma rays lose energy by:

1. Pair production

2. Compton scattering

3. Photoelectric effect,

which covers the range of important gamma interactions (10).

Figure 4.4 shows the total gamma energy deposition in the blanket due to both local fission events and core leakage. Seven different cases of various blanket enrichments were analyzed, ranging from $0.2 \mathrm{w} / \mathrm{o}$ to $2.5 \mathrm{w} / \mathrm{o} \mathrm{U}-235$, including two cases with different fissile enrichments $(w / o)$ in each blanket row $(0.71 / 1.2 / 2.0$ and 2.0/1.2/0.71). These cases cover a wide range of available enrichments as might be considered for blanket seeding. Furthermore, these fissile uranium enrichments (especially the mixed enrichment cases) roughly simulate the fissile plutonium enrichment that might be experienced in a radial . blanket after irradiation or after out-in or in-out fuel management.

For clarity, only the $0.2 \mathrm{w} / \mathrm{o}, 1.2 \mathrm{w} / \mathrm{o}$, and $2.5 \mathrm{w} / \mathrm{o}$ enriched. blankets are plotted in Fig. 4.4. All the other cases a re similar to, and within the bounds of, the $0.2 \mathrm{w} / \mathrm{o}$ and $2.5 \mathrm{w} / \mathrm{o}$ blankets. A few pertinent observations can be made. Most noticeable is the characteristic exponential attenuation of the gamma deposited energy for all enrichments, giving an e-folding distance between 13 and $15 \mathrm{~cm}$. Other general features are the nonlinearity of the curves at both extremes of the blanket, which is attributed to the discontinuities in material composition at the core-blanket and blanket-reflector interfaces.

To evaluate the effect of core gamma rays leaking into the blanket, the effect of blanket-fission-produced gammas was decoupled from the total production of gamma rays. This was achieved by making the assumption that gamma rays produced by fission events were absorbed locally, the usual "infinite medium" assumption made when calculating energy deposition rates from fission rates in reactors (11). 


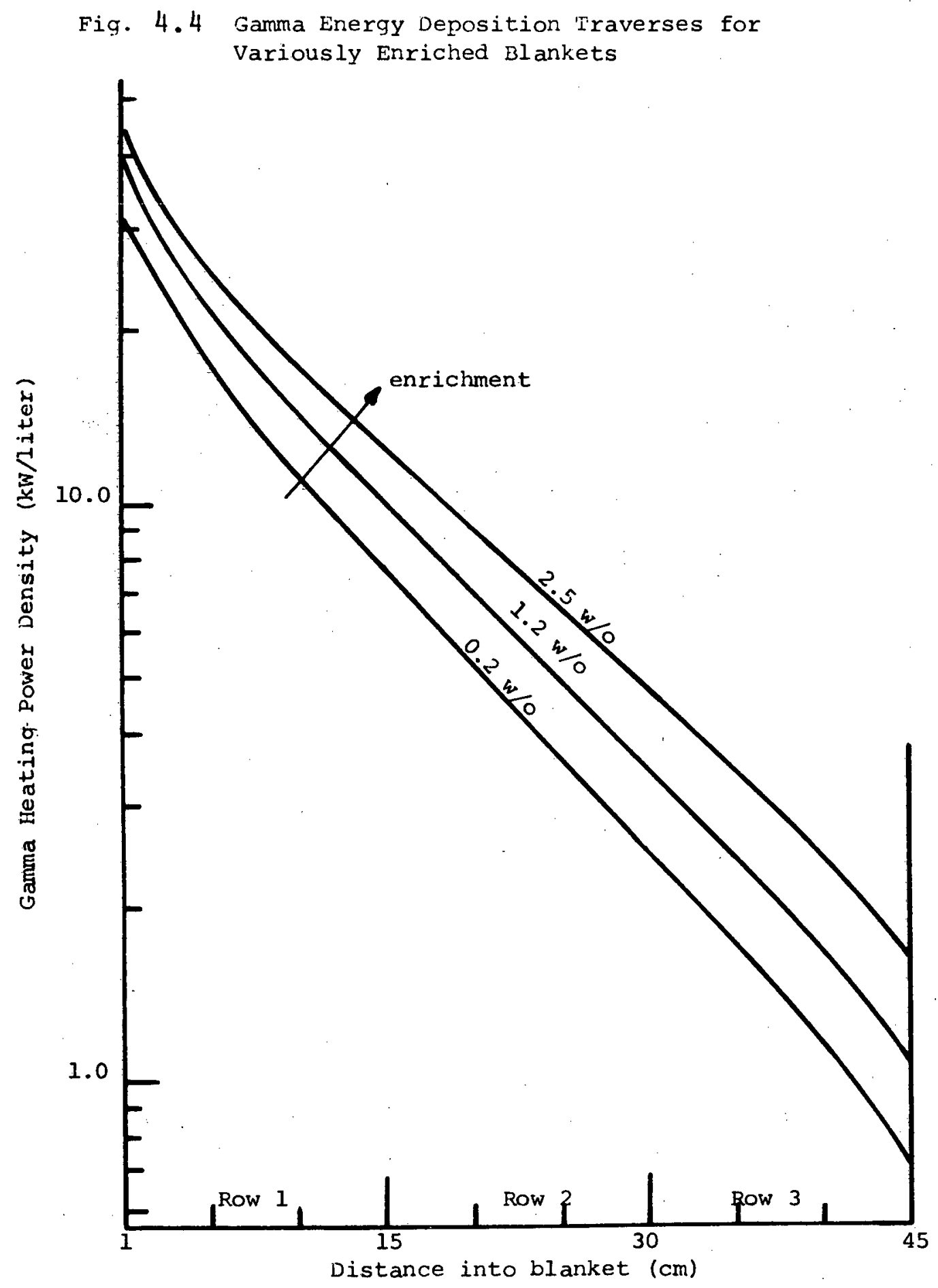


Thus $25 \mathrm{MeV}$, the sum of the gamma ray energy released per local fission (including $4 \mathrm{MeV}$ of inelastic scatter gammas) as given in Table 4.2, was subtracted from the calculated local gamma energy deposition, leaving the excess gamma energy, i.e., that gamma energy not attributable to local fissions, but rather due to leakage of core gamma rays. Figure 4.5 shows the excess gamma energy as a function of enrichment and distance into the blanket.

The major consequence of Fig. 4.5 follows from the closeness of the curves for the different enrichments. This figure implies that the excess gamma heating is essentially independent of enrichment, and therefore independent of blanket fission rate. This result is important since it permits inclusion of gamma rays in the heating analysis by simply adding a component, independent of the local fission rate, to the local fission heating rate. This component, $E_{\gamma}(\mathrm{kw} / \ell)$, is a function only of distance from the core, $\mathrm{x}_{\mathrm{cm}}$, and can be represented by the following equation:

$$
\mathrm{E}_{\boldsymbol{\gamma}}=\mathrm{P}(0.864) \mathrm{e}^{-0.0715 \mathrm{x}},
$$

where $P$ is the reactor power in units of $100 \mathrm{MW}_{\mathrm{T}}$; in this case, $P=25$. Table 4.3 lists the maximum percent deviation between the gamma heating results presented in Fig. 4.5 and those predicted by Eq. 4.2. Figure 4.6 shows the ratio of excess gamma energy, predicted by Eq. 4.2, to the local fission heating rate, and indicates the importance of including gamma heating in a heating analysis of the blanket. As can be seen, the ratio decreases with enrichment. Except for the depleted blanket which has a ratio of about 1.0 , the ratio is less than 0.5 , decreasing to about 0.08 . Thus considering that Eq. 4.2 correlates the data presented in Fig. 4.6 to within better than a 20 percent discrepancy, errors less than 10 percent would be expected in predicting the total heating rate. 


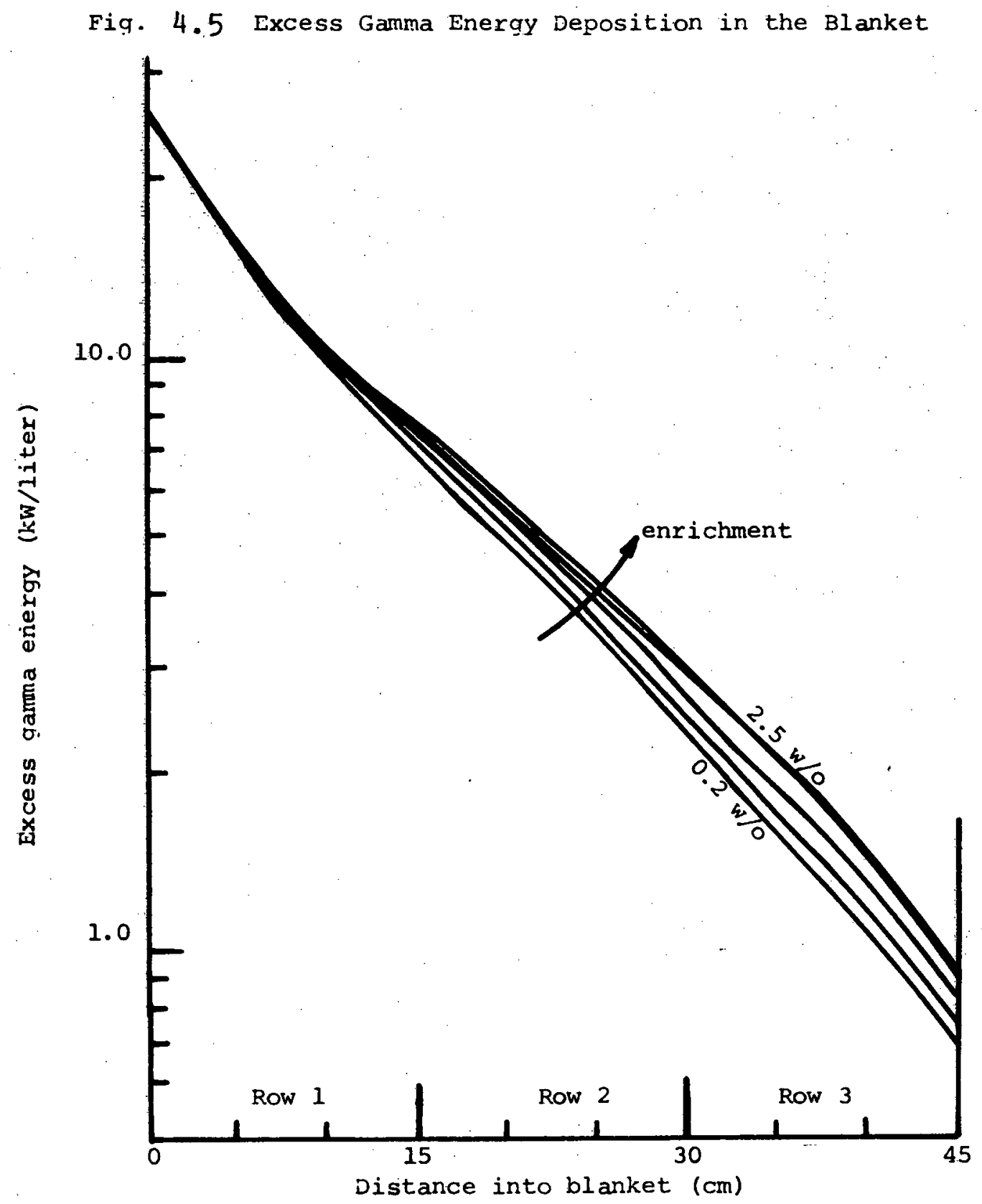


Fig. 4.6. Ratio of Excess Gamma Energy to Fission Energy Deposition in the Blanket

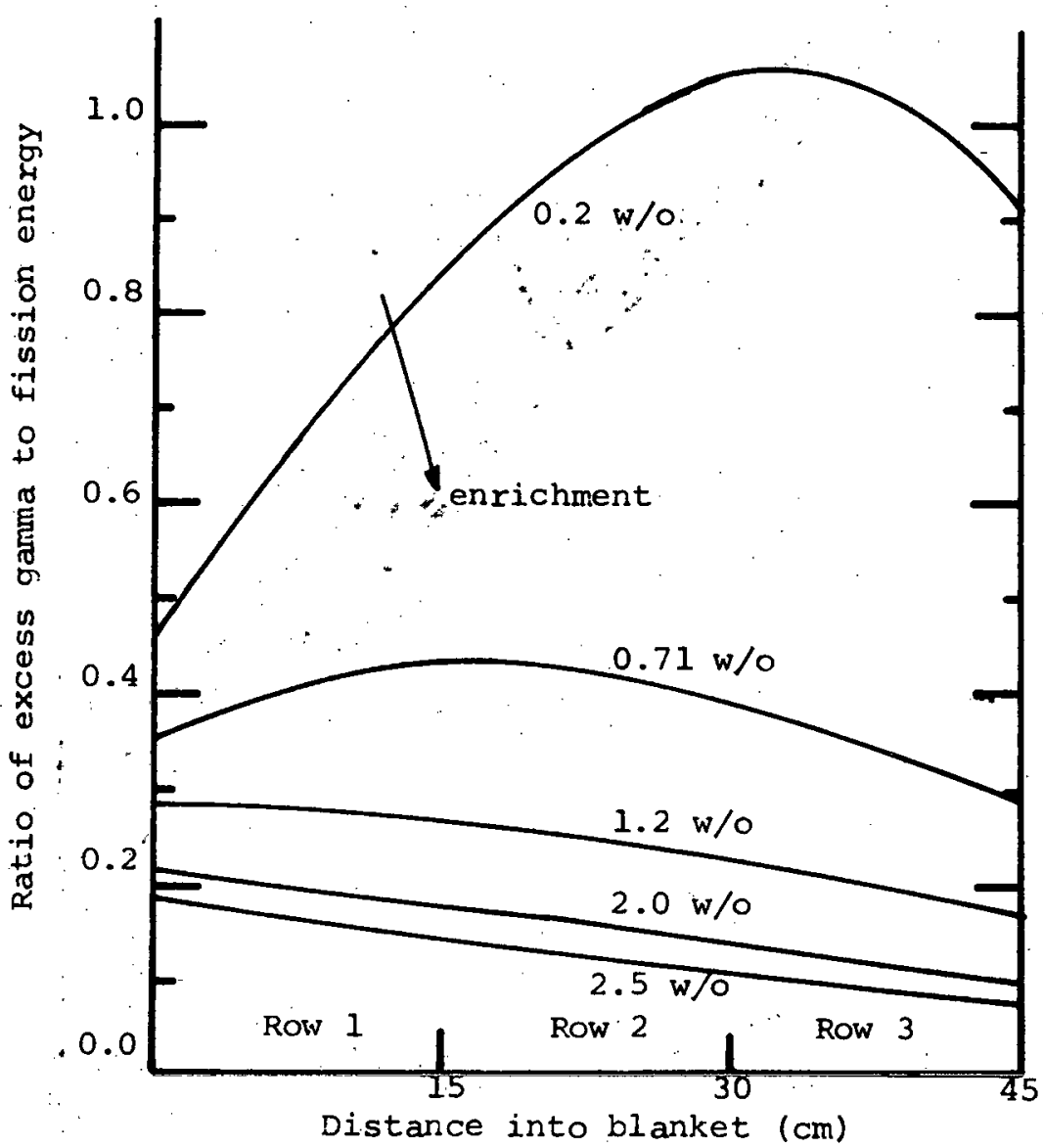


TABLE 4.3

Excess Gamma Energy Deposition

\begin{tabular}{ccc}
\hline $\begin{array}{c}\text { Depth } \\
\text { into } \\
\begin{array}{c}\text { Blanket } \\
(\mathrm{cm})\end{array}\end{array}$ & $\begin{array}{c}\text { Excess } \\
\text { (Energy } \\
(\text { Eq. 4. 2) } \\
(\mathrm{kW} / \text { liter })\end{array}$ & $\begin{array}{c}\text { Maximum } \\
\text { Deviation* } \\
(\%)\end{array}$ \\
\hline 2.5 & 18.06 & +12.8 \\
7.5 & 12.64 & +8.96 \\
12.5 & 8.837 & -5.94 \\
17.5 & 6.181 & +10.7 \\
22.5 & 4.323 & +10.9 \\
27.5 & 3.024 & -11.8 \\
32.5 & 2.115 & -16.5 \\
37.5 & 1.479 & +18.9 \\
42.5 & 1.044 & -17.9 \\
\hline
\end{tabular}

*Percent difference between excess gamma energy predicted by Eq. 4.2 and the excess gamma energy plotted in Fig. 4.5.

\subsubsection{Neutron Heating Analysis}

Three different events were considered to contribute to the neutron heating rate:

1. neutron elastic scattering

2. neutron inelastic scattering

3. neutron capture.

Actually, these three events are similar in the sense that the energy associated with each is a recoil energy determined by the law of conservation of momentum. Thus the microscopic energy absorption cross section for event $x$, material $j$, energy group $i, x_{i j}^{E}$, defined for use in Eq. 4.1, is determined by simply multiplying the mean energy loss per event $\left(\overline{\Delta E}_{i j}\right)$ by the microscopic cross section for event $\mathrm{x}, \mathrm{x} \sigma_{i j}$, given by the 26 -group cross section set $(\underline{8})$,

$$
{ }_{x} \sigma_{i j}^{E}=\left({ }_{x} \sigma_{i j}\right)\left(\overline{\Delta E}_{i j}\right)
$$


Table 4.4 gives the appropriate expressions for the terms in Eq. 4.3 for the three types of neutron heating events listed above. A detailed derivation of these relationships can be found in reference 3 .

The results of the neutron heating analysis for the variously enriched blankets. are shown in Fig. 4.7, where the variation with fissile enrichment is emphasized. In order to determine the effect of the core on the total neutron heating rate, the contribution to the neutron heating rate due to neutrons produced by fissions in the blanket was determined by extrapolating the lines in Fig. 4.7 to the appropriate (negative) effective enrichment where the fission rate is zero, as determined in Fig. 4.3. The portion of the neutron heating due to neutrons originating in the core, or excess neutron heating, was found to be independent of enrichment, depending only on the distance from the core, as shown in Fig. 4.8.

This general result, isolating the excess neutron heating (due to core neutrons) parallels the previous result which isolated the excess gamma heating in the blanket caused by gammas leaking from the core. Equation 4.4 correlates the excess neutron heating, $E_{n}(\mathrm{kw} / \ell)$ :

$$
E_{n}=P(0.096) \mathrm{e}^{-0.1098 x} \text {, }
$$

where $\mathrm{P}$ is the reactor power in units of $100 \mathrm{MW}_{\mathrm{T}}$; in this case, $\mathrm{P}=25$.

Comparison of Eq. 4.4 to Eq. 4.2 indicates that the excess neutron heating is almost an order of magnitude less than the excess gamma heating, and decreases more rapidly with distance into the blanket.

\subsubsection{Summary of Heating Analysis}

Careful analysis of the three main contributions to the total blanket heating rate, fission heating, gamma heating, and neutron heating, has led to the development of equations to determine the total blanket heating rate. in a manner which separates in-leakage from the core from local contributions. The total blanket heating rate (BHR) was approximated as the sum of the fission heating rate (FHR), treated as a local source at $200 \mathrm{MeV} /$ fission, plus the gamma heating rate (GHR) (given by Eq. 4.2) and the neutron heating rate (NHR) (given by Eq. 4.4) given here in combined form as the shield heating rate (SHR): 
TABLE 4. 4 Summary of Microscopic Energy Absorption Cross Sections for Evaluation of Neutron Heating

\begin{tabular}{|c|c|c|}
\hline Mechanism & $\begin{array}{l}\text { Energy per } \\
\text { Event }\left(\Delta \overline{\mathrm{E}}_{\mathrm{ij}}\right)\end{array}$ & $\begin{array}{l}\text { Microscopic } \\
\text { Cross Section } \\
\left(\sigma_{i j}\right) \\
\end{array}$ \\
\hline Elastic Scattering & $\bar{E}_{i}\left(1-e^{-\xi}\right)$ & $e 1^{\sigma}{ }_{i, j}$ \\
\hline $\begin{array}{l}\text { Inelastic Scattering Recoil } \\
\qquad \text { due to incident neutron, } \overline{\mathrm{E}}_{\mathrm{i}}\end{array}$ & $\left(\frac{1}{\mathrm{~A}+1}\right) \overline{\mathrm{E}}_{\mathrm{i}}$ & in $^{\sigma} i, j$ \\
\hline due to re-emitted neutron, $\overline{\mathrm{E}}_{\mathrm{n}}$ & $\left(\frac{1}{\mathrm{~A}}\right) \overline{\mathrm{E}}_{\mathrm{n}}$ & in $^{\sigma_{i \rightarrow n, j}}$ \\
\hline due to de-excitation gamma, $\mathrm{E}_{\gamma}$ & $\frac{1}{A}\left(\frac{E_{\gamma}^{2}}{2 m_{0} c^{2}}\right.$ & $\operatorname{in}_{i \rightarrow n, j}$ \\
\hline $\begin{array}{l}\text { Neutron Capture Recoil } \\
\quad \text { due to incident neutron, } \overline{\mathrm{E}}_{i}\end{array}$ & $\left(\frac{1}{A+1}\right) \bar{E}_{i}$ & $c^{\sigma} \cdot \mathbf{i}, j$ \\
\hline due to gamma, $E_{\gamma}$ & $\frac{1}{A}\left(\frac{E_{\gamma}^{2}}{2 m_{o} c^{2}}\right)$ & $e^{\sigma_{i, j}}$ \\
\hline
\end{tabular}

Total microscopic energy absorption cross section for neutron heating:

$\sigma_{i j}^{E}=\bar{E}_{i}\left(1-e^{-\xi}\right)\left(e_{e l} \sigma_{i, j}\right)+\left(\frac{\bar{E}_{i}}{A+1}\right)\left(_{i n} \sigma_{i, j}\right)+\left(\frac{\bar{E}_{n}}{A}+\frac{E_{\gamma}^{2}}{2 m_{o} c^{2} A}\right)\left({ }_{i n} \sigma_{i \rightarrow n, j}\right)+\left(\frac{\bar{E}_{i}}{A+1}+\frac{E_{\gamma}^{2}}{2 m_{o} c^{2} A}\right)\left(c_{i, j}\right)$. 


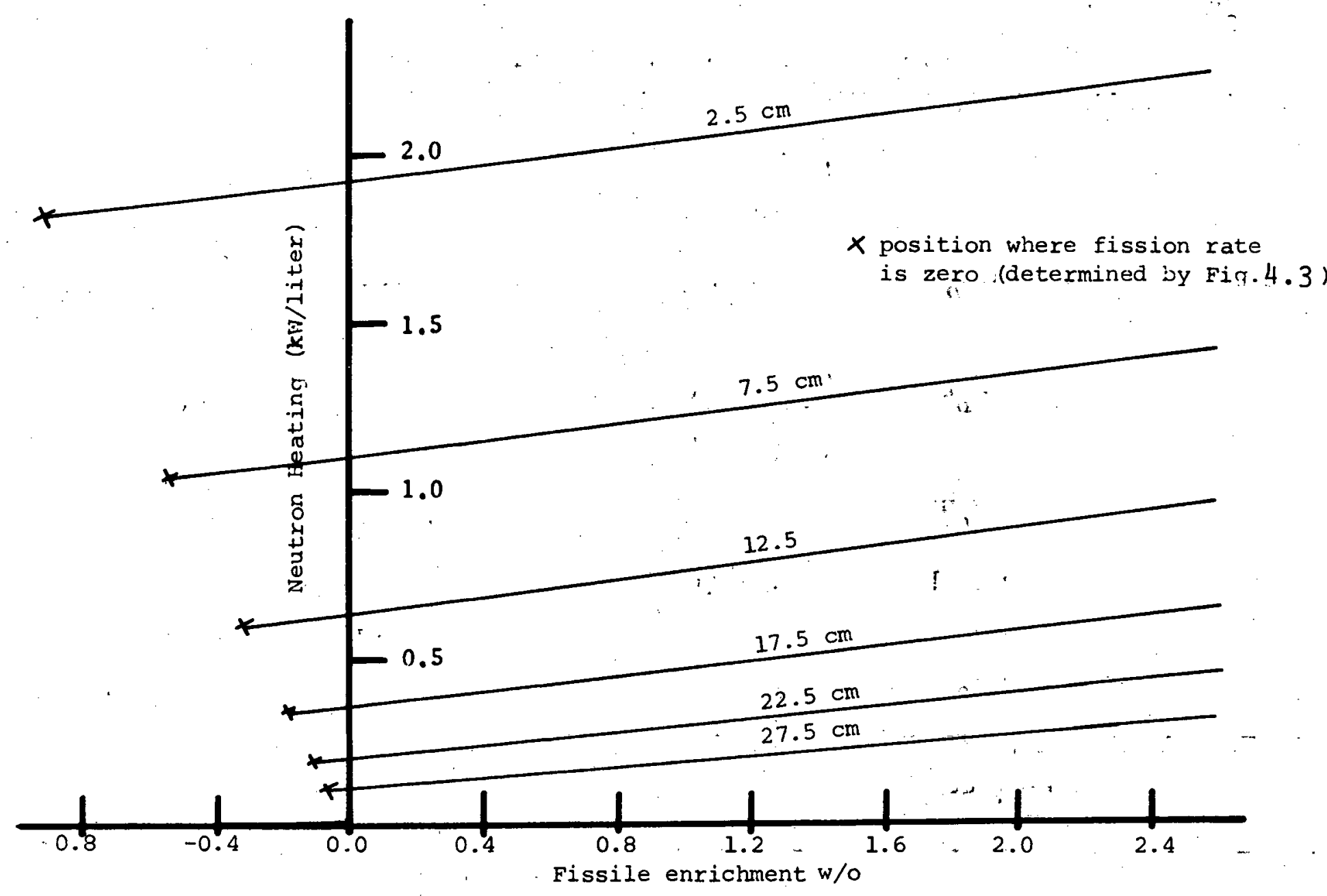

Fic. 4.7 Effect of Enrichment on Neutron Heating 


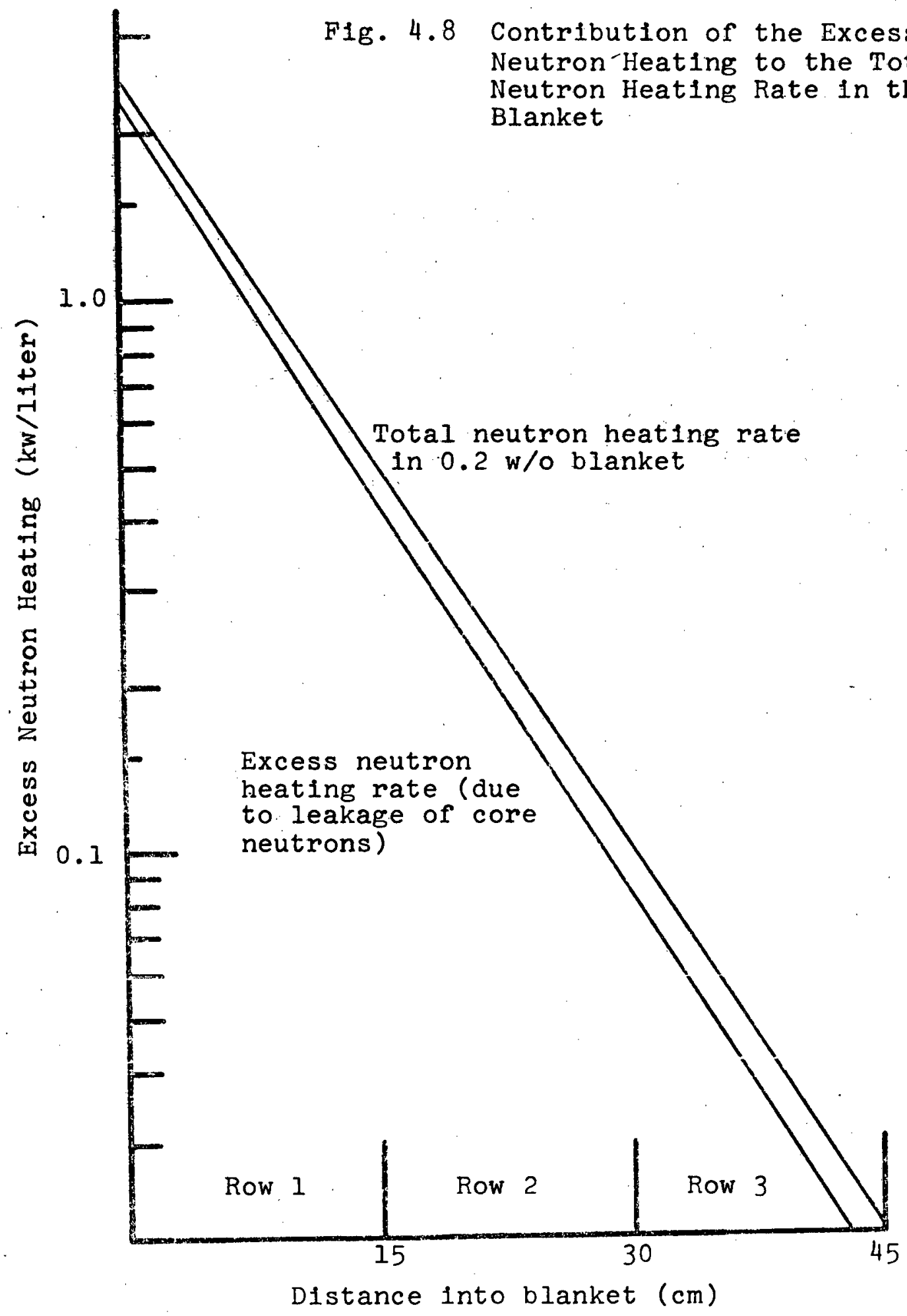




$$
\mathrm{BHR}=\mathrm{FHR}+\mathrm{SHR},
$$

and

$$
\mathrm{SHR}=\ddot{G H R}+\mathrm{NHR}=\mathrm{P}\left[0.864 \mathrm{e}^{-0.0715 \mathrm{x}}+0.096 \mathrm{e}^{-0.1098 \mathrm{x}}\right],
$$

where $\mathrm{P}$ is the reactor power in units of $100 \mathrm{MW}_{\mathrm{T}}$; in this case, $\mathrm{P}=25 ; \mathrm{x}$ is the distance into the blanket in centimeters; and the heating rates are in units of kilowatts per liter.

Figure 4.9 shows the contributions to the total heating rate for the $0.2 \mathrm{w} / \mathrm{o}$ and $2.5 \mathrm{w} / \mathrm{o} \mathrm{U}-235$ enriched blankets. It is clear that neglecting the contribution of the shield heating rate can lead to substantial underprediction of the total blanket heating rate. In the $0.2 \mathrm{w} / \mathrm{o}$ blanket, the BHR would be underpredicted by 50 to 100 percent, whereas in the $2.5 \mathrm{w} / \mathrm{o}$ blanket the BHR would be underpredicted by about 10 percent. The smaller underprediction of the more highly enriched blanket would be expected since the FHR is higher and the SHR becomes correspondingly less important than for a lower enrichment blanket.

\section{3 Evaluation of Blanket Configurations}

The objective of the work summarized in this section was the evaluation of the relative economic performance of various blanket configurations considering both blanket burnup and thermal-hydraulic contributions to the total power cost. The method of burnup is discussed in Section 4.3.1. The burnup economic determination follows conventional analysis (e.g., see reference 12), and is reviewed in Section 4.3.2. A model to treat thermal-hydraulic-economic considerations has been developed and is summarized in Section 4.3. 3 . Section 4.3.4 summarizes the results obtained by applying these economic methods to a variety of blanket-reflector configurations which differed in initial enrichment, thickness and reflector composition.

\subsubsection{Method of Burnup}

Studies of various blanket-reflector configurations were carried out using the representative two-zone core, 1000-MWe LMFBR depicted in Fig. 4.1. The primary calculational tool used in comparing 


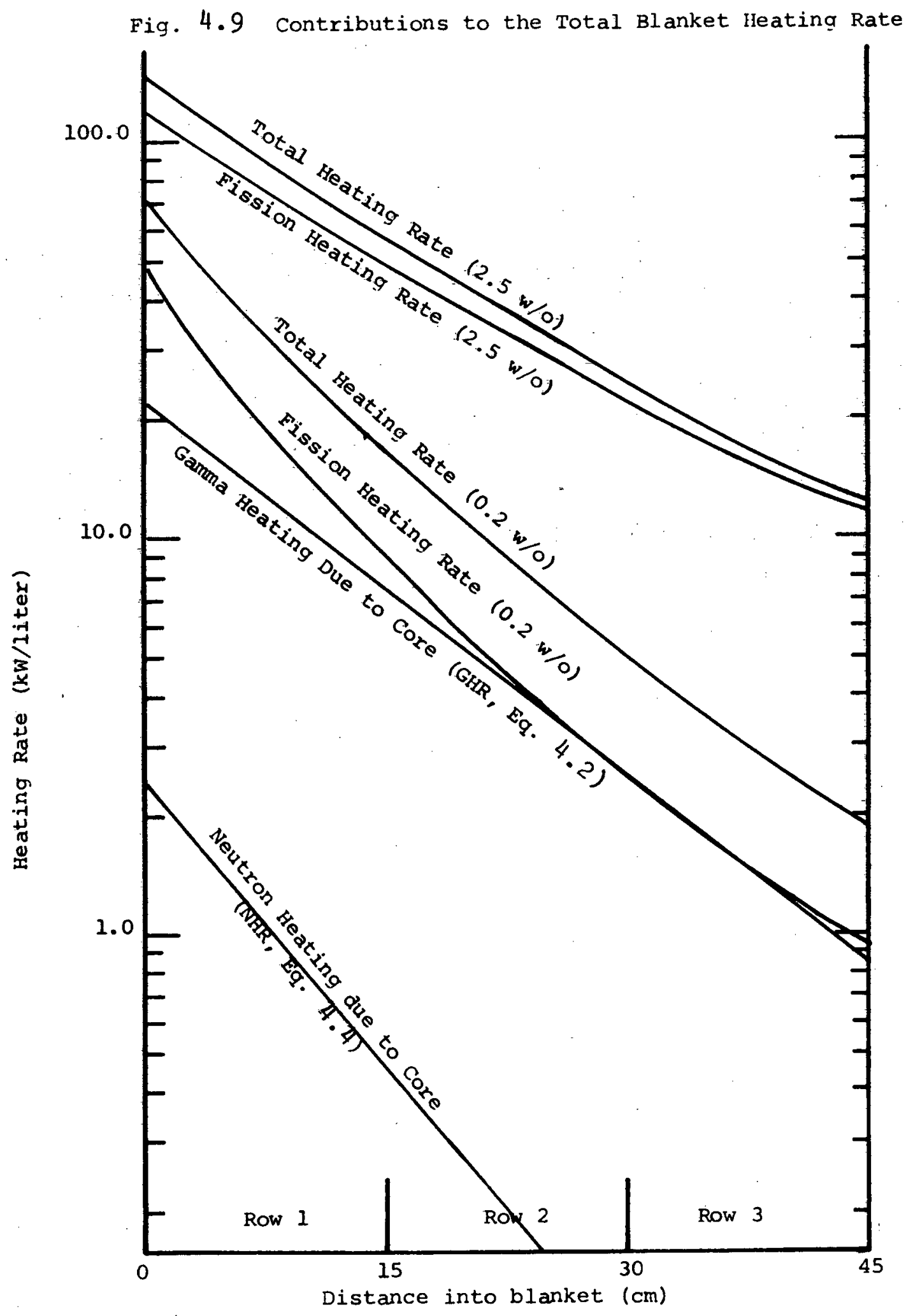


the neutronic performance of the cases studied was the two-dimensional diffusion theory burnup code $2 \mathrm{DB}$ (13). A 4-group region-wide cross section set was employed. This set was prepared by collapsing the 26group $A B B N$ cross section set (8) over spectra appropriate to the various reactor regions using the one-dimensional transport theory code ANISN (6). Region-wide 4-group cross sections have been shown here and elsewhere (14) to compare favorably to multigroup calculations, especially in the inner regions of the blanket which contribute most of the blanket plutonium production.

Since long burnups (up to six years) were performed in studying the blanket burnup behavior, an "equilibrium" core and axial blanket were defined which remained fixed in time. Constant core and axial blanket material concentrations (including pois on concentration) at the time-average values expected in these regions were used, obviating the need to fuel-manage the core. It should be noted that although considerable care was taken to define a realistic core and axial blanket composition around which the radial blanket was irradiated, other investigators $(\underline{3}, \underline{12}, \underline{15})$ have looked into the effect of different core-management methods on radial blanket economics, and have concluded that there is an insignificant effect on the results. Furthermore, since the same core treatment is used for all cases studied, any systematic bias (however.small) should cancel out so long as relative comparisons are emphasized.

\subsubsection{Burnup-Economic Model}

The burnup-economic analysis was performed utilizing the cash flow method contained in the computer code BRECON developed by Brewer (2), and modified by Wood (3) to permit direct use of $2 \mathrm{DB}$ burnup results as input. This method capitalizes, and consequently depreciates for tax purposes, the material purchases and fabrication charges; whereas reprocessing charges and material credit are treated as an expensed cost and taxable revenue, respectively.

The economic results generated by BRECON are the local levelized fuel component of the energy cost (mills/kW-hr) which can be applied to 
an entire region (e.g., radial blanket) or subregion (e.g., radial blanket row). This facilitates the determination of the minimum fuel cycle cost contribution (i.e., optimum irradiation time) for a blanket row or for the entire blanket.

Table 4.5 lists the basic economic parameters used in this study of radial blanket burnup fuel economics. These conditions (except for fissile U-235) are the same as those presented by Brewer (2) and Wood ( 3 ) and are within the range projected for the mature U.S. nuclear fuel cycle economy (16). The range of values for fissile $\mathrm{U}-235$ is based on $\$ 38.50$ per kilogram of separative work (17).

\subsubsection{Therma1-Hydraulic Economic Model}

An economic model has been developed to treat the effects of power gradients in the radial blanket. Two effects were analyzed: the decrease in thermal efficiency and the increase in pumping power attributable to blanket overcooling. The results of this analysis are embodied in the following expressions:

Thermal efficiency effect

$$
\frac{\mathrm{e}_{2}-\mathrm{e}_{1}}{\mathrm{e}_{1}}=\frac{\mathrm{f}-\eta_{2}}{\eta_{2}}\left(\frac{\mathrm{W}_{2}}{1+\mathrm{W}_{2}}\right)\left(\frac{1}{1+\frac{\mathrm{T}_{\mathrm{i}}}{\Delta \mathrm{T}_{\mathrm{r}^{\prime}}}}\right)\left(\frac{\mathrm{F}_{\mathrm{b}_{2}}-\mathrm{F}_{\mathrm{b}_{1}}}{\mathrm{~F}_{\mathrm{b}_{2}}}\right)
$$

Pumping power effect (generally much smaller)

$$
\frac{\mathrm{e}_{2}-\mathrm{e}_{1}}{\mathrm{e}_{1}}=\frac{\mathrm{p}_{\mathrm{P}}}{\mathrm{p}_{\mathrm{E}}}\left(1-\eta_{1}\right)\left(\frac{\mathrm{W}_{2}}{1+\mathrm{W}_{2}}\right)\left(\frac{\mathrm{F}_{\mathrm{b}_{2}}-\mathrm{F}_{\mathrm{b}_{1}}}{\mathrm{~F}_{\mathrm{b}_{2}}}\right)
$$

The subscripts 1 and 2 refer to any two cases being analyzed. The parameters appearing in Eqs. 4.7 and 4.8 are defined in Table 4.6.

It should be emphasized that Eqs. 4.7 and 4.8 reflect the economic penalty due to spatial gradients in the blanket. Another power gradient, the temporal gradient, exists in the radial blanket, and it also contributes to the total overcooling of the blanket. The temporal gradient, $R$, is defined as the end-of-life power divided by the beginning-of-life power. This gradient is due to the buildup with time of the fissile plutonium and consequently the fission rate. 
TABLE 4.5

Economic Environment

Financial Parameters

Income Tax Rate, $\tau$

0.5

Capital Structure

Bond (debt) fraction, $f_{b}$

0.5

Stock (equity) fraction, $f_{S}$

0.5

Rates of Return
Bonds, $r_{b}$
0.07
Stocks, $\mathrm{r}_{\mathbf{S}}$
0.125
0.08

Discount Rate, $\mathrm{x}$

Unit Blanket Fuel Processing Costs ( $\$ / \mathrm{kg} \mathrm{HM}$ )

Fabrication, $\mathrm{C}_{\text {fab }}$
Reprocessing, $\mathrm{C}_{\text {repr }}$

Is otopic Market Value $(\$ / \mathrm{kg})$
$\mathrm{Pu}-239, \mathrm{C}_{\mathrm{Pu}}$
$\mathrm{Pu}-241, \mathrm{C}_{\mathrm{Pu}}$
10,000
$\mathrm{Pu}-240$
10,000
$\mathrm{Pu}-242$
0
$\mathrm{U}-238$
$\mathrm{U}-235$ (17), $\mathrm{C}_{\mathrm{U}}$
$0.2 \mathrm{w} / \mathrm{o}$
1,500
0.711
3,300
1.00
5,140
1.50
7,130
2. 00
8,360
3.00
9,190
98.00
15,190 
TABLE 4.6

Definition of Parameters in the

Thermal-Hydraulic Economic Model

\begin{tabular}{|c|c|c|}
\hline Parameter & Definition & $\begin{array}{c}\text { Typical or } \\
\text { Reference Value }\end{array}$ \\
\hline e & Cost of electricity & $10 \mathrm{mills} / \mathrm{kW}-\mathrm{hr}$ \\
\hline$\eta$ & Thermal efficiency & 0.4 \\
\hline f & $\begin{array}{l}\text { Ratio of actual to Carnot } \\
\text { efficiency }\end{array}$ & 0.62 \\
\hline$T_{i}$ & Reactor inlet temperature & $1210^{\circ} \mathrm{R}\left(750^{\circ} \mathrm{F}\right)$ \\
\hline$\Delta \mathrm{T}_{r}$ & $\begin{array}{l}\text { Mean reactor temperature } \\
\text { rise }\end{array}$ & $300^{\circ} \mathrm{R}\left(300^{\circ} \mathrm{F}\right)$ \\
\hline $\mathrm{p}_{\mathrm{P}}$ & Reactor pumping power & 10.5 MW \\
\hline $\mathrm{p}_{\mathrm{E}}$ & Reactor electric power & $1000 \mathrm{MW}$ \\
\hline $\mathrm{W}$ & $\begin{array}{l}\text { Ratio of blanket to core } \\
\text { coolant flow rate }\end{array}$ & $\begin{array}{l}0.44 \text { ( } 3 \text {-row } \\
\text { radial blanket) }\end{array}$ \\
\hline $\mathrm{F}$ & $\begin{array}{l}\text { Ratio of peak to average } \\
\text { power density }\end{array}$ & $\begin{array}{l}3.4 \text { ( } 3 \text {-row } \\
\text { radial blanket) }\end{array}$ \\
\hline
\end{tabular}

The spatial gradient is due to the radial power distribution, and it occurs throughout the blanket irradiation lifetime.

Figure 4.10 shows how the spatial gradient, $F$, and the temporal gradient, $R$, act in concert in creating blanket overcooling. The figure is roughly. to scale for the base-case 3-row blanket, where it has been shown that $R$ varies very nearly linearly with time and $F$ is roughly constant. The cross-hatched triangular a rea represents the degree of overcooling in the blanket attributable to the temporal effect. The upper rectangular area bounded by the horizontal lines at $\mathrm{P}_{\mathrm{EOL}}^{\mathrm{max}}$ and $\mathrm{P}_{\mathrm{EOL}}$ is a measure of the degree of overcooling due to the spatial gradient. The contribution of spatial overcooling relative to temporal overcooling is the ratio of the rectangular area to the cross-hatched triangular area: 

Fig. $4.10 \begin{aligned} & \text { Overcooling Due to Temporal and } \\ & \text { Spatial Gradients }\end{aligned}$

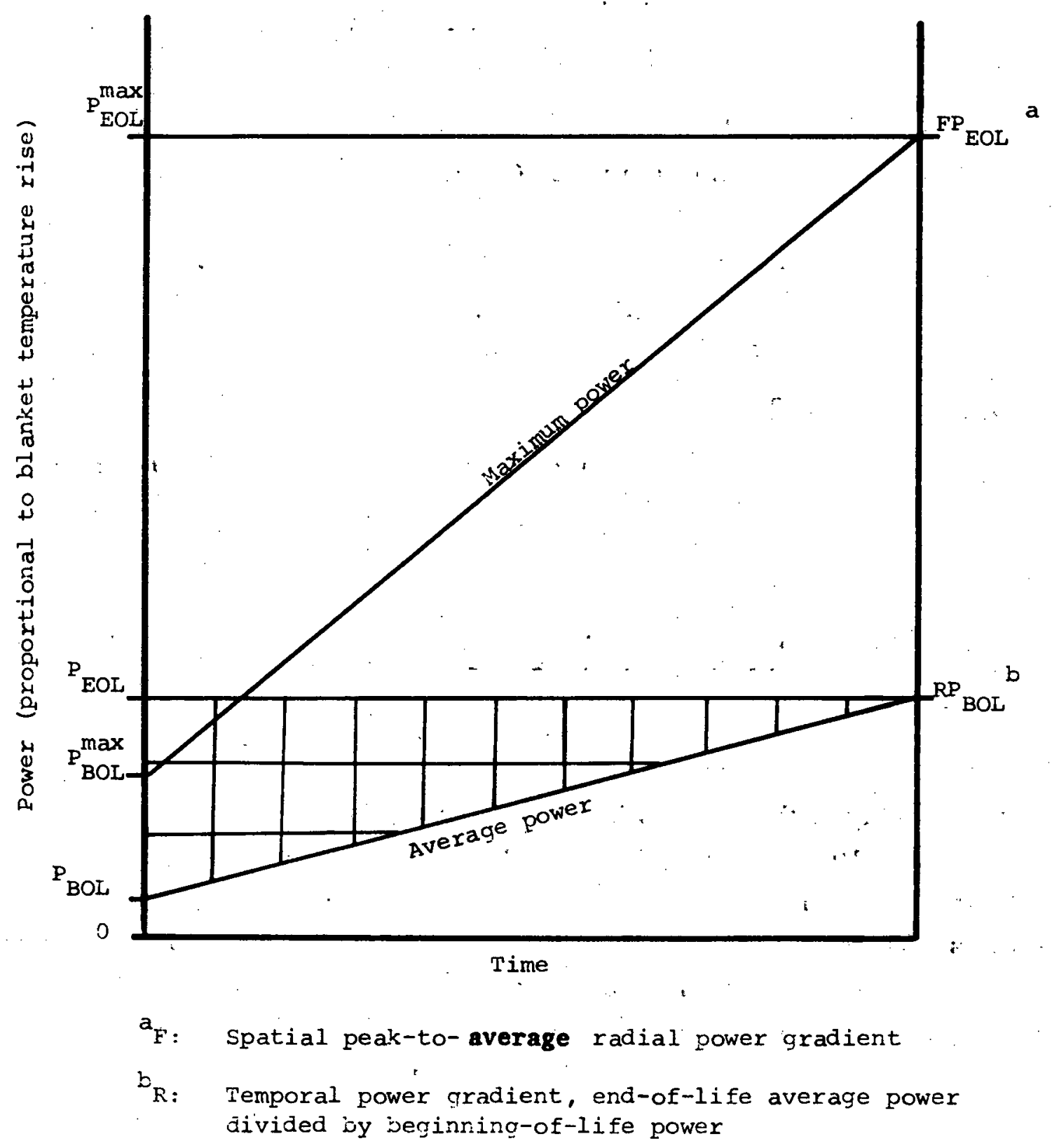




$$
\frac{\text { Spatial overcooling }}{\text { Temporal overcooling }}=\frac{2(\mathrm{~F}-1) \mathrm{R}}{\mathrm{R}-1}
$$

It should be emphasized that $\mathrm{F}$ is the power gradient that exists in the blanket at the end of its irradiation lifetime, and $R$ is the ratio of the blanket power produced at this time to the blanket power produced at the beginning of blanket irradiation. For both factors, the effects of the shield heating rate (Eq. 4.6) must be included, being most important in determining $R$; since a substantial amount of blanket power at the beginning of life is due to this effect (see Fig. 4.9).

\subsubsection{Results}

Table 4.7 presents the results of the burnup and thermalhydraulic analyses of the various blanket-reflector configurations. These configurations were determined by varying three design variables: blanket thickness, initial blanket enrichment, and reflector composition; with the constraint that the new reflector fit within the 45-cm-thick annulus taken up by the 3-row reference blanket (see Fig. 4.1), and that only whole rows $(15 \mathrm{~cm})$ could be manipulated.

The first column in Table 4.7 designates the particular blanketreflector configuration studied. The first digit designates the number of blanket rows (1,2 or 3) and the following two letters designate the initial enrichment of the blanket fuel, and the reflector material, respectively. The uranium enrichments studied were depleted, $0.2 \mathrm{w} / \mathrm{o} U-235$ (D), natural, $0.71 \mathrm{w} / \mathrm{o}(\mathrm{N}), 2.5 \mathrm{w} / \mathrm{o}$ enriched (E), and a 2-row mixed case having a depleted inner row and a natural outer row (M). The reflector compositions were either steel (S) or graphite (C).

The next column, $E_{\text {opt }}$, summarizes the burnup-economic analysis. $\mathrm{E}_{\text {opt }}$ is the absolute difference in dollars per year between the base case burnup economics and the particular case of interest. Column 3 ,

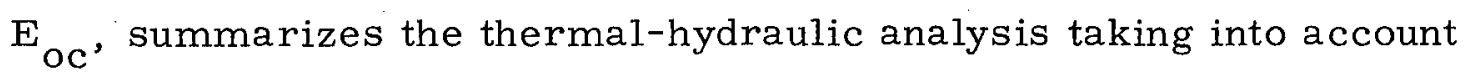
both spatial and temporal effects. E ence in dollars per year between the base case and the particular case of interest. It should be noted that for this analysis all blanket rows were assumed to be uniformly orificed, determined by the innermost 
TABLE 4.7

Relative Savings Realized by Various Advanced Blanket Configurations $\left(10^{5} \$ / \mathrm{yr}\right)^{\mathrm{a}}$

\begin{tabular}{|c|c|c|c|}
\hline $\begin{array}{l}\text { Case } \\
\text { Number }\end{array}$ & $\begin{array}{l}\text { Burnup } \\
\mathrm{E}_{\text {opt }} \mathrm{C}\end{array}$ & $\begin{array}{c}\text { Thermal-Hydraulic } \\
\text { E }_{\text {oc }}\end{array}$ & $\begin{array}{l}\text { Total } \\
\mathrm{E}_{\text {net }}^{\mathrm{c}}\end{array}$ \\
\hline $3 \mathrm{DS}$ & - & $-\quad(-8.22)^{\mathrm{d}}$ & $(-8.22)^{\mathrm{d}}$ \\
\hline $2 \mathrm{DS}$ & -1.14 & $-7.56(-11.78)$ & $-8.70(-12.92)$ \\
\hline $2 N S$ & -0.84 & $-8.05(-12.27)$ & $-8.89(-13.11)$ \\
\hline $2 \mathrm{MS}$ & -1.06 & $-7.71(-11.93)$ & $-8.77(-12.99)$ \\
\hline $2 \mathrm{ES}$ & +6.44 & $-10.57(-14.79)$ & $-4.13(-8.35)$ \\
\hline $2 \mathrm{DC}$ & -1.36 & $-8.61(12.83)$ & $-9.97(-14.19)$ \\
\hline $1 \mathrm{DS}$ & -0.23 & $-7.91(-7.91)$ & $-8.14(-8.14)$ \\
\hline $1 \mathrm{DC}$ & -0.93 & $-3.36(-3.36)$ & $-4.29(-4.29)$ \\
\hline
\end{tabular}

$\mathrm{a}_{10^{5}} \mathrm{\$} / \mathrm{yr} \sim 0.014 \mathrm{mills} / \mathrm{kW}-\mathrm{hr}$ (assuming $7 \times 10^{9} \mathrm{~kW}-\mathrm{hr} / \mathrm{yr}$ ).

$\mathrm{b}_{\text {Key: }}$ 3DS

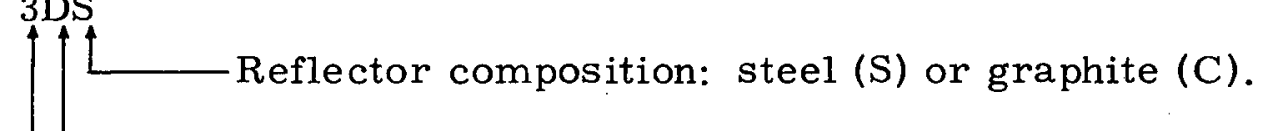
Fuel: depleted (D), natural (N), enriched (E) or mixed (M). Number of rows.

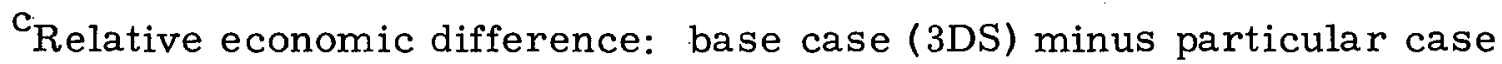
of interest. $\mathrm{E}_{\mathrm{opt}}=$ fuel cycle costs; $\mathrm{E}_{\mathrm{oc}}=$ cost of blanket overcooling; $\mathrm{E}_{\text {net }}=\mathrm{E}_{\text {opt }}+\mathrm{E}_{\text {oc }}$.

$\mathrm{d}_{\text {Values in parentheses are for individually row-by-row orificed }}$ blankets relative to the uniformly orificed base case. 
row's peak power density. The values given in parentheses indicate the relative savings that could be achieved by going to individually row-by-row orificed blankets. The last column, $E_{n e t}$, is the sum of the previous two columns and represents the total economic difference between the base case and the particular. case of interest taking into account both burnup and thermal-hydraulic considerations. Note that in all cases a minus sign indicates a cost savings in going to an advanced blanket-reflector configuration.

From an analysis of the work summarized in this section, the following conclusions have been drawn:

1. An optimum blanket-reflector configuration can only be selected by considering both the burnup performance and the thermalhydraulic performance.

2. Initial blanket enrichment is undesirable due to the added cost of fissile U-235, which outweighs the improved thermal-hydraulic performance.

3. Graphite reflectors are to be preferred to steel reflectors for 2 -row blankets, the difference amounting to $\sim \$ 10^{5}$. per year.

4. Individual row orificing offers improved thermal-hydraulic performance, representing a potential present worth savings on the order of $\$ 4.0 \times 10^{6}$ over the blanket lifetime of the base case configuration; and perfect local flow-to-power matching, both spatially and temporally, can represent a present worth savings of over $\$ 1.1 \times 10^{7}$.

5. Two-row blankets are preferable, since even the improved burnup-economic performance of a graphite-reflected 1-row blanket can not compensate for the lost revenue due to the removal of blanket row 2 .

The results presented in Table 4.7 indicate that case $2 \mathrm{DC}$, a 2-row, individually orificed, depleted-uranium fueled, graphitereflected blanket, offers the largest potential savings $(\sim 1.4$ million $\$ /$ year) relative to the base case configuration. 


\section{4 Experimental Studies}

The work summarized in the previous section has indicated an economic advantage for graphite-reflected blanket configurations, a result which suggested experimental confirmation, since it was not clear that methods and cross section sets previously proven adequate for core calculations would suffice, particularly in view of the severe spectral changes in the blanket-reflector regions, here accentuated by the presence of graphite.

\subsubsection{Description of the Experiment}

A blanket-reflector mockup (Number 3) was irradiated using the Blanket Test Facility (BTF) at the M.I.T. Research Reactor. A detailed description of the design and construction of the BTF is presented in Reference 1. For present purposes, the only point requiring reiteration is that the BTF converter assembly provides neutrons closely simulating the leakage spectrum from a 1000-MWe LMFBR core, which can be used to drive blanket mockups.

Blanket-reflector mockup No. 3 had an axial thickness of $105 \mathrm{~cm}$ (corresponding to the radial thickness in a cylindrical configuration) consisting of two rows of blanket subassemblies (totalling $30 \mathrm{~cm}$ ), $30 \mathrm{~cm}$ of graphite and $45 \mathrm{~cm}$ of steel. The overall dimensions of this parallelepiped was approximately $132 \mathrm{~cm}$ high, $152 \mathrm{~cm}$ wide by $105 \mathrm{~cm}$ thick. The blanket subassemblies were identical to those used in previous irradiations (7). They consist of 5/16-inch, carbon steelclad (clad o.d.), uranium metal fuel rods arranged in a square lattice with a pitch of 0.511 inches, surrounded by anhydrous sodium chromate. The material concentrations were chosen to provide a realistic homogenized blanket composition simulating $37 \mathrm{v} / \mathrm{o}$ depleted $\mathrm{UO}_{2}$ (at $90 \%$ t.d.), $20.7 \mathrm{v} / \circ$ Type 316 stainless steel, $32 \mathrm{v} / \mathrm{o}$ sodium, and $10.3 \mathrm{v} / \mathrm{o}$ void.

Figure 4.11 shows an overhead view of blanket mockup No. 3 indicating the location of the forty-three foil tubes which provide for the irradiation of various foils in the blanket and graphite reflector in the axial and transverse directions. 


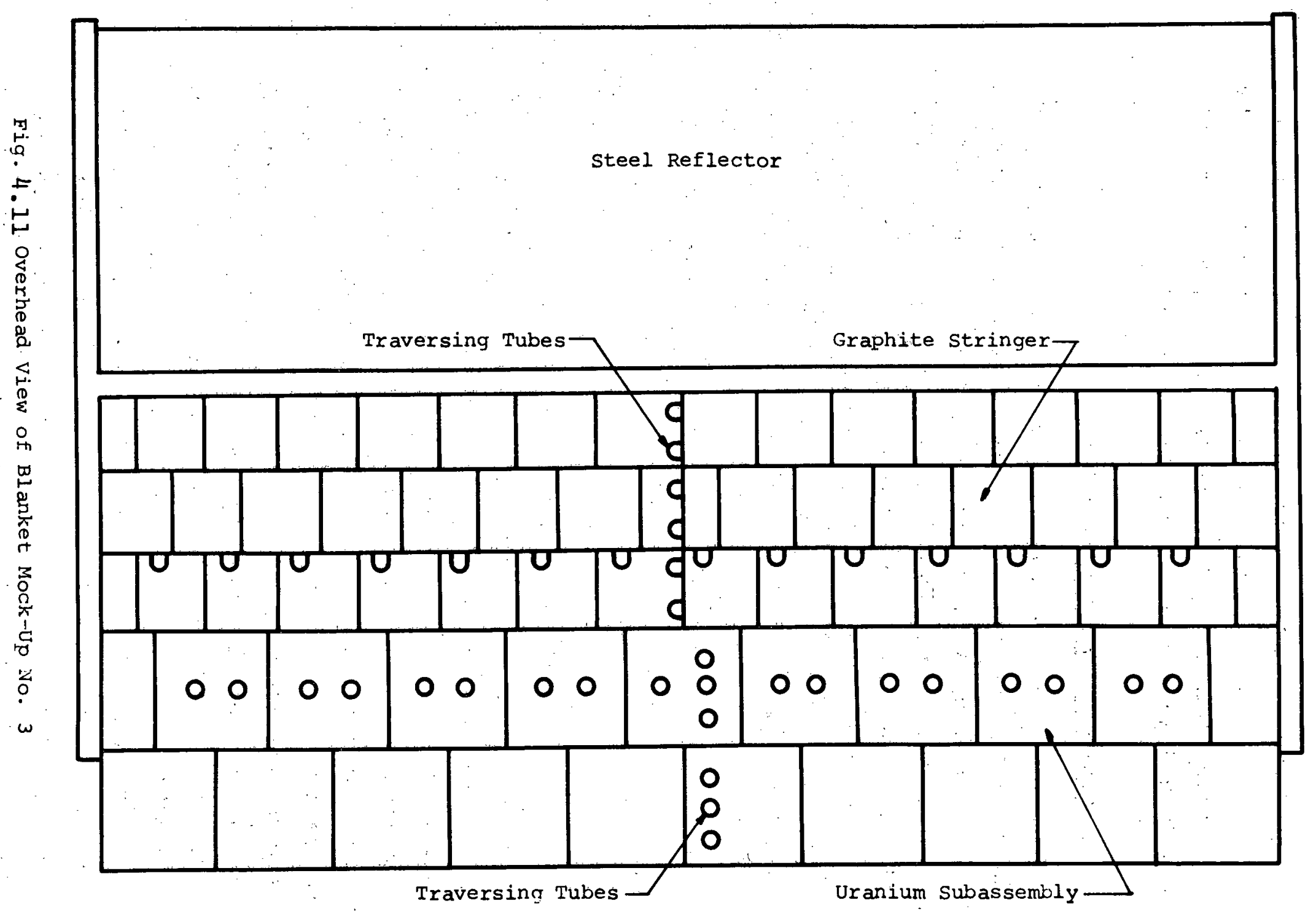


The primary task in the present experiments was to obtain the necessary data to evaluate the transverse buckling and axial reaction rates for various foil materials. The foil materials employed are listed in Table 4.8 along with the reaction of interest.

\subsubsection{Analysis of Experimental Results}

Although the axial experiments were the most important for checking the analytic methods, the transverse experiments were needed to confirm the fact that spectral equilibrium in the central region of the reflector was achieved. This was shown to be true and also, that the transverse buckling traverses in the blanket and reflector conformed to cosine distributions having the same extrapolated dimensions. found in the analysis of Blanket No. 2 (7). This confirmed the applicability of one-dimensional calculations for blanket analysis.

Axial traverses were made in the blanket and graphite reflector assemblies, simulating traverses in the radial direction in cylindrical geometry. These experimental traverses were compared with analytical axial reaction rates which were computed by means of the onedimensional transport theory code, ANISN ( $\underline{6}$ in the S-8 option, using the 26-group ABBN cross section set () for all materials except for the Au-197 capture, In-115 (n, n') and Np-237 fission cross sections, which were developed from the SAND II Library (18). It should be noted that the cross section data used to evaluate the foil activities were not self-shielded, except for in-rod U-238 captures.

The general conclusion that can be drawn from this effort is that the analytical methods adequately describe the neutronic behavior of the graphite-reflected blanket for present purposes, and at least as well as they do conventional, steel-reflected blankets. In particular, the important U-238 capture event is adequately calculated, in agreement with similar observations reported by Leung (7) and Wood (3) in their studies of Blanket No. 2 and Blanket No. 4, respectively: .. Figure 4.12 displays plots of the measured in-rod and ex-rod $U-238$ capture data. As expected, the ex-rod foils are more active, being shielded only by neighboring fuel and not by the host fuel rod. 
TABLE 4.8

Activation Foils Used in BTF Blanket Mockup No. 3

\begin{tabular}{|c|c|c|}
\hline Foil & Reaction & Remarks \\
\hline Gold & $A u^{197}(n, \gamma) A u^{198}$ & $\begin{array}{l}\text { Measures entire energy } \\
\text { spectrum }(A, B) *\end{array}$ \\
\hline Molybdenum & $\mathrm{Mo}^{98}(\mathrm{n}, \gamma) \mathrm{Mo}^{99}$ & Emphasizes keV range $(A, B)$ \\
\hline Indium & $\operatorname{In}^{115}\left(n, n^{\prime}\right) \operatorname{In}^{115 m}$ & $\begin{array}{l}\text { Threshold reaction } \mathrm{E}>0.2 \\
\mathrm{MeV}(\mathrm{A}, \mathrm{B})\end{array}$ \\
\hline Manganese ${ }^{\dagger}$ & $\mathrm{Mn}^{55}(\mathrm{n}, \gamma) \mathrm{Mn}^{56}$ & Emphasizes keV range (A) \\
\hline Sodium & $\mathrm{Na}^{23}(\mathrm{n}, \gamma) \mathrm{Na}^{24}$ & Typical LMFBR material (A) \\
\hline Chromium & $\mathrm{Cr}^{50}(\mathrm{n}, \gamma) \mathrm{Cr}^{51}$ & Typical LMFBR material (A) \\
\hline Uranium & - & Typical LMFBR material \\
\hline-238 in-rod & $\mathrm{U}^{238}(\mathrm{n}, \gamma)$ & (A) \\
\hline-238 ex-rod & $\mathrm{U}^{238}(\mathrm{n}, \gamma)$ & $(A, B)$ \\
\hline-238 in-rod & $\mathrm{U}^{238}(\mathrm{n}, \mathrm{f})$ & $\begin{array}{l}\text { Threshold reaction } \\
\mathrm{E}>1.0 \mathrm{MeV}(\mathrm{A})\end{array}$ \\
\hline-238 ex-rod & $\mathrm{U}^{238}(\mathrm{n}, \mathrm{f})$ & $(A, B)$ \\
\hline-235 & $\mathrm{U}^{235}(\mathrm{n}, \mathrm{f})$ & (A) \\
\hline Plutonium-239 & $\mathrm{Pu}^{239}(\mathrm{n}, \mathrm{f})$ & Typical LMFBR material (A) \\
\hline Thorium $^{\dagger}$ & $\mathrm{Th}^{232}(\mathrm{n}, \mathrm{f})$ & $\begin{array}{l}\text { Threshold reaction } \\
\mathrm{E}>1.75 \mathrm{MeV}(\mathrm{A}, \mathrm{B})\end{array}$ \\
\hline Neptunium ${ }^{\dagger}$ & $\mathrm{Np}^{237}(\mathrm{n}, \mathrm{f})$ & $\begin{array}{l}\text { Threshold reaction } \\
\mathrm{E}>0.75 \mathrm{MeV} \text { (A) }\end{array}$ \\
\hline
\end{tabular}

* A indicates foil used for axial activation traverse.

$B$ indicates foil used for transverse activation traverse (i. e., buckling determination).

$\dagger_{\text {New materials, not used in BTF No. } 2 .}$ 


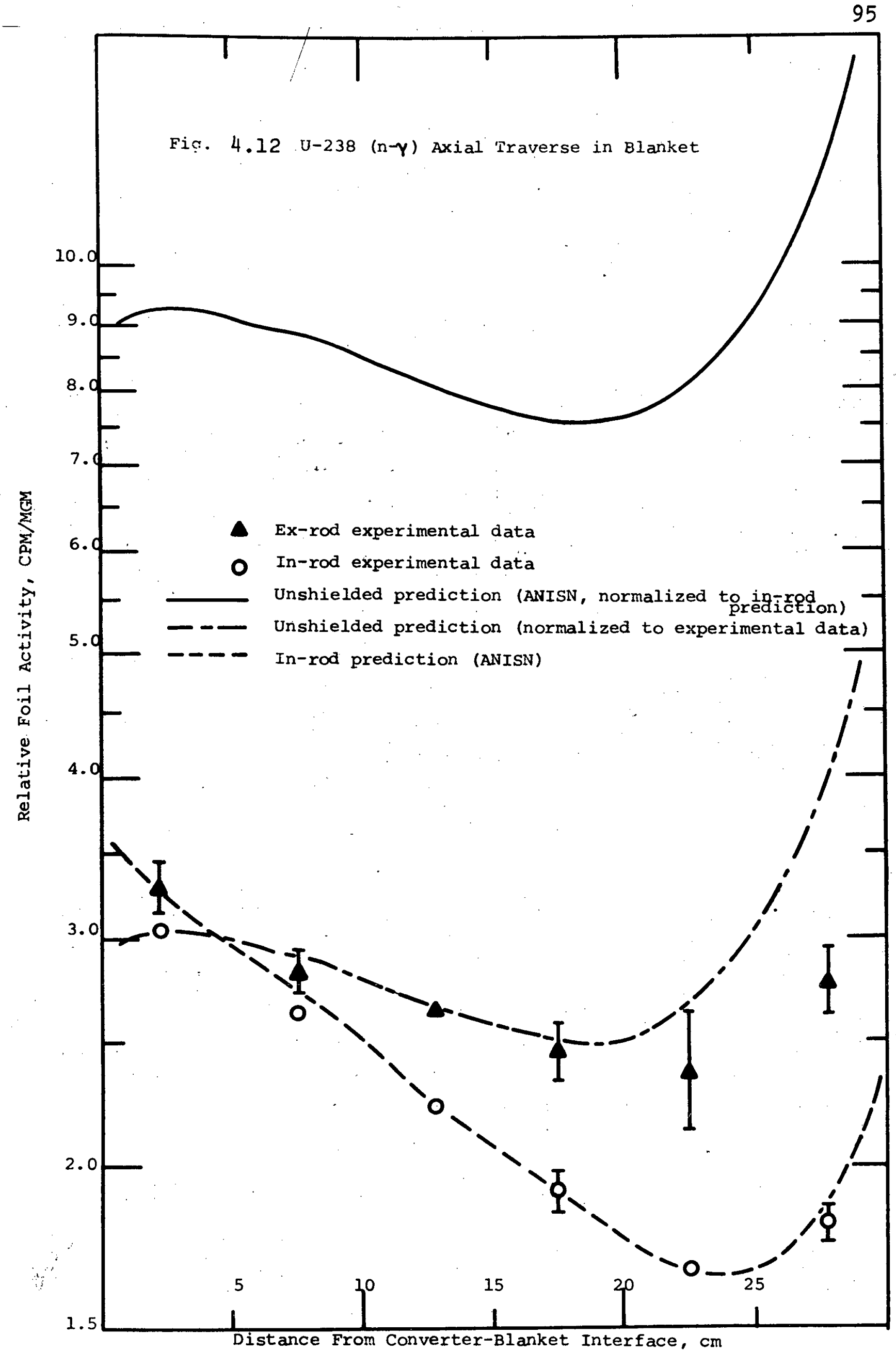


Also shown are the calculated in-rod traverses (normalized to the experimental data) and a comparable traverse calculated using infinitely-dilute U-238 cross sections (solid line at top of graph) correctly normalized relative to the in-rod traverse. The same traverse is also shown renormalized to the ex-rod data (dot-dash line). While it is clear that the ex-rod activities are less shielded than those in-rod, they are far from being in an infinitely-dilute environment. Even so, the shape of the infinitely-dilute calculated traverse is in fair agreement with that of the ex-rod measurements. The results of Fig. 4.12 also display the expected effects of spectral softening near the graphite reflector: the in-rod flux depression is enhanced and the spread between the in-rod and ex-rod traverses widens, and both the in-rod and ex-rod capture rates are enhanced near the graphite reflector.

Although the experimental data agree quite well with the predictions in the blanket region, the threshold-detector activations in the graphite reflector do not. Uranium-238 fission and indium $\left(n-n^{\prime}\right)$ data deep in the reflector are an order of magnitude higher than calculated. It should be noted that this same problem was observed in the steel reflector of Blankets No. 2 and No. 4. Choong (19) has examined this problem in some detail and concluded that the anomalous results are due to a variety of causes, such as subthreshold fission in U-238, and probably do not, therefore, indicate excessive fast neutron penetration, which would indicate a significant shielding problem. In late 1974 , Blanket No. 5, with a special steel reflector designed to permit more detailed, and more precise measurements, is scheduled for irradiation, so that further experimental information can be acquired to aid in the resolution of this problem.

\section{5 Conclusions and Recommendations}

The objectives of the present work have been met, resulting in the selection of a 2-row, depleted-uranium fueled, graphite-reflected blanket as the advanced blanket configuration offering the largest potential savings $(\sim 1.4$ million $\$ /$ year $)$ relative to the base case 3-row, depleted uranium fueled steel-reflected blanket. Also, 
experimental verification of the neutronic behavior of a graphitereflected blanket was satisfactorily accomplished, indicating that nuclear design can be accomplished at least as well as that for conventional steel-reflected blankets.

Special attention was given to a complete analysis of the blanket heating rates where it was confirmed that fission heating (heating proportional to the local fission rate) is not the only contribution to the heating rate, but rather gamma and neutron heating, empirically attributable to core-leakage gamma rays and neutrons, form a significant fraction of the total heating rate (up to $50 \%$ at the beginningof-life of a depleted-uranium fueled blanket). An expression has been developed (Eq. 4.6) which treats this. "shield heating rate" independently of the local fission rate.

Also, an economic model to deal with the thermal-hydraulic performance of the blanket was developed (Eqs. 4.7 and 4.8) and used in conjunction with a conventional burnup economic model to identify the best blanket-reflector configuration previously mentioned. The thermal-hydraulic model was also utilized to determine that the maximum economic potential of a perfectly orificed blanket, both spatially and temporally, was about $\$ 1.1 \times 10^{7}$ present worthed over the sixyear lifetime of the batch-managed base-case blanket-reflector configuration: about $\$ 5 \times 10^{4}$ per subassembly.

In meeting the goals of the present work, certain items have been identified that merit further analysis. These include:

1. a detailed mechanical and thermal-hydraulic design of a graphite-reflector assembly and a fabrication cost comparison with a standard steel assembly. The cost advantage of graphite cited previously considers only fuel cycle and overcooling costs and amounts to a present worth savings over the plant lifetime of about $\$ 15,000$ per reflector subassembly, a margin which is much greater than the fabrication cost differential (even a blanket assembly costs only $\sim \$ 15,000$ );

2. a more thorough evaluation of the effect of blanket fuelmanagement schemes on the thermal-hydraulic performance of the blanket; 
3. a more detailed study of blanket-orificing schemes, with particular attention to ways of decreasing the spatial gradient (e.g., via mixing) and the temporal gradient (e.g. , via time-varying orifices);

4. an investigation of the applicability of graphite reflectors to thorium-fueled blankets. Steel-reflected thorium blankets were shown by Wood (3) to offer improved burnup economic performance over uranium-fueled blankets;

5. an evaluation of the applicability of graphite reflectors for use in a gas-cooled fast reactor;

6. analysis of the applicability of graphite reflectors for use in large, commercially competitive $(2000+\mathrm{MWe})$, breeder reactors. This would appear attractive since the reduced radial blanket breeding contribution in large reactors would favor thinner (e.g., 1-row) blankets whose performance would be significantly improved by the use of a graphite reflector.

7. further evaluation of the discrepancy between calculations and measurements of the fast neutron penetration deep in the reflector region. Blanket No. 5, which will be irradiated at the M.I.T. Research Reactor in the near future, will help resolve this item.

8. the empirical method applied in this investigation of separating gamma and neutron heating contributions into local and core-leakage components, as it appears to have potential for eliminating complicated coupled neutron/gamma calculations in the determination of blanket heating rates.

In conclusion, the 2-row, depleted-uranium fueled graphitereflected blanket offers sufficient prospects for improved fast breeder reactor performance and economic savings to merit its consideration as the reference design for future fast breeder reactors. 


\subsection{References}

(1) I. A. Forbes èt al., "Design Construction, and Evaluation of a Facility for the Simulation of Fast Reactor Blankets," MITNE-110, MIT-4105-2, Feb. 1970.

(2) S.T. Brewer, et al., "The Economics of Fuel Depletion in Fast Breeder Reactor Blankets," COO-3060-4, MITNE-123, Nov. 1972.

(3) P.J. Wood and M.J. Driscoll, "Assessment of Thorium Blankets for Fast Breeder Reactors," MITNE-148, COO-2250-2, July 1973.

(4) W.P. Barthold, "Fuel Shuffling in LMFBR Blankets," Applied Physics Division, Argonne National Laboratory, FRA-TM-40, August 1972 .

(5) Westinghouse Advanced Reactor Development, "Radial' Blanket Design and Development," Quarterly Progress Report, WARD 3045T2 B-6, August 1972.

(6) W.W. Engle, "A User's Manual for ANISN," L-1693, March 1967.

(7) T.C. Leung et al. , "Neutronics of an LMFBR Blanket Mockup," COO-3060-1, MIT NE-127, Janua ry 1972.

(8) L.P. Abagyan et al., Group Constants for Nuclear Reactor Calculations, I.I. Bondarenko (Ed.), Consultants Bureau, New York, 1964.

(9) G.W. Morrison et al. , "A Coupled Neutron and Gamma Ray Multigroup Cross Section Library for Use in Shielding Calculations," Radiation Shielding Information Center, ORNL-4464, Oak Ridge, Tenn., Dec. 1969.

(10) F.C. Engle and R.A. Markley (WARD), "Design Considerations Unique to LMFBR Radial Blanket Assemblies," Trans. Am. Nucl. Soc. 16, 1, June 1973 .

(11) J.R. Lamarsh, Introduction to Nuclear Reactor Theory, AddisonWesley Publishing Company, Inc., Reading, Mass., 1966.

(12) W.P. Barthold, "Utilization and Economic Potential of Different Uraniums in LMFBRs, "Applied Physics Division, Argonne National Laboratory, FRA-TM-50, Feb. 1973.

(13) W.W. Little, Jr., and R.W. Hardie, "2DB User's Manual, Revision I," BNWL-831, Rev. 1, August 1969.

(14) J. Hoover and D.A. Menley, "Alternative Neutron Energy Group Collapsing Schemes Applied to Fuel Cycle Calculations,' ANL-7710 (Jan. 1971). 
(15) T.J. Hirons and R.D. O'Dell, "Calculational Modeling Effects on Fast Breeder Fuel Cycle Analysis," LA-4187, Sept. 1969.

(16) "Reactor Fuel Cycle Costs for Nuclear Power Evaluation," WASH-1099, 1971.

(17) Federal Register, Vol. 38, No. 30, Feb. 19, 1973, p. 4432.

(18) W. N. McElroy, "A Computer-Automated Iterative Method for Neutron Flux Spectra Determination by Foil Activation," AFWL-TR-67-41, August 1967.

(19) T. Choong, "Fast Neutron Spectrometry in an LMFBR Blanket Reflector," M.S. Thesis, Nuclear Engineering Department, M.I.T., August 1973. 


\section{THORIUM BLANKETS}

The work summarized in the present chapter is primarily concerned with the evaluation of the use of thorium in place of uranium as the fertile material in fast reactor blankets. The complete results are presented in the topical report:

P.J. Wood and M. J. Driscoll, "Assessment of Thorium
Blankets for Fast Breeder Reactors," COO-2250-2,
MITNE-148, July 1973 .

\subsection{Introduction}

The primary function of the radial and axial blankets of Liquid Metal Cooled Fast Breeder Reactors (LMFBR) is to utilize effectively core leakage neutrons for the conversion of fertile material (U-238 or $\mathrm{Th}-232$ ) into fissile material ( $\mathrm{Pu}-239$ or $\mathrm{U}-233)$. Most design studies published to date (1) have considered only U-238 as the blanket fertile material. This study has evaluated the use of thorium for this same application, both from the economic and from the system performance points of view.

The primary reas on for considering thorium in LMFBR blanket applications is, as a number of recent studies $(2,3)$ have suggested, its high value as a fuel in thermal reactor systems; U-233 is an economically more desirable product than fissile plutonium. Thus, during the early years following commercial introduction of the LMFBR, lower fuel cycle costs should be achievable if plutonium produced in Light Water Reactors (LWR) is used as fuel for LMFBRs, and fast breeder reactor blankets are used to produce the more economically desirable fuel, U-233, through neutron capture in thorium $(\underline{4}, \underline{5}, \underline{6}, \underline{7})$. The reason that an LMFBR system operating completely on the $\mathrm{U}-233 /$ thorium cycle in both core and blankets has not been given serious consideration in this study is that earlier investigators $(\underline{8}, \underline{9}$, $\underline{10}, \underline{11}, 12, \underline{13}$ ) have shown that it is inferior to a plutonium fueled system in fuel cycle cost, achievable core power density, doubling time, and required fissile loading. 
Work presented in this summary will include sections discussing:

1. Physics-depletion analyses, in which comparisons will be made between thorium and uranium blanket breeding periormance for a number of blanket management schemes. The implications of experimental studies performed using the M.I.T. Blanket Test Facility, Blanket Mockup No. 4 on the analytical work will also be discussed in this section.

2. Economic analyses, in which the economic performance of thorium and uranium blanketed systems will be compared for various blanket management schemes. A model which allows correlation of economic optimum irradiation time and the corresponding fissile enrichment against an economic parameter will also be discussed in this section, and

3. Engineering and physics aspects of uranium and thorium blanketed systems, in which the thermal and physics characteristics of the two systems will be compared with a view to the interchangeability of uranium and thorium blankets in a system originally designed to accommodate only one type of blanket.

Finally, recommendations will be made for additional work needed to complete the proposed implementation of the use of thorium blankets in LMFBR systems.

\section{2 Physics-Depletion Analysis}

\subsubsection{Comparison of Blanket Breeding Performance}

Studies of the breeding performance of thorium and uranium blanketed systems were carried out using a representative two-zone core, 1000-MWe LMFBR (14). A schematic diagram of the reactor is shown in Fig. 5.1. Cross sections for this work were derived from the 26-group ABN-FTR-200 set (15), self-shielded using the shieldfactor method implemented in the code $1 \mathrm{DX}(\underline{16})$, and regionwise collapsed to 4 groups using the one-dimensional transport theory code ANISN (17). The regionwise collapsed 4-group cross section sets were then used with the two-dimensional burnup code 2DB. (18) to evaluate 
Fig. 5.1 Schematic of Reference Reactor Design, $1000 \mathrm{MW}$ LMFBR (14)

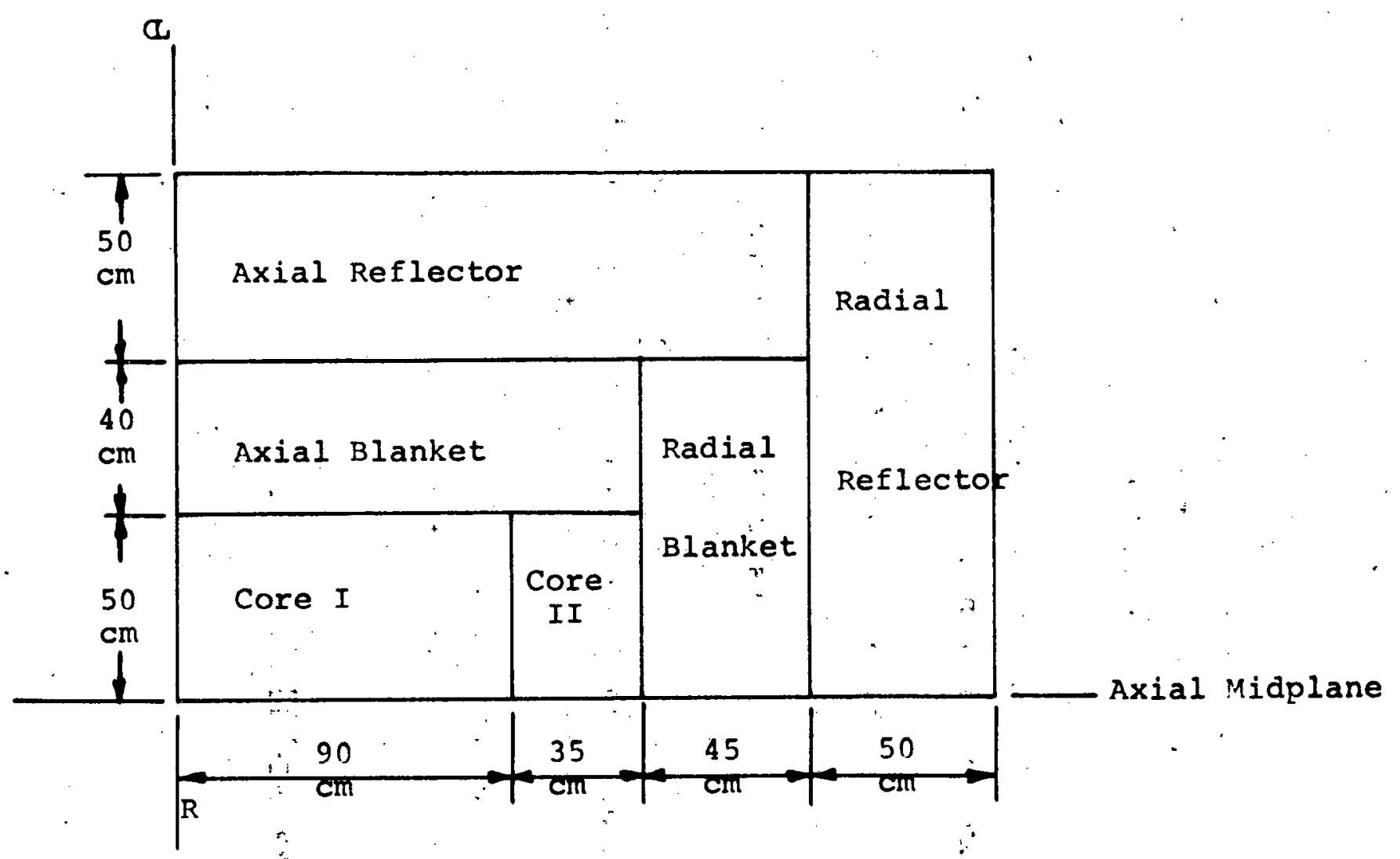


the breeding performance of the systems under consideration. The primary features of the burnup analysis were the following:

1. Batch core and axial blanket burnup for two full power years $(\sim 105,000 \mathrm{MWD} / \mathrm{MTM})$ was assumed for all analyses, and

2. Constant core and axial blanket poison concentration at the time-average values expected in those regions was used.

These assumptions have been shown here and elsewhere (19) to have little impact on blanket economic performance. Consistency of analysis between thorium and uranium blanketed systems has been maintained by assuring that variations in system effective multiplication factor were, as nearly as possible, the same for all cases analyzed.

Consideration has been given in this study to three radial blanket management schemes: batch irradiation, zone scatter management, and in-out shuffle management. Batch irradiation involves, as the name implies, simply loading, irradiating, and removing all three rows of the radial blanket simultaneously. In zone-scatter management, blanket assemblies in any given row are irradiated to their economic optimum, and then replaced with fresh assemblies. The most complex of the three schemes is in-out shuffle management. In this management technique, irradiated assemblies are removed only from the outermost row - in our case, row 3 . When row 3 assemblies are removed, row 2 assemblies are shuffled into row 3 positions, row 1 assemblies replace the old row 2 assemblies, and fresh blanket fuel is loaded into position 1 nearest the core.

Figure 5. 2 shows uranium blanket fissile inventories for the batch managed case, while Fig. 5. 3 shows the difference between total thorium and uranium blanket fissile product for axial and radial blankets, again for the batch managed case. As shown, more fissile material is produced in the radial blanket than in the axial blanket (as defined in Fig. 5.1). Also, Fig. 5.3 shows that the uranium radial blanket produces significantly (roughly $8 \%$ ) more fissile material than the corresponding thorium blanket, while the thorium axial blanket produces marginally more fissile material than the uranium axial blanket. 
Fig. 5.2

Fissile Material Inventory in Batch Managed Uranium Radial and Axial Blankets
Fig. 5.3

Difference in Total Fissile Product Between Thorium and Uranium Blankets
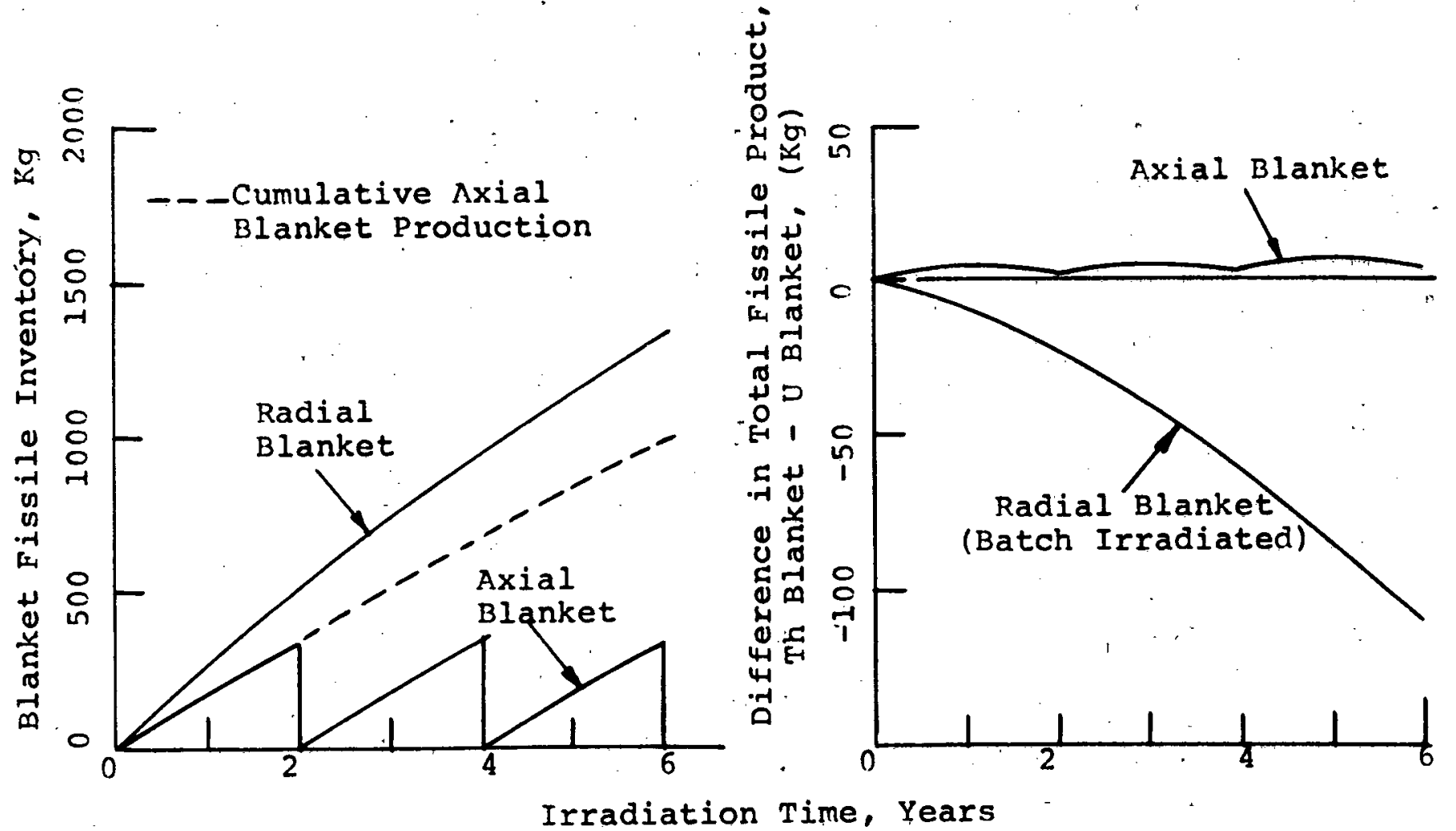
The inventories shown in Figs. 5.2 and 5. 3 have been used to evaluate equilibrium cycle breeding ratios, which are 1.19 and 1.21 for thorium and uranium blanketed systems, respectively. These values are in good agreement with those reported by Wolfe et al. (20) of 1.26 for a 1000-MWe LMFBR.

Figures 5.4 and 5.5 show that, for a uranium blanketed system, little difference exists between the total amount of fissile material produced in the radial blanket for the three management schemes considered, while, for a thorium radial blanket, the difference between the mass of fissile material produced in a batch irradiated blanket and a zone-scatter managed blanket is nearly twice as large as for a comparable uranium blanketed system. These differences among management schemes for the two types of blankets can be traced to the frequency of replacement of row 1 of the radial blanket (every $3-1 / 3$ years for a uranium blanket and every 2 years for a thorium blanket), which, in turn, is dictated by the time required for the blanket to reach its economic optimum residence time.

In section 5. 3, economic comparisons will be presented between batch irradiated thorium and uranium blanketed systems. The feature revealed by Figs. 5.4 and 5.5 which is relevant to this comparison is that consideration of managed rather than batch irradiated radial blankets would lead to improved relative performance for the thorium blanketed system.

\subsubsection{Experimental Studies}

A series of experiments has been performed which allowed comparison between the experimentally determined capture and fission rates for thorium and uranium foils irradiated in a spectrum typical of an LMFBR demonstration reactor blanket (M.I.T. Blanket Test Facility, Blanket Mockup No. 4) and the corresponding analytical predictions made using the same methods and cross sections as employed in the remainder of this study. Figure 5.6 shows that the comparison between experimental and analytically determined fission rates for thorium and uranium is reasonably good. A similar comparison, however, shows that significant discrepancy existed between experimental 
Fig. 5.4 Comparison of Uranium Radial Blanket Fissile Inventories for Various Management Schemes

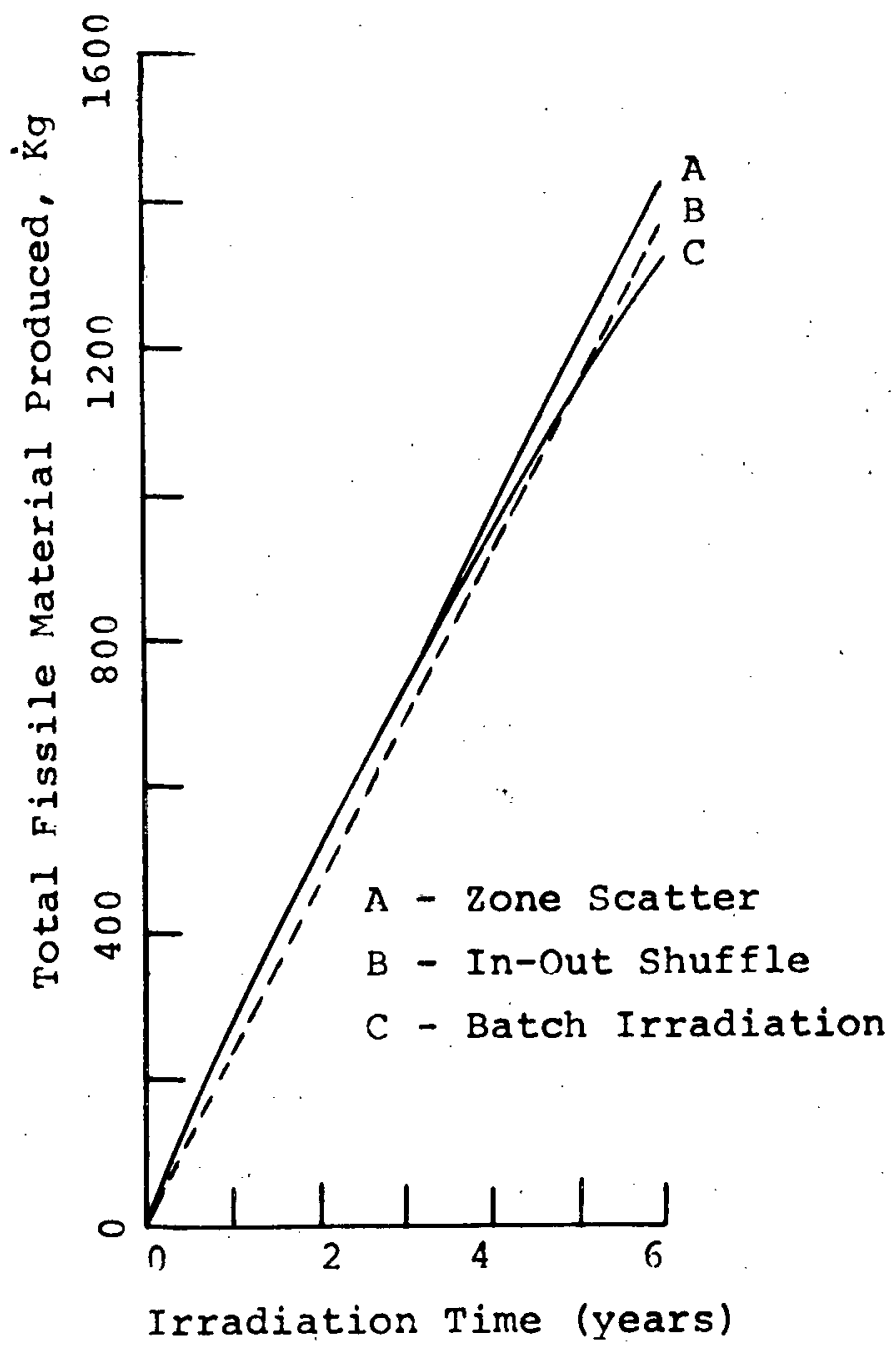

Fig. 5.5

Comparison of Thorium Radial Blanket Fissile Inventories for Batch Management and zone Scatter Management

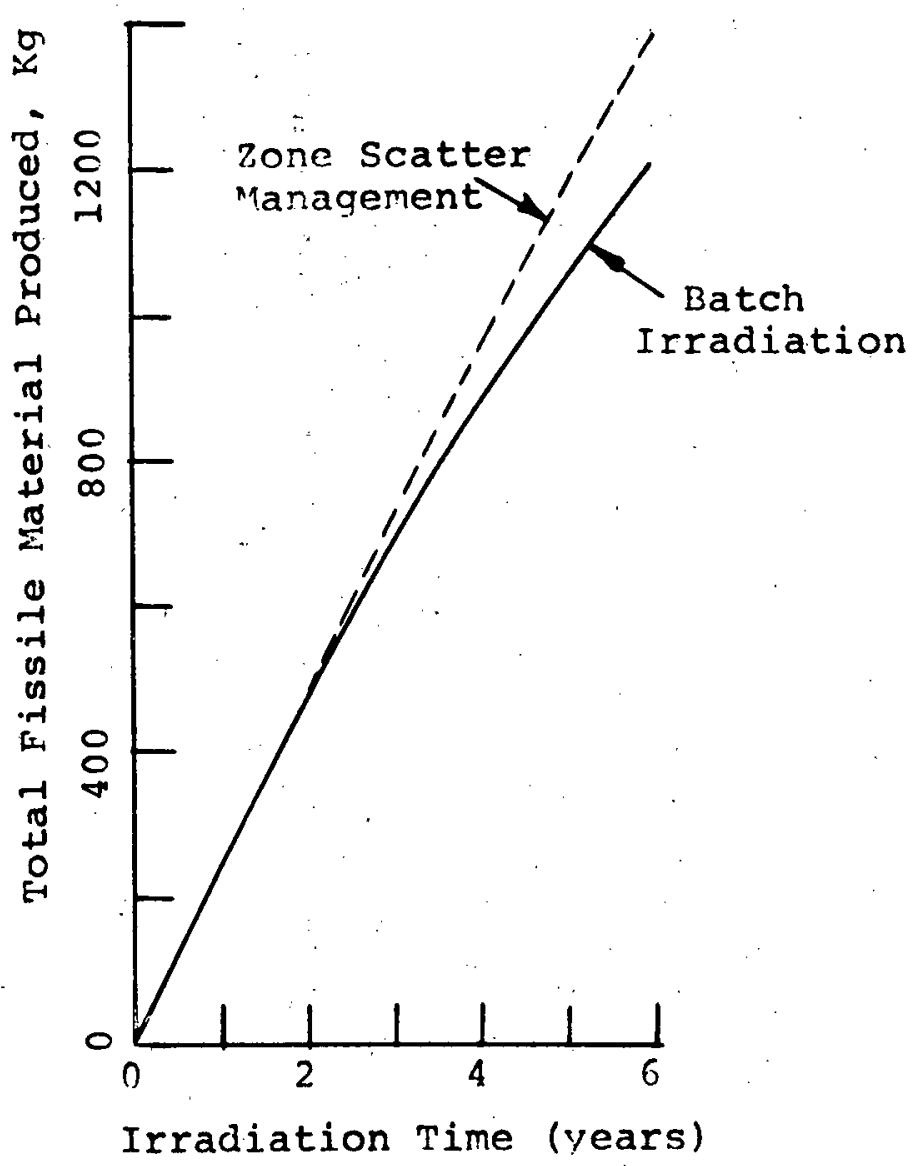


Fig. 5.6 Comparison of Calculated and Experimental Fission Rates for Thorium and Uranium Foil Traverses in BTF 4 , Cross sections from ABBN-FTR-200 set (15)

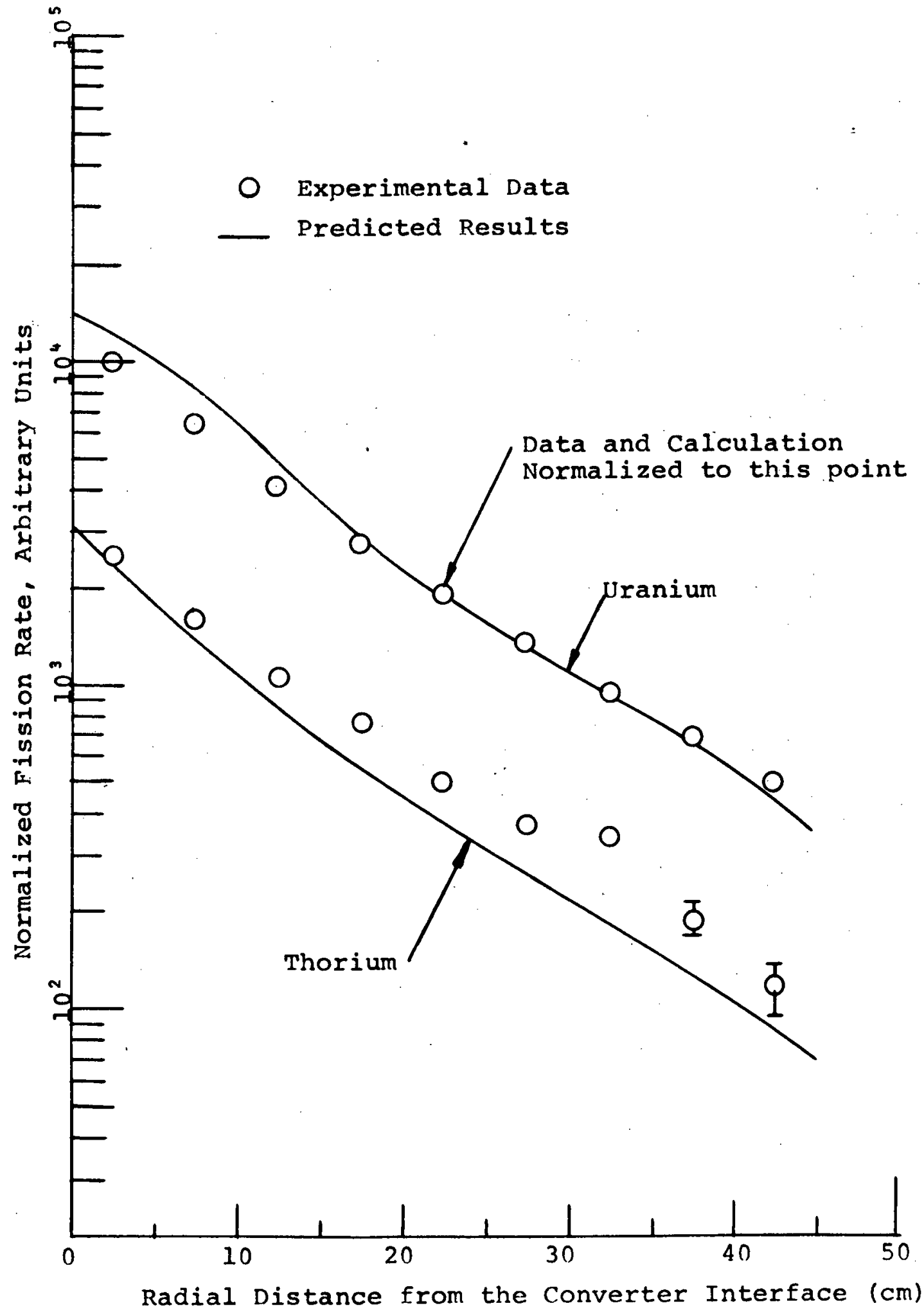


and analytically determined capture rates in thorium and uranium foils. This observed discrepancy has been attributed to errors in the elastic downscatter cross section in the ABBN-FTR-200 set arising from the fact that this cross section set was generated using a $1 / \mathrm{E}$ weighting spectrum. These errors lead to a softer predicted spectrum than observed, which, as shown in Fig. 5.7, would cause the predicted capture rate in a thorium foil irradiated in a uranium blanket to be higher, relative to the uranium capture rate in the same environment, than observed experimentally. Other investigators (21) have confirmed that this discrepancy in the elastic downscatter can be corrected by use of a technique involving iterating on the spectrum. In this study, the erroneous downscatter cross section was compensated for by expanding the initial 26-group cross section set into 106 groups. Figure 5.8 shows that the agreement between experimental capture rates and those predicted using the 106-group cross section set is much better than when the unmodified 26-group set was used for the prediction. However, the modified analysis has predicted a much steeper slope of the capture rate distribution in uranium foils than was observed experimentally.

A series of diagnostic experiments in which gold and manganese foils were used as secondary standards has suggested that at least part of the discrepancy between the experimental data and the 106-group predictions can be attributed to overestimation of the resonance selfshielding used for uranium. It would be expected that at the very least, reduced self-shielding is required near the blanket-reflector interface because uranium blanket pins in that region are not surrounded by an effectively infinite sea of other uranium pins. Additional experiments have shown that, within experimental accuracy, the relative capture rates for thorium and uranium are the same as predicted in a fission spectrum (where uranium resonance self-shielding is not a factor), while the experimentally observed thorium capture rate is approximately $30 \%$ low relative to uranium in the mid-blanket spectrum, and approximately $10 \%$ high relative to uranium in the softer spectrum of the reflector (again where uranium resonance self-shielding is not a factor). 
Fig. 5.7 Comparison of Differential Capture Rates in Radial Blanket

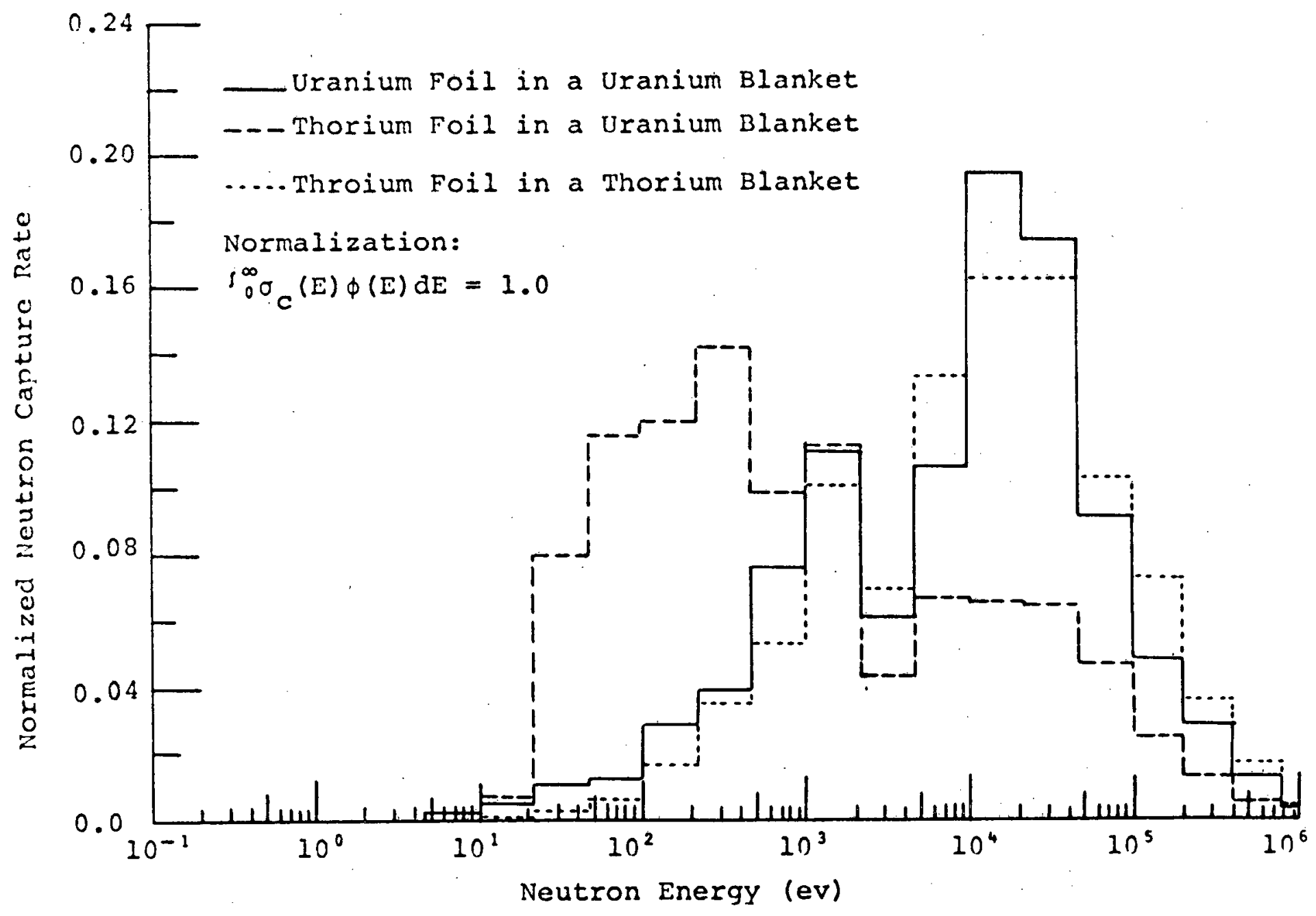


Fig. 5.8 Comparison of Calculated and Experimental Capture Rates in Thorium and Uranium Foils; Predictions were made using the 106 Group Modified ABBN cross section set

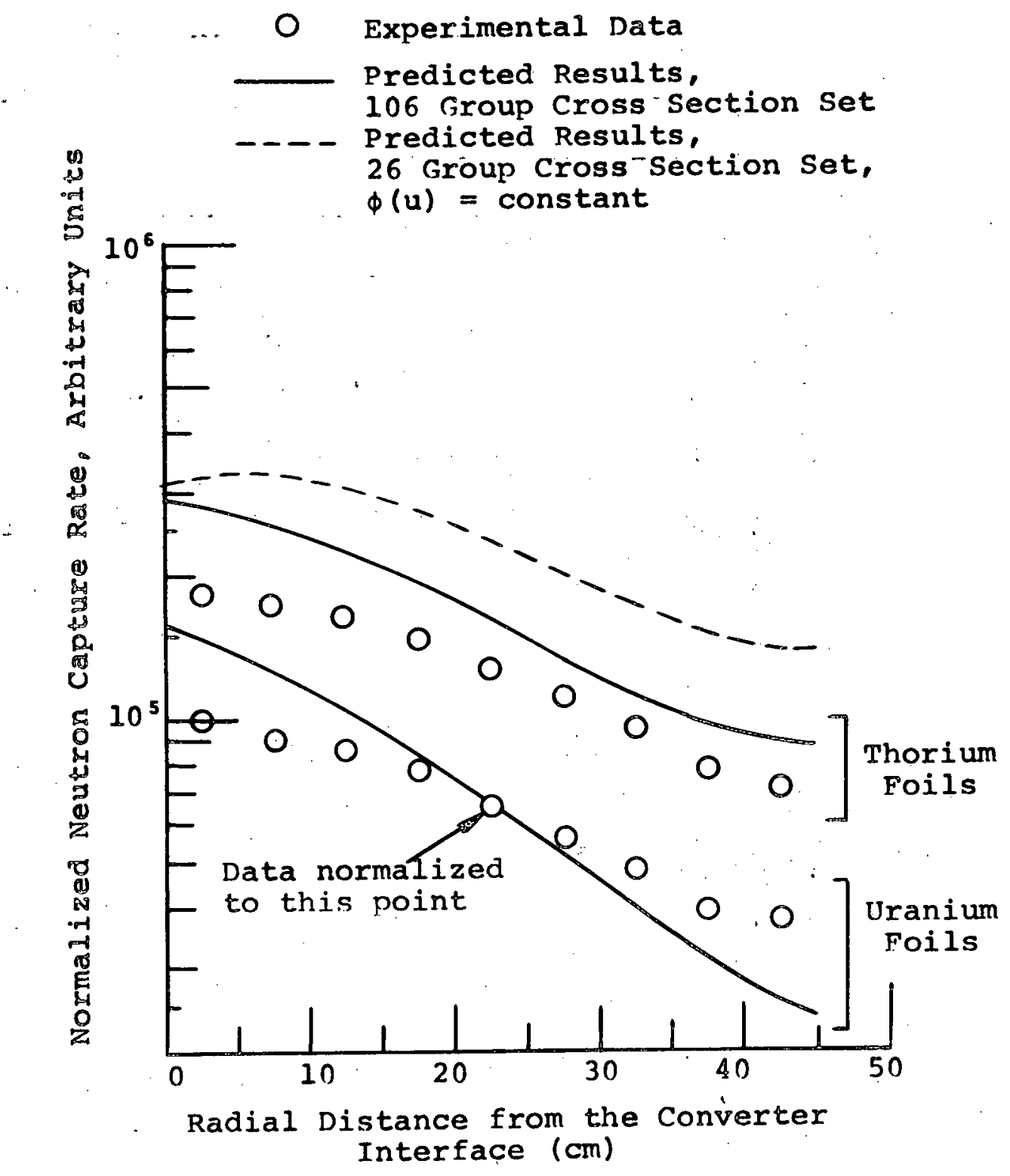


The impact of these experimental observations on the burnup analyses discussed earlier is difficult to characterize because, as shown in Fig. 5.7, significant differences exist between the energydependent capture rate distribution for neutron capture in thorium foils irradiated in a thorium and a uranium blanket. First, consider the effect of the softer predicted blanket spectrum arising from the erroneous downscatter cross section. Analysis of the energy distribution of fertile neutron capture events in thorium and uranium blankets reveals that a higher percentage of thorium capture events occurs in the high energy end of the spectrum. Thus, if the analysis were corrected to compensate for the faulty downscatter, hardening the spectrum, then the breeding performance of the thorium blanketed system would undoubtedly improve relative to the uranium blanketed system. (Calculations have shown that the downscatter correction will lead to a decrease in the total uranium blanket $\mathrm{Pu}$ production by as much as $10 \%$.) The net effect of the reduction in effective resonance self-shielding of the fertile material near the reflector interface is also difficult to characterize. Qualitatively, this effect will be very similar in both thorium and uranium blankets: consequently, little difference in relative blanket performance would be expected. This is a reasonable conclusion in view of the small contribution to total radial blanket fissile production from regions near the reflector. The general topic of resonance self-shielding near interfaces deserves considerably more attention than it has been given here because of the impact that it may have on the blanket power production near the endof-life.

Finally, although no conclusive experimental evidence exists to indicate that there are large discrepancies between the relative spectrum-averaged self-shielded cross sections of thorium and uranium, it is interesting to note that a $20 \%$ decrease in the thorium capture cross section in the unresolved resonance region $(\sim 10$ to $\left.10^{4} \mathrm{eV}\right)$, which appears to be the most plausible consequence inferable from the data, was shown to produce less than a $1 \%$ decrease in the breeding capability of a thorium radial blanket. This is readily understandable, since once neutrons are slowed below about $1 \mathrm{keV}$, they will 
be absorbed by fertile material regardless of the degree of selfshielding. The product of the absorption cross section times the flux tends to be fixed by the available source and if the absorption cross section is reduced, the flux will increase to maintain the same product.

\subsection{Economic Analysis}

\subsubsection{Comparative Blanket Economics}

Because the superiority of the thorium blanketed system was expected to lie in its economic performance rather than in its breeding performance, the burnup data discussed in section 5.2.1 were subjected to an economic analysis. For this analysis the cash flow method (CFM) discussed by Brewer (14) was selected. A major advantage of this method is that it allows separate economic analysis of each reactor region, and definition of the contribution of that region to the total power cost. Figure 5.9 shows the power cost contributions from rows 1,2 , and 3 of a batch irradiated thorium radial blanket developed using the CFM. The parameters used in this analysis, hereafter called the reference economic environment (14), are presented in Table 5.1. The curves presented in Fig. 5.9 show that all three rows of the radial blanket make a negative contribution to the total fuel cycle cost after some irradiation time. This "break-even irradiation time" is greater for assemblies irradiated at larger distances from the core interface. Figure 5.9 also shows that the assembly power cost contribution is quite insensitive to variations in the end-point of irradiation near the optimum irradiation time. Figures 5.10 and 5.11 show economic comparisons of uranium and thorium blankets for the reference economic environment. Figure 5.10 shows radial blanket performance, while Fig. 5.11 shows axial blanket performance. As expected from the fact that the value of U-233 in the standard economic environment exceeds that of fissile plutonium, the power cost contributions for thorium radial and axial blankets are significantly below those for uranium blankets. Also shown is the fact that the differences between optimum radial blanket cost contributions for uranium and thorium blankets is only slightly greater than the 


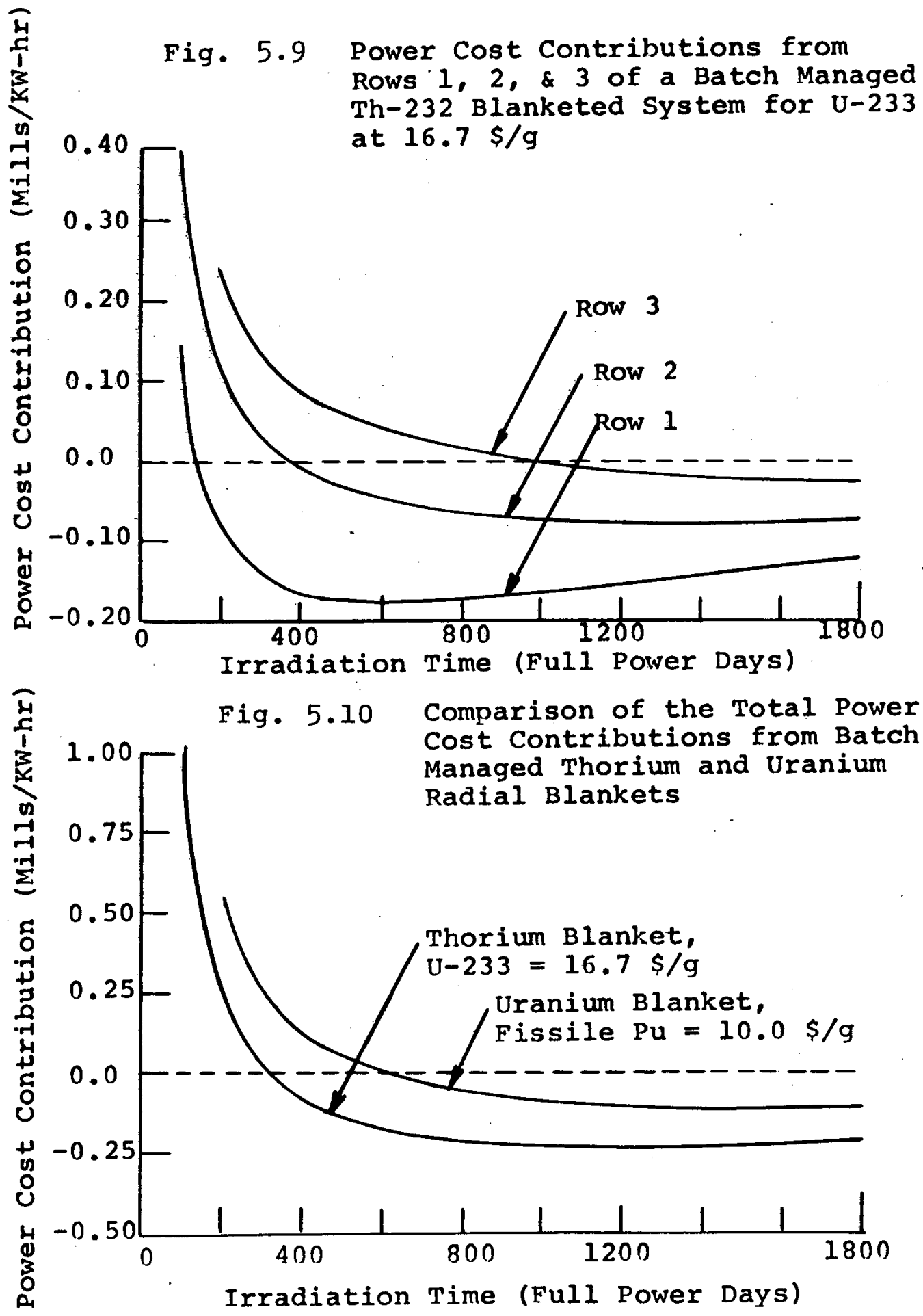


TABLE 5.1 Reference Economic Environment

Unit Fuel Processing Costs, $\$ / \mathrm{kg}$

$\begin{array}{lrcc}\text { Operation } & \text { Core } & \frac{\text { Axial Blanket }}{\text { Radial Blanket }} \\ \text { Fabrication } & 314 & 80 & 69 \\ \text { Reprocessing } & 50 & 50 & 50\end{array}$

Isotope

$\mathrm{U}-238$

$\mathrm{Pu}-239$

$\mathrm{Pu}-240$

$\mathrm{Pu}-241$

$\mathrm{Pu}-242$

Th-232

$\mathrm{U}-233$

Financial Parameter

Income tax rate, $\tau$

Capital structure

Bond (debt) fraction, $f_{b}$

Stock (equity) fraction, $f_{S}$

Rates of return

$$
\begin{aligned}
& \text { Bonds, } r_{\mathrm{b}} \\
& \text { Stocks, } r_{\mathrm{s}}
\end{aligned}
$$

Discount rate, $\mathrm{X}^{*}$

* $X=(1-\tau) r_{b} f_{b}+r_{S} f_{S}$
Is otope Market Value, $\$ / \mathrm{kg}$

0

10,000

0

10,000

0

0

16,700

Value of Parameter

Private Utility

TVA

0.5

0.0

0.5

1.0

0.5

0.0

0.07

0.075

0.125

0.0

0.08

0.075 
Fig. 5.11 Comparison of the Total Power cost Contribution from Batch Managed Thorium and Uranium Axial Blankets

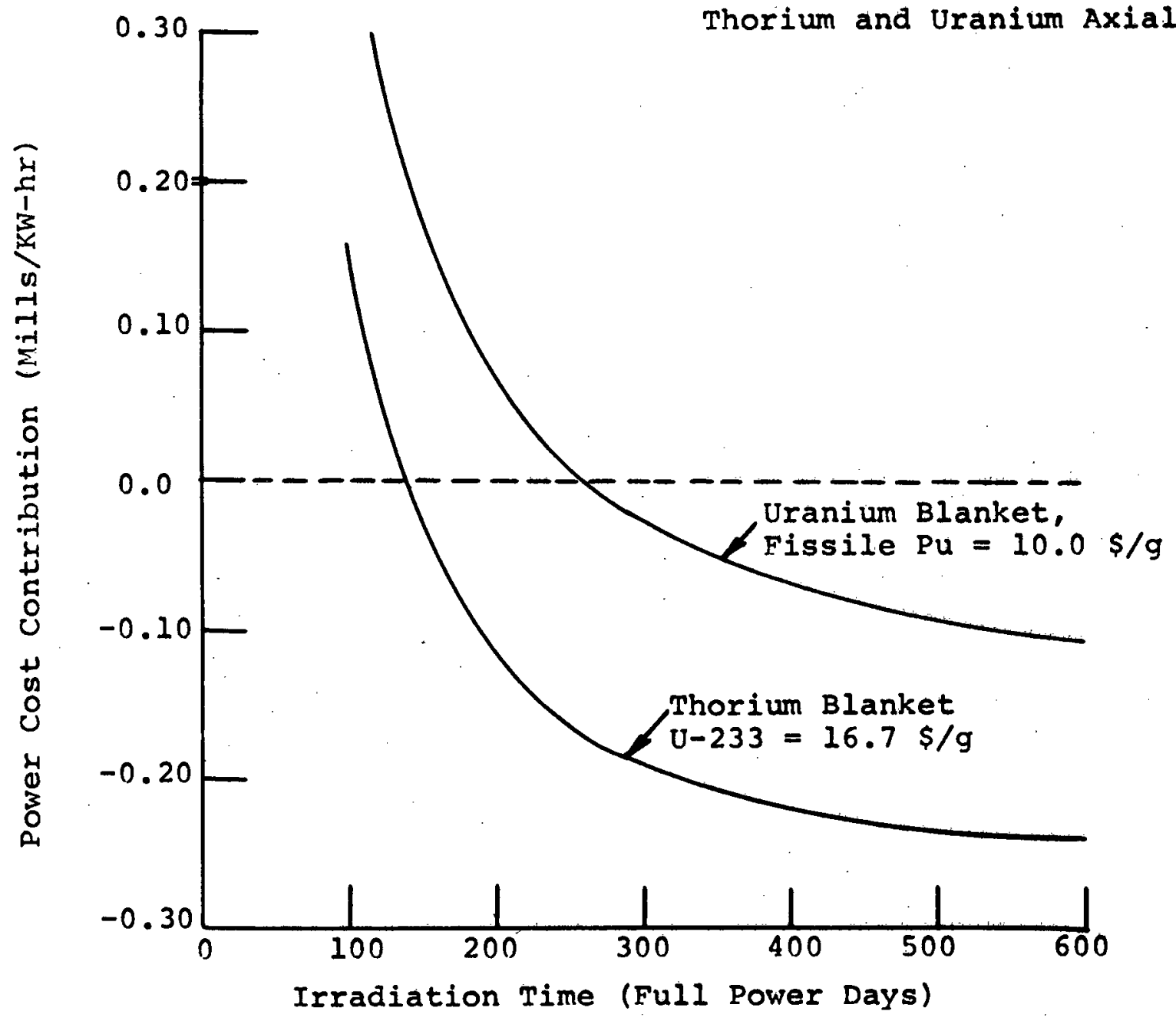


corresponding difference for axial blankets at the end of their useful life (assumed to be 600 full power days, the same as for the core).

Data similar to those shown in Figs. 5.9, 5.10, and 5.11 were developed, using the batch irradiation inventory data, for the core, radial blanket, and axial blanket of both the thorium and the uranium blanketed systems. From this information, economic optimum irradiation times and power cost contributions were developed for a wide range of assumed fissile isotope values. The results of these calculations are shown in Fig. 5.12, which shows the fuel cycle contribution to the cost of power as a function of the price of U-233 and fissile plutonium. It is clear that thorium blanketed systems are substantially superior under the current economic environment, which presumes an excess of LWR produced plutonium and a premium market for U-233 in the HTGR or advanced LWRs. Because of the linearity of the relationships presented in Fig. 5.12, a simple empirical expression, Eqs. 5.1 and 5.2, can be developed to summarize these data:

U-238 Blanketed System

$$
\mathrm{C}=0.02173 \mathrm{P}^{49}+0.6203
$$

Th-232 Blanketed System

$$
C=0.07613 P^{49}-0.04793 P^{23}+0.6648
$$

where $\mathrm{C}=$ the total fuel cycle cost (mills $/ \mathrm{kw}-\mathrm{hr})$,

$$
\begin{aligned}
& \mathrm{P}^{49}=\text { price of fissile plutonium }(\$ / \mathrm{g}), \text { and } \\
& \mathrm{P}^{23}=\text { price of } \mathrm{U}-233(\$ / \mathrm{g}) \text {. }
\end{aligned}
$$

Because of the simplicity of the form of these relationships, future studies comparing the economics of two similar systems can be performed using only a.small number of parametric analyses. The data in Fig. 5.12 can be summarized in one other form: the break-even parity ratio, defined as the ratio of the price of U-233 to that of fissile $\mathrm{Pu}$ above which a thorium blanketed system is economically superior. Figure 5.13 shows this ratio as a function of the price of fissile $\mathrm{Pu}$. 
Fig. 5.12 Economic Comparison of Thorium and Uranium Blankets for 1000 MWE LMFBR

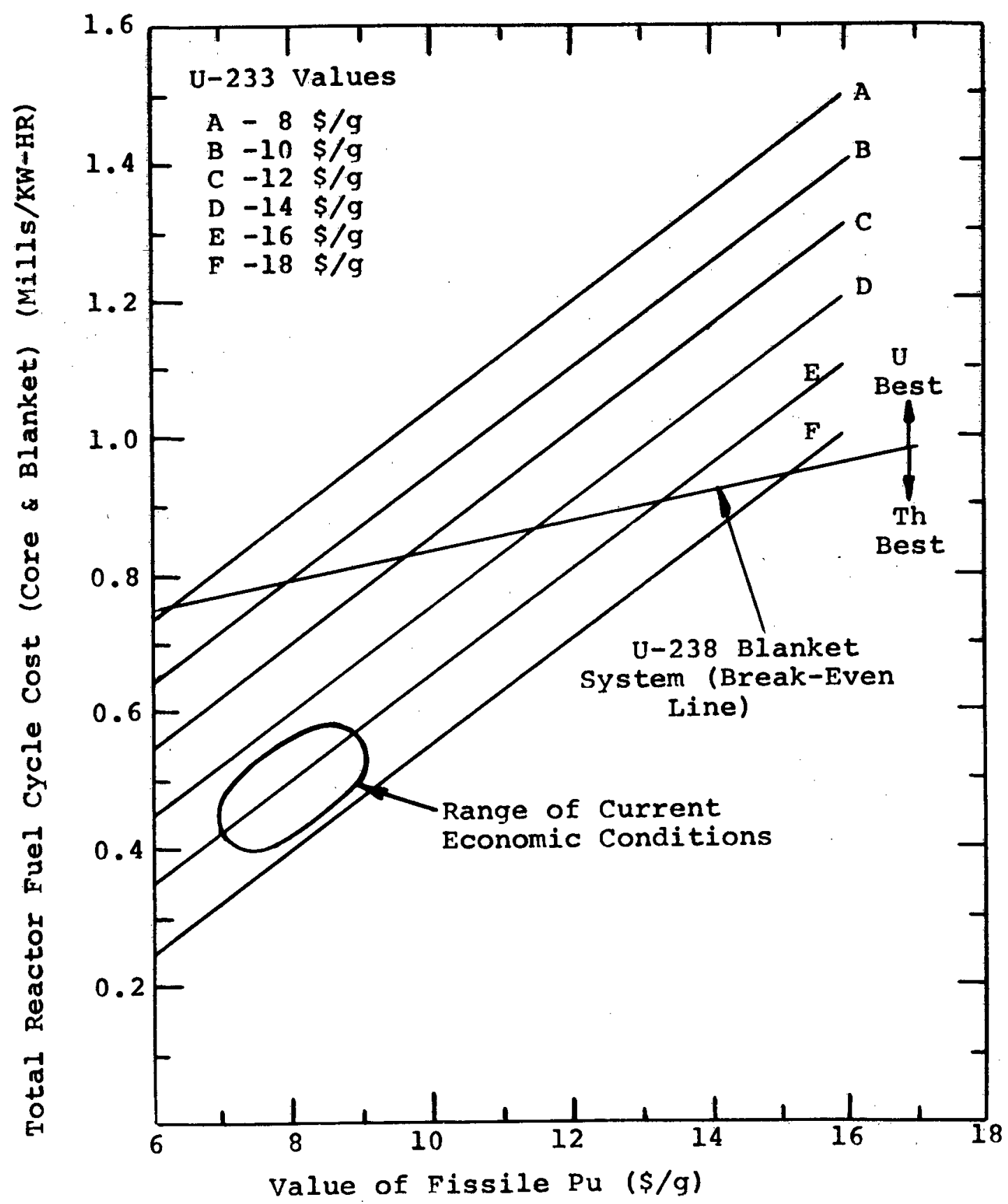


Fig. 5.13 Break-Even Parity Ratio: Ratio of Value of U-233 to that of Fissile $\mathrm{Pu}$ versus Value of Fissile Plutonium

Note:-Estimated Parity Ratio from Table 5.3, Range: 1.53 to 1.88

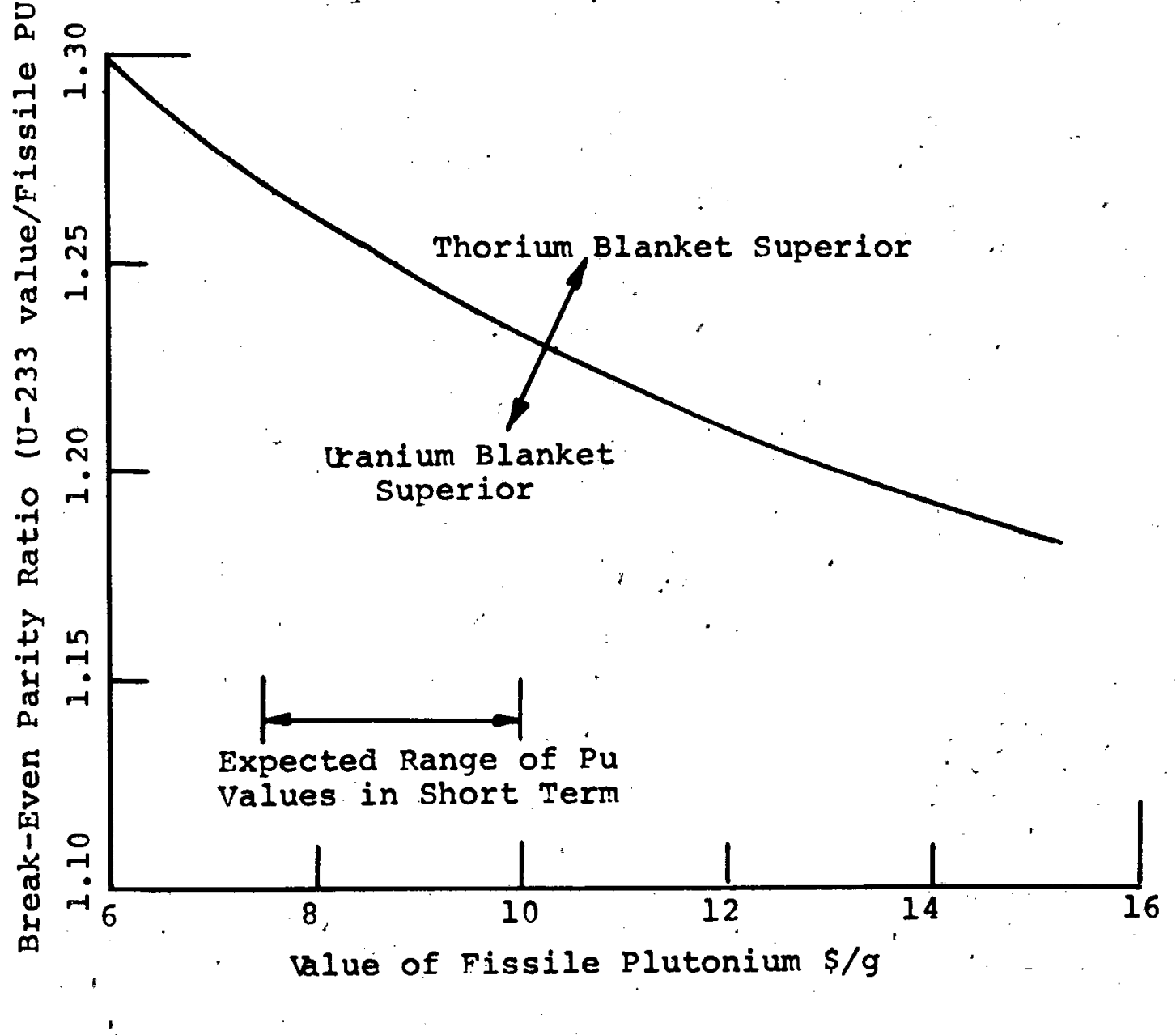


As shown, current estimates of the parity ratio, which range from about 1.5 to about $1.9(\underline{22}, \underline{23}, \underline{4})$, a re significantly above the breakeven value for any reasonable near term price of fissile $\mathrm{Pu}$.

\subsubsection{Comparison of Management Schemes}

Fissile inventory data for the three blanket management schemes discussed earlier were analyzed using the CFM to determine their relative economic performance. Because both zone scatter and in-out shuffle management would require more blanket assembly handling than batch, an economic penalty in the form of an availability. decrease (1 hour per assembly replacement [24], at 100,000\$/day [도]) was assessed for assembly handling. Table 5.2 shows the final comparison among the different management schemes. As shown, the zone scatter management is economically superior, followed by batch and in-out shuffle management. The differences among the management schemes are, however, relatively small when compared to the penalty associated with a several-day loss in system availability.

TABLE 5.2

Comparison of Radial Blanket Power Cost Contributions for Various Management Schemes

\begin{tabular}{llcc}
\hline $\begin{array}{l}\text { Radial } \\
\text { Blanket } \\
\text { Type }\end{array}$ & $\begin{array}{l}\text { Blanket } \\
\text { Management } \\
\text { Scheme }\end{array}$ & $\begin{array}{l}\text { Power Cost } \\
\text { Contribution } \\
(\text { mills } / \mathrm{kw}-\mathrm{hr})\end{array}$ & $\begin{array}{c}\text { Economic Penalty } \\
\text { for Management } \\
\text { Scheme }(\$ / \mathrm{yr})\end{array}$ \\
\hline Uranium & Batch & -0.097 & ${ }_{0}^{(1)}$ \\
Uranium & Zone scatter & -0.103 & $-41,000$ \\
Uranium & In-out shuffle & -0.089 & 58,000 \\
Thorium & Batch & -0.205 & 0 \\
Thorium & Zone scatter & -0.232 & $-193,000$ \\
\hline
\end{tabular}

(1) Basis: Batch irradiation case. 
This conclusion has been corroborated by one other investigator (26), and apparently contradicted by a second investigation (2ㄱ). The discrepancy among these analyses appears to be in the method used to treat carrying charges for fissile material produced in the blanket. In the method used here, only the total irradiation time of a batch of material and the final fissile content are important in determining the carrying charges. It would appear that the contradictory results were derived assuming that carrying charges were in some way related to the time-dependent shape of the fissile inventory history curves for a given subassembly. This apparent disparity in the evaluation of the relative economics of various management schemes requires resolution before the true benefits of blanket management can be assessed.

Finally, it should be noted that engineering lifetime limits for the blanket assemblies, the effect of orificing on outlet temperature variations, and the impact of blanket assembly management either on these limits or on system (e.g., core restraint) désign and economics have not been considered in developing the relative economics for the three management schemes. These considerations might easily swing the scale in favor of in-out shuffle management over the other seemingly more economically attractive schemes. 'Other engineering considerations such as pellet-clad gap closure following movement of blanket assemblies into regions of higher or lower flux must also be weighed prior to final selection of a blanket management scheme.

\subsubsection{Economic Model}

In an attempt to develop a generalized approach to correlating variations in the economic environment against corresponding variations in the blanket optimum irradiation time and fissile enrichment at the optimum, an économic parameter was developed by linearizing Brewer's (14) fuel cycle cost equations and solving the resulting approximate expression for the optimum irradiation time. This approach led to the economic parameter defined below: 


$$
N_{E} \equiv\left[\frac{C_{1} F_{1}\left(-\Delta T_{1}\right)+C_{2} F_{2}\left(\Delta T_{2}\right)}{C_{3} F_{3}\left(\Delta T_{3}\right) X}\right]
$$

where $\quad C_{1}$ = fabrication charge, $\$ / \mathrm{kg}$ heavy metal,

$\mathrm{C}_{2}=$ reprocessing charge, $\$ / \mathrm{kg}$ heavy metal,

$\mathrm{C}_{3}=$ fissile value, $\$ / \mathrm{kg}$ fissile,

$\mathrm{F}_{1}=$ the present worth factor in fabrication charges for

$\Delta \mathrm{T}_{1}=$ the time span between fabrication and loading,

$\mathrm{F}_{2}=$ the present worth factor on reprocessing charges for

$\Delta \mathrm{T}_{2}=$ the time span between discharge and reprocessing,

$\mathrm{F}_{3}=$ the present worth factor on material credit for

$\Delta \mathrm{T}_{3}=$ the time span between discharge and sale, and

$\mathrm{X} \quad=$ the discount factor.

The exact economic model (14) was next used to develop fuel cycle cost data over a wide range of parameters characterizing the economic environment (see Table 5.3). The results were then correlated as a

TABLE 5.3 Range of Variation of Economic Parameters

\begin{tabular}{lll}
\hline \multicolumn{1}{c}{ Parameter } & Units & Range of Variation \\
\hline Value of fissile $\mathrm{Pu}$ & $\$ / \mathrm{g}$ & 6.0 to 16.0 \\
Value of U-233 & $\$ / \mathrm{g}$ & 8.0 to 18.0 \\
Fabricating charges & $\$ / \mathrm{kg}$ & 69 to 140 \\
Reprocessing charges & $\$ / \mathrm{kg}$ & 50 to 100 \\
Discount rate $(\mathrm{X})$ & Years $^{-1}$ & 0.075 to 0.085 \\
\hline
\end{tabular}

function of the economic parameter, $\mathrm{N}_{\mathrm{E}}$. Typical results are shown in Figs. 5.14 and 5.15. As can be seen, linear relationships result on a log-log plot, and these relationships are very similar for both uranium and thorium batch-managed row 1 radial blankets. The dashed lines 

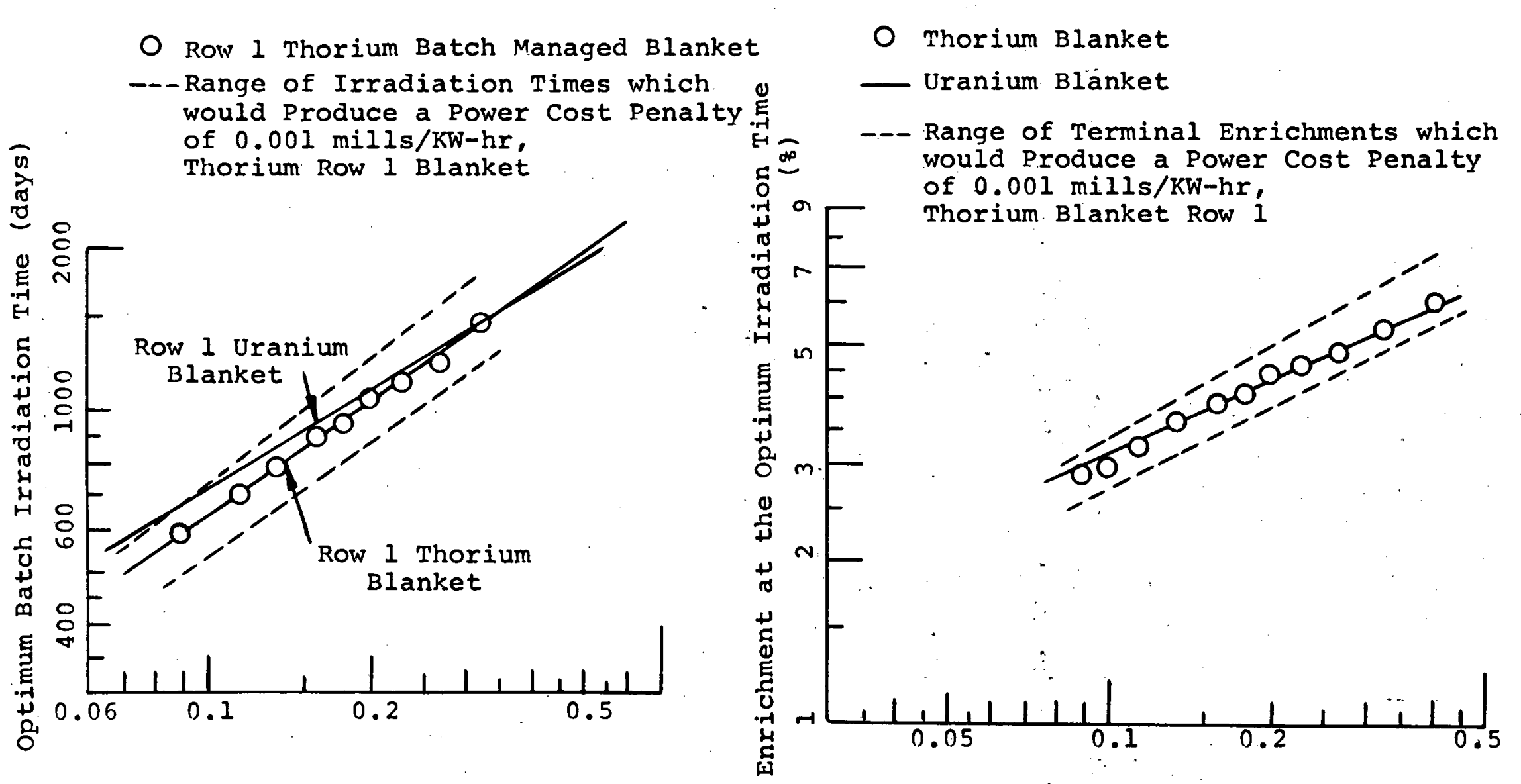

Both " $X$ " Axes have the same label, $N_{E}=\left[C_{1} F_{1}\left(-\Delta T_{1}\right)+C_{2} F_{2}\left(\Delta T_{2}\right)\right] / C_{3} F_{3}\left(\Delta T_{3}\right) X$ 
shown on these'figures represent the range of optimum irradiation times and optimum fissile enrichments within which a power cost penalty of only $0.001 \mathrm{mills} / \mathrm{kw}-\mathrm{hr}$ would be suffered.

Development of these correlations will greatly simplify future economic analyses: one need only compute two cases to completely characterize system economic performance for each system design of interest.

\section{3 .4 Effect of Uncertainties}

The comparative blanket economic analysis presented in section 5.3.1 was for a batch managed blanket in which all the fissile material produced was assumed to be sold under some specified set of market conditions. Several features of that analysis, both methods and assumptions, will have an impact on the conclusions developed earlier. Table 5.4 summarizes these features. As shown, the maximum impact which the parameters in that table might have on the

TABLE 5.4

Effect of Methods and Assumptions on Thorium Blanket Relative Economic Performance

Axial blanket head-end losses

0.038

Erroneous downscatter cross sections

0.031

Blanket management

$-0.021$

U-232 mixing in reprocessing

0.006

Erroneous thorium resonance cross sections

0.005

Reprocessing losses (1\%)

0.003

Reprocessing delay (per month)

0.002

Core management variations

0.002

Total (excluding reprocessing delays)

0.064 
blanket comparative economic analysis is approximately $0.064 \mathrm{mills} /$ $\mathrm{kw}-\mathrm{hr}$. This penalty on the thorium blanket economics should be weighed against the earlier anticipated benefit associated with the use of a thorium blanketed system: approximately $0.286 \mathrm{mills} / \mathrm{kw}-\mathrm{hr}$. Thus, even when all reasonable sources of error are considered, the thorium blanketed LMFBR still shows a net economic advantage of approximately 0.222 mills $/ \mathrm{kw}-\mathrm{hr}$ when compared with a uranium blanketed system.

\subsection{Engineering and Physics Comparisons}

\subsubsection{Blanket Heating Characteristics}

Among the most troublesome engineering problems related to the design of radial blankets is the variation of the assembly heat generation rate both in space (from the core interface to the reflector interface) and in time (from beginning to end of life). Because of the differences in fertile material fission cross section and in the fissile production rate distribution between thorium and uranium radial blankets, it was necessary to evaluate space and time dependent heating rates. In this analysis the three major mechanisms for energy deposition in the blanket were considered: fission product heating, gamma heating, and neutron heating. Figure 5.16 shows the axial average beginning-of-life (BOL) heating rates in the radial blankets and reflectors of thorium and uranium blanketed systems. As shown, the BOL heating rate in the uranium blanket is nearly twice that in the thorium blanket. Nearly all of the BOL heating in the thorium blanket arises from gamma heating, while approximately half of that in the uranium blanket can be attributed to fission product heating. In neither case does neutron heating contribute significantly to the total heating rate.

Figure 5.17 shows uranium and thorium blanket heating rates in batch irradiated systems after 2 years at power. As shown, the peak heating rate is nearly the same for the two systems, while the heating rate gradient in the thorium blanket is somewhat steeper. Cross comparison between Figs. 5.16 and 5.17 shows that during the two-year 
Fig. 5.16 Comparison of BOL Heating

Rates External to the Core

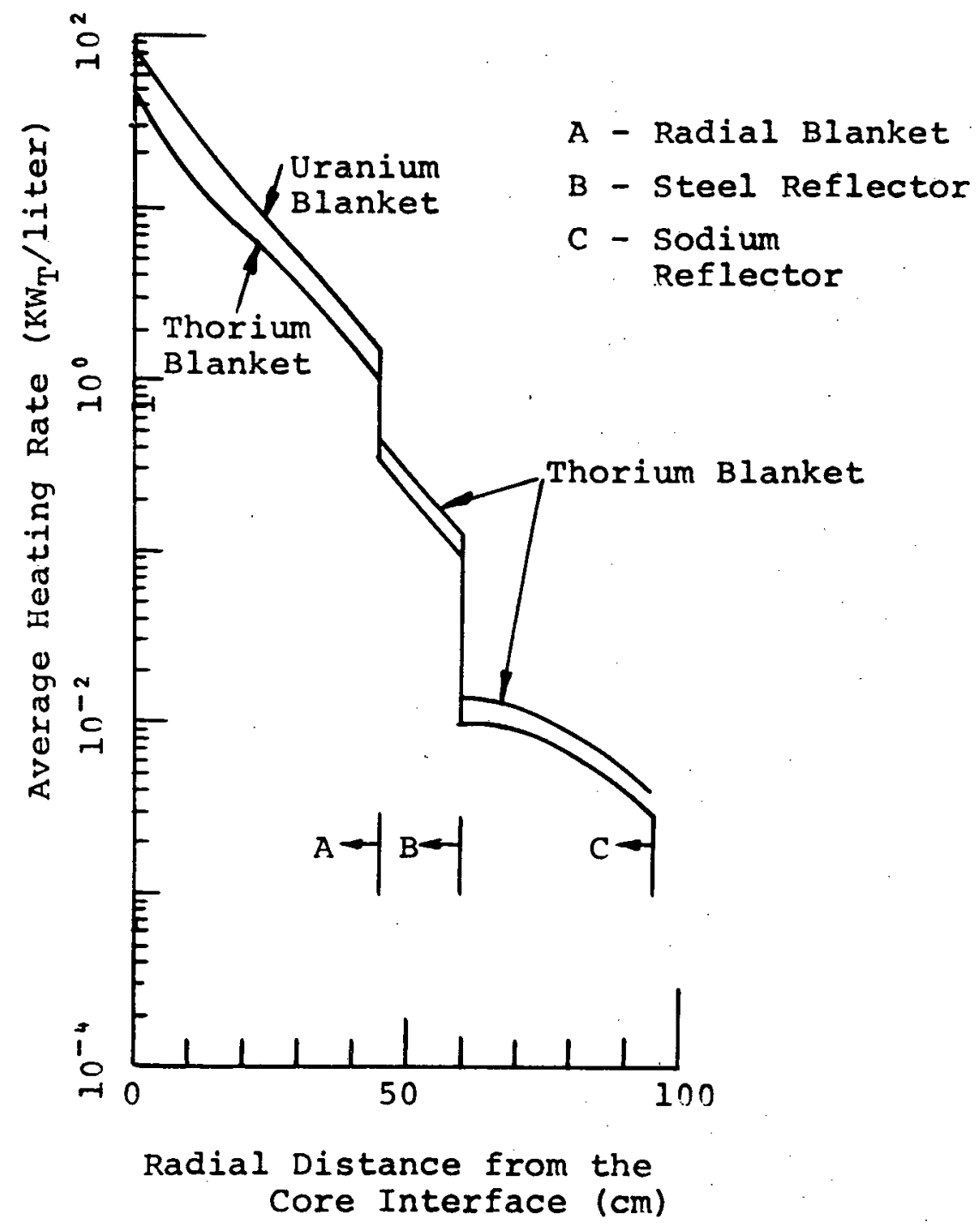

Fig. 5.17 Comparison of Uranium and Thorium Radial Blanket Heating Rates after 600 Days

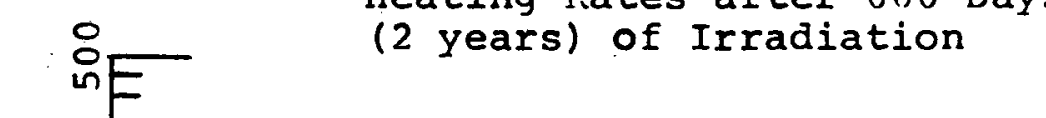


irradiation, the peak heating rate in the uranium blanket more than doubled while that in the thorium blanket reached over four times its $B O L$ value. Analysis has shown that nearly all of the increase in blanket heating rate can be attributed to fission product heating. The main conclusion to be drawn from Figs. 5.16 and 5.17 is that the use of a thorium radial blanket somewhat complicates design problems (e.g., orificing and core restraint) related to temporal and spatial heating rate variations in the blanket. An evaluation of the effect of blanket management scheme on power variations has shown that

1. In-out shuffle management is superior to the other schemes in minimizing both spatial and temporal power variations in the blanket,

2. Both power gradients and assembly power vs. time variations are somewhat larger in a thorium blanket than in a uranium blanket.

A comparison of the post shutdown heating rates in uranium and thorium blankets has shown that the heating rate immediately after shutdown is about $80 \%$ as large in a thorium blanket as in a uranium blanket, and that the required coolant flow rate to remove the fission and capture product decay heat is dictated in both cases by the core cooling requirements.

\subsubsection{Reactor Physics Characteristics}

Although the differences between the dynamic characteristics of uranium and thorium blanketed systems were not expected to be great, analyses were performed to characterize these differences. Table 5.5 is a summary of the results of those studies, including the results of static physics calculations. As shown, the two systems have very similar BOL characteristics. Of the tabulated parameters, the only one favorable to the thorium blanketed system is the smaller isothermal Doppler coefficient. However, the differences between the two systems for all the remaining parameters, with the possible exception of core fissile loading and control requirements, are smaller 
TABLE 5.5

Summary of Differences in System Physics Characteristics Between Uranium and Thorium Blanketed LMFBRs

System

Characteristic
Beginning-of-Life Ratio Thorium System/Uranium System
Core fissile loading

Control requirements

Central core sodium void coefficient

Isothermal Doppler coefficient

Doppler power coefficient

Adiabatic power coefficient

Delayed neutron fraction, $\beta$

Prompt neutron lifetime, $\Lambda$
1.040

1.093

1.028

0.910

0.938

0.958

0.981

than the expected uncertainties associated with the calculation of the properties $(\underline{28}, \underline{29})$. Therefore, these variations are within the limits inside which system designers are reconciled to operate.

Account has been taken in the economic analysis, discussed earlier, of the effect of core fissile loading on system economic performance and of the effect of control poison concentration (homogeneous) on system breeding performances. No account, however, has been taken of the cost associated with additional control rods on system economics. It is likely that a more detailed analysis of the control requirements, associated with a core management study, would show a smaller difference between the two systems relative to control requirements.

The difference between prompt neutron lifetimes shown in Table 5.5 appears significant until it is noted that a simple analysis to determine the energy release associated with a disassembly transient following a ramp reactivity insertion ( $\underline{30}$ ) shows that the $11 \%$ difference in $\Lambda$ results in only about an $8 \%$ difference in energy release. This is certainly small when compared with the uncertainty on the total energy release in a disassembly transient. 


\subsubsection{Blanket Interchangeability}

Since projections of the relative values of U-233 and fissile

$\mathrm{Pu}(\underline{2}, \underline{3})$ show that each fuel will experience a period during which its value will be higher, a discussion of the ease with which a thorium blanket on an LMFBR can be replaced by a uranium blanket is in order. Because the thermophysical properties of thoria $\left(\mathrm{ThO}_{2}\right)$ and urania $\left(\mathrm{UO}_{2}\right)$ are substantially the same, no major design limits should apply to one system and not to the other. One possible exception to that generalization is that the melting point of thoria is about $1000^{\circ} \mathrm{F}$ higher than that of urania. Some differences exist between the two systems relative to the power generation shape and history, but the two systems become more similar as burnup proceeds. This can be seen by comparison of Figs. 5.16 and 5.17. One potential problem associated with a thorium blanket is that its spatial power gradients are somewhat larger (about $30 \%$ after two years of exposure), but this problem may be significantly reduced through the use of perforated blanket ducts as suggested by Weiss et al. (31). One important feature of a thorium blanket which will have the effect of reducing the temporal power variations is that, in the reference economic environment considered here, more frequent replacement or shuffling is dictated by the higher value of the product U-233. This shorter irradiation time will also reduce the extent of environmental damage suffered by the blanket while in the reactor.

A comparison of the static and dynamic physics characteristics for the two systems, Table 5.5, has shown that insignificant differences exist for all properties except, possibly, the required core fissile loading and the control requirements. Preliminary analysis has shown the thorium blanketed system to require approximately $4 \%$ more fissile material and approximately $9 \%$ more control poison than a comparable uranium blanketed system. In the transition from a uranium to a thorium blanketed system, therefore, a small penalty would be assessed in the form of more frequent refuelings or lower power density prior to the complete replacement of the core, and care must be taken to assure that sufficient control poison is available to accommodate the differences in burnup characteristics. Because of 
the differences in blanket albedo between thorium and uranium blankets, the power gradient in core zone 2 should be steeper relative to a uranium blanketed system; consequently, the thorium blanketed system power density penalty may be significantly reduced by optimum control rod programming. Other considerations, such as shielding characteristics, sodium activation contribution, and decay heating properties are sufficiently similar for the two systems that no related problems in the transition from a thorium to a uranium blanket or vice versa should be encountered.

\subsection{Recommendations for Future Work}

The major areas in which additional work is needed to characterize the performance of LIMFBR blankets include development of a consistent cross section set in which elastic downscatter is accommodated correctly, and evaluation of the variation in effective fertile resonance self-shielding near the blanket-reflector interface. Both of these effects must be well characterized before reliable absolute blanket breeding predictions and comparisons can be made. The M.I.T. Blanket Test Facility can be used to evaluate corrective techniques if future data taken in the facility are accompanied by normalization data from simultaneous irradiation in the thermal and fission spectrum facilities. Also, foil spectrometry can be used to generate experimental spectra for comparison with those calculated using cross sections which have been corrected for errors in downscatter and interface region resonance self-shielding.

Several aspects of the work presented here should be assessed in more detail to further define economic differences between uranium and thorium blanketed systems. Included in this category are:

1. The effect of separation between the core and thorium axial blankets using an inert buffer zone (e.g., NiO) on blanket breeding performance, required core fissile loading, and ease of core-blanket separation in head-end processing should be assessed (as shown in Table 5.4, head-end losses during reprocessing constitute the single largest penalty for a thorium system). 
2. The impact of various blanket management schemes on system control requirements for thorium and uranium blanketed systems should be considered to better define control requirement differences.

3. A study of the reprocessing problems and related economics associated with thorium blankets should be performed with emphasis on the possible use of HTGR fuel reprocessing facilities in conjunction with LMFBR head-end processing units.

4. A detailed comparison of irradiation experience with thoria and urania would help to define possible differences in blanket lifetime limits between the two types of blankets. It should be noted that irradiation data from the Indian Point 1 reactor, in which thoria-urania pins have acquired peak burnups greater than those expected for thorium blankets, are available to provide quantitative insight into thorium blanket irradiation behavior.

5. Potential difficulties associated with the transition between thorium and uranium blankets, or vice versa, might be uncovered through an approach-to-equilibrium evaluation in which both core and blanket management are considered simultaneously.

6. Thorium blanket economic performance should be evaluated for use in Gas Cooled Fast Reactors, and advanced blanket fuels (e.g. , ThC) should be assessed for both GCFR and LMFBR application.

Finally, because of the apparent discrepancy in the techniques used to make economic comparisons among various blanket management alternatives, a review of the methods in current use with the goal of unifying the analytical methods would be useful. Particular emphasis in this study should be given the various methods of handling carrying charges on fissile material produced in the blanket.

In conclusion, it is recommended that thorium blankets (radial at the very least) be strongly considered as the reference design for the LMFBR program in view of their demonstrated near-term economic benefits which amount to on the order of 1.1 million dollars added income per year for a 1000-MWe system, an amount sufficient to materially enhance the attractiveness of the LMFBR relative to other 
competing systems. Because thorium blanketed systems appear to require slightly wider system design allowances than uranium blanketed systems, interchangeability between thorium and uranium blankets would be assured.

\subsection{References}

(1) Argonne National Laboratory, 1000-MWe LMFBR Follow-On Study: Evaluation Report, Draft (January 16, 1970).

(2) DRDT, USAEC, "Potential Nuclear Power Growth Patterns," WASH-1098 (November, 1969).

(3) Kasten, P.R., L.L. Bennett, and W.E. Thomas, "An Evaluation of Plutonium Use in High Temperature Gas Cooled Reactors," ORNL-TM-3525 (October, 1971).

(4) Lang, L. W. , "Power Cost Reduction by Crossed-Progeny Fueling of Thermal and Fast Reactors," Nuclear Applications, 5, 302-310 (November, 1969).

(5) Lang, L.W., "Thorium Can Reduce Power Costs for Thermal and Fast Reactors," Trans. Am. Nuc. Soc. , 11, p. 38 (June, 1968).

(6) Lang, L.W., "Dependence of Fast Reactor Start-Ups on the Thorium Fuel Cycle," Trans. Am. Nuc. Soc., 12, p. 443 (December, 1969).

(7) Wenzel, P., "Crossed Uranium-Plutonium and ThoriumUranium Fuel Cycles for a Developing Nuclear Power System with Thermal Converters and Fast Breeder Reactors," Kernenergie 14, July-August, 1971.

(8) Allen, W.O., D.J. Stoker, and A.V. Campise, "Fast Breeder Reactors with Mixed Fuel Cycles," Proceedings of Second International Thorium Fuel Cycle Symposium, Gatlinburg, Tennessee, May, 1966.

(9) Hanke1, R., et al. , "An Evaluation of U-233/Thorium Fast Breeder Power Reactors," NDA-2164-3, United Nuclear Corporation, April, 1962.

(10) Loewenstein, W.B., and D. Okrent, "The Physics of Fast Power Reactors; A Status Report," Proceedings of the Second International Conference on the Peaceful Uses of Atomic Energy, Vol. 12 (1958). 
(11) Loewenstein, W.B., and B. Blumenthal, "Mixed Fuel Cycle Fast Breeder Reactors: Nuclear, Safety, and Materials Considerations," Proceedings of the Converence on Safety, Fuels, and Core Design in Large Fast Power Reactors,. ANL-7120, October, 1965.

(12) Okrent, D. ; K.P. Cohen, and W.B. Loewenstein, "Some Nuclear and Safety Considerations in the Design of Large Fast Power Reactors," Proceedings of the Third International Conference on the Peaceful Uses of Atomic Energy, Vol. 6 (1965).

(13) Sofer, G. A., et al., "Economics and Safety Aspects of Large Ceramic U-Th Fast Breeder Reactors," ANL-6792 (October, 1963).

(14) Brewer, S.T., E.A. Mason, and M.J. Driscoll, "The Economics of Fuel Depletion in Fast Breeder Reactor Blankets," COO-3060-4, MITNE-123 (November, 1972).

(15) Nelson, J.V., "Cross Sections for Preliminary Design of FTR, FTR Set No. 200," HEDL-7ME-71-65 (1971).

(16) Hardie, R.W., and W.W. Little, Jr., "1DX, A One-Dimensional Diffusion Code for Generating Effective Nuclear Cross Sections," BNWL-954 (March, 1969).

(17) Engle, W.W., Jr., "A User's Manual for ANISN, A OneDimensional Discrete Ordinates Transport Code with Anisotropic Scattering," K-1693 (March 30, 1967).

(18) Little, W.W., Jr., and R.W. Hardie, "2DB User's Manual Revision 1," BNWL-831 Rev. 1 (August, 1969).

(19) Hirons, T.J , and R.D. O'Dell, "Calculational Modeling Effects on Fast Breeder Fuel Cycle Analysis," LA-4187 (September 1969).

(20) Wolfe, B., et al., "Towards a 1000-MWe LMFBR: The Influence of Component Development, Prototypes, and Construction Experience," Nuclear News (January, 1973).

(21) Kidman, R.B., et al., "The Shielding Factor Method for Generating Multigroup Cross Sections," Trans. Am. Nucl. Soc., 16, 1,125 (June, 1973).

(22) Asmussen, K.E., and R.K. Lane, "U-233 Indifference Value for Use in HTGRs," Gulf-GA-A 12204 (August, 1972).

(23) George, C.H., Gulf General Atomic, Personal communication, November 11,1972 .

(24) Vendryes, G.A., "Fuel Management and Economics," Proceedings of the 1972 International Conference on Nuclear Solutions to World Energy Problems (November, 1972). 
(25) Taylor, J.J., and N.A. Petrick, "LMFBR: Keys to Industrial Success," Nuclear News (January, 1973).

(26) Barthold, W.P., "Fuel Shuffling in LMFBR Blankets," Argonne National Laboratory, FRA-TM-40 (August, 1972).

(27) Markley, R.A., et al. , "Design Analysis of the LMFBR Radial Blanket," WARD-3045T2B-9 (March, 1973.).

(28) Greebler, P., and B.A. Hutchins, "Significance of Integral Parameters in the Design and Performance of Fast Breeder Reactors," National Topical Meeting on New Developments in Reactor Physics and Shielding," pp. 928-939 (September, 1972).

(29) Küsters, H. , "Progress in Fast Reactor Physics in the Federal Republic of Germany," KFK-1632, EACRP-U-46 (1972).

(30) Komata, M. , "Qualitative Evaluation of Fast Reactor Meltdown Accidents," Nucl. Sci. Eng. , 40, 150 (1970).

(31) Weiss, E., R. A. Markley, and A. Battacharyya, "Open Duct Cooling Concept for the Radial Blanket Region of a Fast Breeder Reactor," Nuclear Engineering and Design, 16, 375-386 (1971). 


\section{THE PARFAIT BLANKET CONCEPT}

The work summarized in the present chapter will be discussed in detail in the forthcoming topical report:

G.A. Ducat, M.J. Driscoll and N.E. Todreas, "Evaluation of the Parfait Blanket Concept for Fast Breeder Reactors," COO-2250-5, MIT NE157, January 1974 (est.).

\subsection{Introduction}

The purpose of the research summarized here has been to evaluate the neutronic, thermal-hydraulic, mechanical and economic characteristics of the advanced liquid-metal cooled fast breeder reactor configuration shown in Fig. 6.1. This configuration, called the parfait blanket concept, consists of conventional axial and radial external blankets surrounding a short cylindrical core into which a thin horizontal layer of blanket material has been inserted at the core midplane. This internal blanket region is limited in radial extent to the inner core zone, is an integral part of the core fuel assemblies, as are the upper and lower axial blanket regions, and is made up of standard axial blanket pellets. This study has yielded results which indicate a substantial advantage for the parfait configuration over more conventional designs. In particular, the parfait configuration has demonstrated a reduced burnup reactivity swing, an increased breeding ratio and a substantially reduced peak flux. This latter characteristic, together with a flatter radial power profile in the inner core enrichment zone, results in reduced wrapper tube dilation due to swelling and reduced unrestrained fuel element bowing due to radial flux and power gradients. The parfait configuration also exhibits substantially improved sodium void characteristics. The groundrules employed in the evaluation of the parfait concept are discussed below and the performance characteristics mentioned above are discussed in more detail in subsequent sections. 


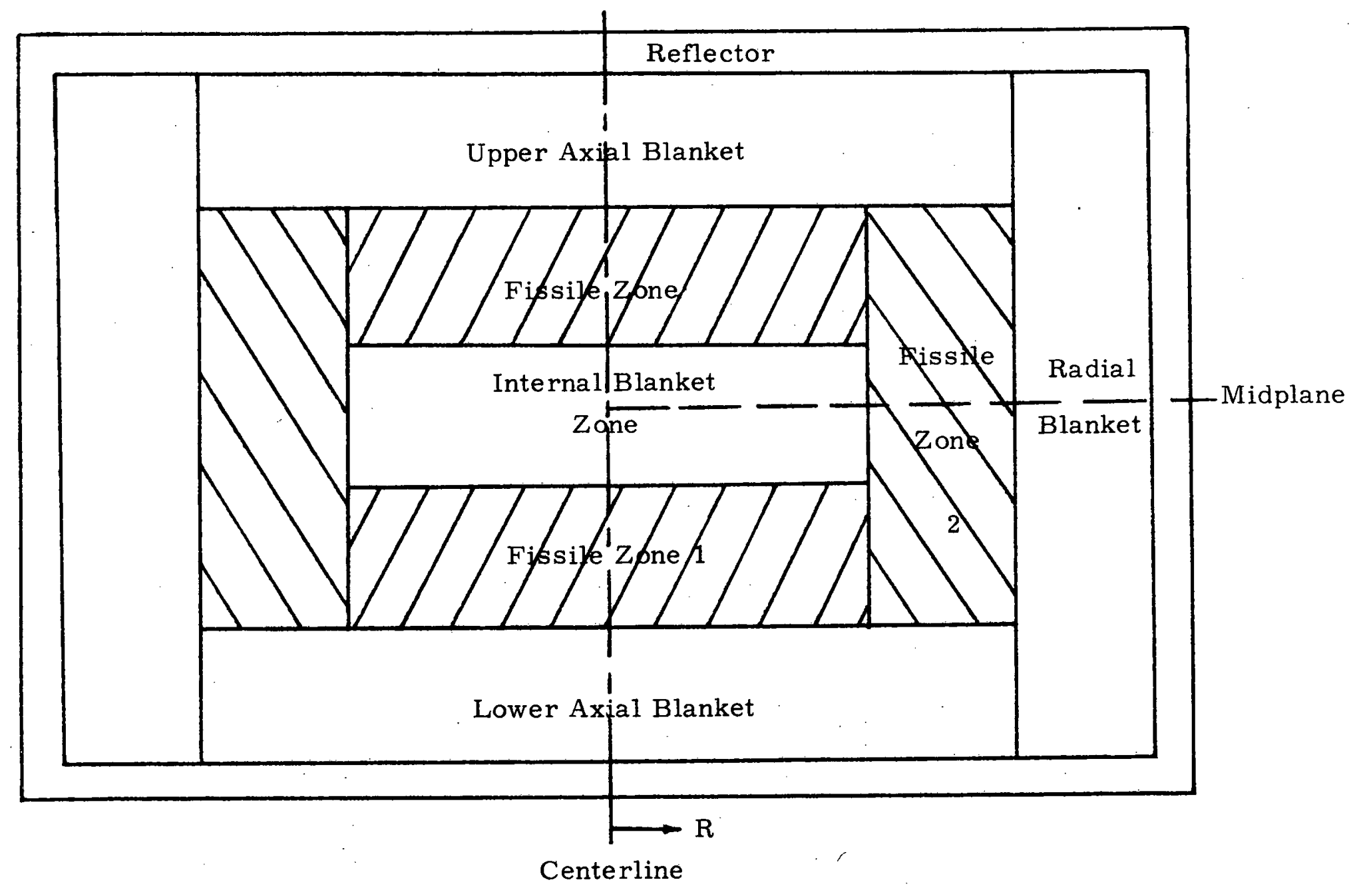

FIG. 6.1. The Parfait Blanket Concept 
Although a large number of internal blanket concepts, including annular and modular designs, have been investigated in the past, these early studies appear to have optimized a fast reactor design for a single performance characteristic (e.g., to minimize sodium void effects) and were carried out at a time when many of the difficult fast reactor design problems, such as swelling, were, as yet, not fully appreciated. None of these earlier internal blanket concepts is currently the reference design for large fast power reactors.

The product of the present study is a comparative evaluation of the merits and demerits of the parfait blanket concept. It was performed for the purpose of assessing the potential for the application of this configuration to large fast breeder power reactors. The method of evaluation has been to perform a series of parallel calculations employing the same methods and basic data to compare the equilibrium cycle performance of a parfait system with that of a conventional twozone 1000-MWe LMFBR. Every effort has been made to identify the major differences between the parfait and the conventional design and to focus on a quantitative evaluation of the major items of concern.

Since there are currently no firm designs for a large LMFBR, the conventional, or reference, reactor characteristics were chosen from the final round designs of the AEC-sponsored 1000-MWe LMFBR Follow-On Studies (1). The overall characteristics of the reference and parfait designs of this study are given in Table 6.1. The characteristics of the reference design are similar to those of the Atomics International 1000-MWe LMFBR design in reference 1 , except that the fuel volume fraction in the core has been decreased to conform with current practice as reflected in the FFTF and demonstration plant designs.

Many of the characteristics of the reference and parfait configuration were required to be the same so that the two concepts could be readily compared. Both configurations were required to generate the same total thermal power, use the same materials and have external blankets of the same dimensions and initial composition. With the exception of the fissile enrichments and the internal blanket region, the characteristics of the fuel assemblies in both cores were required 
TABLE 6.1. Dimensional and Material Characteristics of the Reference and Parfait Systems

\begin{tabular}{|c|c|c|}
\hline & Reference & Parfait \\
\hline Thermal power $\left(\mathrm{MW}_{\mathrm{t}}\right)$ & 2500 & 2500 \\
\hline Core volume ${ }^{*}$ (liters) & 5780 & 5780 \\
\hline Core height $(\mathrm{cm})$ & 108.8 & 108.8 \\
\hline Core radius $(\mathrm{cm})$ & 130.0 & 130.0 \\
\hline Axial blanket thickness $(\mathrm{cm})$ & 38.1 & 38.1 \\
\hline Radial blanket thickness $(\mathrm{cm})$ & 28.4 & 28.4 \\
\hline Reflector thickness $(\mathrm{cm})$ & 14.2 & 14.2 \\
\hline$\frac{\text { Region Compositions: }}{\text { Core }}$ & $\begin{array}{c}\text { Axial and } \\
\text { Internal Blankets }\end{array}$ & Radial Blanket \\
\hline $\begin{array}{l}\text { Fuel } \\
\text { Volume fraction } 0.30\end{array}$ & 0.30 & 0.50 \\
\hline $\begin{array}{r}\text { Mixed } \\
\text { oxide }\end{array}$ & $\begin{array}{l}\text { Mixed oxide } \\
\text { (initially } \\
\text { depleted } \mathrm{UO}_{2} \text { ) }\end{array}$ & $\begin{array}{l}\text { Mixed oxide } \\
\text { (initially } \\
\text { depleted } \mathrm{UO}_{2} \text { ) }\end{array}$ \\
\hline Fraction of T.D. 0.85 & 0.95 & 0.95 \\
\hline $\begin{array}{lr}\text { Coolant } & \\
\text { Volume fraction } & 0.50 \\
\text { Material } & \mathrm{Na}\end{array}$ & $\begin{array}{r}0.50 \\
\mathrm{Na}\end{array}$ & $\begin{array}{r}0.30 \\
\mathrm{Na}\end{array}$ \\
\hline $\begin{array}{ll}\text { Structure } & \\
\text { Volume fraction } & 0.20 \\
\text { Material } & 316 \text { SS }\end{array}$ & $\begin{array}{l}0.20 \\
316 \mathrm{SS}\end{array}$ & $\begin{array}{l}0.20 \\
316 \mathrm{SS}\end{array}$ \\
\hline \multicolumn{3}{|c|}{ Isotopic Compositions } \\
\hline $\mathrm{Pu}-239$ & $U-238$ & 0.9975 \\
\hline $\mathrm{Pu}-240$ & $U-239$ & 0.0025 \\
\hline $\mathrm{Pu}-241$ & & \\
\hline $\mathrm{Pu}-242$ & & \\
\hline
\end{tabular}

* The core volume of the parfait design includes the internal blanket region.

***k LWR discharge at $\sim 30,000 \mathrm{MWd} / \mathrm{T}$. 
to be the same. The requirement was also imposed that the core of the parfait configuration consist of only two types of fuel assemblies as is the case in the reference design. Imposing these constraints allowed this study to focus solely on the effects of the internal blanket.

\subsection{Neutronics}

The primary calculational tool used in comparing the reference and parfait configurations was the two-dimensional, diffusion theory code, $2 \mathrm{DB}(2)$. The cross section set used in these calculations was a four-group set, collapsed from a 26-group, modified Bondarenko set using the ANISN code (3). The neutron energy group structure is shown in Table 6.2.

TABLE 6.2

Neutron Energy Group Structure

\begin{tabular}{ccc}
\hline Group & $\begin{array}{c}\text { Upper Energy Limit } \\
(\mathrm{MeV})\end{array}$ & $\begin{array}{c}\text { Fraction of Fissile Neutrons } \\
\text { Born in Group }\end{array}$ \\
\hline 1 & 10.0 & 0.5894 \\
2 & 1.35 & 0.3948 \\
3 & 0.111 & 0.0141 \\
4 & 0.0248 & 0.0017 \\
\hline
\end{tabular}

The primary design variables in the evaluation of the parfait concept included the axial and radial extent of the internal blanket and its initial composition. In this study, the axial blankets and the internal blanket were both initially composed of depleted uranium oxide. The practical consideration of minimizing the number of different types of fuel pellets loaded in the core fuel assemblies dictates that the internal blanket pellets be identical to those of the axial blanket. It was also shown that the selection of depleted uranium oxide as the internal blanket material is consistent with the aim of maximizing the yield of bred fissile material. 
The primary criterion used in defining the axial and radial dimensions of the internal blanket was that the peak power density in the parfait configuration not exceed that in the reference reactor. This limit was imposed because of the strong influence of the power density (or equivalently, the linear power rating) upon the fuel pin centerline temperature. A configuration in which the internal blanket extended across both the inner and outer enrichment zones was investigated; however, it was found that the maximum power density of this design exceeded that of the reference reactor for a wide range of internal blanket thicknesses. The radial extent of the internal blanket was, therefore, required to be the same as that of the inner enrichment zone. This requirement meant that varying the radial extent of the internal blanket was accompanied by moving the boundary between the inner and outer core zone - a procedure which has a substantial effect on the flux and power distributions in the core. The most favorable radially-flattened power profiles for the parfait configuration were obtained when the inner core zone had roughly the same dimension as in the reference reactor. A small advantage in radial flux flattening and in the breeding ratio were realized by extending the inner zone of the parfait configuration to $100 \mathrm{~cm}$ as compared to $90 \mathrm{~cm}$ in the reference core. It should be noted that the radial extent of the inner core zone and the internal blanket is only discontinuously variable; it may only be increased or decreased by integral numbers of fuel assembly rows. The parfait configuration, however, offers considerable design flexibility because the axial and radial dimensions of the internal blanket may be varied simultaneously to achieve the desired power profile.

The axial extent, or thickness, of the internal blanket was treated as a continuously variable parameter because oxide pellets may be fabricated and assembled into any specified length. The effects of varying the thickness of the internal blanket were evaluated by comparing the cores shown in Fig. 6.2. The blankets of each configuration were loaded with a fissile content representative of the beginning of a cycle of equilibrium operation. The enrichments in the core zones were adjusted to obtain the minimum peak power density 

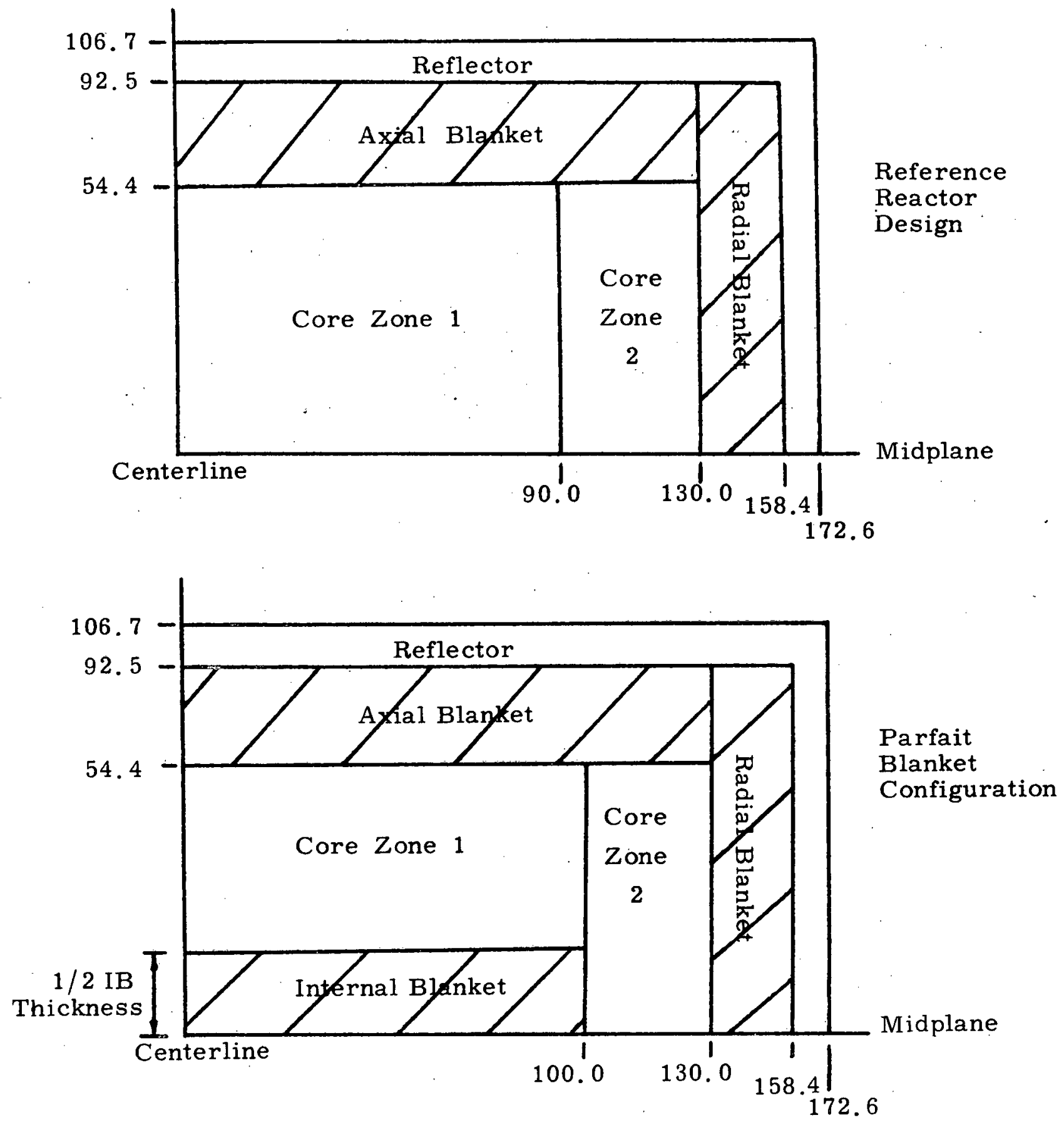

FIG. 6.2. Core Configurations for Evaluating the Effects of Internal Blanket Thickness 
throughout the burnup cycle and allow a reactivity-limited core lifetime of 300 full power days. The performance and design parameters of the parfait configuration are summarized in Table 6.3 as a function of internal blanket thickness.

The performance of the parfait configuration relative to the reference reactor is presented in Fig. 6.3, where the results are plotted as the ratio of the parameter for the parfait design to that of the reference system. Very briefly, this figure demonstrates the following characteristics of the parfait configuration:

1) The initial core fissile inventory increases monotonically as a function of internal blanket thickness.

2) The breeding ratio of the parfait configuration is slightly improved over that of the reference core. The maximum improvement of about $2 \%$ is diminished, however, as the internal blanket is made so thick that the fertile material at its center becomes less efficient at breeding.

3) The peak power density is reduced compared to the reference reactor. This is a result of axial and radial flux (and power) flattening which, in the case of the $50-\mathrm{cm}$ internal blanket, is so dramatic that even though $27 \%$ of the fissile-loaded volume of the core is replaced by blanket material, the parfait configuration is able to generate as much power as the reference reactor while operating within the same power density limit. The beginning of cycle (BOC) and end of cycle (EOC) axial and radial flux profiles of the reference reactor and a $30-\mathrm{cm}$ internal blanket parfait configuration are shown in Figs. 6.4 and 6.5. During irradiation the flux profiles of the parfait configuration become progressively more similar to those of the reference reactor.

4) The burnup reactivity loss of the best parfait configuration is $25 \%$ smaller than that of the reference reactor. This characteristic is a consequence of the enhanced breeding of fissile material in the high-worth central region of the reactor. 
TABLE 6. 3. Parfait System Performance as a Function of Internal Blanket Thickness

\begin{tabular}{|c|c|c|c|c|c|c|c|c|}
\hline $\begin{array}{l}\text { Internal } \\
\text { Blanket } \\
\text { Thickness } \\
\text { (cm) }\end{array}$ & $\begin{array}{l}\text { BOC } \\
\text { Core } \\
\text { Fissile } \\
\text { Inventory } \\
\quad(\mathrm{kg})\end{array}$ & $\frac{\Delta \mathrm{k}}{300 \text { days }}$ & $\begin{array}{c}\mathrm{BR} \\
(\mathrm{BOC})\end{array}$ & $\begin{array}{l}\text { Peak } \\
\text { Power } \\
\text { Density } \\
(\text { BOC) } \\
(\mathrm{MW} / \ell)\end{array}$ & $\begin{array}{l}\text { Peak } \\
\text { Flux }\left(\times 10^{-16}\right) \\
(\mathrm{BOC}) \\
\left(\mathrm{n} / \mathrm{cm}^{2} \mathrm{sec}\right)\end{array}$ & $\begin{array}{l}\text { Peak } \\
\text { Power } \\
\text { Density } \\
(150 \text { days }) \\
(\mathrm{MW} / \ell)\end{array}$ & $\begin{array}{l}\text { Peak } \\
\text { Flux }\left(\times 10^{-16}\right) \\
(150 \text { days }) \\
\left(\mathrm{n} / \mathrm{cm}^{2} \mathrm{sec}\right)\end{array}$ & $\epsilon_{2} / \epsilon_{1}^{*}$ \\
\hline 0 & 2065.02 & 0.052 & 1. 2291 & 0.600 & 0.929 & 0.573 & 0.946 & 1.327 \\
\hline 20 & $* *$ & 0.040 & 1. 2500 & 0.560 & 0.740 & 0.544 & 0.766 & 1.216 \\
\hline 30 & 2146.12 & 0.040 & 1.2500 & 0.570 & 0.676 & 0.536 & 0.696 & 1.150 \\
\hline 40 & $* *$ & 0.040 & 1.2500 & 0.573 & 0.626 & 0.537 & 0.648 & 1.074 \\
\hline 50 & 2187.30 & 0.044 & 1.2430 & 0.593 & 0.599 & 0.551 & 0.608 & 1.000 \\
\hline
\end{tabular}

* (Outer zone enrichment)/(Inner zone enrichment)

***ailed calculations not performed. 


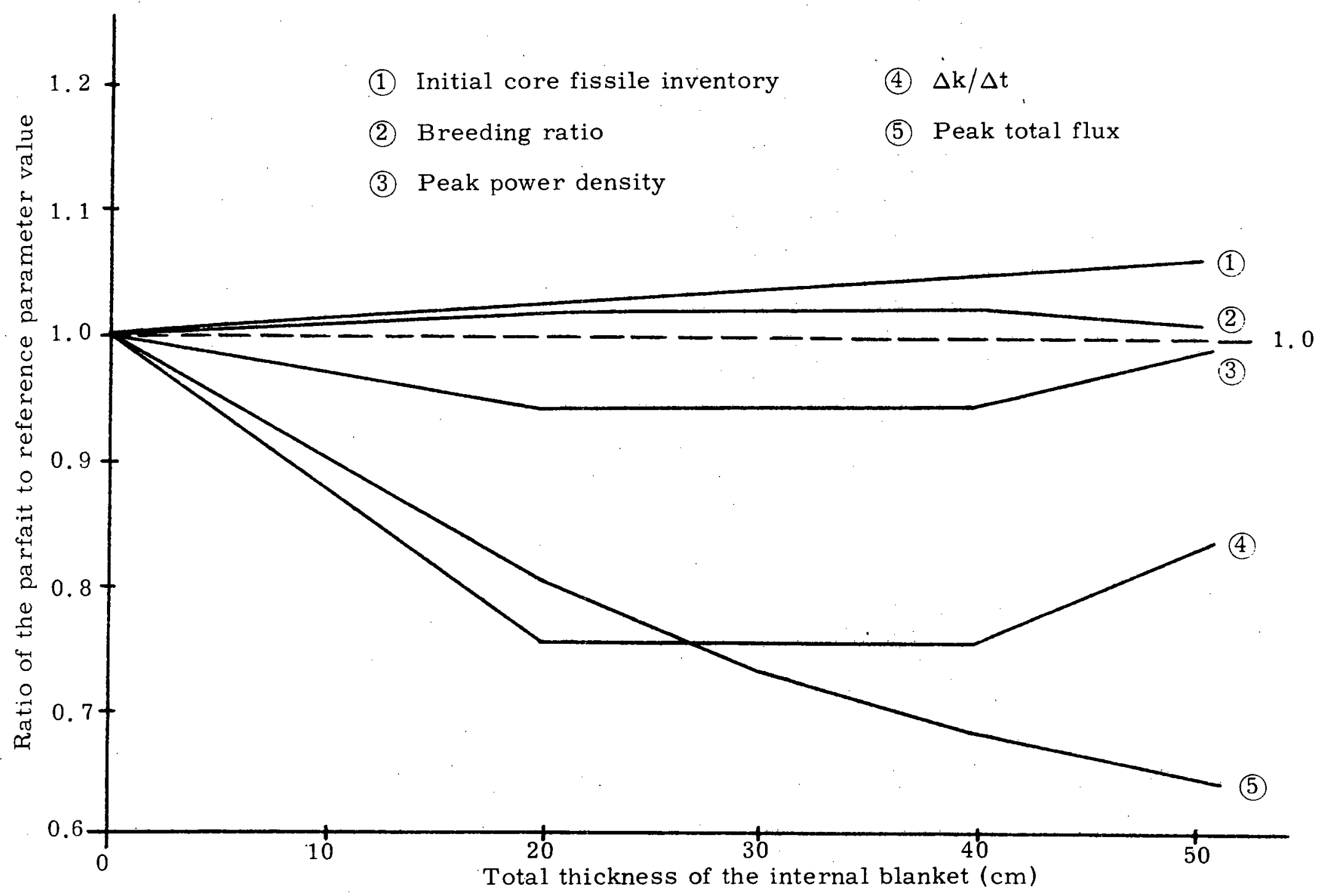

FIG. 6.3. Parfait Performance Relative to the Reference Core as a Function of Internal Blanket Thickness 


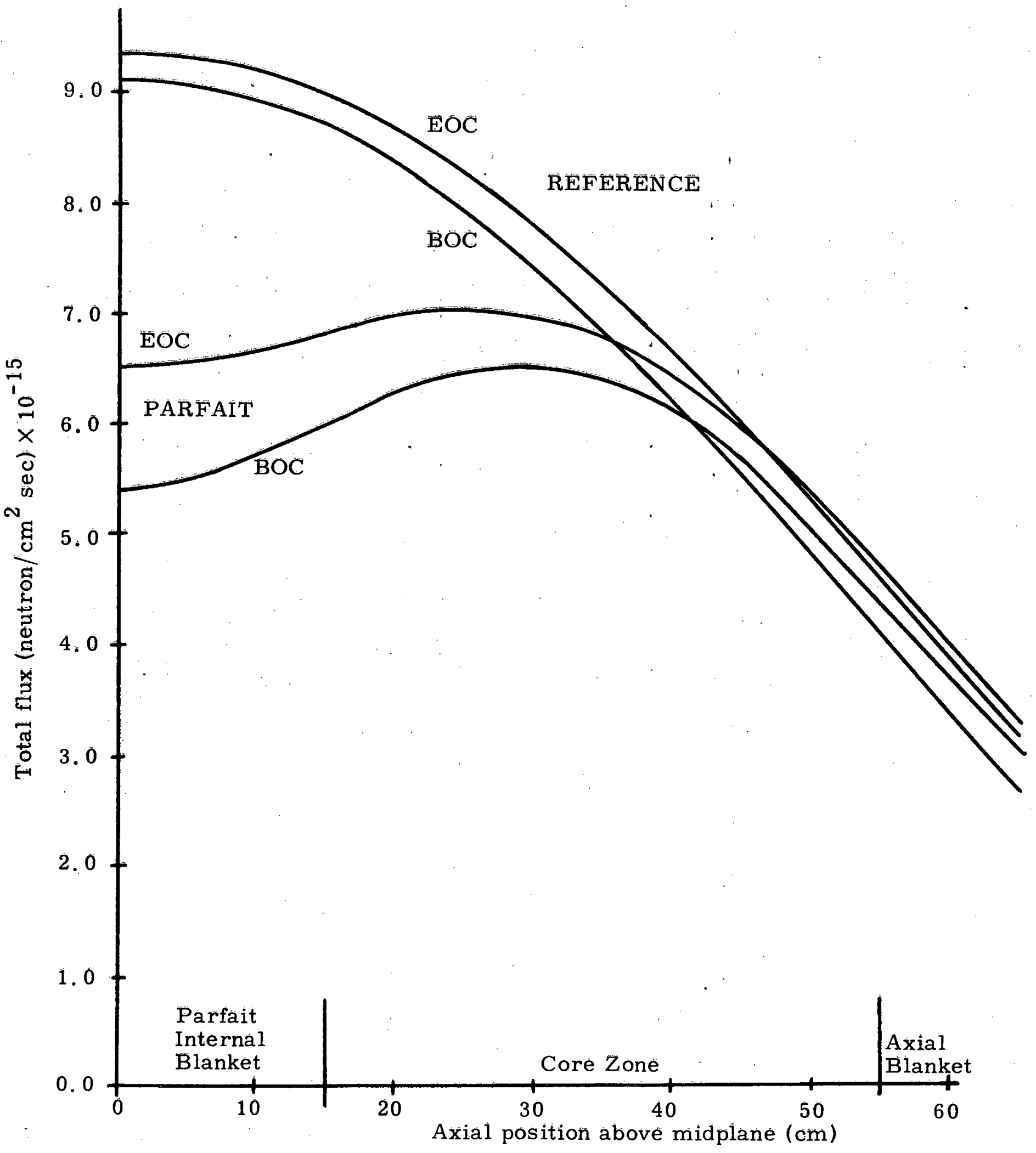

FIG. 6.4 Total Flux Along Core Centerline for Reference Core and $30-\mathrm{cm}$ Internal Blanket Parfait 


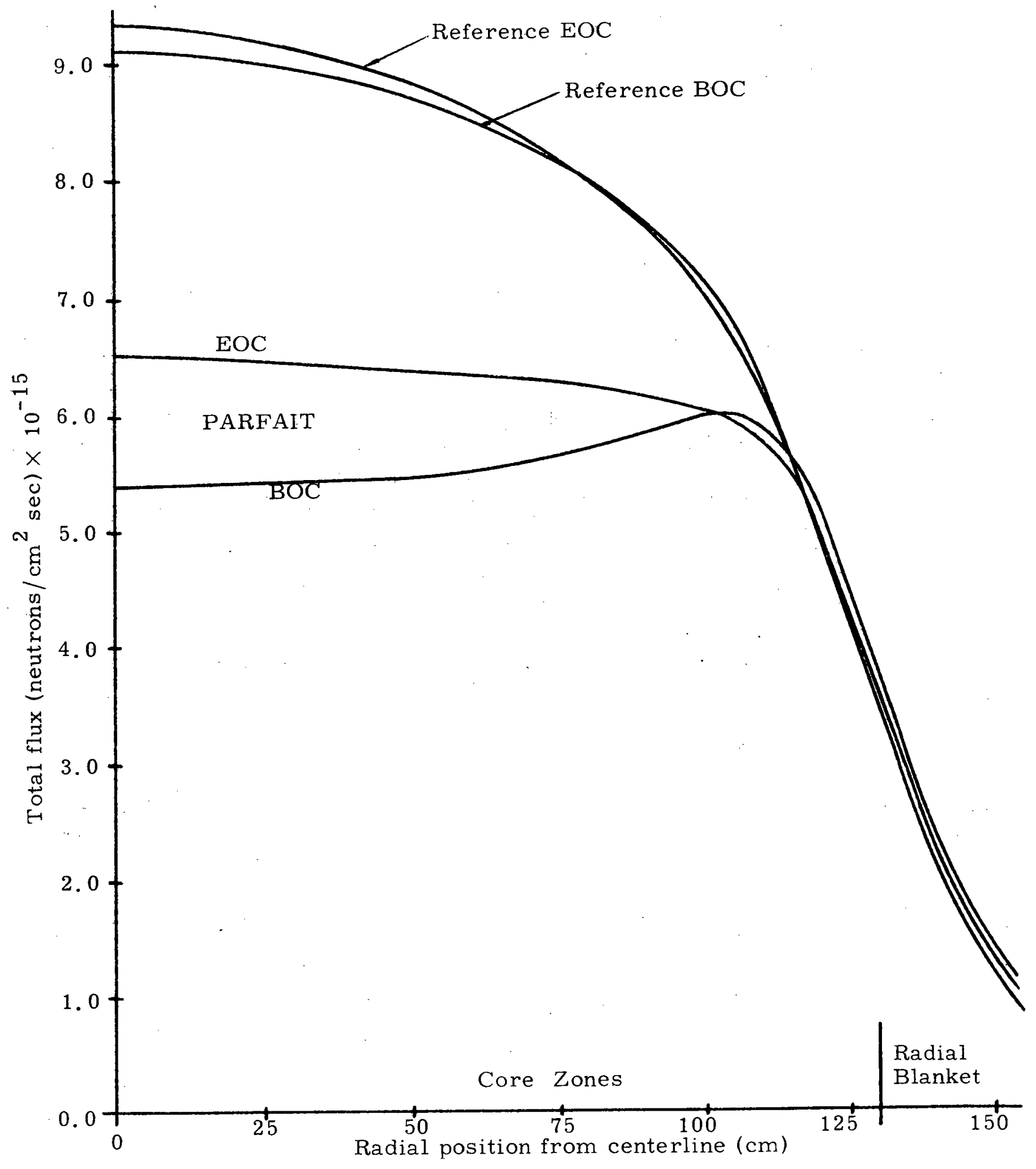

FIG. 6.5. Total Flux at Core Midplane for Reference Core and $30-\mathrm{cm}$ IB Parfait 
5) The ratio of the fissile enrichment in the outer core zone to that of the inner core zone decreases as the internal blanket thickness is increased. As indicated in Table 6.3, the enrichment for the two core zones was equal for the $50-\mathrm{cm}$ internal blanket parfait configuration.

6) The peak flux in the core decreases substantially with an increase in the internal blanket thickness. For a $30-\mathrm{cm}$ internal blanket, the peak flux is reduced by $27 \%$. A commercial LMFBR of the parfait design could thus be introduced which would experience a substantially reduced peak fluence and therefore require less of an extrapolation with regard to fluence effects than for the reference design.

Figure 6.3 also demonstrates that the attractive performance characteristics of the parfait configuration exhibit broad maxima and minima, thus affording the reactor designer considerable flexibility in varying the internal blanket thickness to achieve a specific core characteristic without sacrificing overall system performance.

Characteristics and advantages similar to those described above were also confirmed for parfait configurations of a demonstration size LMFBR (2510 liter core volume), a gas-cooled 1000-MWe reactor and a 1000-MWe carbide-fueled LMFBR.

The fuel volume fraction in the core is a design parameter which was identified as having a significant impact upon the performance of both the reference and parfait designs. Figure 6.6 illustrates this effect for two major performance characteristics, the breeding ratio and the burnup reactivity loss. This comparison was made for cores of equal volume and equal reactivity-limited lifetimes. Figure 6.6 demonstrates that the performance of both configurations improves as the fuel volume fraction increases and that the advantage enjoyed by the parfait configuration in both of these parameters is slightly diminished at the higher fuel volume fractions. A key point, however, as will be illustrated in later sections, is that the parfait configuration is more suited to a higher fuel volume fraction because of reduced fuel and metal swelling and reduced control rod requirements. 


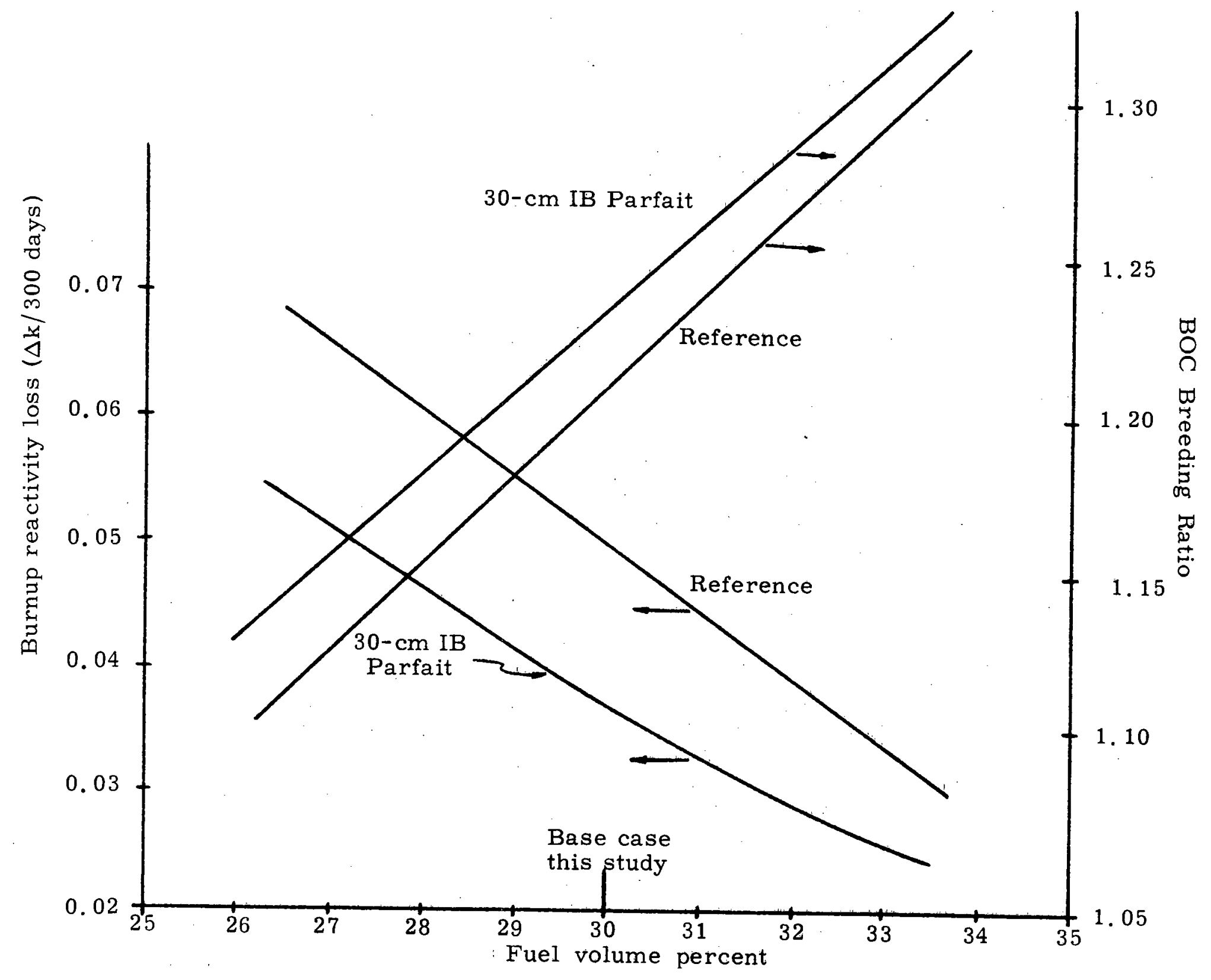

FIG. 6.6. Performance Sensitivity to Fuel Volume Percent in Core 
A comparison of the control requirements for both the reference and parfait configurations demonstrated that including an internal blanket in a fast reactor core introduces no unique control problems. The average worth per unit mass of control poison in both configurations is nearly equal. The only major difference between the control systems of the two designs is that the parfait configuration, with its reduced burnup reactivity swing, would require fewer and/or lower worth burnup control rods than the reference reactor. This would allow more fuel assemblies to be included in the parfait configuration, resulting in a further decrease in the average linear. power rating in the core and an increase in the core fuel volume fraction. Both changes enhance the performance of the parfait configuration relative to the reference core.

It was also shown in the evaluation of the control requirements for the parfait configuration that the interaction of the internal blanket and a control rod bank could cause a small axial flux tilt such that the local power density in the lower core volume could, at times during the burnup cycle, be as much as $4.5 \%$ higher than if the effect of the control rods had been neglected. In this calculation, the control rod bank was simulated as an annulus of control material. Since this distribution of control poison would spatially isolate the inner core zone more effectively than discrete control rods, it is believed that the magnitude of the power shift has been overestimated. In any event, the magnitude of the power shift could be reduced by employing appropriate control rod withdrawal patterns.

\subsection{Core Engineering}

The reference and parfait configurations were compared in the areas of thermal performance, materials' performance and core mechanical design. The parfait configuration evaluated had an internal blanket thickness of 30 centimeters. This configuration, as illustrated in Fig. 6.3, exhibited the most favorable performance characteristics identified for the parfait concept, including a significantly reduced peak total flux. 
The thermal analysis of the reference and parfait cores included a calculation of the mixed-mean core coolant outlet temperature. Fuel elements were treated as annular core and blanket regions and two different fixed coolant orificing schemes were employed. In one scheme, coolant flow was supplied such that the maximum coolant outlet temperature from each channel during irradiation was $1050^{\circ} \mathrm{F}$. In the other scheme, one coolant flow rate was supplied to each of the fuel annuli in an enrichment zone based on the coolant requirements of the highest powered assembly within the zone. The maximum coolant outlet temperature during the irradiation cycle was again fixed at $1050^{\circ} \mathrm{F}$. The mixed-mean core coolant outlet temperatures calculated using both orificing schemes demonstrated that the reference and parfait configurations perform very similarly and that for a realistic orificing scheme, the mixed-mean core coolant outlet temperatures for the two systems would be nearly identical.

The axial temperature profiles in the coolant, clad and fuel were also determined in this analysis. The maximum fuel centerline temperature in the reference configuration was slightly greater than that in the parfait core because of the slightly higher power density in the reference configuration as illustrated in Fig. 6.3. The fuel centerline temperature in the parfait configuration exhibits step changes in the core at the interfaces between the fissile-loaded region and the internal blanket. These power discontinuities produce axial temperature gradients that are very similar to those at the core-external axial blanket interface, and are not expected to lead to any fuel performance limitations. The parfait configuration actually exhibits a slight advantage over the reference configuration in that the average clad and coolant temperatures are lower in the important region above the core midplane.

Throughout this evaluation, the reference and parfait configurations have been compared on the basis of equal thermal output. The two configurations, however, operate at different peak power densities and therefore with different margins between normal full power operation and the overpower condition for which the hottest pins achieve centerline melting. This characteristic of the parfait concept's 
capabilities relative to the reference system was assessed by comparing the fraction of the core volume of each configuration in which fuel centerline melting occurs as a function of the overpower ratio. This analysis assumed a coolant flow such that each fuel annulus operated with a maximum coolant outlet temperature of $1050^{\circ} \mathrm{F}$. The results revealed that the reference reactor first experiences fuel melting for a $15 \%$ overpower condition. Fuel melting does not occur in the parfait configuration until $22 \%$ overpower is reached. The parfait configuration the refore enjoys a $7 \%$ greater overpower operating margin than the reference reactor. Or conversely, for equal operating margins, the parfait configuration is capable of generating $7 \%$ more power than the reference system.

The primary factor contributing to the greater operating margin for the parfait configuration is its reduced peak power density. This characteristic is also one of the factors contributing to a $7.6 \%$ smaller peak burnup in the parfait configuration. Since burnup has to correlate with fuel swelling (4), the parfait configuration also enjoys an added operating margin in this respect. Fuel swelling has been accommodated in fast reactor designs by reducing the asfabricated fuel density, and therefore the reduced fuel swelling in the parfait configuration may be viewed as a means of allowing a slight increase in the effective core fuel volume fraction. Alternatively, this characteristic could allow the parfait configuration the economic advantage of higher average fuel burnups.

The effects of metal swelling $(20 \%$ cold-worked, type 316 stainless steel) in the parfait configuration are also diminished because of the reduced fast flux $(\mathrm{E}>0.1 \mathrm{MeV})$ in the core. An estimate of the end-of-cycle (EOC) wrapper tube dilation due to metal swelling as a function of axial and radial position is presented in Fig. 6. 7. (This analysis neglected the effects of axial temperature variations along the wrapper tube which, if considered, would have the effect of moving the location of peak dilation slightly above the core midplane.) The peak wrapper tube dilation in the parfait configuration is $37 \%$ smaller than in the reference system. The parfait core may therefore be made more compact and have a higher fuel volume fraction. 


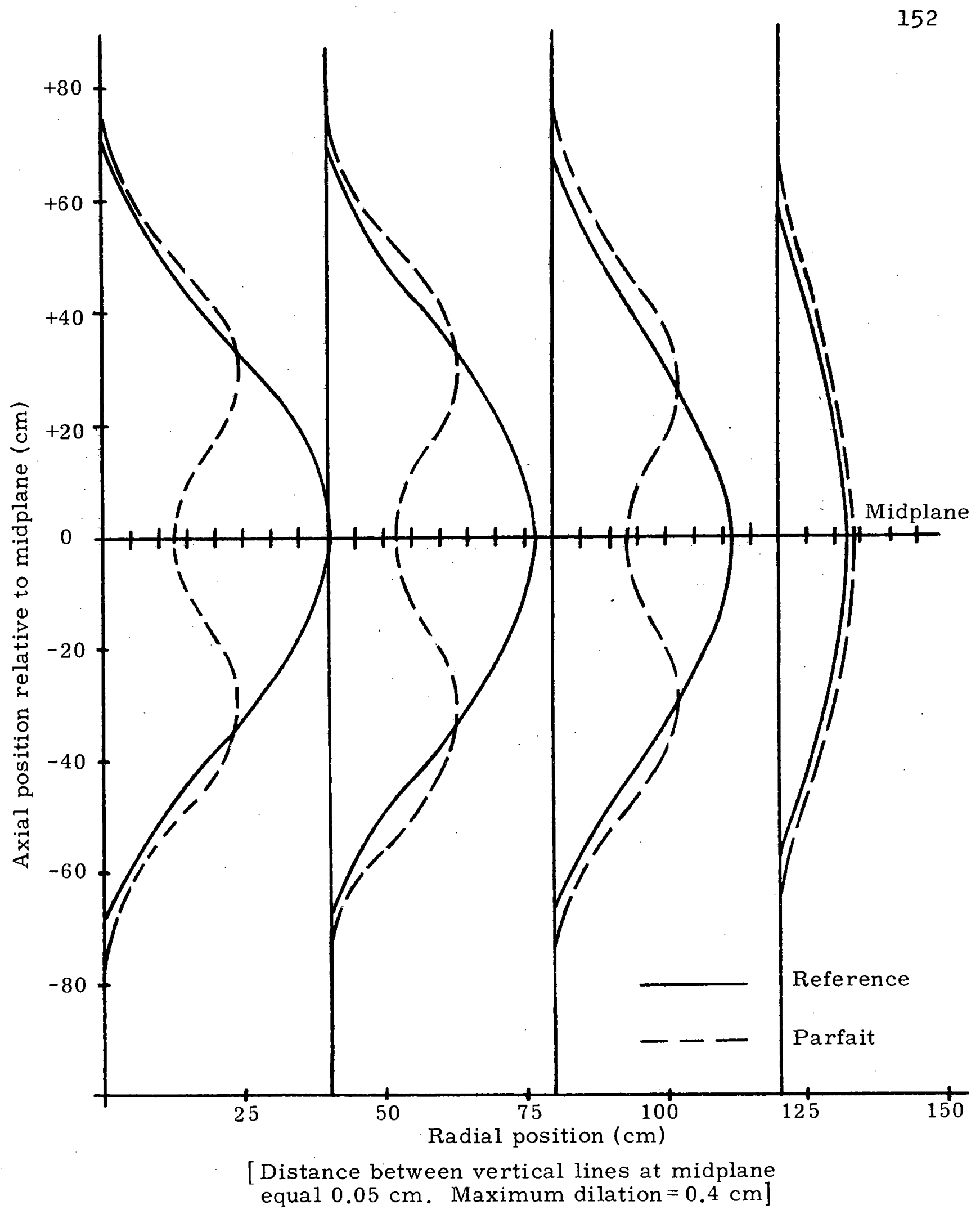

FIG. 6.7 EOC Wrapper Tube Dilation Due to Swelling 
Elongation of the wrapper tubes is another manifestation of metal swelling which is reduced in the parfait configuration because of the reduced fast flux. Figure 6.8 presents an estimate of the EOC wrapper tube elongation in the reference and parfait configurations. This figure clearly demonstrates the reduced peak elongation in the parfait core. In addition, this figure illustrates that the radial gradient in the wrapper tube elongation, the cause of fuel element bowing, is significantly reduced in the inner core zone of the parfait configuration. The analysis which produced these results neglected the effect of temperature differences between opposite faces of the wrapper tube. These temperature differences arise from radial power gradients in the core and including their effect would improve the relative advantage for the parfait configuration.

\subsection{Safety Considerations}

The response of the reference and parfait configurations to changes in core characteristics which are not encountered in normal full-power operation were calculated with particular emphasis given to those nuclear parameters which influence safety, including the delayed neutron fraction, the prompt neutron lifetime, the partial and complete coolant voiding coefficients, the isothermal Doppler coefficient and the power Doppler coefficient. In the analysis described here, as with all of the other calculations of this evaluation, it is the consistently calculated relative values of these parameters which are of most interest in assessing the potential of the parfait concept. This is particularly true of these safety-related parameters. For example, the calculational uncertainty on an absolute basis has been estimated to be $\pm 15 \%$ in the Doppler coefficient and $\pm 1.5 \$$ in the sodium void reactivity (ㅁ): discrepancies which are sufficiently large to mask the small differences calculated here.

Table 6.4 summarizes the results of these calculations for the reference and parfait configurations.

The power Doppler coefficient, reflecting the reactivity effect of a change in the system power, is the primary mechanism for terminating a power excursion in fast reactors. The magnitude of this 


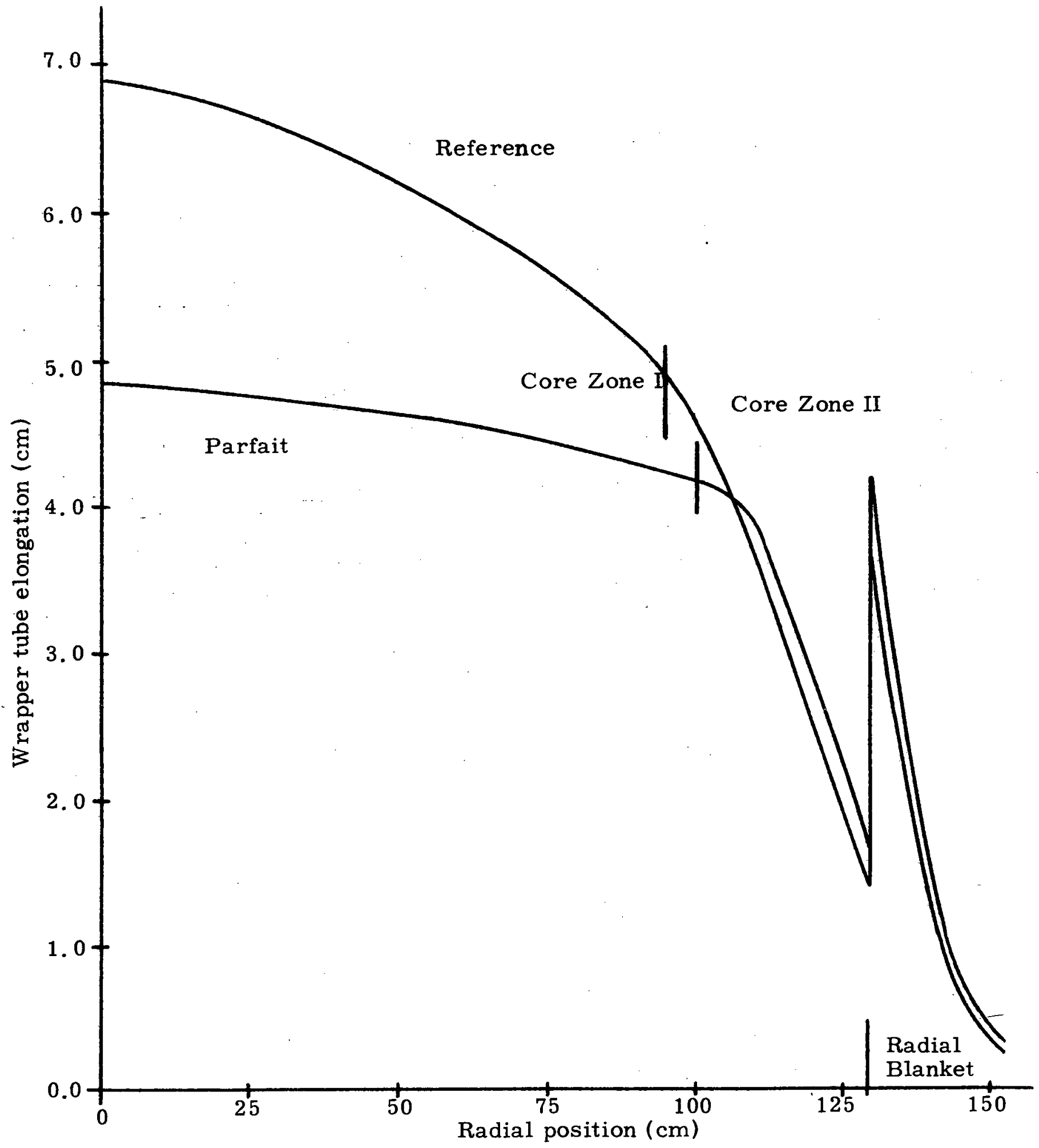

FIG. 6.8. EOC Wrapper Tube Elongation Due to Swelling 
TABLE 6.4

Comparison of Safety-Related Nuclear Parameters of the Reference and Parfait Configurations

\begin{tabular}{|c|c|c|c|}
\hline Parameter & Reference & Parfait & $\begin{array}{c}\text { Ratio } \\
\text { Parfait/Reference } \\
\end{array}$ \\
\hline Delayed neutron fraction & 0.00416 & 0.00412 & 0.990 \\
\hline Prompt neutron lifetime (sec) & $2.98 \times 10^{-7}$ & $2.90 \times 10^{-7}$ & 0.973 \\
\hline $\begin{array}{l}\text { Inner core zone sodium void } \\
\text { reactivity effect }(\$)\end{array}$ & +1.82 & +1.22 & 0.670 \\
\hline $\begin{array}{l}\text { Is othermal Doppler coefficient, } \\
\qquad \frac{1}{\mathrm{k}} \frac{\Delta \mathrm{k}}{\Delta \mathrm{T}}\left({ }^{\circ} \mathrm{K}^{-1}\right)\end{array}$ & $2.19 \times 10^{-5}$ & $2.27 \times 10^{-5}$ & 1.036 \\
\hline $\begin{array}{l}\text { Power Doppler coefficient } \\
\left(c / \mathrm{MW}_{t}\right)\end{array}$ & -0.039 & -0.036 & 0.923 \\
\hline
\end{tabular}


coefficient is $8 \%$ smaller in the parfait configuration; however, this apparently unfavorable characteristic is, in some sense, offset by a substantially reduced sodium void reactivity effect. Voiding of sodium from the internal blanket of the parfait configuration was. found to contribute a smaller positive reactivity increment than voiding a comparable region in the reference core. The complete and partial voiding of the core zones (and internal blanket) of each configuration was found to result in a positive reactivity insertion that was, on the average, about $25 \%$ smaller in the parfait configuration.

A calculation of the reactivity losses during reactor startup was performed by making use of the reactivity coefficients mentioned above. The calculation revealed that the reference and parfait configurations experience equal reactivity losses in going from cold startup to hotfull-power conditions.

\section{5. Feasibility and Economics}

In addition to allowing a ready comparison between the reference and parfait configurations, the constraints imposed in defining the scope of this evaluation guaranteed the technical feasibility of the parfait concept. The parfait concept uses the same core materials and the same basic fuel element design as the reference reactor. As related in the previous sections, there are no apparent obstacles to the operation of a fast reactor with an internal blanket. The same appears to be true for the pre-irradiation and post-irradiation steps in the fuel cycle. A detailed evaluation of the fuel fabrication process was carried out based on reference 6 which indicated that including an internal blanket region in one half of the fuel assemblies of a core would have a negligible effect on the core fabrication costs. It was also found that enrichment scanning techniques already exist (7) which may be used to quality-assure the distribution of fissile material in individual fuel rods. The parfait configuration may also make use of all of the fuel management schemes applicable to the reference reactor including intra-zone fuel element shuffling and/or rotation. 
The flatter radial power profile in the inner core zone of the parfait configuration, however, lessens the need to employ such schemes. And finally, the current plans call for the reprocessing of axial blanket material and core material as a mixed batch ( $\underline{8})$, and therefore the operation of a fast reactor with fuel containing an internal blanket introduces no unique fuel reprocessing problems.

The economic performance of the reference and parfait configurations were compared on the basis of equilibrium fuel cycle costs for several variations in financing charges, fabrication costs and fuel volume fractions. The fast reactor fuel cycle cost code, BRECON $(\underline{9}, 10)$, was used in this analysis. This code employs the cash flow method for calculating fuel cycle costs; a unit energy cost (mills/kwhr $\mathrm{e}_{\mathrm{e}}$ ) is determined such that revenues from the sale of electricity generated in a cycle offset all net, direct and indirect fuel cycle expenses incurred in the cycle. Beginning and end-of-cycle fissile and fertile material inventories required in BRECON were generated in burnup calculations using the 2DB code. Core fuel elements were assumed to have a two-year (two-cycle) residence time in the core and radial blanket assemblies a four-year residence time, and all blanket regions were loaded with fissile concentrations characteristic of equilibrium operation. The fuel cycle costs by region and by item are presented in Table 6.5 for the base case ( $30 \mathrm{v} / 0$ fuel in core) for the reference reactor and two parfait configurations. Total fuel cycle costs as a function of core fuel volume percent for these configurations are shown in Fig. 6.9.

These curves demonstrate that the reference reactor and the $30-$ $\mathrm{cm}$ internal blanket configuration have essentially equal fuel cycle costs for the base case. Throughout the range of fuel volume fractions investigated, the fuel cycle costs differ by at most $0.05 \mathrm{mills} / \mathrm{kwhr}_{\mathrm{e}}$, or the equivalent of $\$ 360,000 / \mathrm{yr}$. There are, however, several characteristics of the parfait configuration which will enhance its economic performance relative to the reference reactor. The analysis which produced the above results assumed equal unit fabrication costs $(\$ 314 / \mathrm{kgHM})$ for the core regions and the internal blanket. If, on the other hand, fabrication costs for the internal blanket are equal to those 
TABLE 6.5

Equilibrium Fuel Cycle Cost Contributions by Region

(Base Case: $30 \mathrm{v} / 0$ Fuel in Core)

\begin{tabular}{|c|c|c|c|}
\hline & \multicolumn{3}{|c|}{ Cost Contribution, mills/kwhr } \\
\hline & Reference & $\begin{array}{c}30-\mathrm{cm} \text { IB } \\
\text { Parfait }\end{array}$ & $\begin{array}{c}50-\mathrm{cm} \text { IB } \\
\text { Parfait } \\
\end{array}$ \\
\hline \multicolumn{4}{|l|}{ Core } \\
\hline $\begin{array}{l}\text { Direct burnup } \\
\text { Inventory carrying charges } \\
\text { Direct fabrication } \\
\text { Fabrication carrying charges } \\
\text { Net reprocessing charges }\end{array}$ & $\begin{array}{l}0.1964 \\
0.6568 \\
0.3093 \\
0.0990 \\
0.0456 \\
\end{array}$ & $\begin{array}{l}0.3385 \\
0.6687 \\
0.2533 \\
0.0810 \\
0.0373 \\
\end{array}$ & $\begin{array}{l}0.4144 \\
0.6804 \\
0.2210 \\
0.0706 \\
0.0326 \\
\end{array}$ \\
\hline Subtota1 & 1.3071 & 1.3788 & 1.4190 \\
\hline \multicolumn{4}{|l|}{ Internal Blanket } \\
\hline $\begin{array}{l}\text { Net material credit } \\
\text { Net reprocessing charges } \\
\text { Direct fabrication } \\
\text { Fabrication carrying charges }\end{array}$ & $\begin{array}{l}- \\
- \\
-\end{array}$ & $\begin{array}{r}-0.1092 \\
0.0083 \\
0.0560 \\
0.0180 \\
\end{array}$ & $\begin{array}{r}-0.1556 \\
0.0130 \\
0.0883 \\
0.0284 \\
\end{array}$ \\
\hline Subtotal & & -0.0269 & -0.0259 \\
\hline \multicolumn{4}{|l|}{ Axial Blanket } \\
\hline $\begin{array}{l}\text { Net material credit } \\
\text { Net reprocessing charges } \\
\text { Direct fabrication } \\
\text { Fabrication carrying charges }\end{array}$ & $\begin{array}{r}-0.1873 \\
0.0356 \\
0.0616 \\
0.0196 \\
\end{array}$ & $\begin{array}{r}-0.2052 \\
0.0356 \\
0.0616 \\
0.0196 \\
\end{array}$ & $\begin{array}{r}-0.2113 \\
0.0356 \\
0.0616 \\
0.0196 \\
\end{array}$ \\
\hline Subtotal & -0.0705 & -0.0884 & -0.0945 \\
\hline \multicolumn{4}{|l|}{ Radial Blanket } \\
\hline $\begin{array}{l}\text { Net material credit } \\
\text { Net reprocessing charges } \\
\text { Direct fabrication } \\
\text { Fabrication carrying charges }\end{array}$ & $\begin{array}{r}-0.2120 \\
0.0349 \\
0.0520 \\
0.0333 \\
\end{array}$ & $\begin{array}{r}-0.2338 \\
0.0349 \\
0.0520 \\
0.0333 \\
\end{array}$ & $\begin{array}{r}-0.2420 \\
0.0349 \\
0.0520 \\
0.0333 \\
\end{array}$ \\
\hline Subtotal & -0.0918 & -0.1136 & -0.1218 \\
\hline Total Expenses & 1.5441 & 1.6981 & 1.7857 \\
\hline Total Material Credits & -0.3993 & -0.5482 & -0.6089 \\
\hline TOTAL FUEL CYCLE COSTS & 1. 1448 & 1. 1499 & 1.1768 \\
\hline
\end{tabular}




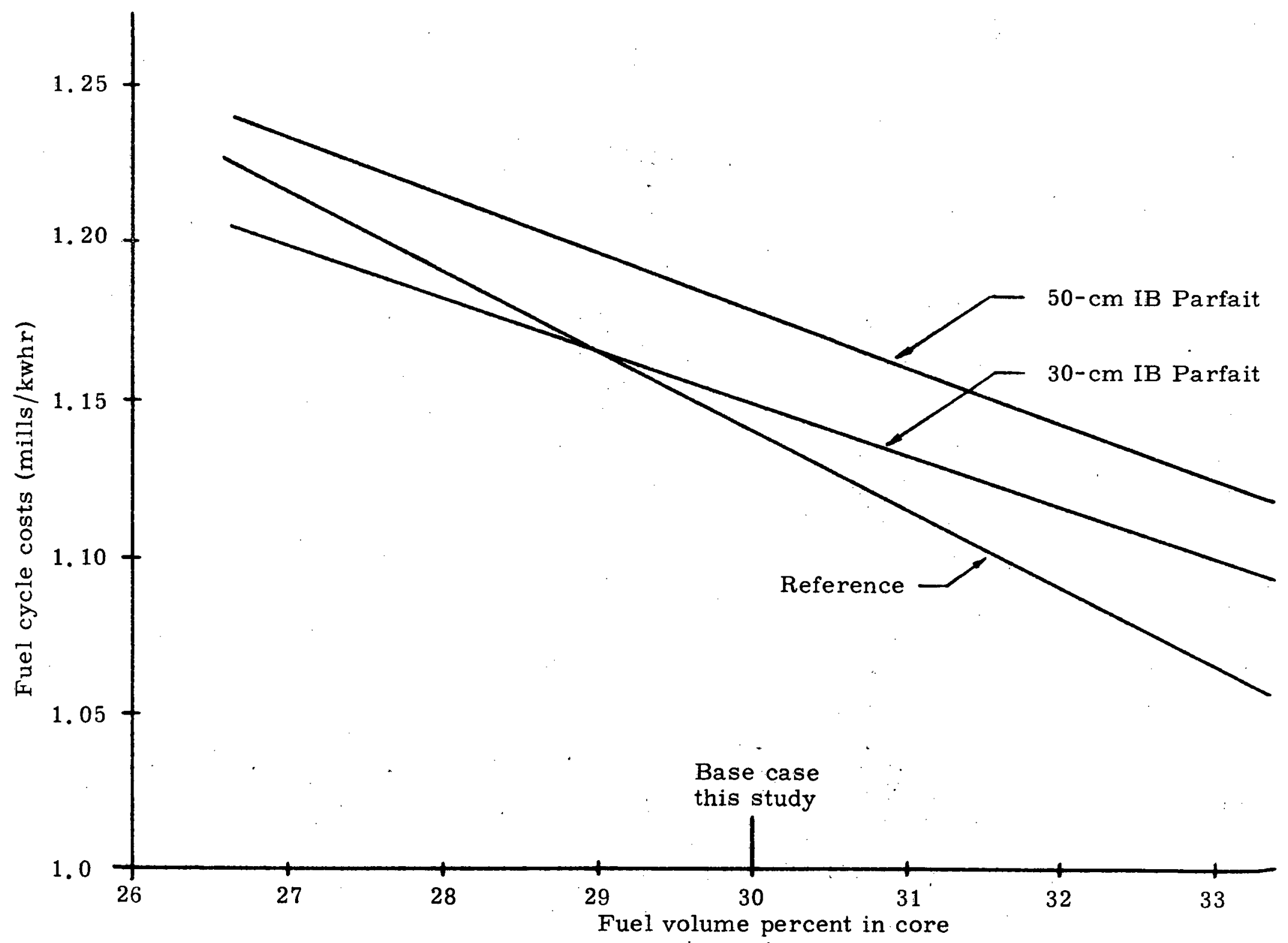

FIG. 6.9. Fuel Cycle Costs as a Function of Fuel Volume Percent (Fabrication Charges for All Cores Normalized to the Reference Core with $30 \mathrm{v} / 0$ Fuel in Core) 
estimated for the axial blanket, $\$ 80 / \mathrm{kgHM}$, the curve for the $30-\mathrm{cm} \mathrm{IB}$ parfait configuration in Fig. 6.9 is displaced downward by $0.055 \mathrm{mills} / \mathrm{kwhr}_{\mathrm{e}}$ and the curve for the $50-\mathrm{cm}$ IB parfait configuration is displaced downward by $0.075 \mathrm{mills} / \mathrm{kwhr}_{\mathrm{e}}$. In addition, the capability of employing higher core fuel volume fractions in the parfait designs as the result of reduced fuel swelling, reduced metal swelling and reduced control rod requirements would further enhance the economic performance of the parfait concepts.

\section{6 Conclusions and Recommendations}

The design and performance characteristics of the parfait blanket concept are summarized in Table 6.6. The advantageous characteristics of the parfait blanket concept may be exploited in a variety of ways. For example, the decreased peak power density relative to the reference reactor may be viewed as a means of providing an extra overpower operating margin, a means of obtaining a higher thermal power output or a means of reducing the fissile-loaded core volume. Such changes, however, affect the design of the entire reactor. In the present work, the evaluation of the parfait system was carried out under a strict set of conditions which, in effect, assured that the parfait design could be employed as a replacement core in a system designed to accommodate a conventional core. Although indicating that the parfait concept is a superior replacement, the present results do not fully exploit the advantages of the concept. Therefore, the principal recommendation of this report is that the parfait blanket concept be subjected to a complete core design in which the arbitrary constraints on parameters such as the dimensions of the core and external blankets are removed. Particular attention should be given to full exploitation of the reduced fuel and metal swelling potential of the parfait concept. In addition to this major effort, a number of minor refinements should be incorporated: the effect of gamma heating in the internal blanket should be included, and the radiation dose to core externals should be evaluated. The parfait concept should also be examined to determine its susceptibility to and behavior during hypothetical core disruptive accidents relative to conventional core designs . 


\author{
TABLE 6.6 \\ Summary Evaluation of the $30-\mathrm{cm}$ IB \\ Parfait Blanket Configuration Relative \\ to the Reference Reactor
}

Advantages

Increased breeding ratio $(2 \%)$

Decreased doubling time (10\%)

Decreased peak fast flux (25.5\%)

Decreased wrapper tube elongation (29\%)

Decreased wrapper tube dilation (37.5\%)

Decreased burnup reactivity swing (25\%)

Fewer control rods in core

More fuel assemblies in core

Reduced losses of neutrons to control poisons

Decreased peak power density (5\%)

Decreased peak fuel burnup (7.6\%)

Decreased fuel swelling

Increased overpower operating margin

Flatter radial flux and power profiles in the inner core zone

Decreased thermal bowing

Decreased fluence-induced bowing

More favorable sodium void characteristics

Potential for higher core fuel volume fraction

\title{
Disadvantages
}

Increased core fissile inventory ( $3.9 \%)$

Reduced power Doppler coefficient ( $8 \%)$

Higher peak clad temperature $\left(17^{\circ} \mathrm{F}\right)$ 
In conclusion, the parfait blanket concept offers sufficient prospects for improved fast breeder reactor performance and reduced power costs to merit its consideration as the reference design for future liquid-metal cooled fast breeder reactors.

\subsection{References}

(1) Argonne National Laboratory, Evaluation Report - 1000-MWe LMFBR Follow-On Studies, Volume I - Summary, Volume IIPlant Design Part I, Draft, January 16, 1970.

(2) Little, W.W., Jr., and Hardie, R.W., 2DB User's Manual Revision 1, BNWL-831 Rev. 1, August 1969 .

(3) Engle, W.W. , Jr., "A User's Manual for ANISN, A OneDimensional Discrete Ordinates Transport Code with Anisotropic Scattering," K-1693, March 1967.

(4) Boltax, A., et al., "Mixed-Oxide Fuel Pin Performance Analysis Using the OLYMPUS Computer Code," Conference on Fast Reactor Fuel Element Technology, ANS Proceedings, 1971.

(5) Greebler, P. and Hutchins, B. A., "Significance of Integral Parameters in the Design and Performance of Fast Breeder Reactors," National Topical Meeting on New Developments in Reactor Physics and Shielding, CONF-720901, Kiamesha Lake, New York, 1972.

(6) Burnham, J.B., et al. , "Comparative Costs of Oxide Fuel Elements, Volume I," BNWL-273 Vol. 1, Battelle Northwest Laboratory, July 1966.

(7) Forster, R.A., et al. , "252 Cf Assay System for FBR Fuel Pins: Description and Operating Procedures Manual," LA-5071-M, October 1972.

(8) McVey, W.H., Personal communication, December 14, 1973.

(9) Brewer, S.T., et al. , "The Economics of Fuel Depletion in Fast Breeder Reactor Blankets," MITNE-123, COO-3060-4, November 1972 .

(10) Wood, P.J. and Driscoll, M.J., "Assessment of Thorium Blankets for Fast Breeder Reactors," COO-2250-2, MITNE-148, July 1973 . 


\section{GAMMA HEATING MEASUREMENTS}

\subsection{Introduction}

Gamma heating is an important contributor to local energy deposition rates in the blanket region of fast breeder reactors, equaling and even exceeding fission energy contributions near the beginning of life (1). During the past year, work has been initiated on the blanket project to measure gamma heating traverses and to compare the results with state-of-the-art calculations.

\subsection{Calculations}

A 40-group coupled neutron (18-groups) and gamma (22-groups) cross section set was obtained from ORNL (ㅁ) and used in the ANISN program to perform gamma transport calculations for LMFBRs and the MIT Blanket Test Facility. Figure 7.1 compares the ratio of gamma to neutron fluxes in blanket and reflector regions driven by a representative LMFBR core (in cylindrical geometry) and by the BTF converter (slab geometry). As can be seen, the blanket mockup simulates the complete reactor quite well, which justifies its use for benchmark studies of FBR gamma heating. This was not unexpected, since neutron absorptions in blanket fuel are the source of over $90 \%$ of the blanket gamma flux, and we have previously shown that the MIT blanket mockups correctly simulate LMFBR neutronics both on a homogeneous and a heterogeneous scale.

During the coming year, a critical evaluation of the cross sections and the required level of sophistication employed in the calculations will be made and a final set of gamma heating traverses calculated for comparison with the experimental determinations. 


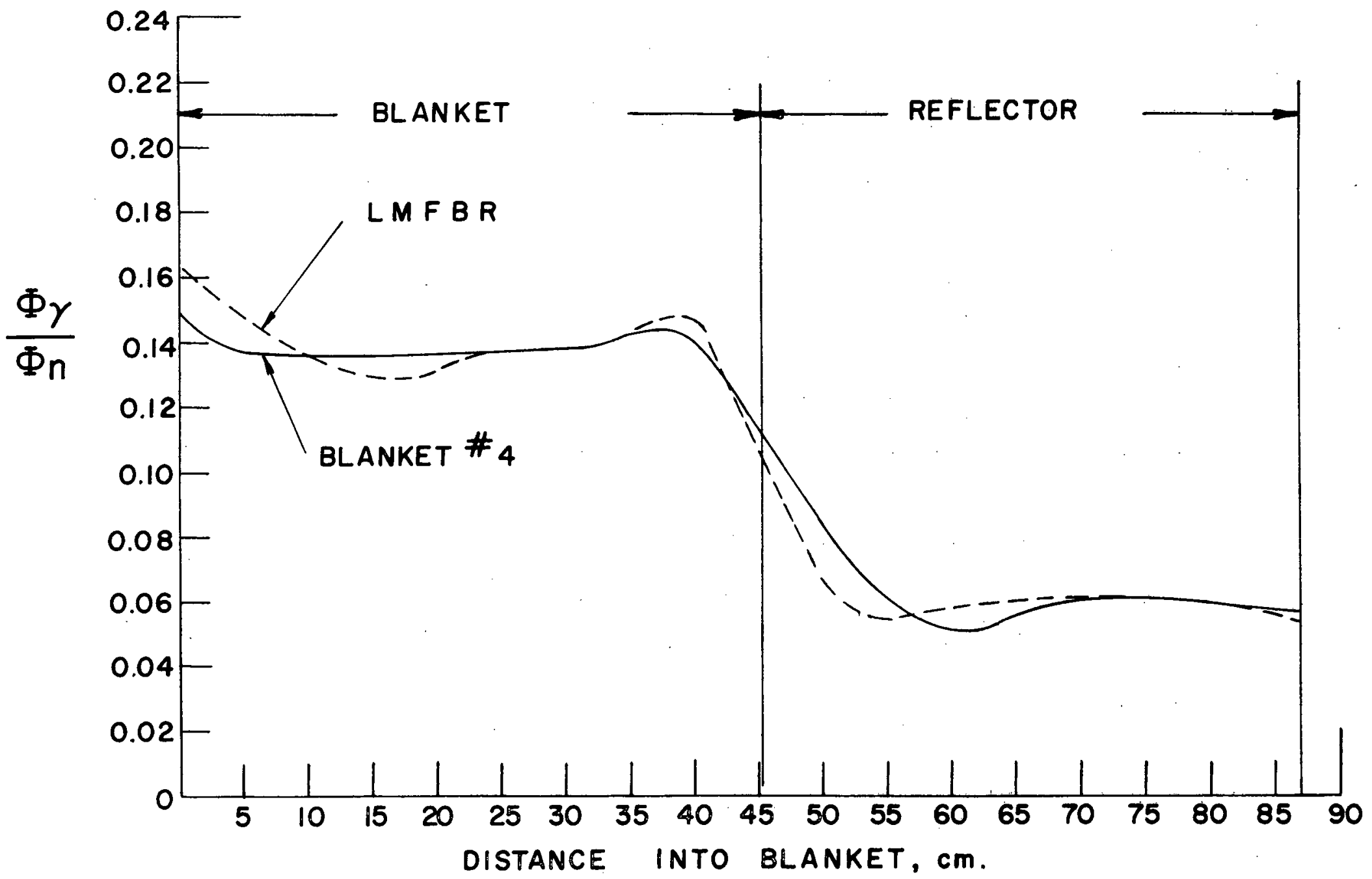

FIG.7.1 RATIO OF GAMMA TO NEUTRON FLUX IN

홍 BLANKET AND REFLECTOR 


\section{3 Experimental Methods}

Work has just lately been initiated to acquire a state-of-the-art capability for gamma heating measurements. Three dosimeters have been selected for use and intercomparison: thermoluminescent dosimeters (TLD), miniature ion chamber/dosimeters (ICD), and radiophotoluminescent dosimeters (RPL). Development of the latter two has been deferred until next year; to date we have concentrated on tooling up for the TLD method, which is the current consensus choice for measurements of this type (3). A batch of Li-7 fluoride dosimeters has been obtained and arrangements made with the Massachusetts General Hospital to use their Co-60 calibration source and TLD readout instrumentation.

The following preliminary results have been obtained:

(a) TLD measurements in the BTF have been shown to be feasible: the dose rate in the first blanket row is about $100 \mathrm{R} / \mathrm{hr}$ with the MITR at full power.

(b) The transverse gamma buckling has been measured and found to be the same as that for the neutrons. This justifies use of onedimensional calculations for the heating traverses. Furthermore, large variations in the transverse buckling (e.g., decreasing it to zero) did not significantly affect the axial/radial traverse calculations.

Future work is planned in the following areas:

(a) TLD traverses through the blanket and reflector using three different sleeve materials encapsulating the TLD: stainless steel, lead (simulating $\mathrm{UO}_{2}$ ) and aluminum (simulating sodium). Use of these data, together with the RESPOND program ( $\underline{4})$, will permit measurement of gamma heating rates in all important blanket constituents.

(b) A variety of different sleeve materials will be used with a set of TLDs at the blanket center, and an attempt made to unfold a gamma spectrum -- analogous to the use of foil methods for neutron spectrometry. 
(c) RPL and ICD dosimeters will be used to check the stainless steel sheathed TLD measurements.

(d) An in-house gamma calibration facility for TLDs will be constructed.

It is expected that this work can be completed in the coming year, reported in a topical report and summarized in the 1974 Annual Report.

\section{4 References}

(1) P.J. Wood and M.J. Driscoll, "Assessment of Thorium Blanketsfor Fast Breeder Reactors," COO-2250-2, MITNE-148, July 1973.

(2) G.W. Morrison et a1. , "A Coupled Neutron and Gamma Ray Multigroup Cross Section Library for Use in Shielding Ca1culations," Trans. Am. Nuc. Soc., Vol. 15, No. 1, p. 535, June 1972 .

(3) G.G. Simons and T.S. Huntsman, "Evaluation of ${ }^{7} \mathrm{LiF}$ Thermoluminescent Dosimeters for Gamma Ray Dose Measurements in ZPPR," Argonne National Laboratory, ZPR-TM-68, July 27, 1973.

(4) R.J. Tuttle, "Measurements of Gamma-Ray Heating by Thermoluminescent Dosimeters," Atomics International/ North American Rockwell, TI-707-140-022, May 5, 1972. 


\section{PARAMETRIC STUDIES}

\subsection{Introduction}

A considerable number of parametric and sensitivity studies, and methods development evaluations, both analytic and experimental have been done in support of the main stream of the research. They will be discussed in the present chapter under the following headings:

(a) The effect of errors in group elastic downscatter cross sections on blanket spectra.

(b) Calculation of threshold detector traverses in the reflector region.

(c) Calculation of future blanket configurations.

(d) Development of a $1 / \mathrm{E}$ spectrum calibration facility.

(e) Application of fission track counting methods.

(f) The effect of $\mathrm{H}_{2} \mathrm{O}$ contamination on blanket experiments.

(g) Investigation of the effect of core size on radial blanket performance.

\subsection{Elastic Group-Transfer Cross Sections}

It is well known that the shape assumed for the intra-group neutron spectrum can have an important effect on the elastic downscatter cross section, and that the effect becomes more pronounced as group width increases. In the ABBN or "Russian" type sets, a constant flux per unit lethargy weighting is generally employed. To determine what effect this might have on blanket calculations, a set of comparative calculations were performed using a 26-group and a 106-group cross section set (1). The 106-group set was prepared by splitting each of the lower 16-groups of the 26-group set into six fine groups. The group transfer cross sections were modified according to the following prescriptions: 


$$
\begin{array}{ll}
\text { Selfs catter: } & \sigma_{\mathrm{g} \rightarrow \mathrm{g}}^{*}=\sigma_{\mathrm{g} \rightarrow \mathrm{g}}+\sigma_{(\mathrm{g}-1) \rightarrow \mathrm{g}}(1-\mathrm{x}) \\
\text { Downs catter: } & \sigma^{* *}(\mathrm{~g}-1) \rightarrow \mathrm{g} \\
& =\mathrm{x} \cdot \sigma_{(\mathrm{g}-1) \rightarrow \mathrm{g}} .
\end{array}
$$

where $\mathbf{x}=$ number of fine groups per coarse group (six in the present instance)

$\sigma=$ transfer cross section in the coarse (26) group set

$\sigma *=$ transfer cross section in the fine (106) group set

(same for all $\mathrm{x}$ fine groups into which a given coarse group is split).

The downscatter cross section from the lowest unmodified coarse group to the first fine group was kept the same as in the 26-group set, since the new fine groups were still wide enough to exceed the lethargy gain per collision, $\xi$, of the lightest major constituent in the blanket.

Figure 8.1 compares the 26-group and 106-group neutron spectra calculated at the center of Blanket Mockup No. 4. The strong and accumulative effect of the coarse group structure in the sub-kev region is evident. While this discrepancy does not have a strong effect upon the key U-238 capture reaction, which is heavily selfshielded at low energies, it is clear that this phenomenon must be taken into account when resonance absorption in other materials must be calculated accurately. This discrepancy is in qualitative agreement with the foil-method results of Chan, discussed in Chapter 2, which indicated that the measured spectrum was harder than the spectrum calculated using 26 groups.

It was also found that use of a 26-group set prepared using a more realistic intra-group weighting spectrum gave results comparable to the 106-group calculations. Thus in future work where accuracy is of concern, it is recommended that separate cross section sets be prepared for zones such as the blanket and reflector, where the sub-kev spectrum is important.

Finally, some additional evaluation was performed on a method proposed by Leung et al. (2), in which upscatter cross sections are 
FIG. 8.1 COMPARISON OF CALCULATED MID-BLANKET NEUTRON

SPECTRA FOR BLANKET MOCK-UP NUMBER 4

- Calculated using 26 Group Cross Sections

Self Shielded using IDX

-.. Calculated using 106 Group Cross Section Set

Developed from the Initial 26 Group IDX set

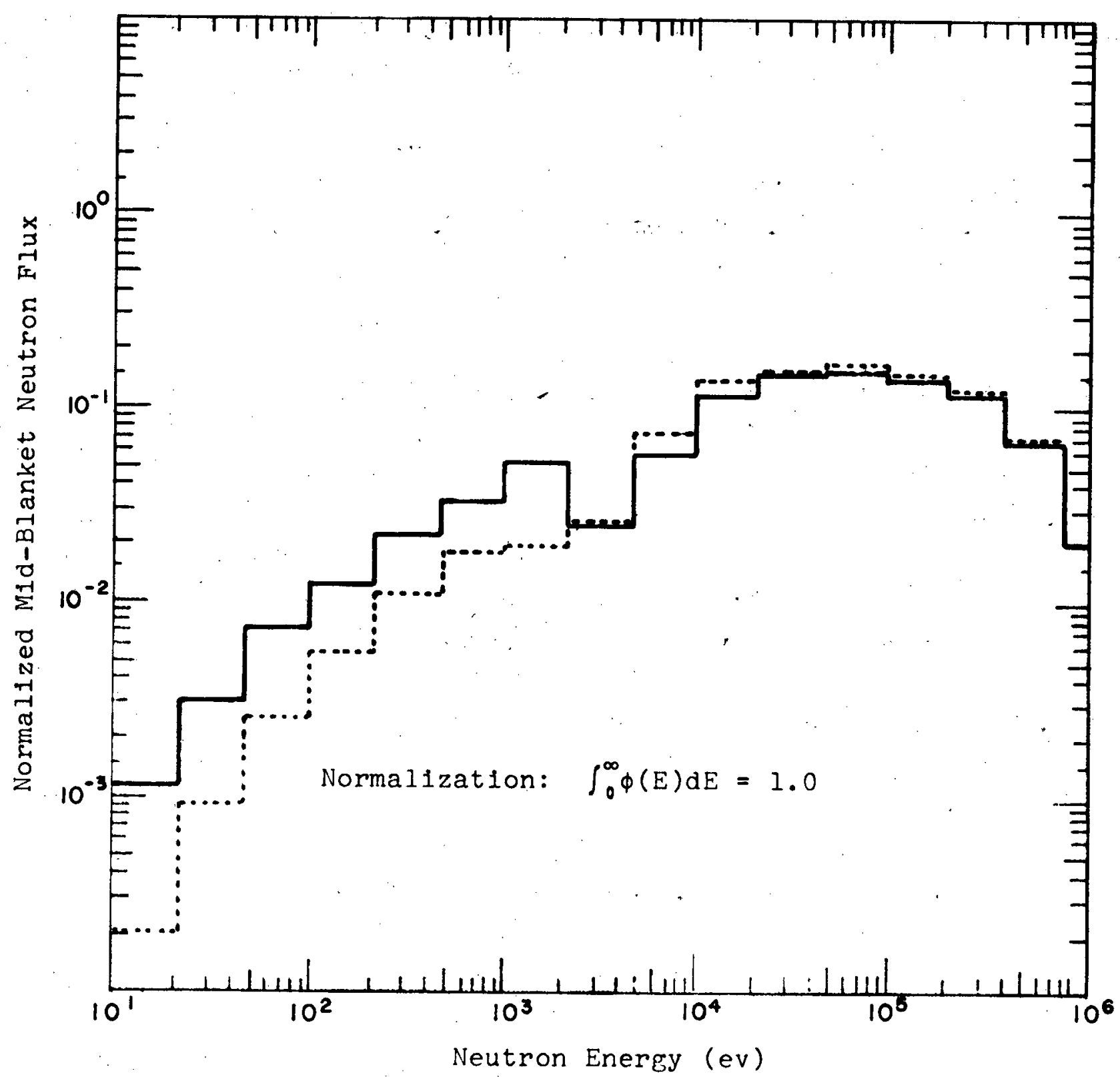


added to the cross section set to put into effect a self-correcting algorithm for the group transfer cross sections. It was confirmed that this approach severely debilitated the convergence properties of the ANISN program, and therefore, despite its superficially attractive features, could only be applied in practice if an entirely new neutron transport program could be developed around it.

\section{3 Threshold Detector Traverses}

A detailed evaluation has been performed (3) of previously observed (2) discrepancies between some measured and calculated threshold detector traverses in the iron reflector external to the blanket mockups. In particular, $U-238(n, f)$ and $I n\left(n, n^{\prime}\right)$ reaction rate traverses (but not others) gave results which were an order of magnitude higher than calculated values at deep ( 12 in.) penetrations.

The following results were obtained:

(a) A Li-6 spectrometer was used to demonstrate that the neutron spectrum did not show anomalous augmentation in the region just above the In $\left(n, n^{\prime}\right)$ and $U-238(n, f)$ thresholds relative to higher energies, as a function of depth into the reflector. This makes disagreement between these and other threshold traverses, such as $\operatorname{Th}(n, f)$, implausible.

(b) Re-evaluation of the U-238 (n,f) cross section was carried out to account for improved data near threshold, to add in the hitherto neglected contribution of subthreshold fission, and the contribution of the 18-ppm U-235 contamination in the highly depleted uranium foils. Figure 8.2 compares the results of these calculations: the combined effect can account for a factor of five increase in the calculated fission rate.

(c) The U-238 $(n, f)$ fission rate was recalculated using the ORNL coupled $\mathrm{n} / \gamma$ cross section set mentioned in Chapter 7 , and compared to the previous results, in which the ABBN cross section set was used. The ORNL set has more groups above $100 \mathrm{keV}$ than the ABBN (13 vs. 8), and was specifically designed for shielding 


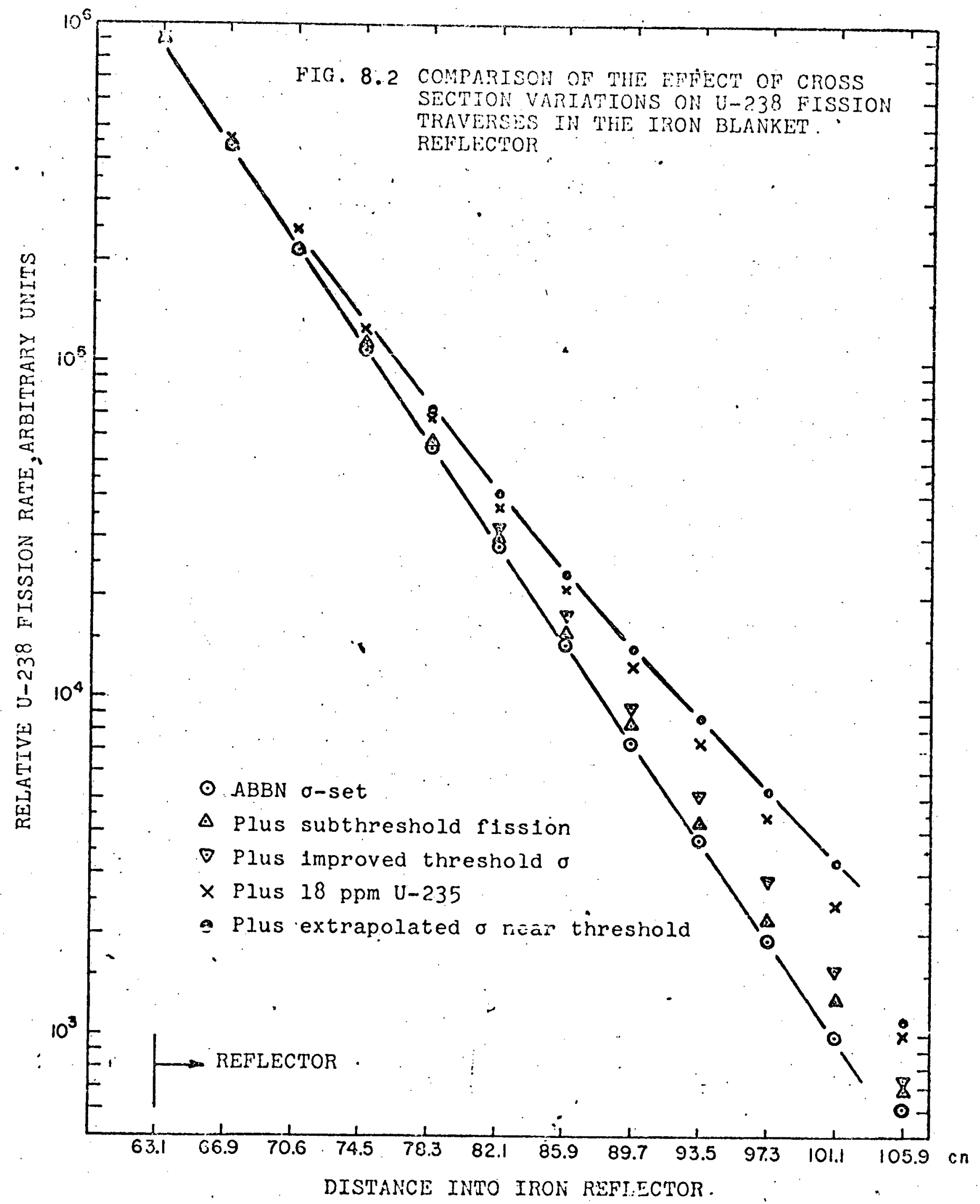


calculations. The ORNL set predicted a factor of two higher $U-238(n, f)$ reaction rate deep inside the reflector. Since the reflector is almost pure iron, these results reflect cross section differences between the two sets.

(d) U-238 and indium foils were irradiated both bare and covered by a $1-\mathrm{cm}$ radius, enriched B-10 sphere. At a depth of 13 inches into the iron reflector, the bare uranium foils had a reaction rate a factor of ten higher than the shielded foils, while both indium foils had the same specific activity. The result for the uranium confirms that subthreshold and U-235 fission are important contributors to the bare foil traverses.

(e) A suggestion by Swedish researchers (4), that gamma excitation of In-115m could explain similar anomalous results, was looked into. Numerical calculations using the ORNL $\mathrm{n} / \gamma$ set, and an experimental test using a Co-60 irradiation facility were performed. This potential effect was conclusively eliminated.

It is concluded that the previously reported discrepancy between calculated and measured threshold detector traverses is almost certainly due to errors in cross sections, both for the foil materials and for fast neutron transport in iron.

Plans are being made to build a new steel reflector for the blanket, using a subassembly arrangement rather than the present laminatedsheet configuration. This will greatly facilitate experimental measurements in the reflector. The new reflector is scheduled for operation in FY 1975, at which time more detailed threshold detector traverses will be made, and a more definitive assessment of calculated vs. measured results carried out.

\subsection{Future Blankets}

Some consideration has been given to blanket compositions and configurations which might be proposed for investigation starting in FY 1976. Cases considered included: thorium fueled blankets, both 
LMFBR and GCFR; GCFR (or voided LMFBR) radial blankets; and axial blankets. It was concluded that all cases could be successfully simulated using the MIT Blanket Test Facility. In order to make maximum use of fuel inventories which are likely to be available for this purpose, and to minimize the incremental cost of a combined LMFBR/GCFR program, it was decided that use of oxide fuel in place of the present metal fuel would be preferable. By cladding the oxide fuel in steel, a GCFR lattice could readily be simulated; insertion of aluminum rods in the coolant channels could then simulate sodium channels for the LMFBR case. The use of aluminum in place of sodium has been previously validated in some of the early ANL critical assemblies; we also use aluminum in place of sodium in the BTF converter assembly. In order to examine the consequences of this substitution, a series of calculations were performed on Blanket Mockup No. 4. Figure 8.3 shows a comparison of the original sodiumcontaining system with a case in which aluminum replaces sodium on a 2/1 atom ratio basis (the best of several cases considered). Figure 8.4 compares U-238 capture traverses in the same two systems. In general, the agreement is quite good. The largest discrepancy is due to the large scattering resonance in sodium near $3 \mathrm{keV}$ (group 13). Since the mean free path is quite small near this resonance, it would be possible to obviate this effect by using sodiumfilled subassemblies along the traversing path. We have previously successfully constructed and employed a sodium-filled subassembly in Mockups No. 2 and No. 4 , hence this is a feasible alternative.

\section{5 Epithermal Spectrum Facility}

Standard calibration spectra are useful for both foil method and instrumental neutron spectrometry. The Transistor Irradiation Facility (TIF) in the hohlraum beam port $6 \mathrm{CH} 1$ has been previously used as a fission spectrum calibration facility. The TIF consists of an annular ring of $2 \%$ enriched, half-inch-diameter, $\mathrm{UO}_{2}$ fuel rods, the 3 -inch I.D. cavity of which provides a relatively uniform fission spectrum for specimen irradiations. Confirmation that the TIF delivers a fission spectrum has been made using both foil-method 


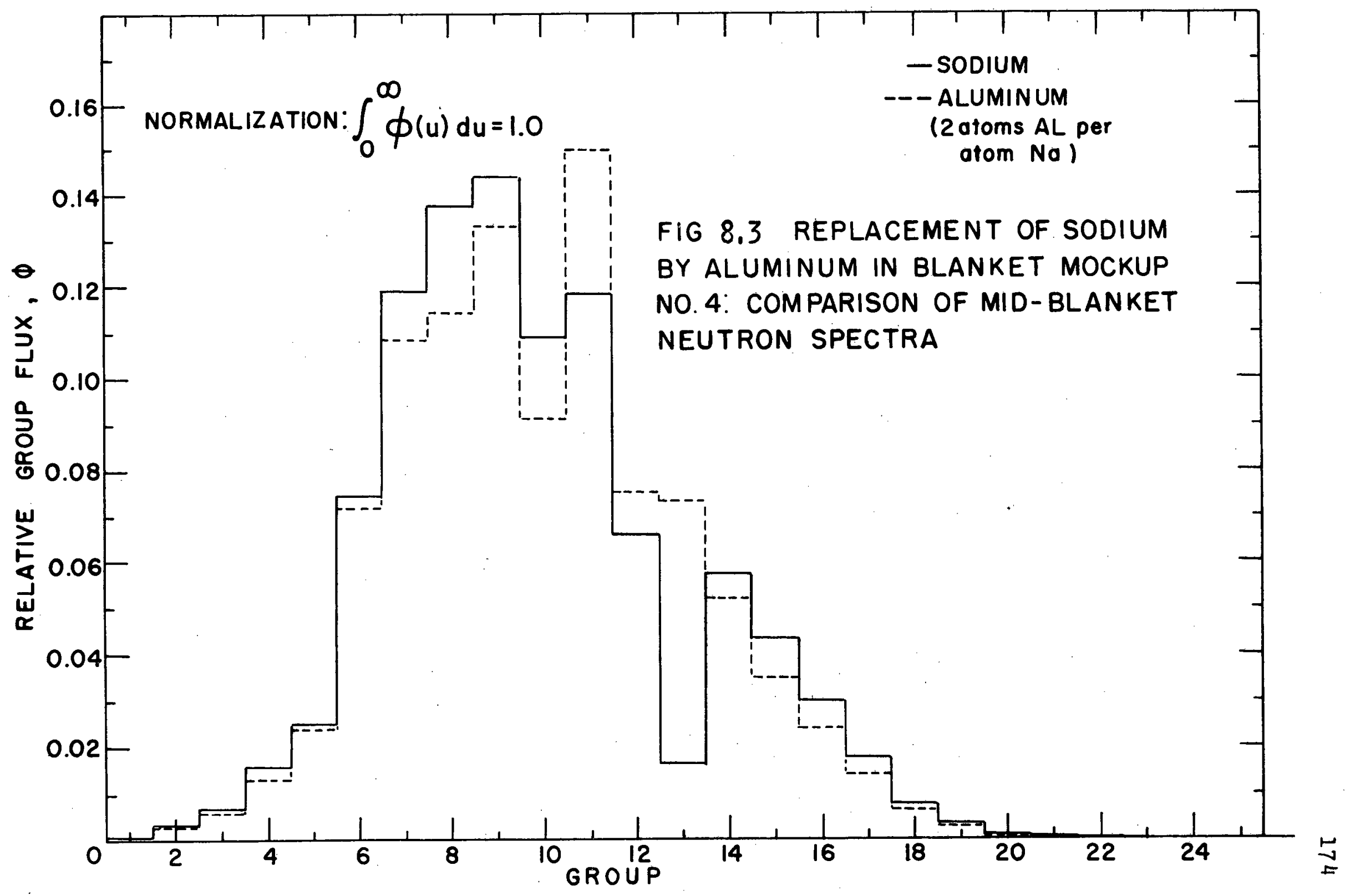




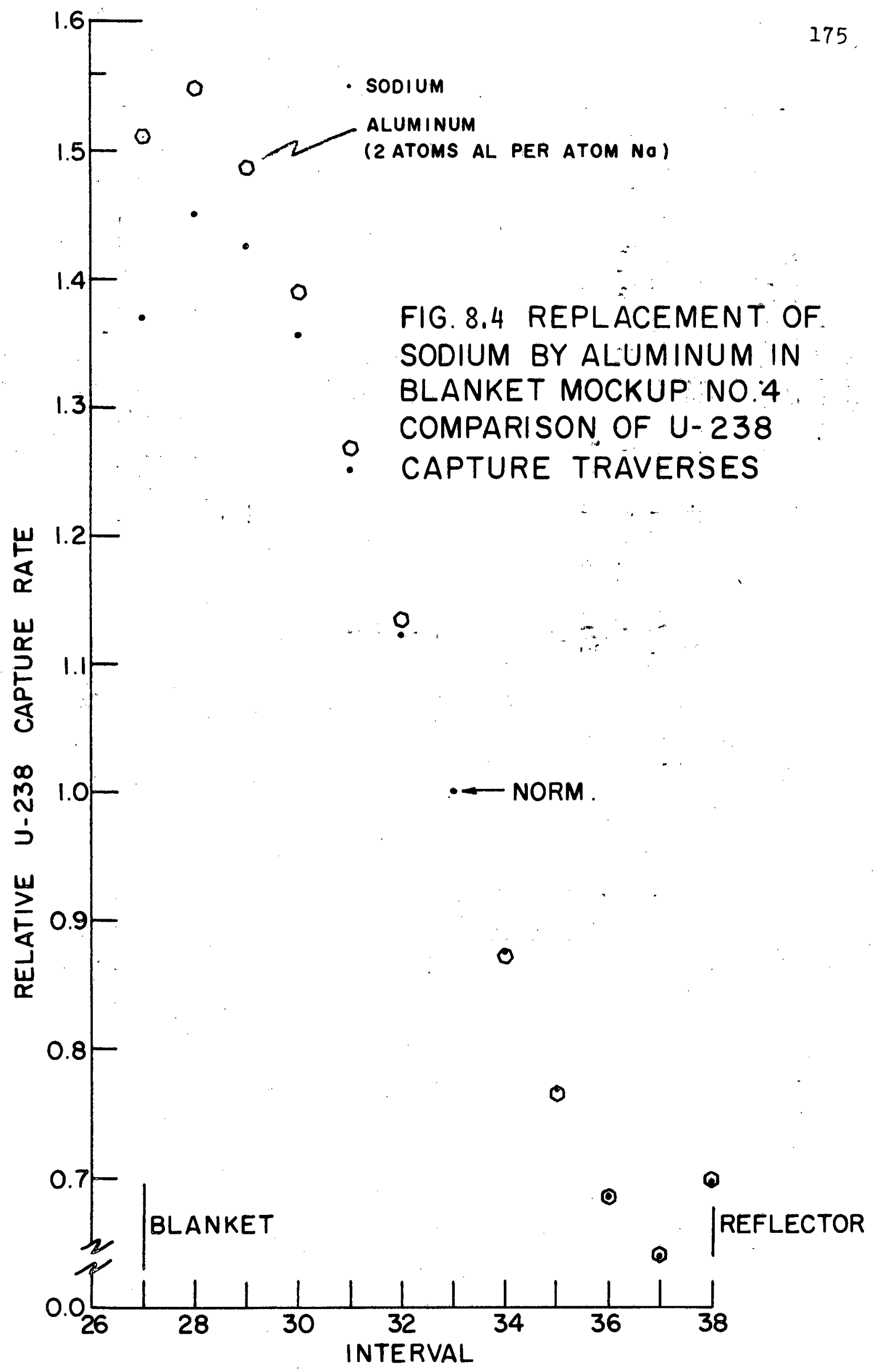


and instrumental spectrometry. Figure 8.4 compares calculated TIF and fission spectra.

For many applications the TIF fission spectrum is too hard. Because of this, and because resonance integrals are a standard parameter in reactor physics, a $1 / \mathrm{E}$ spectrum generator was designed for installation in the TIF. The final, optimized design consists of a 2.25-inch O.D. polyethylene cylinder having a 0.5 -inch O.D. central hole lined with 20 mils of cadmium. Figure 8.6 shows the centerline neutron spectrum calculated using the 26 -group ABBN set and the ANISN program in the $\mathrm{S}_{8}$ option. As can be seen, $\phi(u)$ is essentially constant in the range from $1 \mathrm{eV}$ to $100 \mathrm{keV}$; the peak centered around $1 \mathrm{MeV}$ is not detrimental because most capture cross sections are small in this range compared to their epithermal value.

\section{6 Fission-Track Counting}

High precision measurements of fast fission traverses in the reflector region are difficult because of the low induced activity and the high natural foil background. A survey of possible improvements, as part of the planning for experiments on the new steel reflector in FY 1976, led to selection of the particle-track method as the most promising candidate for further evaluation.

A set of screening experiments were performed using 0.25 -inchdiameter Lexan plastic foils. Two Lexan foils were irradiated at the blanket/reflector interface of Mockup No. 4 for one hour: one sandwiched between U-238 metal foils to record fission tracks, the other bare to record fast neutron/proton recoil background. A third foil was sandwiched between U-238 metal foils, but not irradiated in-pile, in order to record alpha background. The foils were subsequently acid-etched and examined under $250 \mathrm{x}$ magnification. Thousands of well-defined fission fragment tracks were clearly evident, but no proton or alpha background was observed. It was concluded that fission track counting is a feasible approach for making low signal/low background fission traverses. The increased precision will help resolve some of the discrepancies between experiment and calculation discussed in section 8.3 of this chapter. 
FIG. 8.5 COMPARISON OF FISSION AND

TRANSISTOR IRRADIATION

FACILITY FLUXES

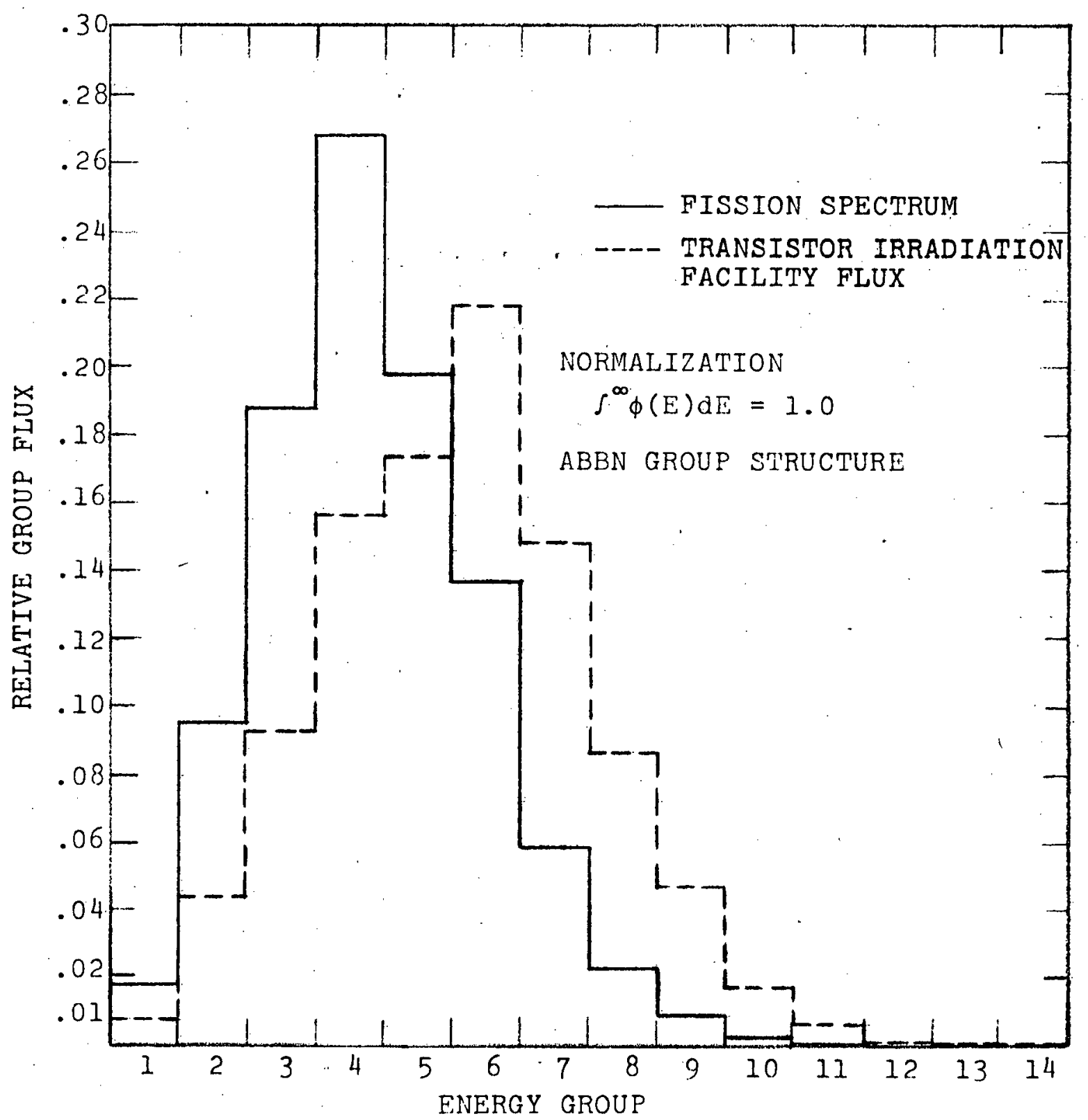




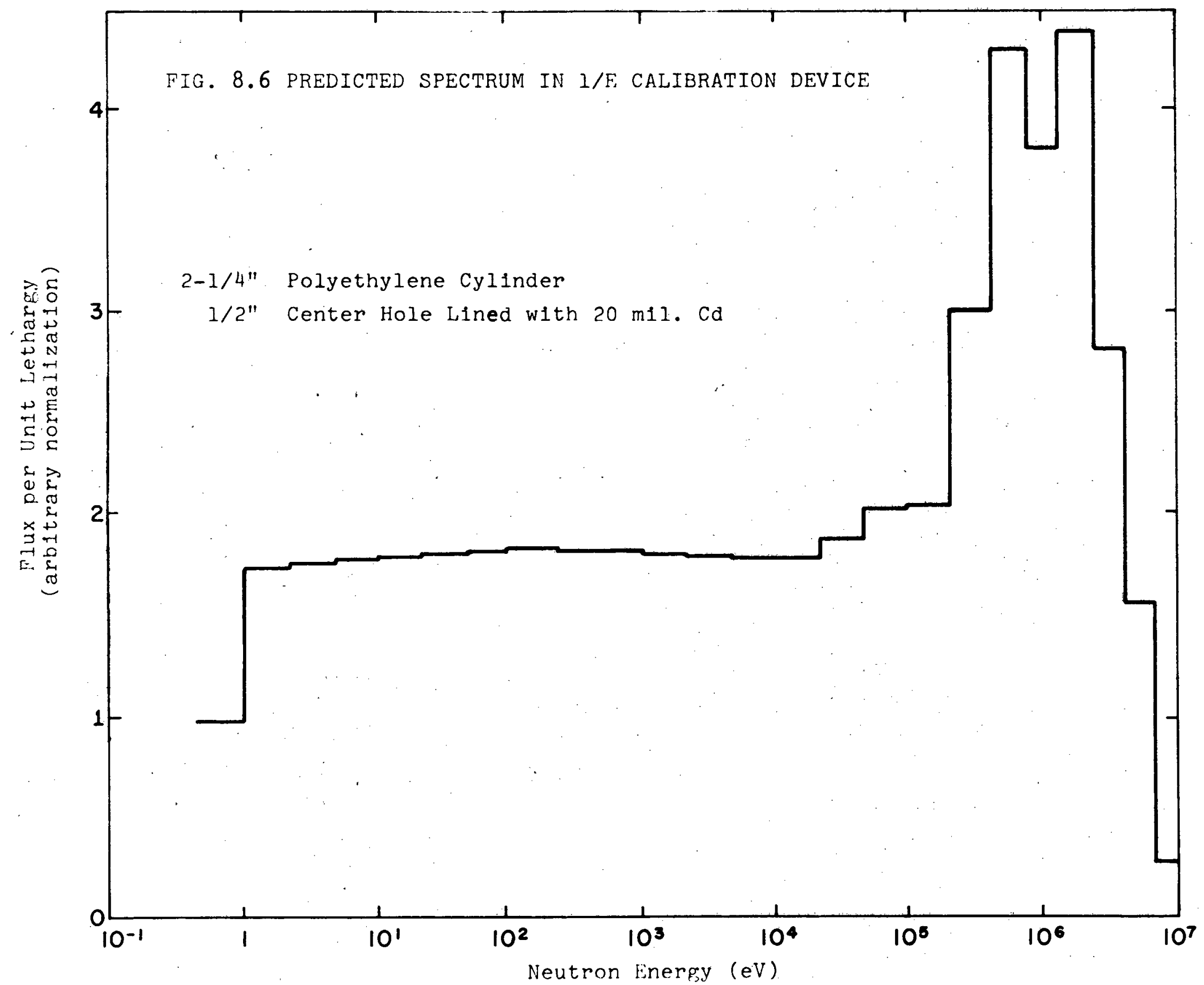




\section{7 Effects of $\mathrm{H}_{2} \mathrm{O}$ Contamination}

The effects of the possible residual contamination of the $\mathrm{Na}_{2} \mathrm{CrO}_{4}$ used in the fuel assemblies of the blanket mockups by as much as 0.1 wt. $\% \mathrm{H}_{2} \mathrm{O}$ has been studied previously by Leung (2). He calculated a perturbation of less than $2 \%$ in foil activation traverses in the blanket. Development of the 106-group set described in section 8.2 of this chapter permitted a more detailed evaluation to be made. Table 8.1 shows some selected results from this evaluation: as shown, the effect of $\mathrm{H}_{2} \mathrm{O}$ contamination is confirmed to be small.

One of the blanket subassembly boxes was constructed with a transparent plastic top to permit visual observation of the condition of the enclosed chromate powder. The powder shows less than $0.5 \%$ decrease in fill height -- hence negligible densification, and no visible effects of moisture pickup.

Finally, it is speculated that the $\mathrm{H}_{2} \mathrm{O}$ content of the chromate may actually have decreased over the past several years. The fuel assembly contains a large exposed surface area of clean carbon steel (fuel pin cladding plus subassembly box walls) which can consume moisture in the corrosion process, and thereby liberate molecular hydrogen, which has the well-known capability of diffusing through carbon steel.

It was concluded that no great concern over moisture contamination is warranted. This will be confirmed by analysis of chromate samples removed during subassembly disassembly following conclusion of the present experimental program.

\subsection{The Effect of Core Size on Radial Blanket Performance}

Although analysis of most of the broader aspects of blanket design justifiable within the scope of the MIT Blanket Research Project have been completed, one major area still requires investigation: the effect of projected increases in core size on radial blanket performance. Brewer ( $\underline{6}$ ) analyzed a simplified one-zone core design and concluded that a plant as small as 1500 MWe might be better off, under nearterm economic conditions, with a reflector in place of the radial 
TABLE 8.1

Errors in Blanket Flux and Capture Rates Due to Neglect of $\mathrm{H}_{2} \mathrm{O}$ Contamination

\begin{tabular}{|c|c|c|c|}
\hline \multicolumn{2}{|c|}{$\begin{array}{c}\text { Neutron Flux } \\
\text { at Center of Blanket }\end{array}$} & \multicolumn{2}{|c|}{ U-238 Capture Rate } \\
\hline $\begin{array}{l}\text { Neutron } \\
\text { Group (1) }\end{array}$ & $\% \operatorname{Error}^{(2)}$ & Interval $^{(3)}$ & $\% \operatorname{Error}^{(2)}$ \\
\hline 1 & 0.036 & 27 & -0.030 \\
\hline 2 & 0.081 & 28 & -0.157 \\
\hline 3 & 0.185 & 29 & -0.130 \\
\hline 4 & 0.282 & 30 & -0.023 \\
\hline 5 & 0.499 & 31 & 0.155 \\
\hline 6 & 1.319 & 32 & 0.379 \\
\hline 7 & 2.276 & 33 & 0.640 \\
\hline 8 & 3.281 & 34 & 0.925 \\
\hline 9 & 4. 198 & 35 & 1.227 \\
\hline 10 & 4.594 & 36 & 1.535 \\
\hline 11 & 1.330 & 37 & 1.838 \\
\hline 12 & -0.891 & 38 & 2.101 \\
\hline 13 & -3.515 & 39 & 2.384 \\
\hline 14 & -4.453 & 40 & 2.721 \\
\hline 15 & -4.781 & 41 & 3.070 \\
\hline 16 & -6.325 & 42 & 3.398 \\
\hline 17 & -8.532 & 43 & 3.681 \\
\hline 18 & -11.042 & 44 & 3.901 \\
\hline 19 & -13.752 & 45 & 4.059 \\
\hline 20 & -17.507 & 46 & 4.157 \\
\hline 21 & -21.979 & 47 & 4.212 \\
\hline 22 & -11.836 & 48 & 4.232 \\
\hline 23 & -3.078 & 49 & 4.227 \\
\hline 24 & -3.251 & 50 & 4.179 \\
\hline 25 & -3.110 & & \\
\hline 26 & -7.911 & & \\
\hline
\end{tabular}

(1) ABBN group structure.

(2) (Without $\mathrm{H}_{2} \mathrm{O}-$ With $\mathrm{H}_{2} \mathrm{O}$ ) $\times 100 \div$ With $\mathrm{H}_{2} \mathrm{O}$

(3) Each interval represents $3.759 \mathrm{~cm} ; 27-38=$ blanket, $\geqslant 39=$ reflector. 
blanket. If this conclusion can be substantiated, or even if it can be shown that only one row of blanket assemblies is potentially profitable in the commercially competitive LMFBR, then present radial blanket development programs might well warrant re-examination: axial blankets, on the other hand, will merit continuing interest, and, indeed, increased attention.

Detailed work in this area has just begun. However, it has been shown (7) that the external breeding ratio of the radial blanket surrounding a power-flattened core falls off as the inverse of the core's geometric radius; much less precipitously than for the one-zone core, for which the radial blanket's breeding ratio falls off as the inverse of the square of the core's extrapolated radius. Thus it is anticipated that the radial blanket will remain useful for reactor sizes larger than those suggested in Reference 6 . This work will continue through FY 1975.

\subsection{References}

(1) P.J. Wood and M.J. Driscoll, "Assessment of Thorium Blankets for Fast Breeder Reactors," COO-2250-2, MITNE-148, July 1973.

(2) T.C. Leung, et a1. "Neutronics of an LMFBR Blanket Mockup," COO-3060-1, MITNE-127, Jan. 1972.

(3) T.P. Choong, "Fast Neutron Spectrometry in an LMFBR Blanket Reflector," S.M. Thesis, MIT Dept. of Nucl. Eng., Sept. 1973.

(4) E. Aalto, et al., "Measured and Predicted Variations in Fast Neutron Spectrum in Massive Shields of Water and Concrete," AE-197, 1965.

(5) S. Park, "Prediction and Testing Techniques for Neutron Induced Gain Degradation on Transistors," E-228F, MIT Instrumentation Laboratory, Aug. 1968.

(6) S.T. Brewer, et al. , "The Economics of Fuel Depletion in Fast Breede $\bar{r}$ Reactor Blankets," COO-3060-4, MITNE-123, Nov. 1972.

(7) A. Alvim, Course 22.90 Special Topic Report, M.I. T. (1973). 


\section{SUMMARY, CONCLUSIONS AND FUTURE WORK}

\subsection{Introduction}

This is the fourth annual report of the LMFBR Blanket Physics Project at MIT. During the past year work has been concerned primarily with the following areas:

(1) Measurements on Blanket Mockup No. 4, a threesubassembly-row, steel-reflected blanket driven by a simulated demonstration plant core leakage spectrum.

(2) Completion of the analysis of a number of advanced blanket concepts, including the use of thorium, high-albedo reflectors, and a completely internal (parfait) blanket.

(3) Methods development work, chiefly in the areas of gamma heating measurements and foil-method neutron spectrometry.

\subsection{Discussion}

The most important conclusions which may be drawn from the past year's work are as follows:

(1) The previously observed discrepancy between measured and calculated $\mathrm{U}^{238}(\mathrm{n}, \mathrm{f})$ threshold detector traverses in the reflector region is now attributed to errors in both iron and $\mathrm{U}^{238}$ cross sections, primarily the latter, including such effects as subthreshold fission, previously considered negligible.

(2) Areas of major continuing interest primarily involve the region of the neutron spectrum below about $10 \mathrm{keV}$ including: $\mathrm{U}^{238}$ resonance self-shielding, particularly near the blanketreflector interface; accurate calculation of sub-keV neutron spectra, including the effects of weighting spectra on elastic downscatter cross sections; and the measurement of such spectra using foil methods, for comparison with the experimental data. 
(3) Several advanced blanket configurations have been shown to be attractive, including the use of thorium in place of uranium as the fertile material, replacement of steel by high-albedo reflector material such as graphite, and the use of a completely internal blanket, surrounded by core in both the axial and radial directions.

(4) Although the Blanket Test Facility was originally designed solely with neutronic simulation in mind; analysis has shown that it also provides a photonic environment which is sufficiently. close to that experienced by a real LMFBR blanket to permit useful gamma heating experiments.

\subsection{Future Work}

During the coming contract year, July 1, 1973 through June 30 , 1974, work will be concerned mainly with the following:

(1) Completion of foil irradiation experiments scheduled for Blanket No. 4, with an emphasis on absolutely normalized spectral indices (foil activation ratios). Since the MIT Reactor will be shut down for renovation May - September 1974 , it is convenient to extend operation of Mockup No. 4 until that time and change over to Mockup No. 5 during the reactor shutdown.

(2) Completion and publication of a benchmark blanket problem centered a round Blanket No. 4, including both neutronic and photonic data, calculations and parametric studies.

(3) Completion of the fabrication of the reflector subassemblies for Blanket No. 5; this blanket will be identical to No. 4 except that the present laminated-sheet-type reflector will be replaced by the more realistic subassembly configuration, which will also permit extended and improved experimental investigations in the reflector region.

(4) Intensified efforts on the measurement and calculation of sub$\mathrm{keV}$ neutron spectra. 
During the final contract year July 1, 1974 through June 30, 1975, work is tentatively scheduled to include the following:

(1) Threshold and other foil activation traverses throughout the reflector region to obtain definitive evidence on the fast neutron penetration.

(2) Gamma heating measurements in the reflector.

(3) Foil method and instrumental neutron spectrometry in the reflector region.

(4) Blanket region measurements supplementing those collected in Mockup No. 4, particularly on aspects identified as crucial or uncertain based upon the completed data analysis for Mockup No. 4.

(5) Preparation of a final report.

Beyond the present contract period, two areas have been identified as being of potential interest:

(1) Measurements on a mockup of a thorium blanket. Potential fuel cycle savings of on the order of $30 \%$ have been identified if thorium can be substituted for uranium in LMFBR blankets (1). At the same time it was found that thorium irradiations in a uranium blanket mockup were inadequate to confirm thorium capture rate calculations, and it appears that a sufficiently reliable experiment could only be done in a thorium blanket mockup. Assuming that thorium metal or oxide fuel can be made available, blanket fabrication and experimentation would be fairly straightforward, paralleling the work already done in the present uranium blanket experiments.

(2) Measurements in a gas-cooled reactor blanket mockup. Here the interest lies in the ability to predict neutron and gamma transport in configurations in which coolant channel voids provide paths for streaming and anisotropic diffusion. It is important to be able to assess the capability of state-of-the- 
art methods, proof-tested on LMFBRs to do an adequate job in the considerably different GCFR situation; results would also be applicable to the LMFBR in the sodium-voided state. The MIT Blanket Test Facility is ideal for these measurements in a number of ways, the most important being the fact that it utilizes the realistic rod geometry, rather than the plate geometry used in most critical assemblies.

In general, the project has entered a phase in which the emphasis has narrowed to a number of very specific objectives of well-defined scope, but whose elucidation is essential to permit accurate design calculations of blanket neutron and photon balances. For the most part, the concern is now with insuring precision within better than $\pm 20 \%$ in the calculations and $\pm 5 \%$ in the experimental measurements.

\subsection{References}

(1) P.J. Wood and M.J. Driscoll, "Assessment of Thorium Blankets for Fast Breeder Reactors," COO-2250-2, MITNE-148, July 1973 . 


\section{Appendix A \\ BIBLIOGRAPHY OF BLANKET PHYSICS PROJECT PUBLICATIONS}

In this appendix are tabulated all publications associated with work performed in the MIT Blanket Physics Project. Sc.D. theses are listed first, followed by S.M. and B.S. theses and then by other publications.

\section{A. 1 Doctoral Theses}

(Also see section 3 for corresponding topical reports.)

Forbes, I. A.

Design, Construction and Evaluation of a Facility for the Simulation of Fast Reactor Blankets, Feb. 1970.

Sheaffer, M.K.

A One-Group Method for Fast Reactor Calculations, Aug. 1970.

Tzanos, C.P.

Optimization of Material Distributions in Fast Breeder Reactors, Aug. 1971.

Kang, C.S.

Use of Gamma Spectroscopy for Neutronic Analysis of LMFBR Blankets, Nov. 1971.

Leung, T.C.

Neutronics of an LMFBR Blanket Mockup, Jan. 1972.

Ortiz, N.R.

Instrumental Methods for Neutron Spectroscopy in the MIT Blanket Test Facility, May 1972.

Brewer, S.T.

The Economics of Fuel Depletion in Fast Breeder Reactor Blankets, Oct. 1972. 
A. 1 Doctoral Theses (continued)

Gregory, M.V.

Heterogeneous Effects in Fast Breeder Reactors, Dec. 1972.

Wood, P.J.

Assessment of Thorium Blankets for Fast Breeder Reactors, July 1973.

Ducat, G.A.

The Parfait Blanket Concept for Fast Breeder Reactors, est. Jan. 1974.

Brown, G.J.

Evaluation of High-Performance LMFBR Blanket

Configurations, est. May 1974.

A.2. S.M. and B.S. Theses

Ho, S.L.

Measurement of Fast and Epithermal Neutron Spectra Using Foil Activation Techniques

S.M. Thesis, MIT Nucl. Eng. Dept., Jan. 1970

Mertens, P.G.

An Evaluation of a Subcritical Null-Reactivity Method for Fast Reactor Applications

S. M. Thesis, MIT Nucl. Eng. Dept., May 1970

Westlake, W.J.

Heterogeneous Effects in LMFBR Blanket Fuel Elements

S. M. Thesis, MIT Nucl. Eng. Dept., June 1970

Shupe, D.A.

The Feasibility of Inferring the Incident Neutron Spectrum from Prompt Capture Gamma-Ray Spectra

S.M. Thesis, MIT Physics Dept., Aug. 1970

Pant, A.

Feasibility Study of a Converter Assembly for Fusion

Blankets Experiments

S. M. Thesis, MIT Nucl. Eng. Dept., Jan. 1971 


\section{A.2 S.M. and B.S. Theses (continued)}

Passman, N.A.

An Improved Foil Activation Method for Determination of Fast Neutron Spectra

S.M. Thesis, MIT Nucl. Eng. Dept., Jan. 1971

Forsberg, C.W.

Determination of Neutron Spectra by Prompt GammaRay Spectrometry

M.S. Thesis, MIT Nucl. Eng. Dept., June 1971

Brown, G.J.

A Study of High-Albedo Reflectors for LMFBRs

S. M. Thesis, MIT Nucl. Eng. Dept., March 1972

Thompson, A.M.

Activation Profiles in Reactor Fuel Elements

B.S. Thesis, MIT Physics Dept., June 1972

Lal, D.

Determination of the Neutron Spectrum in the MITR

Transistor Irradiation Facility

B.S. Thesis, MIT Chem. Eng. Dept., June 1972

Ho, S. Y-N.

Selection of Foil Materials for LMFBR Neutron Spectrometry

S.M. Thesis, MIT Nucl. Eng. Dept., May 1973

Choong, T.P.

Fast Neutron Spectrometry in an LMFBR Blanket Reflector

S.M. Thesis, MIT Nucl. Eng. Dept., Aug. 1973

Kennerley, R.J.

Proton-Recoil Neutron Spectrometry in a Fast Reactor Blanket

S.M. Thesis, MIT Nucl. Eng. Dept., Aug. 1973

Chan, J.K.

A Foil Method for Neutron Spectrometry in Fast Reactors

S.M. Thesis, MIT Nucl. Eng. Dept., Jan. 1974 (est.) 


\section{A. 3 Other Publications}

I.A. Forbes, M.J. Driscoll, T.J. Thompson, I. Kaplan and D. D. Lanning

Design, Construction and Evaluation of a Facility for the Simulation of Fast Reactor Blankets MIT-4105-2, MITNE-110, Feb. 1970

M.K. Sheaffer, M.J. Driscoll and I. Kaplan

A One-Group Method for Fast Reactor Calculations MIT-4105-1, MITNE-108, Sept. 1970.

I. A. Forbes, M.J. Driscoll, D.D. Lanning, I. Kaplan and N. C. Rasmussen

LMFBR Blanket Physics Project Progress Report No. 1 MIT-4105-3, MITNE-116, June 30, 1970

I. A. Forbes, M.J. Driscoll, T.J. Thompson, I. Kaplan and D.D. Lanning

Design, Construction and Evaluation of an LMFBR Blanket Test Facility

Trans. Am. Nucl. Soc., Vol. 13, No. 1, June 1970

S.T. Brewer, M.J. Driscoll and E.A. Mason

FBR Blanket Depletion Studies - Effect of Number of Energy Groups

Trans. Am. Nucl. Soc., Vol. 13, No. 2, Nov. 1970

M. K. Sheaffer, M.J. Driscoll and I. Kaplan

A Simple One-Group Method for Fast Reactor Calculations

Trans. Am. Nucl. Soc., Vol. 14, No. 1, June 1971

T.C. Leung, M.J. Driscoll, I. Kaplan and D.D. Lanning Measurements of Material Activation and Neutron Spectra in an LMFBR Blanket Mockup

Trans. Am. Nucl. Soc., Vol. 14, No. 1, June 1971

S.T. Brewer, E.A. Mason and M.J. Driscoll

On the Economic Potential of FBR Blankets

Trans. Am. Nucl. Soc., Vol. 14, No. 1, June 1971 


\section{A. 3 Other Publications (continued)}

I. A. Forbes, M.J. Driscoll, N.C. Rasmussen, D.D. Lanning and I. Kaplan

LMFBR Blanket Physics Project Progress Report No. 2

$$
\text { COO-3060-5, MITNE-131, June } 1971
$$

C.P. Tzanos, E.P. Gyftopoulos and M.J. Driscoll

Optimization of Material Distributions in Fast Breeder Reactors

MIT-4105-6, MITNE-128, August 1971

T.C. Leung and M. J. Driscoll

A Simple foil Method for LMFBR Spectrum Determination

Trans. Am. Nucl. Soc., Vol. 14, No. 2, Oct. 1971

C.S. Kang, N.C. Rasmussen and M. J. Driscoll

Use of Gamma Spectros copy for Neutronic Analysis of LMFBR Blankets

COO-3060-2, MITNE-130, Nov. 1971

T.C. Leung, M.J. Driscoll, I. Kaplan and D. D. Lanning Neutronics of an LMFBR Blanket Mockup COO-3060-1, MITNE-127, Jan. 1972

N.R. Ortiz, I.C. Rickard, M.J. Driscoll and N.C. Rasmussen Instrumental Methods for Neutron Spectroscopy in the MIT Blanket Test Facility

$$
\text { COO-3060-3, MITNE-129, May } 1972
$$

V.C. Rogers, I.A. Forbes and M.J. Driscoll

Heterogeneity Effects in the MIT-BTF Blanket No. 2

Trans. Am. Nucl. Soc., Vol. 15, No. 1, June 1972

S.T. Brewer, E.A. Mason and M.J. Driscoll

The Economics of Fuel Depletion in Fast Breeder Reactor Blankets

COO-3060-4, MITNE-123, Nov. 1972 


\section{A. 3 Other Publications (continued)}

M. K. Sheaffer, M.J. Driscoll and I. Kaplan

A One-Group Method for Fast Reactor Calculations Nucl. Sci. Eng., Vol. 48, p. 459 (1972)

C.P. Tzanos, E.P. Gyftopoulos and M.J. Driscoll Optimization of Material Distributions in Fast Reactor Cores Nucl. Sci. Eng., Vol. 52, p. 84 (1973)

M.J. Driscoll, D.D. Lanning and I. Kaplan LMFBR Blanket Physics Project Progress Report No. 3 COO-3060-6, MITNE-143, June 1972

M. V. Gregory, M.J. Driscoll and D.D. Lanning Heterogeneous Effects in Fast Breeder Reactors COO-2250-1, MITNE-142, Jan. 1973

P.J. Wood and M.J. Driscoll

Assessment of Thorium Blankets for Fast Breeder Reactors COO-2250-2, MITNE-148, July 1973

G.A. Ducat, M.J. Driscoll and N.E. Todreas The Parfait Blanket Concept for Fast Breeder Reactors Trans. Am. Nucl. Soc., Vol. 16, No. 1, June 1973

G.A. Ducat, M.J. Driscoll and N.E. Todreas The Parfait Blanket Concept for Fast Breeder Reactors COO-2250-5, MITNE-157, (est. Jan. 1974)

G.J. Brown and M.J. Driscoll

Evaluation of High-Performance LMFBR Blanket Configurations COO-2250-4, MITNE-150 (est. 1974) 